\title{
Testing theories on structure and strategy : an assessment of organizational knowledge
}

Citation for published version (APA):

Prins, G. (2000). Testing theories on structure and strategy : an assessment of organizational knowledge. [Doctoral Thesis, Maastricht University]. Eburon. https://doi.org/10.26481/dis.20001018gp

Document status and date:

Published: 01/01/2000

DOI:

10.26481/dis.20001018gp

Document Version:

Publisher's PDF, also known as Version of record

\section{Please check the document version of this publication:}

- A submitted manuscript is the version of the article upon submission and before peer-review. There can be important differences between the submitted version and the official published version of record.

People interested in the research are advised to contact the author for the final version of the publication, or visit the DOI to the publisher's website.

- The final author version and the galley proof are versions of the publication after peer review.

- The final published version features the final layout of the paper including the volume, issue and page numbers.

Link to publication

\footnotetext{
General rights rights.

- You may freely distribute the URL identifying the publication in the public portal. please follow below link for the End User Agreement:

www.umlib.nl/taverne-license

Take down policy

If you believe that this document breaches copyright please contact us at:

repository@maastrichtuniversity.nl

providing details and we will investigate your claim.
}

Copyright and moral rights for the publications made accessible in the public portal are retained by the authors and/or other copyright owners and it is a condition of accessing publications that users recognise and abide by the legal requirements associated with these

- Users may download and print one copy of any publication from the public portal for the purpose of private study or research.

- You may not further distribute the material or use it for any profit-making activity or commercial gain

If the publication is distributed under the terms of Article $25 \mathrm{fa}$ of the Dutch Copyright Act, indicated by the "Taverne" license above, 
Testing Theories on Structure and Strategy

An Assessment of Organizational Knowledge 
ISGN $905166803-1$

Uitgeverij Eburon/Eburon Publishers

P.O. Box 2867

2601. CW Delf

intoraburom.ni

Why ebulon.n

Cover design by Jan Begeer

(C2000 G. Prins. All rights reserved. No part of this publication may be reproduced, stored in a retrieval systern, or transmitted, in any form or by any means, electronic, nechanical, photocopying, recording, or otherwise, without the prior permission in writing from the proprietor(s). 


\section{Testing Theories on Structure and Strategy}

\section{An Assessment of Organizational Knowledge}

\section{PROEFSCHRIFT}

ter verkrijging van de graad van doctor aan de Universiteit Maastricht, op gezag van de Rector Magnificus, Professor dr. A. C. Nieuwenhuijzen Kruseman volgens het besluit van het College van Decanen, in het openbaar te verdedigen

op woensdag 18 oktober 2000 om 14.00 uur

door Gerrit Prins,

geboren 12 maart 1932

te Amsterdam 
promotoren:

Prof. dr. H. Visser

Prof. dr. ir. J. E. van Aken (Technische Universiteit Eindhoven)

beoordelingscommissie:

Prof. dr. H.J. van den Herik (voorzitter)

Prof. dr. ir. K.L. Boon

Prof. dr. ir. P.A. Kroes (Technische Universiteit Delft)

Prof. dr. J.J. Ramondt (Erasmus Universiteit Rotterdam)

Prof. dr. C.W. Vroom 


\section{Testing Theories on Structure and Strategy}

An Assessment of Organizational Knowledge

\section{Contents}

1. Introduction: Scientific background

2. Scope and objective of the research

3. From traits of theories to the A - F - scheme

4. The systematic assessment of organizational theory

5. A multiple case study of organization theories

6. Six contemporary theories

7. Conclusion, discussion, and afterthoughts 


\section{DETAILED CONTENTS}

1. INTRODUCTION: SCIENTIFIC BACKGROUND

1.1. Organization theory is necessary, but can it be trusted? .....................................................

1.2. Problems with theory development ................................................................................







2. SCOPE AND OBJECTIVE OF THE RESEARCH ................................................................ 17





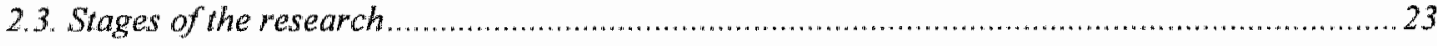

3. FROM TRAITS OF THEORIES TO THE A - F - SCMEME......................................................24













3.7. The complete cycle of observation, conjecture and derivation...........................................50



3.9. The concept of theory as used in this study ................................................................... 54

4. THE SYSTEMATIC ASSESSMENT OF ORGANIZATIONAL THEORY ................................55












5.1. The material.

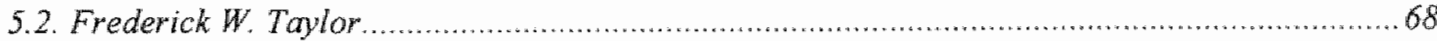





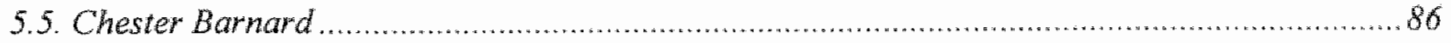



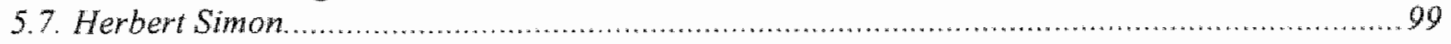

5.8. James March and Herbert Simon ................................................................................ 105

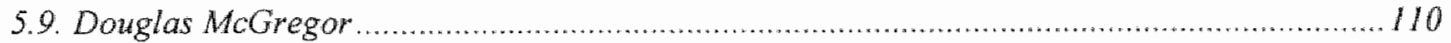

5.10. Tom Burns and George M. Stalker ............................................................................ 115

5.11. Peter Blau and W. Richard Scott ............................................................................... 120

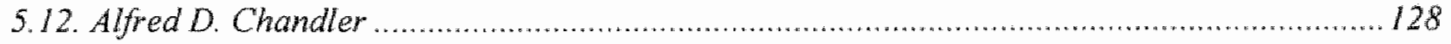

5.13. Richard M. Cyert and James G. March ................................................................. 133

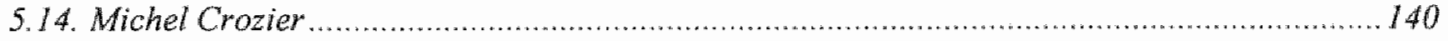

5.15. Daniel Katz and Robert Kahn.......................................................................... 149

5.16. Paul R. Lawrence and Joy W. Lorsch.......................................................................... 155

5.17. James D. Thompson ............................................................................................ 165

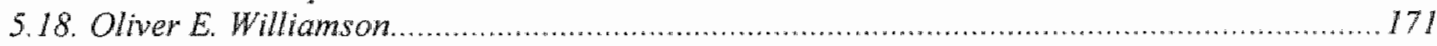





5.21. Michael Porter ............................................................................................................. 194

5.22. Tom J. Peters and Robert H. Waterman ................................................................. 198

5.23. Paul J. DiMaggio and Walter W. Powell ................................................................203



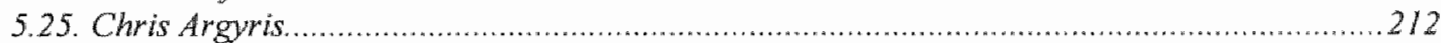

5.26. Christopher A. Bartlett and Sumantra Ghoshal ...........................................................218

5. 27. Rosabeth Moss Kanter ............................................................................................. 228

5.28. Michael T. Hamnan and Jahn Freeman ........................................................................ 236



5.30. Results of the examination of 20 th-century theories ....................................................251









6.4. Joseph Bower and Clayton Christersen ........................................................................27I



6.6. Leonard H. Lynn and Hayagreeva Rao .....................................................................27 277

6.7. James Robins and Margarethe Wiersema................................................................279

7. CONCLUSION, DISCUSSION, AND AFTERTHOUGHTS .....................................................284












\section{The rendering of citations}

The nature of this study makes it necessary to quote, sometimes large, passages from the works examined. To facilitate the recognition of citations comprising more than one sentence, these are printed in a distinct font and layout, as shown hereafter. They are placed between single quotation marks.

Underlining is used for my emphasizing of parts of the text. Non-relevant parts of the text may be replaced by three dots. If such omitting requires a grammatical reconstruction of a cited sentence the repair words will be placed in square brackets.

"The nature of this study makes it mecessary to quote, sometimes large, passages from the works examined. To facilitate the recognition of ... [larger] ... citations ..., thesere are printed in a distinct font and layout, as shown ... They are placed between single quotation marks.
Underlining is used for my emphasizing of parts of the text. Non-relevant parts of the text may be replaced by three dots. If such omiting requires a grammatical reconstruction of a cited sentence the repair words will be placed in square brackets." 


\section{Introduction: Scientific background}

\subsection{Organization theory is necessary, but can it be trusted?}

Matters of structure and strategy of the organization are among the most important for managers and consultants to deal with. Therefore systematized knowledge of this field is essential. Organization science, management science, and business administration are supposed to generate valid and useful theories on the subject. So it might be expected that the ABC-community (academics, businesspeople and consultants) produce many, well-formulated theories on a thorough scientific basis. Whether the expectation is justified is one of the questions this study tries to answer.

\subsection{Problems with theory development}

\section{Empirical generalizations may fail}

Management consultants (and sometimes, managers) publicize many, often weighty books on structure and strategy of organizations. Much of the knowledge they present is based on case studies or specific observation. But frequently the relation between observed reality and related explanatory theory seems to be absent or is not clarified. Moreover, completely ungrounded propositions can be found.

A well-known example of a theory that fails is proposed in In Search of Excellence (1982) by Peters and Waterman. Critical comment states (Micklethwait \& Wooldridge, 1996, p. 17):

[they] identified forty-three excellent companies and tried to distil the sources of their success. But fewer than five years after the publication of the book two. thirds of the companies studied had ceased to be excellent. Some, like Atari and Avon, were in serious trouble; others, like Wang and Dupont, were no longer outstanding. IBM was well advanced in serious decline." 


\section{Greed and fear}

Often the yearning for truth and utility is not the first motive of writers on organization. Burrell (1989) coins the expression 'Heathrow Organization Theory" for the type of management books that are abundant in the bookstalls at airports. Micklethwait and Wooldridge, using the same term, are equally disdainful toward practitioners' management literature and contributions from the academic world. As an example of the first category they mention the notorious case of "The Discipline of Market Leaders', a book by two consultants, that was on the New York Times bestseller list for fifteen weeks and sold 250000 copies, despite indifferent reviews.

Micklethwait and Wooldridge report that there was a trick behind. The authors themselves, their consultancy, and conspiring third parties bought 50000 copies of the book, all over the country, in small quantities. The New York Times was utterly misled and believed in a huge readers" interest. Earlier, Gemini Consulting did the same but on a more modest scale.

These cases indicate that, in the words of Micklethwait and Wooldridge, "fear and greed are the basic human instincts that propel management theory'. They are not proof that all theoretical pretense of practitioners is false and useless, as we will see. But one has to be vigilant.

\section{Academic myopism}

Universities and business schools too are developing knowledge in the areas of organization science, management science and business administration, based on different academic disciplines. However, both the practical usefulness and the scientific level of many of their findings are subject to criticism. One point of such criticism is the deep disagreement among scholars and schools, with no attempt being made to distil any truth from le choc des opinions.

As far back as 1961 Koontz wrote an article called The Management Theory Jungle. The following quotation reflects his position (p. 185):

"It is important that steps be taken to disentangle the management theory jungle. Perhaps, it is too soon and we must axpect more years of wandering through $a$ thicket of approaches, semantics, thrusts, and counterthrusts. But in any field as important to society where the many blunders of an unscientifically managerial art can be so costly, I hope that this will not be long."

In connection he formulates four considerations (p. 186): 'T. The need for definition of a body of knowledge. ... 2. Integration of management and other disciplines. ... 3. The clarification of management semantics. ... 4. Willingness to distil and test fundamentals.'

He recommends that 'we should not forget a few criteria' (p. 188):

"1) The theory should deall with an area of knowledge that is "manageable"; no great advances in knowledge were made as long as man contemplated the whole universe: 
2) The theory should be useful in improving practice and the task and person of the practitioner should not be overlooked;

3) The theory should not be lost in semantics, especially useless jargon not understandable to the practitioner:
4) The theory should gwe direction and efficiency to research and taching: and

5) The theory must recognize that it is a part of a larger universe of knowledge and theory."

In view of the continuing critique, it may be stated that Koontz' was a voice crying in the wilderness.

Now, about 40 years later, the debate is still going on as Micklethwait and Wooldridge demonstrate. From time to time, there is an outburst of the discussion with old or renewed assertions concerning the quality of organization science. In 1979, Burrell and Morgan express their concern about 'mountains of theory and research ...[without] ... obvious links outside narrow discipline areas, ... the essential ephemeral nature of our subject, ... academic sectarism reflected ... in open hostility, ostrich-like indifference ... poor-quality dialogue and debate between essentially related schools of thought" (p. ix).

In 1989, The Academy of Management Review devoted a special issue to organization theory building. Although the tone is less ironic the reader can only conclude that many experts" views are not yet reconcilable.

Examples of the myopia of academic schools can also be found in Reed and Hughes (1992). In this collection Aldrich (p. 36) re-states the problem of fragmentation in the discipline:

Too often theoretical developments appear driven primarily by responses to other theorizing, rather than by the accum ulation of empirically tested thypothesis and well-grounded generalizations. Organization studies resemble many other social sciences in the way that it systematically disdains the two processes central to scientific endeavor: attempted replication of previous findings, and publication of negative findings. Instead, we are treated to 'new' concepts and 'positive' findings, as authors try to differentiate their products from their potential competitors."

Brown quotes a statement of Pfeffer (p. 67): 'It is often difficult to discern in what direction knowledge of organizations is progressing - or indeed if it is progressing at all'. And in the same book Ackroyd comes to the conclusion '...that the paradigm idea, and kindred approaches to organizations produced at about the same time, were at least as much designed to defend threatened academic authority as to induce the development of the field' (p. 104). Another recent report about a discipline in distress comes from Eccles and Nohria (1992). They criticize the fads and fashions that plague the trade.Contributors from outside the AngloSaxon sphere join the same debate from time to time, for instance Van der Zwaan in the Dutch journal Bedrijfskunde (1996, p. 12). He states (my translation):

The particularism among practitioners in the field is striking. This applies to actuailly connecting the findings of research, concepts and theories.. the integration of actual knowledge. But neither do we see attempts for cooperation in projects." 
Language barriers have postponed the cross-fertilization of ideas on organization. Fayol (1920) was only recognized in American and British literature after the publication in 1949 of an English translation of his seminal work Administration Industrielle et Générale - Prévoyance, Organisation, Commandement, Coordination, Contrôle in the Bulletin de la Société de l'Industrie Minérale. An early version of this work was published already in 1916.

An example of parochialism in academic disciplines can be found in the belated reference to French philosophers by American organization scientists. It took fifteen years for French philosophers like Foucault (power structures and the importance of discourse and text) and Derrida (déconstruction), who are salonfahig nowadays, to be cited in American and British organization journals. Derrida wrote De la Grammatologie in 1967; the translation of Grammatology was published in 1974 en first quoted by Gergen in 1982. The belated reference was not due to a language barrier (in international philosophical journals the discourse on the French ideas started right from the beginning), but to one of the many walls between academic specialisms.

Parochialism of academic schools may be concluded from the study by Üsdiken and Pasadeos (1995, p. 503). "Results do show that there is divergence in the perspectives that are currently dominant in Europe and North America, and, to some degree, between Britain and elsewhere in Europe.' Lammers (1995) supported the conclusion in his review of Bacharach et al. This 1995 issue of a yearly account of the sociology of organization seeks to find evidence of a cultural gap between American and European intellectual tradition. As Lammers points out, the set-up of the attempt was ill-designed because typical European contributions to this field (from reputed scholars not publicizing in English) were missing in the volume.

Hickson describes the preference for certain schools in America versus the rest of the world, and its developnent from 1964 until the mid-nineties. Banteringly he writes that the journal Organization Studies was initiated in 1977 by 'a coterie of Europeans' (Hickson, 1996, p. 218). It was seen as 'an alternative to Administrative Science Quarterly'. As an editor of ASQ and later of $O S$, Hickson was familiar with both sides of the Atlantic. In his article, he attributes the differences in scientific emphasis between the US and Britain to cultural factors. In explaining the metatheoretical chasm, he underlines the importance of newcomers like Hofstede (1984; Dutch, cross-cultural analysis) and Ouchi (1981; Japanese, AmericanJapanese differences) in the 'Top of the Pops'.

Guillen (1994) shows the different historical patterns in the adoption of major models of organizational management in the US and Britain on one hand, and in Germany and Spain on the other. His study demonstrates that not only the supply side of theories is rooted in their Heimat, but that demand for organizational knowledge may be different too, as it depends on local cultural characteristics. 


\section{Old wine in new bottles}

Many ideas on organization are presented as new, but not rightfully so. Strikwerda (1994, p. 120), after an ample analysis of the progress in organization theory, presents the rhetorical question: 'Does the fact that management literature ... comes down to the usage of new wordings for old themes that new developments in the field are absent?' As far as business administration is concerned his answer is affirmative. For instance, the novelty empowerment is nothing but the ancient theme decentralization, while reengineering the company boils down to the analysis of company processes followed by cost cutting. On page 125 he quotes Drucker, who claims that between 1920 and 1930 all important management subjects have been dealt with, while all developments since are variations and extensions of the body of knowledge of that period.

Eccles and Nohria argue likewise (1992, pp. 5-8).

\section{Scholars lagging behind practitioners}

The natural sciences often lead the way to new industrial applications. In organization science it is the other way around. In the Dutch journal M\&O Buelens (1997, p. 34) comments on a discipline in crisis. He states that the output of organization science from the academic halls is inadequate, and that consultants, practitioners, and even pressure groups have taken over the scientific study of organizations. 'Practice is miles ahead'.

But practice has always been miles ahead in organization science. Taylor, Fayol, Barnard, Handy, to name only a few were, first and foremost, practitioners. As far back as the thirties James McKinsey (1932) introduced the concept of business strategy in an address tot the American Management Association about "Policy". The Boston Consulting Group applied the portfolio matrix theory in the early sixties, long before the first academic contribution on the subject was published. In the early seventies, my own consultancy (KWW, Rotterdam), in a number of industry studies, used a method for explaining and forecasting the competitional strength of companies that was exactly the same as Porter's five forces model which was publicized several years later (1979).

\subsection{The battle for theory and the need for it}

So now we seem to have a serious problem. Both practitioners and academics are under severe criticism with respect to their contribution to the body of organizational knowledge. It is said: to be fragmented, myopic, ethnocentric, parochial, overdue, and driven by the urge to defeat academic and business competitors, if not by greed and fear.

The criticism raises two questions. First, what is wrong with self-interest as a motive for achievement? Clearly nothing, so long as the battle between supplying competitors is in the interest of consumers, i.e., those in need for good theories. But when theorists deliberately or 
out of ignorance pass over sound ideas or findings of other parties, they damage the common interest.

The second question is about the need for theory. Can't practitioners do without it, and rely on experience, intuition and gut feeling? One fine theorist, Kurt Lewin, who had extensive practical experience, phrased the never-to-be-forgotten saying: 'nothing is as practical as a good theory' (Lewin, 1945). Managers sometimes dismiss theory as impractical, but at the same time they consume ever-\|arger quantities of management fads. Out of 25 fashionable management techniques among which re-engineering, total quality management, intrapreneursh ip, and managing-by-objectives the average American enterprise used twelve in 1993, thirteen in 1994, and fourteen in 1995 (Micklethwait \& Wooldridge, 1996, p. 17).

All managers prepare their actions on the basis of knowledge, and by doing so the knowledge is assumed to be theory. The better the theory, the better the actions.

In this day and age, when knowledge is said to be the most important raw material for the company, and its crucial means of production, and its leading edge in competition, knowledge of structure and strategy cannot be left to common sense alone.

\subsection{Conclusions and further steps}

From the foregoing it has become clear that much of what we think to know or pretend to know about organization seems to be false or ungrounded. An urgent need exists to reinforce organization theory, management science and business administration. Henceforward this field will be denoted with the comprehensive term organization theory. For the Dutch expression "bedrijfskunde" and related terms in the US, Britain and The Netherlands reference can be made to Bodewes \& Woudstra (1994).

Despite the laments cited in the preceding sections, there is good news as well. Contributions to organization theory from sociology, psychology, economy and their auxiliary formal sciences (like mathematics) tied together with engineers' systems thinking seem to develop into more valid and applicable formulations. It is even more promising that recently academic workers in these dields have become engaged in exploring their mutual boundaries. The tangent of these domains seems to offer new vistas. At this vantage point, depicting and formal models are used to describe, explain, and predict organizational phenomena (Lindenberg \& Schreuder, 1993).

In this study an attempt will be made to look into the validity and utility of theories on organizational structure and strategy. The validity check looks after the correspondence between the consequences of theoretical propositions and what can be observed. The utility aspect reviews the practical usefulness of established knowledge. Next to the assessment of those qualities, the potential of elements of knowledge to be developed into a more powerful form will be examined. 


\subsection{The essentials of the research}

For practical reasons the scope of the study has to be restricted. In the next chapter details of its delimitation and focus will be discussed and further elaborated upon. For now, to conclude this chapter, its main elements will be briefly mentioned.

\section{The problem}

All of my professional life I have been involved in organizational work, either as a consultant or as a manager. Frequently I had the uneasy feeling of received theory on organization being of poor quality. The overview given above shows that the suspicion is justified.

Intervention in the organization requires knowledge about the desired situation. This means that a design of the aspired state has to be made. When we turn to proposed knowledge as an aid for design, the question is whether the body of knowledge is trustworthy and adequate. In other words, we need an assessment system.

The necessary restriction of this study leads to its limitation to the structure and the strategy of organizations. Furthermore it will be limited to knowledge that has been proposed during the 20th century.

The terms trustworthy and adequate as used above will be translated into the concepts of validity and utility.

The problem of this research now reads: how can 20th-century organizational knowledge be assessed with respect to its validity and utility, in view of its use for the design of structure and strategy of the organization.

\section{Objectives of the study}

The problem leads to the primary objective of the research, namely the development of an instrument for the assessment of organizational knowledge as specified above. With this tool the practitioner can judge whether he can use certain received theory.

A related question may read: 'has there been any progress in theory building over the last century, and what may be expected for the future?' Therefore, as an important secondary result, this study will provide a contribution to this answer by producing a reflection of the body of knowledge as it developed over the 20th century, in comparison with a sample showing the 1995 state of the art.

\section{The method}

The method will consist of the following steps. To start with the position of the research in the contemporary debate on the matter will be established. In relation hereto the metatheoretical basis for the design of an assessment system will be developed as an extension and combination of existing methodological lines of thought (chapter 2). 
In chapter 3 this basis will be further developed by observing received theory. Traits of examples from the body of knowledge will be linked to metatheoretical concepts.

In chapter 4 this will lead to the assessment system proper. The system is meant to provide a systematic appraisal of validity and utility of proposed theories, in relation to their potential for design rules.

Subsequently two samples of theories originating in the 20 th century will be assessed on the basis of the system. Chapter 5 deals with a sample of 28 theories proposed between 1910 and 1990. As will be explained in section 5.1 the sample is taken from theories advanced in books of that period.

Of those theories, the societal and philosophical background, the postulates, the main tenets of their proponents, the course of knowledge development and some more properties will be established systematically.

In section 5.30 a conclusion will be drawn about the efficacy of the assessment system, in other words, to what degree the first objective of this study has been met. Conclusions in relation to the second result -the rendering of a reflection of 20 th-century organization theorywill follow. Trends over time and types of theories will be discussed, together with a comprehensive list of data obtained from the assessed theories.

Chapter 6 goes into some articles published in 1995 in order to compare contemporary contributions to those covering the whole of the 20 -th century.

Finally, in chapter 7, final conclusions will be drawn.

As an encore, in the same chapter afterthoughts will be given.

The intended result

This is an enterprise of the methodology of organization science. The research intends to contribute to a better insight into the scope and limitation of contemporary and future organization theory as far as the design of structure and strategy is concerned.

In the following chapter definitions, scope and limitation as well as the objective of the study, will be specified in more detail. 


\section{Scope and objective of the research}

\subsection{Definitions}

As stated in section 1.5 this study concentrates on theories referring to the structure and strategy of organizations, called organization theories for short. It deals with a design problem, namely the design of an assessment system for such theories. This means that the practical application of knowledge is involved. Therefore definitions are pragmatic descriptions of the concepts involved. An ample analytic-philosophical discussion of concepts like knowledge would be out of order in this study.

\section{Knowledge and theory}

The connotation of the terms knowledge and theory as used in this study can be specified as follows.

The word knowledge has been used so far in 'ordinary language'. In this study it will have the pragmatic connotation as is Dewey"s view (1920). Bunge elaborates on the subject (1967a, p. 9 ). On this page, in figure 1.1 , the author depicts a research cycle, in which a problem is placed on the map of the 'Body of available knowledge'. In accordance with Bunge's position, knowledge is defined in this study as the conceptual means used to solve problems. For a contemporary discussion on the concept of knowledge in relation to problems to be solved, see Visser (1990, 1993).

Theories are general statements referring to observable phenomena. Theories on abstractions like many in medieval scholastic philosophy, and mathematical theories, are excluded.

Theories in our terminology must be more or less corroborated. So theories are grounded knowledge. In the chapters to follow, definitions will be given for different sub-species of knowledge and theory that are more precise.

Validity of a theory means that what it describes and predicts is in accordance with observation. The observation may take place by day-to-day confrontation or by the testing of the theory in an experiment. Testing in the first place requires intersubjective testability. As the 
result of testing, theories may be considered to be more or less supported, subverted or, in the most negative situation, refuted. From the outcome theories are corroborated to a greater or lesser degree.

Utility of theories refers to their practical usefulness. In accordance with the scope of this study theories should contribute to questions regarding the design of the structure or strategy of the organization.

\section{Structure and strategy}

To explain my choice of definitions for structure and strategy, I will start with two examples of the terms structure and strategy as used by two reputed authors. Chandler's definition goes as follows (1962, p. 13): 'Structure can be defined as the design of organization through which the enterprise is administered. ... It includes, first, the lines of authority and communication ... and, second, the information and data that flow through these lines.' Mintzberg's definition is quite different (1979, p. 2): "The structure of an organization can be defined simply as the sum total of the ways in which it divides its labor into distinct tasks and then achieves coordination among them.'

As for strategy, I will refer to the same authors. "Strategy can be defined as the determination of the basic long-term goals and objectives of an enterprise, and the adoption of courses of action and the allocation of resources necessary for carrying out these goals." (Chandler, 1962, p. 14). Mintzberg and Quinn (1992, p. 5) say: 'A strategy is the pattern or plan that integrates" an organization's major goals, policies, and action sequences into a cohesive whole. A wellformulated strategy helps to marshal and allocate an organization's resources into a unique and viable posture based on uts relative internal competencies and shortcomings, anticipated changes in the environment, and contingent moves by intelligemt opponents.'

Apart from the striking differences between the two sources there are common elements as well. In my definitions I will use a combination of the essential elements of Chandler and Mintzberg while omitting less adlequate terms. Restricting structure to a design, like Chandler does, neglects the fact that structures may develop spontaneously. Summing up elements of structure, like both authors do, is either too restrictive or is just meant to exemplify the subject, in which case it should be no part of a proper definition.

The definitions of strategy of both authors can be rephrased more concisely. In my view, both terms must be defined in a way that emphasizes the lasting and persistent character of both structure and strategy, in contrast to day-to-day decisions about the division of work to be done or procedures to be followed, or to short term tactical moves.

Taken these considerations into account, the following definitions are chosen.

Organizations are defined as lasting and persistent forms of cooperation between people and groups, directed at specific goals.

Structures are lasting and persistent properties of the (characteristics of) relations between those people and groups, and their means.

Strategies are those forms of behavior used by organizations, which are aimed at their longterm preservation and improvement, and at the sustainable achievement of their goals. 
Both the terms lasting and persistent in these definitions are of importance. A phenomenon is lasting if the skilled observer is able to conclude that its main features remain constant over considerable time (months or years). If there are any changes, these concern either irrelevant ripples or fundamental long waves and shocks. In the latter case the 'lasting period' has come to an end, as all things must.

Persistency has to do with two points: the role of the will and the inherent stability.

The first refers to the intentional determination of the participants in the organization to maintain its structure and strategy. Despite difference of opinion, and even of dissidence, the resulting force is directed at preservation. In this aspect, structure and strategy are deliberately selected and pursued, in order to counter detrimental or undermining forces, both from outside and from within. The second aspect, inherent stability, concerns the built-in resistance of strategies and structures to internally or externally induced disturbances, independent of determined actions of participants. When deciding upon the question whether a structure or a strategy is persistent, the observation of either of these aspects will suffice.

The relation of the characteristics 'lasting' and 'persistent' is illustrated in the following table.

organization

without built-in persistency

with built-in persistency non lasting

\begin{tabular}{|l|l|}
\hline a busload of passengers & $\begin{array}{l}\text { neighborhood with no social } \\
\text { coherence }\end{array}$ \\
\hline $\begin{array}{l}\text { organization for one occasion } \\
\text { (celebration committee) }\end{array}$ & subject of this study \\
\hline
\end{tabular}

Table 2.1. Domain of organization in this study

\subsection{Objectives of the study}

\section{Rhetoric: ethos, pathos, logos}

In order to make their point many writers on organization seem to follow the ancient line of attacking the audience as was done already long before Socrates. In the old days teaching rhetoric was a thriving business in Greece and Rome. Aristotle discussed the subject at length in his work Rhetorica.

In the art of rhetoric he distinguishes three elements: ethos, pathos, and logos. Ethos aims at making the audience believe that the speaker is a trustworthy and amiable person, sharing values with the listeners. Pathos is the part of evoking emotions among the listeners about the issues proposed. And after having convinced the public of the speaker being a good person, one of their kind, and having aroused the necessary state of feelings, the third step follows, named logos. This involves the making of a well-reasoned exposition about the subject matter 
(Aristotle, Kennedy (ed.), 1991). Today's management gurus are well aware of the trade. They have to 'sell' their ideas to an audience of busy, impatient managers. Managers have not much time to absorb extra information, and they insist on being briefly briefed. In the short time available to keep their attention, most emphasis may be laid on ethos and pathos at the expense of the logical and empirical grounding of the issues proposed. This style suits the manager who is aware that making things happen is more important than scientific contemplation.

In this situation, most important about theory is the belief of participants -or bystanders- in its truth. That is not a matter of scientific rigor, but of conviction. Messages like 'you can do it', "we must change our culture", and "let"s make things better" do not need to rest on grounded theory, although seasoning the dish with a pinch of science may help to make it palatable. In table 2.2 hereafter the two roles of theory are illustrated.

In this respect, an interesting discussion can be found in Eccles \& Nohria (1992). Their book starts with a well-elaborated critique of faddish pretense, as was cited in section 1.2. Next they state that all those somcalled revolutionary changes that would require completely new management techniques are not so revolutionary after all, but just milestones alongside the road of a more or less continuous societal development. They reject fashionable modernism and claim that management should return to its basics, namely action. And action means the effective use of convincing language, in other words: rhetoric. My view is, that design based on knowledge is an indispensable part of managerial action, as it is the logos part of rhetoric. The position of the authors at this point is clearly the same (pp. 54-55).

'Managers must remember that their ultimate aim is to get things done, not to devise elegant designs. ... We are certainly advocates of the action perspective. But. as we will continute to insist, we are not opponents of design. Design can be very useful because they allow the manager to form solid pictures of new possibilities and to discern new relationships."

The authors give examples of 'the knowledge managers use to take action' like some of the theories discussed in chapter 4 of this study.

It may be concluded that the most adamant proponents of rhetoric accept the necessity of design, and of the grounded knowledge (logos) behind it.

This study will be focused on the logos part of knowledge.

\section{The contemporary debate}

In order to position this study in the field of contemporary debate I will shortly go into two lines of related meta-inquiry.

The first stems from Bacharach (1989), who formulated a number of criteria for testing theories relating to organization. He designates these touchstones under the terms of falsifiability and utility and discerns criteria for variables, constructs, and relationships (p. 502). As an example of his method of testing he refers to a critique of Young (1988), who examined the population ecology theory as proposed by Hannan and Freeman (a/o Hannan and 
Freeman, 1977). On the basis of the examination Bacharach points at important flaws in the methodology of these authors.

The remarkable fact is, however, that even a broad but superficial observation of the body of proposed organizational knowledge reveals widespread and more fundamental philosophical weaknesses than those of Hannan and Freeman, as we will see in chapter 5 . Therefore, in my opinion, a system of theory assessment is necessary that is on one hand less severe and on the other hand broader than Bacharach"s touchstone. This is especially important if the system is meant to apply to the particular domain of this study, namely the field of knowledge that is useful for the design of structure and strategy. Designers often have to use knowledge rigorous enough to enable description and prediction, but falling short of explanation. The latter quality however is one of the prerequisites of a theory, according to Bacharach's scheme.

The second strain of discussion can be found in a series of recent articles in the Dutch journal Bedrijfskunde (1994). The history, the methodology, and the discipline to which bedrijfskunde (say, business administration) would belong, are the central subject of the series, which is an exercise in metatheory.

A fundamental weakness in many of those articles is the neglect of observation. The authors refer to other metatheorists, but many of them do not produce systematic examples of what exactly is produced and defended in received organization theory, and if and how results were obtained.

My position is that a metatheorist report should contain findings from observation, in this case the observation of theories, likewise, as a theorist ought to link his propositions to systematized observation of the subject matter. The absence of this link is apparent in most of these articles (and, for that matter, in Bacharach's article as well).

Therefore an important part of this metatheoretical study will concentrate on the observation of theories.

As far as metatheory itself is concerned, many of the tenets in the articles in Bedriffskunde are directly or indirectly based on metatheoretical propositions by A.D. de Groot (for instance Van Strien, 1986). To clarify my position in the debate I will refer to De Groot and Van Strien.

De Groot describes what is called 'the empirical cycle', designating the phases observation, induction, deduction, testing, and evaluation (De Groot 1968, p. 29). By contrast, Van Strien introduces the 'regulative cycle', arguing that in handling practical problems the researcher has to rely on a different methodology. The regulative cycle is said to consist of the phases problem formulation, diagnosis, plan, intervention, and evaluation (Van Strien 1986, p. 19). Van Aken (1994b) discusses the presence of both methodologies.

My position is represented in a meta-model of knowledge development that includes an extension and a specification of De Groot's empirical cycle. In this meta-model Van Strien's regulative cycle is included. It will be exposed in detail in chapter 3 .

The choice for the approach is based on my practical experience as a consultant, together with a broad orientation in the organization literature. I came to the conclusion that in general received theory on organization was not specific enough for Bacharach's lancet. In applying it, 
theories holding certain technical flaws may be pedantically dismissed, thereby depriving us of perhaps brilliant thought, clever constructs and seemingly daring but potentially fruitful speculation. I decided to design an examination system for organization theories that would be tolerant enough to admit fruitful knowledge but at the same time would reveal fundamental metatheoretical flaws that might limit their applicability.

\section{The main products of this study}

The main objective of this study is to develop a metatheoretical method (an assessment system) for the evaluation of organization theories. An impartant secondary result is the rendering of a systematic representation of the body of organizational knowledge as it is observed through the assessment system.

The study has inevitably a limited scope, as it concentrates on those theories that are instrumental to the design of structures and strategies of organizations. A second limitation is its restriction to grounded knowledge, as will be explained hereafter. Both restrictions have to do with the two different roles theory can play in organization science.

In one line of application theory is the basis for preparing new or improved organizational structures and strategies. The second role theory plays is in the process of implementation of the thus planned organizational change.

In the first role, knowledge may have different forms, ranging from rule of thumb to scientific theory. The complete design doctrine usually consists of many of those forms, combined in a set of rules for action. The combination itself is a rule of practice. All forms purport to describe, predict, and explain what will happen when a certain solution is chosen. In the knowledge used, scientific rigor is of importance in order to obtaining the best possible design. Therefore scientific theories are better than speculative generalizations, and these are preferable to non-empirical propositions. The place of a theory on this scale depends on criteria such as intersubjective testability and, if testable, the degree of its corroboration.

\begin{tabular}{|l|c|c|}
\cline { 2 - 3 } $\begin{array}{l}\text { types of knowledge about } \\
\text { structure and strategy }\end{array}$ & $\begin{array}{l}\text { A. relevant for the process of } \\
\text { organizational design }\end{array}$ & $\begin{array}{l}\text { B. relevant for effectuating } \\
\text { organizational change }\end{array}$ \\
\hline 1. non-empirical propositions & possible upbeat to A.2 & $\begin{array}{c}\text { propagandistic, } \\
\text { rhetorical }\end{array}$ \\
\hline 2. speculative generalizations & first step toward A.3 & $\begin{array}{c}\text { an aid to sense making, } \\
\text { 'Verstehen' }\end{array}$ \\
\hline 3. scientific theories & $\begin{array}{r}\text { basis for grounded design } \\
\text { rules }\end{array}$ & $\begin{array}{c}\text { as in B.2, but with the extra } \\
\text { persuasiveness of a } \\
\text { corroborated assertion }\end{array}$ \\
\hline
\end{tabular}

Table 2.2. Types of theory and their meaning for design or implementation 
In its second role, theory is instrumental in influencing individuals and groups. An example of such a situation is a program of change of the organization. In the change process, under the supervision of a managing agency, the organization and its consultants try to bring about the new strategy or structure desired. The process is called organization development. It requires the orchestration of effective group dynamics, introspection ("who are we and what do we want to achieve'), as well as an external appraisal ("what is the relation of our organization with its environment ${ }^{*}$ ). In its influencing role organizational knowledge has a different part to play. It is not the leading part, but nevertheless an essential one.

In table 2.2 three different types of knowledge are connected to their relevancy for either the design of organization or for the change of it. As stated, this study concentrates on column A, in other words, on logos. When applicable, the presence of rhetoric will be reported in the assessment of the theories.

\section{By-products}

In addition to the main products of this study some by-products obtained will be discussed in chapter 7. As the result of the examination of a selection of theories, hypotheses about good and bad organization theories will be formulated. Next, desiderata for research on the future development of theories will be put to order.

\subsection{Stages of the research}

After a broad orientation into organization literature, placed against my background knowledge of the field, I concluded its variety to be stunning, even within the domain of structure and strategy. There were popular "how to" recommendations next to reports of scientific research, all kinds of subjects and aspects were discussed, and a plethora of schools and paradigms were presented. I started with a rough face-value examination of a number of theories and theory-like contentions by means of close reading, keeping in mind general experience. The first attempt to find "method in the madness' of posited theories convinced me that firstly general characteristics of organization theories had to be developed as will be discussed in chapter 3. Only after this exercise fruitful examination would be possible. As a result of the orientation, a checklist for the assessment of organization theories will be constructed as given in chapter 4 . The framework is used for the description and judgment of a sample of 28 organization theories as they were proposed over the 20th century (chapter 5), followed by the examination of six more contemporary theories (chapter 6). 


\section{From traits of theories to the A - F - scheme}

\subsection{Questions on theories}

This chapter starts with general questions on theories. In section 3.2 knowledge development in general will be explained. Existing metatheoretical positions will be combined and developed into the core element of the assessment system that is central to this study, namely the A - F - scheme. In the scheme, six phases of knowledge development will be distinguished. In subsequent sections ( 3.3 through 3.8 ) each of these phases will be elaborated. In the final section (3.9) the definition of the term theory as used in this study will be proposed.

The exploration of the domain of design theories referring to the structure and the strategy of organizations starts with two questions on theories, and a related one on knowledge.

- What is a theory?

- What is the point in having a theory?

- How does knowledge develop?

\section{What is a theory?}

In the preceding chapter theory was defined as general statements referring to observable phenomena which have been corroborated to a greater or lesser degree. However, in the literature on philosophy of science many different meanings of the word theory can be found. The notion of the term may range from speculative generalization to corroborated assertions referring to a well-defined domain. In table 2.1 a gamut of theory types was given in column A. In this study, theories considered will be restricted to those of box A.3, namely scientific theories.

In order to specify the term theory in more detail, certain traditions of the philosophy of science might be followed. However, at this stage this seems unfruitful, given the multitude of differences and controversies found in organizational metatheory so far, like is illustrated, for 
instance, in the special forum on theory building in The Academy of Management Review (1989).

A different approach has been chosen. To start with, examples of elements of -what is claimed to be- organizational knowledge are selected to show their typical traits in various stages of development. Subsequently a definition of the term theory as used in this study will be given.

What is the point in having a theory?

As explained in section 2.1 my position in this study is that a theory is a conceptual instrument for solving problems. In our case, the problem will be related to questions such as 'how to select an adequate organizational structure?', or, 'how to formulate a successful strategy?'.

Now attention must be given to the third question, namely 'how does knowledge develop?'

\subsection{How does knowledge develop?}

The art of knowledge building

Practitioners need cognitive tools (knowledge) as a basis for action. Like good instruments, they should be strong (not yielding under stress), useful (functioning as required), and tuned to the purpose at hand (specific). The more testing of their derived consequences against observation corroborates these tools, the better they will serve as a ground for design. But such corroborations are rare in organization science. So, if the situation is demanding, practitioners either 'muddle through' or they apply any hunch, bowever weak it may be.

In the next chapters a number of reports on the development of organizational knowledge will be examined. This requires some conceptual framework as a background. Dissecting a frog is not a matter of chopping the poor animal into pieces, but the orderly laying apart of skin, muscles, blood vessels and nerves. Correspondingly, a systematic description of theories cannot be established without the preliminary knowledge that eyes, nose and ears are, among others, features of a face.

Two ways of knowledge building can be observed. The first one starts with empirical observation (De Groot, 1968). Practitioners frequently find repeated coincidences, patterns, and other regularities in material observed. They may be tempted to translate these into general statements about the subject matter, like 'all computer companies are profitable', "Japanese management practices are superior to American ones", "the performance of a company is better when the workers get personal attention from their bosses", "power relations completely explain the functioning of an organization'. All these examples, if accepted as valid, may serve as a base for designing structures or strategies, or both. 
The direction when acquiring general insight from specific observation can be seen as upward (from the low levels of day-to-day reality to the high level of knowledge). If such insight is obtained, the problem, reading 'what is useful and valid knowledge', is solved.

The second way starts with so called postulates, namely axioms or beliefs. An axiom is a proposition that is intentionally exempt from verification. A belief is an assumption that is not questioned at all. Examples of axioms are positions like 'human nature is such and such, so an organization should ...", "economic laws rule structure and strategy'. They may be formulated either in the manner 'let us assume that ...', or by way of 'as we/you all know ...". In the latter case a belief is expressed.

Inferred from axioms or beliefs hypotheses are formulated that refer to the problem at hand. The utility of these hypotheses depends on the degree in which their derived consequences pass muster. In other words, the better they are validated, the better they will serve for organizational design.

This direction of knowledge development, i.e., from hypothesis (supposed generalities) to the formulation of derived specific reality, will be called downward. These two paths should be clearly distinguished for reasons that will become clear hereafter.

\section{The empirical and the regulative cycle}

In section 2.2 Bacharach's touchstone was found to be too strict for the assessment of organization theory. The approaches of the authors in the series of articles in Bedrijfskunde led to divergent conclusions. Many of these articles, however, shared support for a metatheoretical appraisal of organization theory in referring to two Dutch authors, namely De Groot (1968), and Van Strien (1986).

In order to position an essential proposition of this thesis within received metatheory I will specifically refer to those two metatheoretical models for the analysis of the development and the practical application of knowledge.

De Groot $(1968$, p. 5$)$ proposes the 'empirical cycle' in reflection. He states that psychological processes in learning can be described as a sequence of:

- observing

- conjecturing

- expecting

- testing

- evaluating.

He further explains that a more developed way of this cycle will ensue when it comes to scientific endeavor. The scientist would aim at systemizing his experience by description, ordering, registration, understanding, and explaining. Finally he seeks to predict what will happen under specific circumstances. The prediction would enable him to control matters and to influence the course of events. Such objectives require that knowledge be explicit and transferable.

In this respect De Groot advances the cycle of empirical-scientific research (p. 19). Its phases are said to include (my translation): 


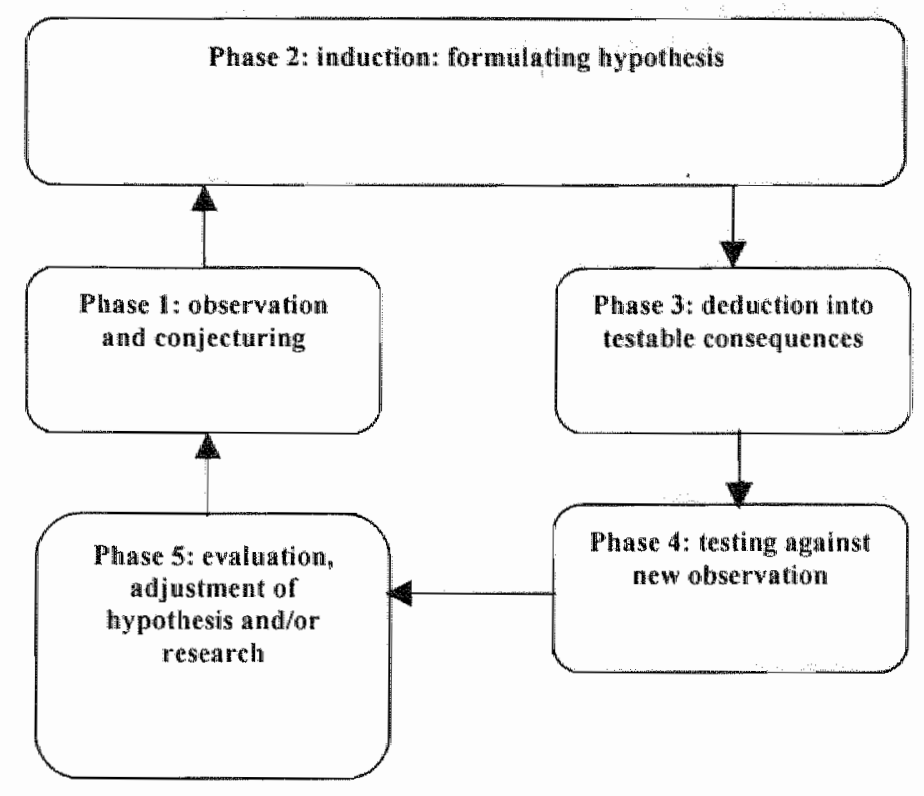

Figure 3.1. Depiction of De Groot's empirical cycle (1968)

'Phase 1: Observation: assembling and ordering of empirical facts; building of hypothesis; Phase 2: Induction: Formulating hypothesis;

Phase 3: Deduction: Derivation of special consequences from hypothesis, in the form of testable predictions;

Phase 4: Testing: of the hypotheses against the outcome of predictions in new empirical material;

Phase 5: Evaluation: of the results of testing, in relation to the proposed hypotheses or theories, and relating to possible new, connected research."

The cycle can be depicted as in figure 3.1 .

This representation reveals four points that deserve comment. First, observation is present in both phases 1 and 4 . Second, observation and the building of hypothesis are combined in phase 1 , while only after induction the hypotheses are formulated (phase 2). Third, a new round of observation is introduced after deduction of hypothesis into their testable consequences. And, finally, as a result of testing, new or adjusted hypotheses are surmised, with or without new observational activities.

A reformulation of the phases would improve the insight that the empirical cycle is supposed to produce. The following adaptations are suggested. The cyclical character of the process would be underlined if observation in all stages were combined in one and the same box. A clearer model of the sequence of intellectual steps would ensue if only induction would generate hypothesis, while all hypothesizing would be combined in one box. Finally, festing 


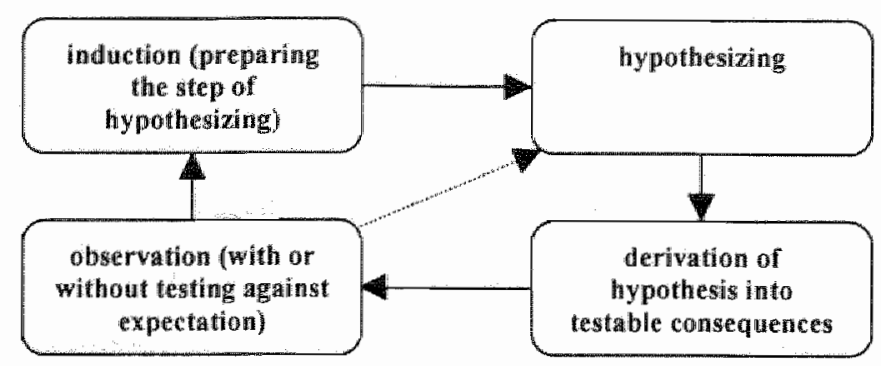

Figure 3.2. Revised model of the empirical cycle

could be combined with new observation. As a matter of terminology the word deduction, with its mathematical connotations, is replaced by derivation.

These adaptations lead to the model as depicted in figure 3.2 .

Now we see that the cycle can and will be run through repeatedly. In the process, all phases will produce improved knowledge as is sought by scientific enterprise. The dotted line will occur when hypothesis is decisively refuted by its testing. In such cases completely new hypotheses have to be conjectured.

This study aims at design. Sometimes the designer can use knowledge that has been developed as described above. In many cases however he has to rely on intuition, heuristics or rules of thumb. In this respect it is worthwhile to note the position of Van Strien (1986). He coins the concept of the 'regulative cycle' as a concept differing from De Groot's empirical cycle. It is said to consist of the following phases (p. 19):

- problem formulation

- diagnosis

- devising of a solution

- intervention

- evaluation.

This approach would obtain in cases where a general theory is absent or insufficient. The professional consultant is called upon to solve a problem of a person or a group. He has to use his professional experience, maybe supported by fragments of applicable theories. None of the latter, however, may specifically and completely relate to the problem at hand. He will have to apply rules for his intervention. Essential is his acting in what he considers to be in the best interest of the client system. In contrast to the layman-helper he is supposed to maintain a professional detachment, based on the best of his professional knowledge.

Van Strien describes his 'regulative cycle' as 'a basic model of problem- and praxis-oriented thinking in its own right'. He juxtaposes it to De Groot's empirical cycle. The regulative cycle would emphasize the individual solution and the right way of acting, based on design rules. He 
claims this to be in contrast with the generalized knowledge and the valid insight that is sought in the empirical cycle.

The regulative way of thinking can be depicted as in figure 3.3 .

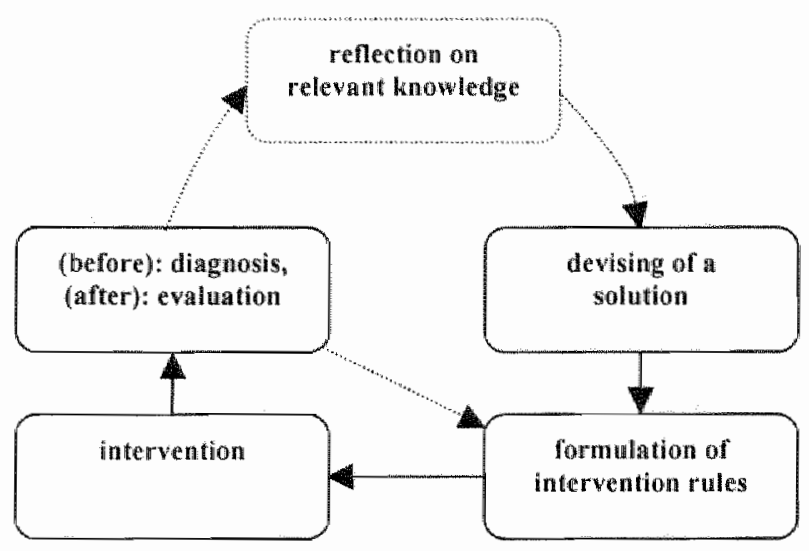

Figure 3.3. Depiction of Van Strien's regulative cycle

It should be noted that diagnosis and evaluation coincide with the box "observation" of the empirical cycle. No professional intervention is conceivable without prior systematic observation. The evaluation is comparable to the testing act of De Groot's model. Planning of a solution will not only rely upon observation, but also as much as possible upon appropriate knowledge. No professional will do without. This phase is represented by the box "reflection on relevant knowledge", connected with the dotted arrows to and from.

After the planning phase the next step in the cycle is the formulation of explicit rules for intervention. Next the intervention proper may take place, followed by the evaluation of its effects.

If the rules do not produce the desired effect, new ones will have to be thought of. This step is indicated by the dotted arrow from "evaluation' back to the "formulation of rules".

\section{Van Aken's reflective cycle}

In one of the articles in Bedrijfskunde Van Aken proposes the reflective cycle (Van Aken, 1994b). He accepts that in absence of a general theory the professional will have to follow the regulative cycle for every individual case. But he draws attention to the fact that reflection on the results of many interventions may lead to improved knowledge that is applicable to a class of problems. This form of the accumulation of knowledge is obtained by following the reflective cycle. He writes (p. 22, my translation): "This cycle consists of the following steps: selection of the class of cases to be studied, choice of the individual case, the application of the 
regulative cycle to solve this problem, reflection on the results, design and documentation of the design knowledge that has been applied, and selection of a new case from the class of cases that has been chosen"

He adds that the term refiection is akin to the concept of induction as used in the empirical cycle.

The A - F-scheme of knowledge development

The essential proposition of this study is the combination of both metatheoretical schemes, together with the expansion of the latter by Van Aken, into one. The model is called the A - F scheme of knowledge development. It is depicted in figure 3.4.



Figure 3.4. Depiction of the A - F-scheme

In the upper four boxes De Groot's adapted empirical cycle can be recognized. The lower four are in accordance with Van Aken's reflective cycle, based on Van Strien's regulative cycle. Together they comprise the cycle of knowledge development that will act as a framework for the assessment of organization theories in this study. The elements of the model will be discussed hereafter. The discussion on the A - F - scheme is summarized in section 3.9 .

\section{Thinking upward and downward in more detail}

As stated, the upward direction seeks to formulate generalized knowledge. It starts with observation and tries to find statements concerning general properties of the observables under specified conditions. This phase is called induction.

The downward direction is the other way around. A set of axioms is postulated. From these, and from general background knowledge, hypotheses are inferred. The concepts from these assertions are translated into expressions that refer to observable phenomena. The step is called 
operationalization (Bunge, 1967a, p. 148). Subsequently, the testable consequences of these expressions are formulated. Thereafter, testing takes place in the sense that tenability is sought for these testable consequences by making empirical observations in the light of the operationalized hypotheses. As far as the operationalized theory holds out against these observations, the knowledge is corroborated after a process of derivation from hypothesis to a greater or lesser degree. We then have "general statements referring to observable phenomena, that are more or less corroborated', as was the temporary description of the term theory from chapter two.

These two archetypes of knowledge development, induction and derivation seldom occur alone. In most cases, observations lead to hypotheses, and then the consequences of these hypotheses are tested against reality, after which a new cycle will begin (see also figure 3.10). The iterative process may start with some unexpected observations for which an explanation is sought, or with the belief that certain principles govern a certain domain of observation. Inductive and derivative phases will follow one another until satisfactory knowledge is obtained. Eventually newly discovered evidence will lead to adaptations of this knowledge; or conjectures may be improved on second or third thought, or with the help of discoveries from other researchers. In other words, there is no observation without prior background knowledge, nor is there hypothesis without prior experience. We will come back to this point in the discussion at the end of this chapter.

There is no straightforward process that yields generalized knowledge. On the one hand researchers are deriving models and observable categories from conjectures. On the other they induce hypotheses from observables via constructs and models.

These reflections again demonstrate that it is not fruitful to start this study with the epistemological formulation of assaying criteria for organization science. Instead, first of all stages of knowledge development have to be described as can be observed in the specific domain of knowledge. In this study observation will take place by looking into publications in the field. The observed steps will be linked to their conventional metatheoretical terms.

Procedures and results

The steps of knowledge development will be discussed now in more detail, by using examples. First, procedures and results in the induction (upward) direction will be sought. After that, the direction from hypothesis to observation (downward) will be elaborated.

Within each step the procedures followed during knowledge building, and the results obtained will be distinguished. 


\subsection{Observation}

\section{Observing and observables}

All organization research starts with observation. Taking stock of raw materials is an example of the observation of simple states or events. The procedure consists of defining, establishing place and time, and counting or measuring. The result is an unambiguous figure.

Sometimes the observation requires a value judgment. The amount of cash in the till is an undisputed figure, but the value of a company requires a due diligence appraisal by an expert. What is observed from observation has been interpreted by the expert.

An example where different observables are used in knowledge development can be found in Likert (1961). He mentions the following ones ( $p, 6)$ :

1. productivity per man hour,

2. job satisfaction and other satisfactions,

3. Iurnōver, absence,

4. costs,

5. Scrap loss.

6. employee and managerial motivation."

\section{Observed simple states and events}

Items 3 (turnover, absence) and 5 (scrap loss) can be observed directly. The other items are constructs and will be discussed in section 3.4. An example of the observation of a somewhat more complex event is given hereafter (figure 3.5, after Verburg, 1959).

In the work analysis form all actions of the worker are meticulously described and the time per action is measured repeatedly with a stopwatch, while several workers are subsequently observed.

The example concerns the break down of an operation over actions. At a lower level actions can be analyzed and divided into movements, as was pioneered by Taylor and Gilbreth. The latter used films, which included a clock ruming simultaneously (Guillén, 1994).

In cases such as these the procedure contains the following elements:

- formulation of what is to be observed, in general and in detail,

- design of observation method,

- design of the reporting method, definition of variables,

- preparation of observation,

- repeated observation,

- the processing of findings,

- the drawing of conclusions. 




Figure 3.5. Example of an operation analysis (after Verburg, 1959)

The result is the standardized time for an operation, which can be put together with other standard times to establish the time and cost of manufacturing completed products, and hence, productivity. But the detailed analysis also offers opportunities for other purposes. Unnecessary movements may be earmarked as an indication of poor skill. The ensuing knowledge obtained may serve for the better design of machinery and tools, for piece rate 
systems, for training workers, for improving labor conditions, for better process scheduling, and for quality control. The insight from the analysis may also lead to the building of theories, like Taylor did in his work on scientific management (Taylor, 1914).

Another example of observables is the annual report of a company. It contains financial data and other relevant figures in relation to the activities performed, which are specified as to products, markets and locations. Such sets of data are produced at fixed intervals as a routine procedure, formalized by strict rules. Next to the report of the company itself its certification by a chartered accountant may be involved. Acceptance of the final version may require the consent of directors, sharehoiders and the workers council. The result is remarkable. This observed state of the company becomes a document of credence that can be trusted by interested parties (shareholders, employees, banks, suppliers, and public authorities). But it also serves as data that enable the comparison of (qualities of) companies, industries, and nations. Aggregated data from annual reports are important bases for organizational research. It should be noted that every given detail is the interpretation of an observation.

\section{Indirect observation}

Usually, as in Likert's (1961) research, items 2 and 6 are measured through questionnaires, in which respondents select the answers seen as most appropriate, from a multiple choice list. The method is used frequently in social research. Here the procedure includes the following steps:

- decide on what is to be gained from the research,

- enumerate and specify the relevant attributes,

- relate them to categories of answers from respondents,

- design the questionnaire,

- conduct the processing of the questionnaire,

- extract results from the survey.

The results are the answers obtained. These are the values of the observed variables. Here again, the answers from the questionnaire are interpretations by the respondents of the data sought.

Questions may also be asked in interviews. In a structured interview questions are prepared and used literally, the answers being forced into predetermined categories.

In an unstructured interview the researcher is free to adapt his questioning to the course the conversation with the respondent takes. Reports of such observations may be written notes, taken minutes, and audio- or videotaped recordings, or more or less standardized forms. This way of observation may be possible with or without altering the conditions. The observer can try to find states or events as they are interpreted by respondents, but beyond that he may need some explanation or comment. If necessary he may ask questions like "what kind of material is this?", or, "what is the function of this machine?", or, 'from whom do you take orders in these circumstances?'. Inducement may be extended to the conducting of experiments. 


\section{Observational case studies}

A special type of the observable process is the case study. The case study method typically starts with the observer's confrontation with the entire caboodle of states, events, processes, financial figures, market characteristics, portraits of people, reported human relations, and technical data of real-life situations. The experienced researcher extracts from these images the comprehensive narrative that represents the real-life situation to the best of his ability: the case report. It may be more than just a text: in order to enhance the report video- and audiotaped documents may be added, oral reports from people involved may be part of the presentation, or parts of the situation may be played out in front of the audience.

As indicated by Yin (1993), case studies are used when there seem to be more variables than data points. The method is appropriate "when investigators desire to (a) define topics broadly and not narrowly, (b) cover contextual conditions and not just the phenomenon of study, and (c) rely on multiple and not singular sources of evidence' (p. xi).

Examples of (a) can be found in much research in organization literature. For instance, Bartlett and Ghoshal (1989) start their investigation of global competition with a phase in which managers of six multinationals are interviewed. During these interviews a host of data are collected. Only after this stage, propositions on further research are formulated. Crozier (1964) did the same. The procedure of the observational case study is the selection of observables from the total image observed, followed by the same steps as those described for process observation. The results are a large set of diverse data.

In figure 3.6 hereafter the relation between the number of observables, and the number of organizations or departments examined is depicted schematically for the different kinds of research.

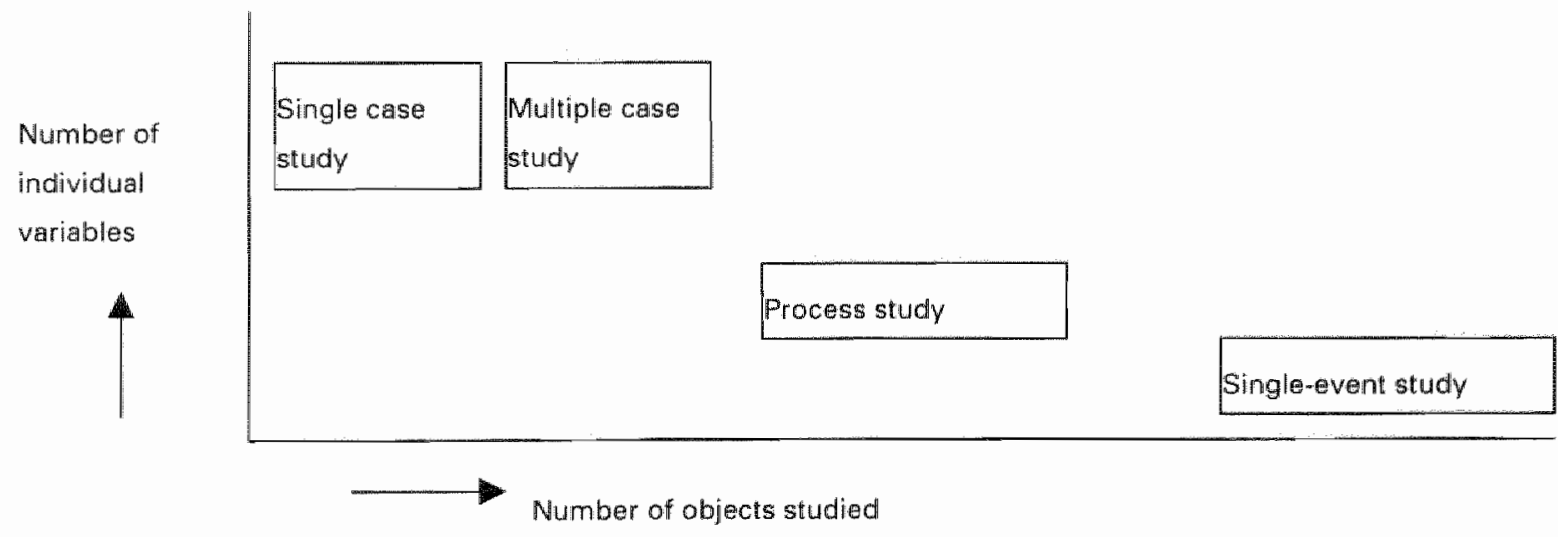

Figure 3.6. Schematic relation between number of variables and number of objects 
In-depth observation

As will be seen in the following sections observation can be more specific and precise after one or more cycles of knowledge development have been followed that include induction, hypothesis, and derivation. In fact, three different situations can be distinguished, depending on the stage of knowledge development.

At the first stage observation is the first step of theory building. It is conducted through a face value orientation into a set of phenomena that are assumed to possess regularities. In organization science this may be done by a series of interviews or a survey. The orientation may lead to the formulation of hypotheses describing relevant attributes of the subject domain and the nature of their relationships.

If these hypotheses are properly operationalized, then at a second stage conclusions about the existence of those relationships can be tested against more specific observation. An example is the presumption of Roethlisberger and Dickson holding that the better the level of lighting, the higher the output of workers would be. If the test is successful the theory may be formulated more precisely by adding or correcting the definition of variables and estimating the parameters determining the exact relationships involved. The observed value of variables can be measured now.

At the third stage series of observations can be made by manipulating the matter observed. In this case the testing produces more information (section 3.9). The testing requires that the cycle of knowledge development be extended to prescription and intervention. Now it is possible to manipulate the states of the phenomena observed and the outcome of events in a more controlled way. In this case, induction can lead to the fine-tuning of hypothesis. The terms used above will be explained in the following sections.

Chapter 5 describes several examples of iterative focusing. For instance Bartlett \& Ghoshal $(1989$, p. 213) conduct a first stage of enquiry comprising 9 case studies of multinational companies, in which 236 managers are interviewed. At a second stage, a survey is performed among three of these companies: 'a multi-indicator, multirespondent mailed questionnaire' (p. 218). Third, a large-scale survey is conducted, aimed specifically at the subject of innovation. Finally, concrete questions are asked concerning rival hypotheses relating to the effectiveness of certain factors on successful innovation.

\section{Summary of the observational phase}

The foregoing examples have indicated that in the development of organizational knowledge the followed procedures may be present during observation:

- selection of observables,

- definition of variables,

- design of observation method,

- observing values of variables,

- processing of variables. 
Henceforward, the results of observation will be called data.

The procedures and results are summarized in figure $3.11 \mathrm{in}$ box $\mathrm{C}$.

Depending on the degree of specification of underlying hypothesis, the effectiveness of operationalization and the possibilities of manipulation of outcomes, observation can be more or less precise and specific.

\subsection{Induction}

\section{Constructs}

Researchers are looking for regularities and patterns among observed phenomena. But frequently these are absent, or the regularities do not meet the expectations of the researcher. In this case it is possible to call up defined variables whose value are presumed to show regularities and patterns. These defined variables are called constructs. The value of these induced variables cannot be determined directly, as they are expressed as a function of one or more observable phenomena. The construct is not invented prior to observations, but as we make observations, we create an idea that - in a manner of speaking - puts the pieces together. Examples of constructs in the natural sciences are "energy', 'spin', and "momentum". In organization science many examples can be given, like the concept 'productivity' "This construct can be defined as the average output per man-hour under specified conditions. It is not observed directly, but induced from observation. After observation of the time spent on the manufacturing of one unit of production we can compare the productivity of different departments, factories, firms, or countries making comparable products. In its turn, productivity can be used as one of the determinants for profitability or competitive strength. (There is another method for the measurement of productivity, namely the macro-economic figure obtained through dividing the total output by total man-hours. This variable contains all influences involved, not only those relating to the organization, the skills and efforts of human labor. Both concepts have their own functionality, depending on the knowledge or the set of design rules one is looking for).

The procedure of making constructs comprises:

- ordering the data obtained from observation,

- attempting to find functions or combinations of data that show regularities,

- from these, selection of constructs for further use.

Clearly, this is a matter of trial and error. It should be noted that trial and error may be "blind" or partially guided by earlier obtained knowledge (see section 3.7).

In the case of micro-productivity, the procedure may be seen as evolving from the following problem. Let us assume that an explanation is sought as to why some manufacturers in industries with a high labor cost content are more profitable than others are. At first, it may seem that the faster workers move, the lower the cost per unit of production will be. But after 
observations of several operations as in figure 3.5 it appears that the avoidance of unnecessary movements, the orderly arrangement of the work space, and the right lighting, influence the output per man-hour too. This leads to the introduction of "standard time per unit of production". But some contradictions may yet remain: Factory A, with a lower standard time, i.e., higher productivity, is undercut by its competitor B. After further research it appears that factory $A$ has a high degree of rejected products, due to poor quality of raw material. Only after the introduction of the construct

labor productivity $=100 /($ (standard time $) \times(100-$ rejection percentage $)\}$

the regularity that this new construct associates with high profitability is discovered.

The result is that new variables are obtained, induced from the observables, which improve the chance that regularities can be found, as irrelevant elements are ruled out.

In this way, relations between subsets of data may become apparent. The "micro'-productivity is related to the profitability of the organization. The "macro'-figure may explain the competitive strength of a nation. High productivity may appear to be associated with welltrained personnel. Negative opinions about work conditions may coincide with bureaucratic characteristics. The micro-construct led to Taylor's way of thinking. The macro-construct was the basis for Crozier's hypotheses (Crozier, 1964).

Ketchen, Thomas and Snow (1993, p. 1284) list over 30 constructs that appear in organization studies, each of which with their connected observables (called variables in their nomenclature).

\section{Descriptive models}

A descriptive model is a schematization of a process or a set of states. Descriptive models are combinations of observables, constructs, and their relationships, put together in a diagram, a spatial form, or a (set of) mathematical formula(e). These types of models can be seen as inductively obtained 'superconstructs' that describe sets and complexes of observations in a particular area, and that may lead to the discovery of hypotheses. In those cases, a bridge is built between observation and generalized knowledge.

Unfortunately, this result does not always ensue. In such cases we have to devise other constructs and models, or we have to start at the upper part of the process of knowledge development, namely hypothesizing.

As stated descriptive models are part of the inductive phase. It means that in the definition of this study they have no predictive or explanatory value. Henceforward, models originating in the derivative phase will be discussed, which may be predictive or explanatory.

\section{Descriptive models in organization science}

In areas of science dealing with less tangible objects like organization studies, descriptive models may become necessary. A familiar example is the organization chart (figure 3.7). 
In this type of model parts of the organization, individual tasks, or personnel, are depicted as boxes, while lines between the boxes represent authority relations. A top-down line means that higher functionaries have authority over their subordinates.

The bottom layer represents the operating level. Each box stands for a member of the personnel, every one of them with their own task. The box at the top represents the highest in command over the organization. In between the layer of the middle management is depicted in $_{3}$ a factory mostly referred to as the bosses. Boss 1.1 has three subordinates, boss 1.2 has two.

Operators 1.1.1, 1.1.2 and 1.1.3 get their instructions from 1.1, and 1.1 on his turn from 1. Line 1.2 can be explained correspondingly.

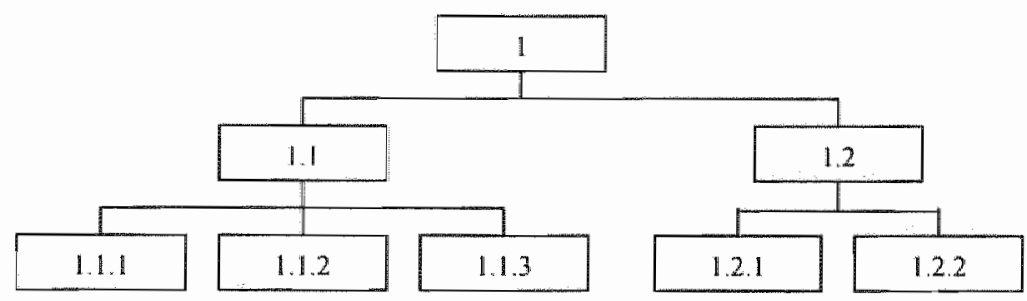

Figure 3.7. Organization chart as an example of a model in organization science

Instead of persons, the boxes may represent groups or departments, or the functions to be fulfilled and the tasks to be executed. In the latter case the nature and quantity of the work to be done is specified. The amount of work can be expressed in FTE"s, short for "full-time equivalents", i.e., the number of full-time personnel needed to fulfill the job.

The representation as in the model above may enable to depict, represent, precisely define, arrange, and classify concepts like competence, responsibility, delegation, duties, task description, department, function, coordination, span of control, process, etc. In doing $\mathrm{sO}^{\text {, a }}$ number of constructs are introduced. At the same time, otherwise elusive categories are defined and delimited. This type of model helps us to bridge the gap between unconnected observables and the constructs and relations that enable hypothesizing.

Many other types of models are used in organization science. Examples are process charts (schematization of the way a product is assembled from its constituent parts, with the indication of time, sequence and place), and time schedules (Gantt charts or PERT diagrams). Other instances are strategic schemes (representing the connection of activities and markets of the firm), and system models representing all kinds of relevant concepts relating to the organization and its environment. 
Reduction: partial and abstracting models

With the help of the simple example of the organization chart two terms can be illustrated. In the case of a partial model certain phenomena that belong to the field of research are deliberately not modeled at all. This is done for two possible reasons: first, in order to avoid unmanageable complexity, and second, because one is interested in a certain part of reality only. For instance one could imagine a box 1.2 .3 to the right of 1.2.2, representing a person or a department that is also observed. However, if this box represents an employee who is permanently on detachment to some other organization, then it may be omitted.

In case of an abstracting model different phenomena are not discriminated, but taken together in one category. In the same example the operators at the lowest level could be combined with the middle management (so 1.1 comprises 1.1.1,1.1.2, and also 1.1.3, etc.). As a result, the bottom line will disappear. The decision to do so will also depend on the purpose of the study. Partialization and abstraction are both forms of reduction. The world of phenomena to be studied is extensive and multiform. By partializing the field becomes limited to the relevant or accessible part, while abstracting makes the diversity manageable.

To summarize, the procedure of descriptive modeling may comprise:

- partialization,

- abstraction,

- definition and delimitation of concepts,

- description of relations between (groups of) data,

- formalizing the model (in mathematical or pictorial form).

The result is a structured collection of data and relationships. They offer possible hints for the conjecturing of hypotheses.

In summary it can be stated that descriptive models are combinations of constructs that form, together with their mutual relationships, new, more elaborated constructs. They describe the set of observed states and events, with deliberate reduction, in order to gain generalized insight leading to hypothesis.

\section{Interpreted elements in case studies}

As has been mentioned earlier in section 3.3, case descriptions may contain interpretations of states and events. When, for instance, Crozier describes the case of the clerical agency, he not only reports on the formal states and events of the organization, but he mixes these reports with contentions about causes and effects of this formalistic and impersonal system.

In doing so, Crozier is reducing reality as observed (partializations and abstractions as a result of interpretation). Interpreted case studies therefore can be considered as a special circumstance of the descriptive model. 


\section{Summary of the phase of induction}

The following procedures have been encountered in the examples of induction:

- ordering data effectively,

- devising constructs,

- seeking regularities,

- building descriptive models.

The results of induction are a set of variables and their interdependencies, combined into verbal, mathematical, physical and spatial theories that are schematized into (two- or threedimensional) models. Henceforward, these will be called descriptive models.

The procedures and results of induction are reported in figure 3.11,

At this point we have described some examples from the upward direction of knowledge development about organization. Now hypothesis is in order.

\subsection{Hypothesis}

\section{Definitions, scope, limitations}

We started the discussion on knowledge development with observation. If what is observed contradicts expectation, surprise is evoked. This is what initiates all scientific endeavor. The hypothesizing phase starts when useful knowledge is needed to solve a particular problem. Researchers will try to use their general background knowledge, stemming from general experience. They also may apply related academic disciplines, or recipes used earlier when related problems were encountered (knowledge on related domains). They will combine these theoretical building blocks with pertinent research findings. Some axiomatic positions may be added. These building blocks will be put together in a set of hypotheses that, if valid and useful, will represent the knowledge needed to solve the problem in question, and, to a certain extent, the solving of similar problems.

In this section hypothesizing as conducted in organization research will be illustrated with the help of some examples. A first step may be to define the subject to which the hypothetical propositions are meant to belong. An example is Schein's definition of the concept of culture $(1985$, p. 9):

"... a pattern of basic assumptions - invented, discovered, or developed by a given group as it learns to cope with its problems of external adaptation and internal integration - that has worked well enough to be considered valid and, therefore, to be taught to new members as the correct way to in ralation to those problems:" 
Culture is defined here as a set of assumptions held by a group about how one should perceive, think, and feel; the assumptions refer to those that are instrumental to coping with external and internal problems; their effectiveness is approved to the extent that they must be taught to new members.

The definition not only formulates what culture is, but also excludes all that is outside the defined area. So it delimits the domain as well.

Definitions of contents and domain may be considered to be part of the procedure of hypothesis.

It should be noted that the definition of culture contains many terms (such as those underlined) that do not directly refer to observable phenomena. A link is needed to make the connection. In the section on operationalization the link will be discussed.

\section{Axioms}

Some hypotheses are postulates, (beliefs or axioms), expressions that are part of the set of lhypotheses, but exempt from verification. Examples are the many lines of thought postulating some model of man. Sometimes they are smuggled in as "absolutely true' or 'self-evident" positions, as seems to follow from Williamson's text (1975), when he states:

"The assumption that individuals behave in a selfinterasted way is so commonplace to economics that it would seem scarcely to warrant separate attention. Opportunism, however, is more than simple selfinterest seeking. It is self-interest seeking with guile: agents who are skilled at dissembling realize transactionall advantages. Economic man, assessed with respect to his transactional characteristics, is thus a more subtle and devious creature than the usual self"nterest seeking assumption reweals."

The example shows that model assumptions can be part of axiomatic propositions. In this case, the author stretches the concept of self-interest, as supposed to be "commonplace" to economics, into a devious model of man. The example shows an axiom. Its formulation suggests that it cannot be doubted and does not need verification. Operationalization is not discussed. In its general terms, Williamson's axiom easily can be challenged: many examples of unselfish behavior in mankind can be given. A quite different position concerning human nature is conceivable.

When it comes to scientific propositions, rival axioms must be transformed into testable statements; in other words, proponents of either side are required to operationalize their tenets.

\section{Original propositions}

Propositions may stem from different roots. An example of a completely new insight is the hypothesis proposed by Hannan and Freeman (1989, p. 11) holding that 'most of the variability in the core structures of organizations comes about through the creation of new organizations and the demise of old ones'. 
Their second hypothesis 'proposes that organizational variability reflects designed changes in the strategy and structure of individual organizations in response to environmental changes, threats, and opportunities.' (op. cit. p.12). The hypothesis is based on findings from previous research by others. Their third hypothesis is a combination of the two types. They call it random transformation theory, and make the following claim:

"... organizations change their structures mainly in response to endogenous grocesses but that such changes are only loosely coupled with the desires of organizational leaders and with the demands and threats of environments (March and Olsen 1976). This view emphasizes the ubiquity of organizational change and the fact that it is usually random with respect to both goals of the organization and the demands of the environment.

The last hypothesis consists of two sentences. The first one is based on research by March \& Olsen (1976), but in the second they extend the view into a novel idea of the authors, namely the randomness of change.

The foregoing examples refer to hypotheses that may be formulated before the researcher starts observation. But hypothesis may also emerge after previous research findings. These will be called inductive hypotheses. They may result from descriptive models, by adding supposed causes of coincidences or limitations of validity when these are described as a general rule. These supplementing hypotheses expand the knowledge obtained from induction.

A well-known example is the theory of Fayol (1920), who based his hypotheses on longstanding experience. He called these principles and contended they were obvious (at least to all grands chefs, see chapter 4 and op. cit. p. 23). The same goes for many writers on organization and for a contemporary of Fayol, Taylor (1914). But the latter, in his quest for science, did a lot of experimenting as well (chapter 4 ).

Sometimes experiment indicates that received theory is false. In those cases rival hypotheses must be formulated. An example is McGregor's Theory $Y$ that was held against Theory $X$ (McGregor, 1960). The summary of Theory $X$ will be quoted here in full in order to demonstrate the author's attack on the rival hypothesis:

In order to avoid the complications introduced by a label, let us call thiis set of propositions "Theory $X$ : Management is responsible for organizing the elements of productive enterprise - money, materials, equipment, people - in the interest of economic ends. With respect to people, this is a process of directing their efforts, motivating them, controlling their actions, modifving their behavior to fit the meeds of the organization.
Without this active intervention by management, people would be passive - even resistant-to organizational needs. They must therefore be persuaded, rewarded, punished, controlled - their activities must be directed. This is mangement "stask. We often sum it up by saying that management consists of getting things done through other people. Behind this conventional theory there are several additional beliefs - less explicit, but widespread: 
The average man is by nature indotent -he works as little as possible.

He lacks ambition, dislikes responsibility, prefers to be led.

He is inherently self certuered, indifferent to organizational needs.

He is by nature resistant to change.
He is gullible, not very bright, the ready dupe of the charlatan and the demagogue.

The human side of economic enterprise today is fashioned from propositions and beliets such as these. Conventional organization structures and managerial policies, practices, and programs reflect these assumptions."

McGregor juxtaposes "Theory $\mathrm{Y}$ ' to these hypotheses, as ' $\mathrm{X}$ " is challenged by evidence from "the laboratory, the clinic, the schoolroom, the home, and even to a limited extent from industry itself'. "Theory $\mathrm{Y}$ ' is at every point the opposite of ' $\mathrm{X}$ '. It is said that working for man is as natural as playing or resting, that he has self-control, that he not only can accept but even may seek responsibilities, and that imagination and creativity are widespread. In chapter 5 this theory will be discussed in more detail.

As we have seen in this section, contentions about the subject matter may come from one or more of the following sources:

1. inference from postulates, or hypothesizing in its own right:

1.1. a completely new theoretical insight

1.2. a new insight based on previous research of others

1.3. existing hypotheses, molded into or combined with postulates

1.4. a combination of existing hypotheses

2. inductive sources:

2.1. from long standing general experience

2.2. from long standing experience, including experiment

2.3. from observations sought that did not correspond with expectations

2.4. from observations that were surprising, because they were non-sought.

Summary of the hypothesizing phase

With the help of the foregoing examples, and completed with logical additional steps, the procedure of the hypothesizing phase of knowledge development in organization theory can be described. It comprises:

- formulation of the problem(s),

- use of general experience (Fayol),

- selection of axioms (Hannan and Freeman),

- attempts to generalize induced observation, and conjecturing hypothesis that expands the knowledge that is inductively obtained (conjecturing),

- formulation (of the set of hypotheses, see Schein),

- rejection (on the basis of testing results, see Roethlisberger and Dickson).

The result is a set of theoretical propositions. 
The procedures and results of hypothesis can be found in box A of figure 3.11.

Now from hypothesis we are descending into derivation.

\subsection{Derivation}

In the phase of derivation, the theoretical propositions as formulated in hypothesis are transformed in order to enable confrontation with derived consequences. It can be done through operationalization and by means of predictive modeling.

\section{Operationalization}

Many organizational phenomena are said to have to do with "power'. Certain dysfunctions, for instance, may be attributed to a supposed imbalance of power between the members of an organization. To remedy such problems it is important to dispose of a theory of power in organizations. A conceivable theory might state (in fact, several do, for instance, Mulder, 1977) that power relations determine organizational patterns. In such a case the term power must be translated in something observable, in order to allow for its testing. This step is called operationalization.

Operationalization is not an unchallenged act (Roskam, 1990). Here two dangers are looming. The first is reification, meaning that by the act of operationalizing the background concept becomes accepted as an existent quality, while in fact it may be no more than a label for the phenomenon that is observed after operationalization. The second point requiring vigilance is that operationalization leads to concepts that differ from the original ones.

Mulder defines power as the capacity of somebody to have more influence onto the behavior of other people than is the case in reverse order. Next, he specifies this definition by distinguishing three different forms of power (formal power, sanction power and expert power). Subsequently, each of these forms is operationalized as power distance. People's proclivity to reduce this power distance is then examined in experiments.

It should be noted that these experiments yield answers to other questions than those originally formulated. Mulder has corroborated a number of hypotheses concerning power distance reduction. On power no more can be said than is implied by the terms of the operationalization.

\section{Derivation by modeling}

Even in rigorous branches of science, like classic mechanics, models mediate between theory and real systems. For instance, the mechanics of falling bodies refer to point masses, also called an 'idealization' of a material object that is not point-like at all. 
Like in the case of descriptive modeling, which took place during induction, here again we see abstraction (aggregating different notions into one concept), and partialization (selecting identifiable parts of larger concepts). This enables the mapping of the theory (through abstraction and partialization) into a system that fits the domain of phenomena at hand. This system predicts the behavior of the defined phenomena under specific conditions. By comparing the prediction with the outcome of experiment the hypotheses can be tested against observation. Predictive modeling can be considered as an advanced type of operationalization. Building the model requires a sufficient degree of formality.

An example of predictive modeling as an intermediary between hypothesis and observation can be found in Wippler's modeling of Michels" 'Iron Law of Oligarchy' (Wippler, 1983, p. 45), which is cited on the next page.

Michels was an early Social Democrat in Germany. His so-called law emanated from his astonishment concerning oligarchic tendencies in democratic institutions, expressed in the question: "Wenn nun aber die sozialrevolutionären und demokratischen Parteien theoretisch ihren wesentlichtsten Lebenszweck in der Bekämpfung der Oligarchie in allen Formen erblicken, wie ist es dann zu erklären, dass sie in sich dieselben befehdeten Tendenzen entwickeln?' (Michels, 1909). There is a problem here: Michels could not believe that the concentration of power in the hands of a small elite followed from their greed and selfishness. Those nasty tendencies whose fighting had been the goal of life of socialist and democratic parties had to be the result of an inescapable law.

This law would read: 'The formation of oligarchies within the various forms of democracy is an organic tendency that is necessarily inherent to every organization, to the socialist one as well, even to the libertine."

At a later stage of knowledge development Wippler has developed a 'mathematical model' (in fact, a mathematical representation of a theory) with functions representing the utility for "ordinary" members and the "elite" under various conditions. The variables are summarized in ligure 3.8 , together with an example of the equations they refer to.

This example demonstrates the intricacies and subtleties of modeling in the derivative phase. At the same time, it specifies the scope and limitations of validity of Michels' Iron Law. As far as the variables can be operationalized, testing against observables comes closer. These models are called predictive models, and insofar the relation between variables can be considered as an explanation they can be designated as explanatory models.

The "mathematical model" is in fact a set of hypotheses, derived from the verbal ones. As a simplification, it is necessarily a reduction of the original hypotheses. If the outcome of the model is in agreement with observation, only the hypotheses in their reduced form are corroborated. 


$$
S E U_{y}=U_{a g}\left(P_{z i}+P_{m i}\right)+U_{i}-U_{i}-U_{v}
$$

with:

SEUV : the expected net utility of the alternative conduct called "voice: (be alert and defend your position when necessery

$U_{c G}$ : the utility for a member when his interests are realized

$U_{\text {i. }}$ : the utiliny of ideological gratification when democratic principles are adhered to

$-U_{1}$ : the cost of membership

- $U_{v}$ : the cost of "vaice' (time, effort and money spent)

$P_{2 i}$ : the subjective probability that members' interests will be realized without one's own effort

$P_{\text {thi }}$ : the subjectively estimated increase of $P_{x i}$ through one's own efforts ...

\section{ENVIRONMENT}

boundary conditions determining the system of interaction

1. absence/presence of alternative organizations to serve members" interests \{relevant for voice preference\}

2. absence/presence of an interactive setting serving recruitment of members (rellevant for hetwork density in organizations)

3. absenc/presence of ideological separations (relevant for internal opposition)

4. favorable/unfaworable conditions for the realization of members' interests

5. legal structure concerning internal vole systems

\section{SYSTEM OF INTERACTION}

basic models for the canduct of members and teaders

a) assumptions about utility-theory

b) conduct of members: equation (1) and (2) of the basic model, description of "exill" as an alterthative

c) conduct of leaders: equation (3) and (4) of the basic model

structural and institution 1 characteristics of onganizations determining the field of decision of the actors

1. number of members

2. networlic density of social relations

3. inhomogenily of cognitive and social skills

4. absencefpresence of an orgarized internal opposition

5. character of the voting system (length of voting chain and possibilities for coalitions)



\section{RESULTS}

degree of oligarchictdemocratic functioning of an organization

(i.e. all combinations of preferences of members' actions combined with the wo altematives for ilhe leaders)

Figure 3.8. Predictive model, quoted from Wippler (1983, p. 45) 
Another example of predictive modeling can be found in a study into the future of the Dutch dredging industry (Krekel, Van der Woerd, Wouterse, 1987). In this research, the profitability and vitality of the sector was supposed to be affected by a large number of factors and their interrelationships. Among these, the behavior of the individual actors (such as their making investments leading to growth of capacity, their attitude toward competitors, and the decisions of potential customers) was considered to be crucial. In figure 3.9 hereafter, the derivative and explanarory model is depicted.

A simplified part of the theory involved reads as follows:

- technological progress enables the construction of ever larger dredging vessels,

- the larger the equipment, the lower the unit cost of dredging,

- the lower the cost for the individual supplier, the stronger his competitive position,

- consequently, all dredging firms maximize the building of new equipment,

- this all leads to an enormous expansion of capacity,

- the over-supply of capacity leads to sharper competition, with lower prices,

- the low prices force the dredging companies to build new, even larger, ships.

This vicious circle is only one of the cycles that comprise the complete theory. It should be noted that the theory seeks to offer a ground for strategic rules for the industry as a whole and for Dutch industrial policy as well. The number of factors involved is much larger than the ones depicted in the model. However, the reduced, predictive model already contains a large number of items to be observed. Among the factors are 'hard' data as well as concepts that have to be operationalized rigorously, like 'solidarity'. It was the aim of the model to explain the working of this particular social-economic complex and to demonstrate to entrepreneurs and public authorities the inevitability of demise lest strategic measures were taken.

\section{Summary of the derivative phase}

The procedures followed during derivation can be summarized as follows:

- operationalization

- abstraction

- partialization

- designing of predictive models.

The results are testable statements. If they hold out against tests that are based on reliable testing techniques, our theory is corroborated as far as operationalization and modeling go. It can be used then to solve the problem involved, for instance, as a set of prescripions about how it should be (this capacity will be treated in section 3.8 ). If not, they may offer a framework for further observation of reality, helpful in a new round of knowledge development.

The procedures and results of derivation can be found in box $\mathrm{B}$ of figure 3.11 . We have now completed our tour along the upper four boxes of the A - F - scheme as discussed in section 3.2 and depicted in figure 3.4 . 


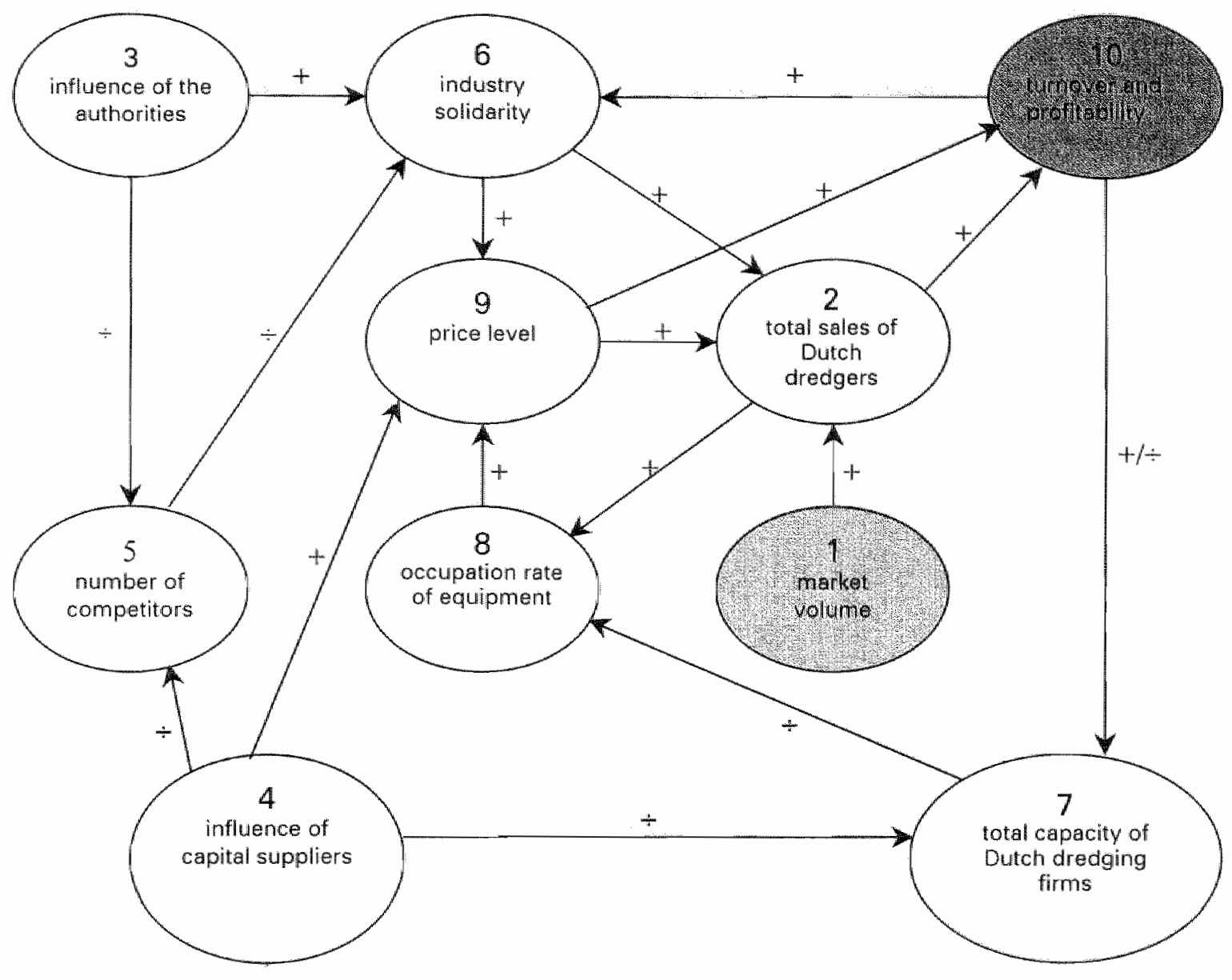

Figure 3.9. A model of the forces and circumstances that affect the future of the Dutch dredging industry (after Krekel, van der Woerd, Wouterse, 1987) 


\subsection{The complete cycle of observation, conjecture and derivation}

The accumulation of knowledge is an iterative process with inductive and deductive phases that seemingly alternate or even occur simultaneously. But on second thoughts this process always follows the same direction, while its start is either in observation or in hypothesis. It is schematically depicted in figure 3.10 .

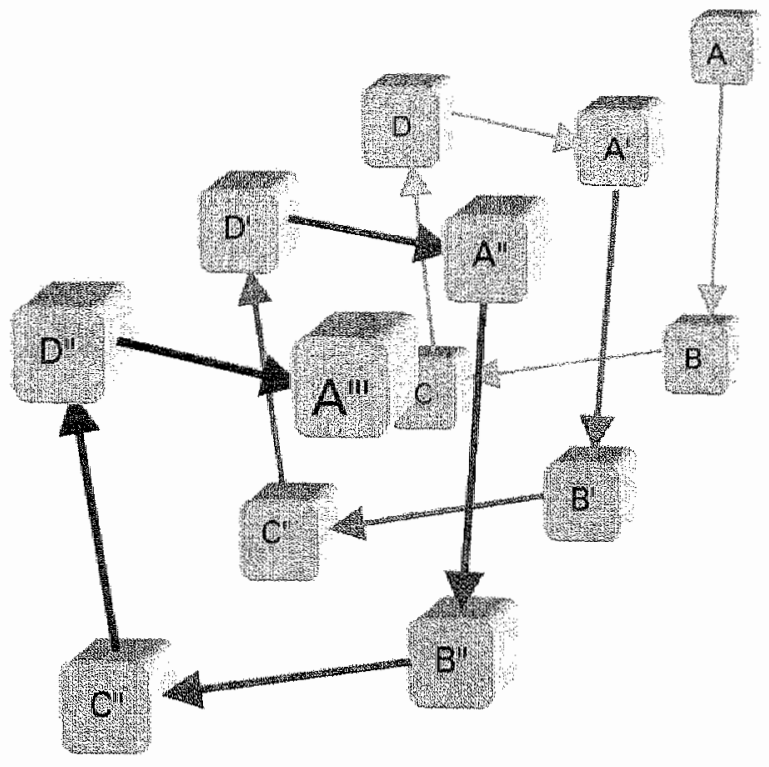

Figure 3.10. The spiral of knowledge development

The four phases of knowledge development encompass:
A. hypothesizing, either on the basis of induction or in a postulated setting,
B. derivation,
C. observation,
D. induction.

These phases follow one another in the direction of the arrows. As stated, the process may originate either in $\mathrm{A}$ or in $\mathrm{C}$. In general the researcher goes to a number of cycles A-B-C-D or C-D-A-B as a thought-experiment before starting to work more systematically. Always some background knowledge will exist. Therefore, it is hard to say whether the very origin of recognizing and stating the problem was in $\mathrm{A}$, or in $\mathrm{C}$. In fact this is of no importance for the usefulness or the value of knowledge. For reasons of simplicity the model depicted in this 
study will be the projection of the figure onto the back plane. If multiple cycles are run through this will be reported in the text. The projection is rendered in figure 3.11 , together with the procedures and results of each step.

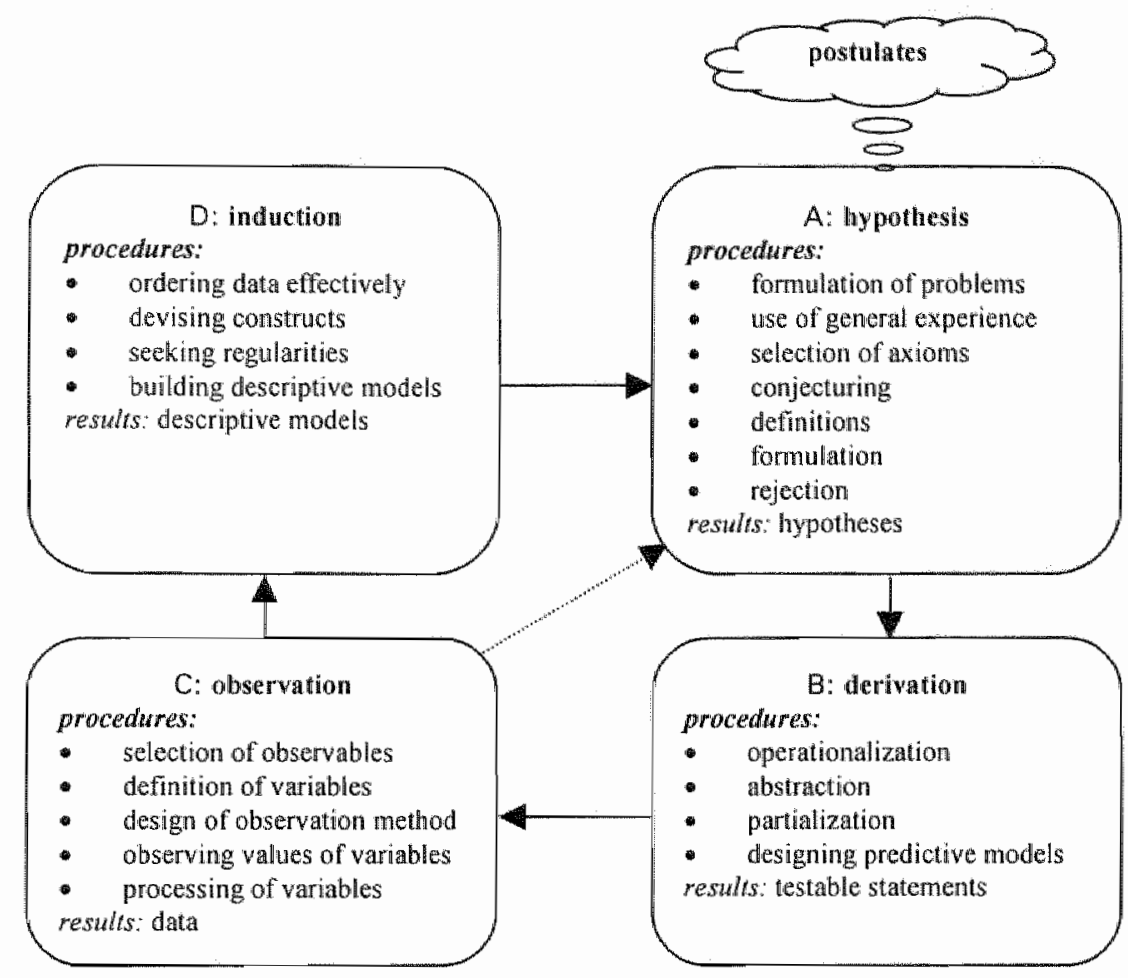

Figure 3.11. The four upper phases of knowledge development with their procedues and results

The dashed arrow represents a special case from $C$ to $A$. This short cut arises when observation is in complete disagreement with the testable consequences of the hypotheses. In this case one has to go back to square $A$ and try to formulate new conjectures.

\section{Prescription and intervention, the lower two boxes of the A - F - scheme}

It is time now to visit the two lower boxes of the $A-F-$ scheme. In the next two sections prescription (section 3.8) and intervention (section 3.9) will be discussed. 


\subsection{Rules for action}

\section{Rules have various purposes}

This study concentrates on the designing of structures and strategies. The problem at this stage is how good or even better solutions for questions regarding structure or strategy can be obtained. Therefore knowledge must be translated into rules for action. These actions may have different purposes, namely testing, designing, and intervention.

In the case of testing the rules are used to indicate the expected state of the object during and after the experiment, and to prepare the right setting for the experiment. By comparing the observed effects of the experimental structure and strategy with the expected one, necessary improvements in knowledge can be identified.

Design rules prescribe how a desired strategy and structure can be constructed.

Finally, rules are necessary in the process of change that will bring about desired new situations. In this case rules guide interventions.

\section{The relation between theory and rules}

Rules are prescriptions for action. They are derived from knowledge. The more rigorous the underlying knowledge, the better the rules are grounded. In order to obtain valid and useful knowledge the cycle A-B-C-D must be run through repeatedly. After satisfactory models have been derived they must be transformed into prescriptions for examination of, or interventions in, existing structures and strategies. Then these prescriptions may be implemented. These new steps are depicted as boxes $\mathrm{E}$ and $\mathrm{F}$ in figure 3.12.

In $\mathrm{E}$ rules are derived from the knowledge that is available, mostly in the form of models. The procedure comprises of:

- establishing the applicability of the general knowledge, as available from the derived model, in the circumstances involved, and:

- translation of the specific knowledge into instructions for action.

The result is the prescription, and may have the form of:

- rules for experimental testing,

- design rules,

- rules for intervention.

In $F$, these rules are used to manipulate the subject matter. This means conducting experiments, designing strategies and structures, or intervening in existing organizations. Here the procedure is the action involved. The results are new, intentionally sought observations, new plans for strategy and structure, or, hopefully, an improved organization. In any case, the discoveries will yield novel information. 
The dashed arrow from $\mathrm{C}$ to E represents a special case. This applies when observation reveals that the rules do not work. The researcher has to go back to box $\mathrm{E}$ in order to devise better ones. It should be noted that the rejection of rules does not imply that the underlying theory is false. The fact that the experiments of Roethlisberger and Dickson failed to support the assumption that better lighting would enhance productivity does not necessarily mean that the thypothesis was false. The point was that it appeared to be impossible to neutralize other factors. In section 5.6 this problem will be discussed in more detail.

The total cycle now becomes A-B-E-F-C-D (figure 3.12).

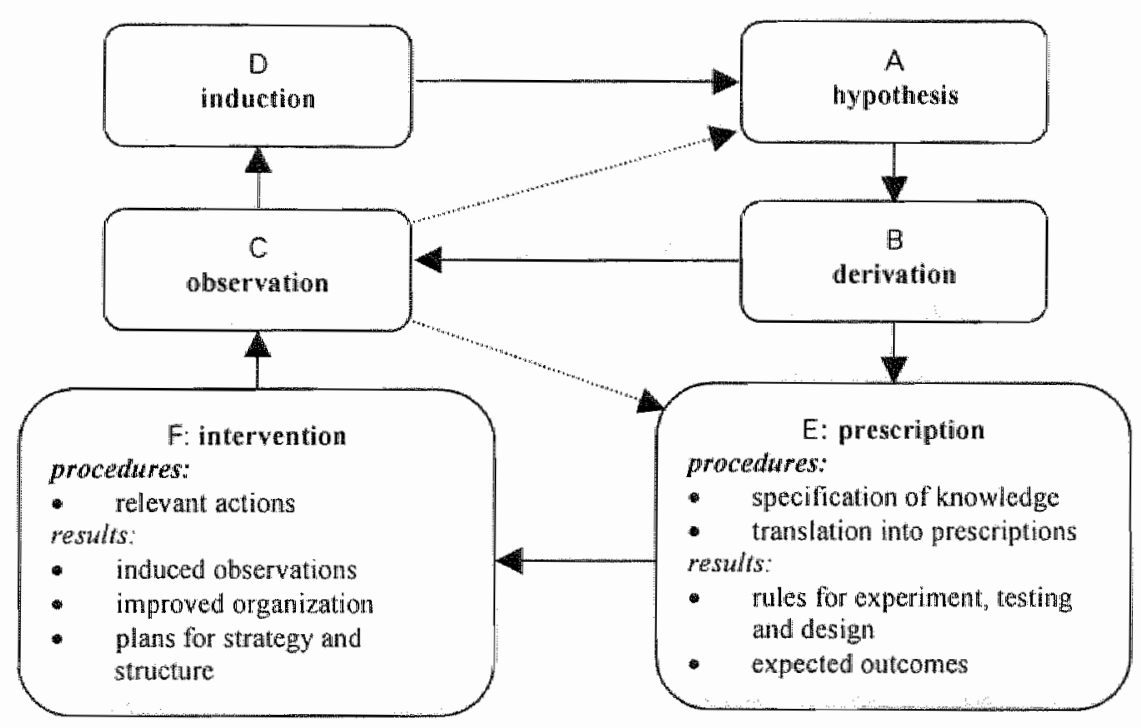

Figure 3.12. Model of knowledge development including prescription and intervention

Some theorists keep running through $\mathrm{A}-\mathrm{B}-\mathrm{C}-\mathrm{D}$ never entering the E-F bypass, others do so frequently. In the next chapters the distinction between contemplation and formalization on the one hand, and contemplation-with-experiment on the other hand, will be examined, together with the consequences for validity and utility.

Sometimes certain phases of the development of knowledge may be combined or skipped. Many 'armchair-theories', based on long-standing experience, formulate proverbs called' principles. These look like a combination of induced observation, hypothesis, and prescription. In this study the absence of individual boxes from our model will be compared to the accidental bypassing of a railway station by a train. This skipping of stops will be discussed when examining the case studies in the following chapters. 


\subsection{The concept of theory as used in this study}

After the examples given and the model of knowledge development proposed, it may become clear that the definition of the term theory should be broad enough to allow for a considerable range of attempts to develop knowledge for solving problems about the design of strategy and the structure of organizations. At the same time it should apply specifically to our field of interest. Moreover a theory should be grounded, meaning that it can stand testing against observation. To this end it should be predictive.

\section{Describe, predict, and explain}

A theoretical (set of) proposition(s) has the general form:

for all \{domain\}, if \{conditions\}, then \{a specific (set of, sequence of) state(s) will be observed\}.

In organization theory, this statement will read:

for all \{(subsets of types of) organizations\}, if \{characteristics of the organization and its environment , then \{what will be observed with respect to the organization\}.

This type of statement describes and predicts what will be observed. It may also explain, but not necessarily so.

From the foregoing is has become clear that predictive models fit within the definition.

The general form of a design rule reads roughly as follows:

if a certain \{state of observables\}, belonging to a domain\}, is desired, then one has to act

\{according to prescripts\}/in compliance with \{conditions\}.

In organization theory:

if certain organizational observables are desired in an organization belonging to a certain domain,

then certain conditions must be satisfied when making a design.

Design knowledge may be expressed as a (part of) an inverse expression of a theoretical (set of) proposition(s), or as (a part of) a design rule.

Therefore the following definition is proposed for the purpose of this study:

An organization theory is a set of general statements referring to observable phenomena, that can be used to describe and predict the observable properties of an organization under certain strategic and structural conditions, and that contribute to the knowledge needed for structural and strategic organizational design. 


\section{The systematic assessment of organizational theory}

\subsection{Different perspectives}

A preliminary orientation to this study made it clear that theories on structure and strategy come in a wide variety of intent, style, way of arguing, axiomatic basis, and methodological rigor. Perspectives appeared to be different, too, with accents on observation or contemplation. Many theories seemed to be closely related to their societal environment, their geographical or academic origin, the 'Zeitgeist' in which they emerged and got attention, and to the idiosyncrasies of their authors. It is most enlightening, especially for the insight into theory development over the 20 th century, to take these general aspects into account, in combination with the metatheoretical characteristics that have to be observed when a theory is examined. Therefore, in the assessments in chapters 5 and 6 , contextual points will be rendered directly after the bibliographic data. In he middle part of the assessment important elements of contents and relevance of the theories will be discussed, followed by an indication of the most important steps in the process of knowledge development. Next a summary of the development will be given, placed in the depiction of the metatheoretical framework (the A - F - scheme) as it was developed in chapter 3. Finally, a concluding appraisal will be given, including the estimated position of a theory between past and future in the total development of organizational knowledge.

\subsection{Bibliographics and contextual points}

As stated, next to the usual bibliographical data contextual points will be discussed. In that section typical personal, historical, and societal circumstances of the proposed theory will be described. For instance, it is assumed elucidating to know about the personal idiosyncrasies of Taylor, together with the social situation in which he lived at the end of the 19 th century. 
Likewise, Fayol's typically French way of thinking and Weber's German touch of philosophy might be helpful to get a better background impression for their contentions. The fact that scholars have a technical or a sociological background may enhance our insight in the potential and limitations of their theory. It is also illustrative to know about proponents' claims of the societal importance of their tenets.

\subsection{Assessment of contents and relevance}

\section{Contents}

In contents, core elements of the theory will be summarized as they are formulated in the sampled texts. The authors' Weltanschaumg, their basic position, and the intent of their research will be demonstrated with examples. Some of the basic contentions on this point will be quoted, to give the reader an idea of the atmosphere and the substance of what is proposed. These contentions may include the authors' axioms, and the most important assertions and claims about the objective of their research. The propositions of the theories considered are taken from the text as rendered by the authors, in order to avoid paraphrasing or interpretation. The first intention of the systematic examination is to describe the features of organization theories. The central reference of enquiry will be the A - F - scheme, i.e., the schematized process of knowledge development as discussed in chapter 3. Special attention will be given to the origin of the thoughts the authors developed, the procedures they followed, the results they obtained, and the tests they conducted. Important metatheoretical points of departure will be reported as well.

\section{Relevance}

As we are primarily interested in design theories on structure and strategy, the theories will be examined for their relevance for this point. In addition, the nature and size of the organization the theory refers to will be indicated.

The first question is whether the theory refers to the structure of organizations. As stated earlier organizations are defined as lasting and persistent forms of cooperation between people and groups, directed at specific goals. Structures are lasting and persistent properties of the relations of those people and groups. The second question deals with the theory's relevance for the strategy of organizations. Strategies have been defined as forms of behavior of (members of organizations aimed at their long-term preservation and improvement, and at the sustainable achievement of their goals.

If neither of these instances is the case the assessment system does not apply.

A theory may have a direct or indirect applicability to design of structure and strategy. In the first case it formulates directly applicable rules for design. This applicability may be more or less direct. Porter (1980) gives very direct prescripts for strategy. If the applicability of a 
theory is indirect, rules for design are not given but they can be derived from the theory. In neither case a theory may still contain metatheoretical propositions from which design theories could be derived. An example can be found in Argyris (1985) whose knowledge concerning the treatment of group and individual conduct seems to refer only remotely to questions of organizational design. From his study however, it follows that in order to implement organizational change substantial effort and investment in time and money will be required. It also becomes clear which specific obstacles may be encountered. This knowledge may teach us that the calculated advantages of a particular new structure or strategy must be offset against the disadvantages relating to its realization. Certain solutions that seem "ideal" on the drawing board may have to be dismissed in favor of more feasible plans, or their implementation must be carried out step by step.

If a theory is in no way applicable to the design of structure and strategy of organizations the assessment system does not apply.

In the case of metatheoretical applicability it is important to estimate what may be expected with respect to further development of relevant knowledge. This will depend on the conceptual proximity of the metaiheoretical propositions to its elements of knowledge development. In this case the steps necessary to develop the theory into practical usefulness are of interest. This question can be answered by imagining the steps $\mathrm{A}$ - F that have to be taken.

Theories may contain rules for organizational design, while not especially referring to structural or strategic concepts. Their prescripts may nevertheless produce substantial knowledge that is fundamental to the final design of structure and strategy. This partial or building block value will be part of the appraisal as well.

In case of direct or indirect applicability it must be established to what types of organization it does refer. Some theories refer to all kinds of organizations, others specifically to small or large organizations, or to either public or private enterprises, or to certain branches of industry only. Dedication may also involve private or public, commercial or not-for-profit organizations. Specific relevance may also refer to certain industries, technologies, or geographical areas.

Relevance may also regard the specific organizational aspects that are addressed, like organizational functions such as production, finance, marketing and sales, personnel, etc. Finally, specific organizational problems may be addressed. In case of structure related theories one could think of efficiency, effectivity, selection of form, and allocation of discretional power. When it cones to strategy conceivable problems are portfolio selection, make-or buy decisions, cooperation tactics, etc.

\section{The process of theory development}

The systematic examination in chapters 5 and 6 is primarily intended to find common features and characteristics as well as salient differences among theories. Central to the assessment method is the analysis of knowledge dewelopment, as modeled in figures 3.11 and 3.12 . The text of some of the proposed theories may not allow for a judgment about their completeness. But the absence or inadequacy of certain boxes of the A - F - scheme will 
indicate a lack of validity and usefulness. Well-elaborated theories may fail to report on conducted tests. In those cases assaying by the means of this study is not possible. The fact that testing is not discussed may be a negative point in their appraisal.

In some cases the proposed theory may contain inappropriate testing methods. If the report on this matter is sufficiently clear, they can be spotted.

Design requires rules (box E) that can be applied to observable, or operationalized, concepts (box B). The testable statements from $B$ about states and events must be grounded on wellformulated hypothesis (box A). The more hypothesis is supported by observation (C), followed by suitable induction (D), the trustworthier the rules are is.

\subsection{Concluding part of the assessment}

\section{Assessment following the $A-F$ - scheme}

The assessment is summarized in the pictorial model of the $\mathrm{A}-\mathrm{F}$ - scheme. In the pictorial model the degree of elaboration the author devoted to each element of knowledge development will be indicated by the thickmess of the frame of the box involved. A thin dotted line represents an element that is ignored or virtually ignored. A thin frame (one point) will indicate an element that is discussed but not elaborated upon. An element that is worked out to a large degree will have a bold frame (6 points). In case of an intermediate degree of elaboration of the element the frame will be drawn in a medium bold line ( 3 points). This aspect will be discussed when the picture is explained.

The completeness and elaboration of knowledge development will be established. It represents an assaying touchstone. Theories can be tested only when they are sufficiently developed. Design, for instance, requires rules (box E) that can be applied to observable, or operationalized, concepts (box B), as was stated above. These testable statements must be grounded on well-formulated hypotheses (box A). As said, the more hypotheses are corroborated by observation (C), followed by suitable induction (D), the trustworthier they are. This means that usefulness mainly follows from the analysis of A- (hypothetical) and B(derivational) aspects of the proposed theory. The question is here if the results from $B$ allow for the formulation of design rules that can be used in practice.

Validity depends on the outcome of the testing of the derived consequences in B against the observed data from $\mathrm{C}$. .

In addition, when applicable, Koontz' considerations and validity criteria as mentioned in 1.2 will be considered. These criteria correspond to those as proposed earlier by Feigl in a more precise way (for instance Feigl, 1953, p. 11). They comprise definiteness, precision, systematic structure, coherence, intersubjective testability, and, finally, veliability, or, in other words, a sufficient degree of confirmation.

Definiteness is the degree of exactness with which the boundaries of the domain are defined, as discussed above in section 3.5. Precision is the degree of preciseness of the definitions 
proposed. Systematic structure relates to the degree of order of the formulation of the theory. Coherence refers to the degree to which propositions align with other fieids of science. When for instance a theory on organization includes psychological tenets, then these must not conflict with reliable theories from the domain of psychology. These aspects will be called the metatheoretical rigor of the theory proposed. Only if a theory has a certain degree of rigor, testing is possible. It should be noted that the assessment of the degree of elaboration, as well as the degree of metatheoretical rigor, is a relative one. An absolute judgment on these matters cannot be given.

Conclusion

A concluding appraisal of the theory, including remarks about its position between past and future, constitute the concluding part of the evaluation. Positive effects the theory have had or might have on future knowledge development will be mentioned under fecund elements. 


\subsection{Summary of the assessment}

The aspects of examination are summarized as follows:

\section{Bibliographical data}

2. Contextual points

- scientific environment, discipline, school, predecessors

- personal background of the author

- historical/social environment and claims of societal importance

3. Contents and relevance

- the author's Weltanschauung, point of departure, and intent of the research

- basic contentions

- pertinence to structure and strategy

- direct or indirect inference

- size and type of organization addiressed

4. Process of knowledge development

- the number of cycles run through

- siarting point of each cycle

- for each cycle the assessment of:

A. hypothesis (formulation of problems, use of general experience, selection of axioms, conjecturing, definitions, with the result of formulation of hypothesis, rejection)

B. derivation (operationalization, abstraction, partialization, deductive modeling, formulation testable statements)

C. observation (design of procedures, selection of observables, definition of variables, selection of observational method, observing, processing of variables, with data as a result)

D. Induction (the ordering of data, making of constructs, looking for regularities, resulting in descriptive models)

E. prescription (specification of knowledge, translation into prescriptions, resulting in rules for experiment, intervention, and design)

F. intervention (kind of action taken, leading to induced observation, improved organization, and the making of plans for structure and structure)

5. Assessment following the A - F -scheme

- assessmemt of knowledge development

- degree of elaboration

- validity, utility

6. Conclusion

- final appraisal

- position between past and future

- fecund elements 


\section{Model of the assessment system}

In figure 4.1 the elements of the system of assessment and their logical interrelationships are schematized in a pictorial model.

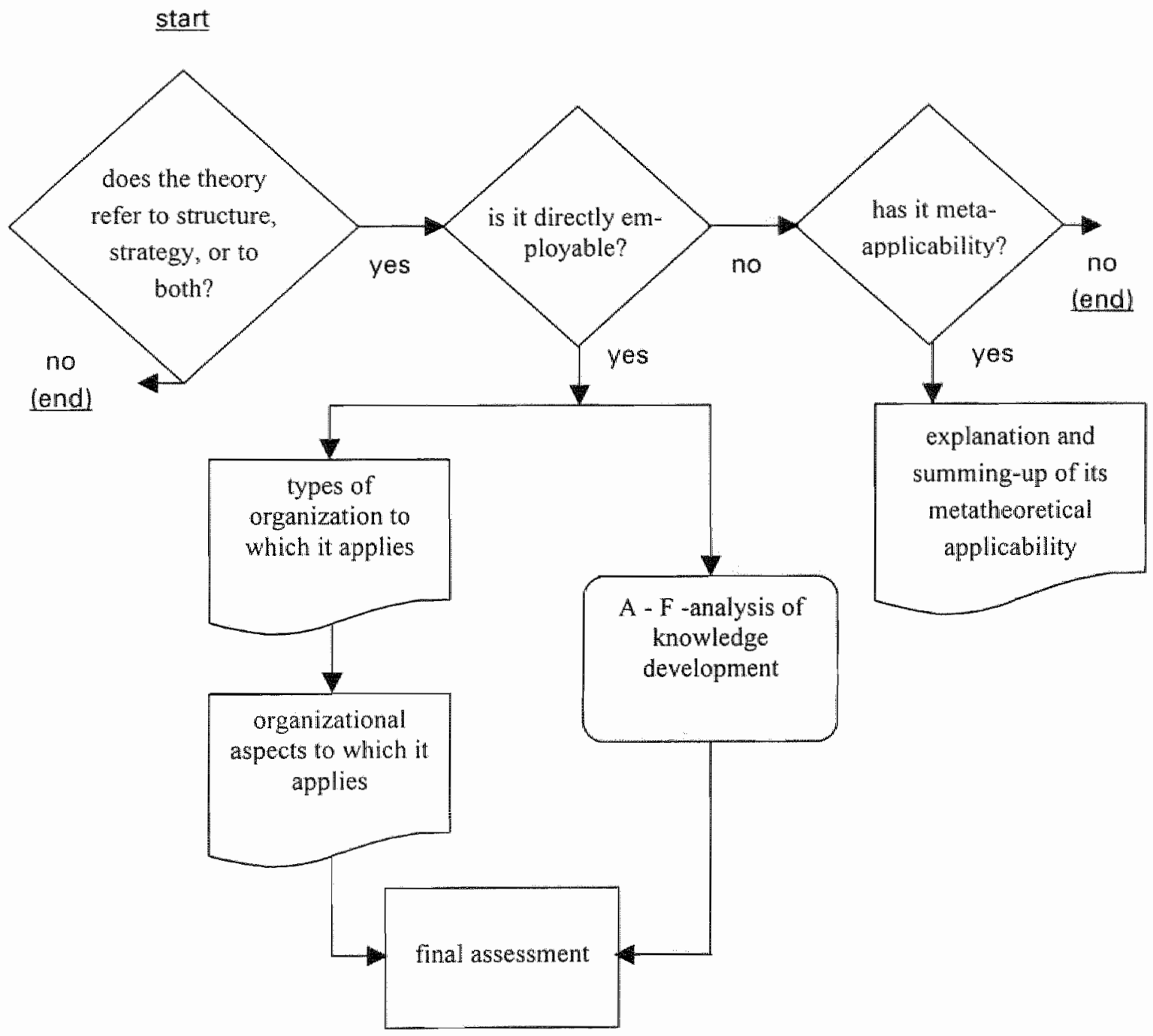

Figure 4.1. Flow chart as a model of theory assessment. 


\title{
5. A multiple case study of organization theories
}

\author{
5.1. The material
}

\section{Choice of organization theories}

The sample for the examination of the 20th-century theories is selected as follows. Although representativeness cannot be claimed, an effort is made to pick cases from different types of theories in order to cover as broad a field as possible and to reflect the body of organizational knowledge of the period.

The following selection criteria for theories are used:

- instrumental (at least potentially) for organizational design,

- frequently cited in leading anthollogies,

- explicitly or implicitly asserting generalizations on structure and strategy.

In order to avoid blind spots, care is taken to include items from:

- main schools and disciplines,

- main periods of recent social-economic history,

- different geographical origin,

- work from academics as well as from practitioners.

In some cases a theory is included that, although not fully satisfying these requirements, has had a substantial influence as a precursor of a later theory that is eligible in itself.

This selection will be discussed in more detail hereafter.

The canon of organization literature

Out of the hundreds of papers in the field that are published every year, a selection had to be made. First, the criteria mentioned above had to be respected. Second the theories had to belong to the group of generally accepted publications. In the third place the theory should be settled, i.e., have survived infant mortality. This final point makes it necessary to accept only those theories that are laid down in books, either monographs or compilations. Brilliant 
thoughts and theoretical breakthroughs that are accepted in leading scientific journals will, in this way, not be overlooked, as these normally will find their way in later publications in the form of books.

The next step was to compile a long list of these books. A start was made by taking three recent repertories of general organization theory.

The first anthology chosen is the one by Shafritz \& Ott (1992). In this compilation a choice of contributions to organization theory is given. The books of the authors from which the theories are taken (or books by the same authors that contain the same subject) are included in our long list, with the exception of items originating before 1900 .

The second source is the frequently rejuvenated work by Weihrich \& Koontz (1994). Their first compilation dates from 1955. The version of 1993 is used for the list. Books on nonscientific subjects, like those proclaiming principles of business ethics, or books on nonstructural or non-strategic management techniques, have been excluded.

The third compilation is the most recent one by Pugh \& Hickson (1997). These authors too have a long-standing reputation as reporters of the state of the art of management science (first edition 1964). The latest version (of 1997) is used as a source for the long list.

\section{The selection of theories}

After completion of the combined list, three areas seemed to remain underexposed, although not completely absent. These concern recent sociologists' approaches of organization study as well as contemporary thoughts on the development of strategic thinking.

To cover the first field the compilation by Lindenberg \& Schreuder (1993) was chosen. Rumelt, Schendel and Teece (1994), who took stock of contemporary strategic knowledge covered the second blind spot.

By applying the same procedure, these two sources added elements to the long list.

Despite the apparent preferences in the repertories, due to editors' academic discipline, professional attitude, personal opinions and paradigmatic roots, a number of the theories appear in more than one compilation. For the choice of the case studies the number of anthologies in which the theory is cited is considered an important determinant. All items with frequency three are chosen. Some with a frequency of two have been added to account for poorly represented but important disciplines, geographical origins, and time periods of the works, like the early works of sociologists Blau and Scott (1963), and the seminal studies of Crozier (1964), Porter (1980), Hofstede (1984), and Kanter (1989). Coleman (1990, cited once) is added as the representative of contemporary organization sociology. The total of theories to be examined amounts to 28 . In table 5.1 the long list with 162 theories is given, with the 28 selected items emphasized by italics and a right position in the collumn. In the following sections each of these theories will be examined on the basis of the entries as derived at the end of chapter 4 (section 4.5 ). 
Table 5.1: Organization theories from repertories and anthologies

$\begin{array}{llll}\text { abbr. } & \text { authors } & \text { abbr. } & \text { authors } \\ \text { S\&O } & \text { Shatritz \& Ott 1992 } & \text { R \& al. } & \text { Rumell et al. 1994 } \\ \text { W \& K } & \text { Weihrich E Koontz } 1993 & \text { PEH } & \text { Pugh \& Hickson 1997 }\end{array}$

L. E S Lindenberg \& Schreuder 1993

\begin{tabular}{|c|c|c|c|c|c|c|c|}
\hline$n r$ & author(s) & Wear & SEO & Wok & Ltrs & Rtoral. & $\mathrm{PGH}$ \\
\hline 1 & Gitbreth & 1911 & & 。 & & & \\
\hline 2 & Tavior & 1914 & - & $*$ & & - & $*$ \\
\hline 3 & Lillian Gilbreth & 1914 & & - & & & \\
\hline 4 & Favot & 1920 & 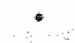 & $*$ & & & 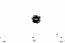 \\
\hline 5 & $\therefore \quad \therefore$ & 1921 & 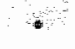 & - & $\bullet$ & & . \\
\hline 6 & Follet & 1926 & $\cdot$ & & & & \\
\hline 7 & Mayo & 1931 & & - & & & - \\
\hline 8 & Schumpeter & 1934 & & & & - & \\
\hline 9 & Coase & 1937 & & & - & - & \\
\hline 10 & Gulick & 1937 & . & * & & & \\
\hline 11 & Parsons (1956) & 1937 & & & $\cdot$ & - & \\
\hline 12 & Barnard & 1938 & & - & $\cdot$ & • & 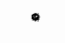 \\
\hline 13 & Foethlisberger \& Dickson & 1939 & & 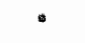 & - & & - \\
\hline 14 & Urwick & 1944 & & $\therefore$ & & & \\
\hline 15 & Mavo & 1945 & 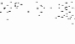 & &  & 3 & $*$ \\
\hline 16 & Simon & 1947 & " & & - & - & \\
\hline 17 & Selznick & 1948 & " & & & & \\
\hline 18 & Lewin $(1948)$ & 1951 & &  & & & \\
\hline 19 & Trist E Bamforth (1997) & 1951 & & & & & $\cdot$ \\
\hline 20 & Juques (1990) & 1952 & - & $\cdot$ & &  & \\
\hline 21 & Drucker & 1954 & & - & & & \\
\hline 22 & Naslow & 1954 & " & $\cdot$ & & & \\
\hline 23 & Aravins (1987) & 1957 & & & & & - \\
\hline 24 & Merton & 1957 & & & & $\therefore$ & \\
\hline 26 & Selemick & 1957 & & & s & 6 & \\
\hline 26 & Homans & 1958 & & & $\cdot$ & & \\
\hline 27 & March \& Simon & 1958 & - & $\cdot$ & - & - &  \\
\hline 28 & Herzberd, Mausmer \& $\mathrm{S}$. & 1959 & & $\cdot$ & & & s \\
\hline 29 & Henderson & 1960 & &  & & $\cdots$ & \\
\hline 30 & MoGreoror & 1060 & * & 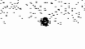 & &  &  \\
\hline 34 & Burns \& Stalker & 1961 & * & - & & $\cdot$ & $\cdot$ \\
\hline 32 & Homans & 1961 & & - & & . & \\
\hline 33 & Likert & 1961 & & $\cdot$ & & & - \\
\hline 34 & McClelland & 1961 & 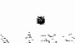 & $\cdot$ & & & \\
\hline 35 & Blan 4 Scon & 1962 & 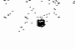 & & & mis & \\
\hline 36 & Chandler & 1962 & & - & 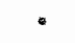 & $\cdot$ & $\cdot$ \\
\hline 37 & Cvert \& March & 1963 & & & - & & $\cdot$ \\
\hline
\end{tabular}




\section{Table 5.1. Continued}

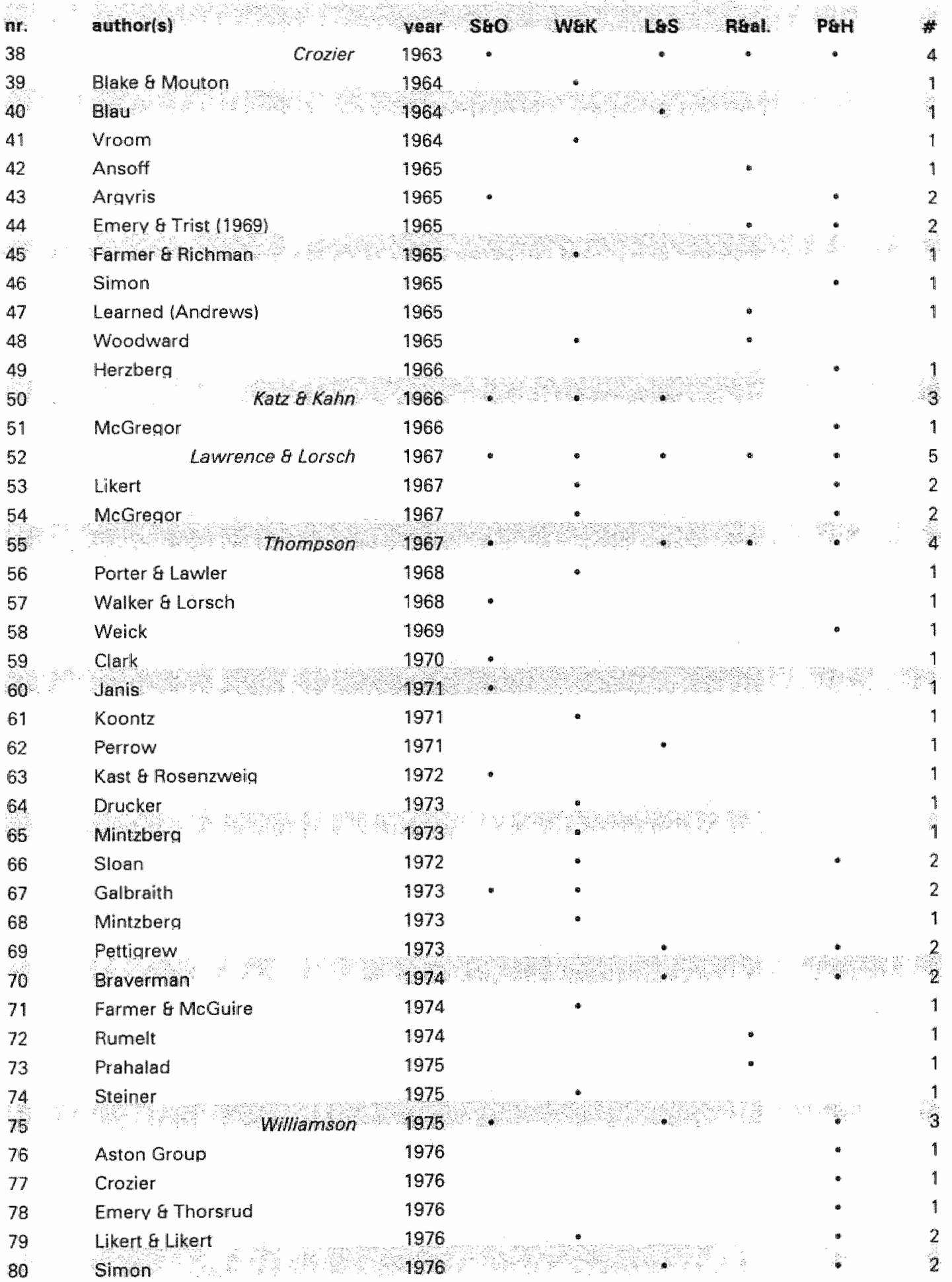


Table 5.1. Continued

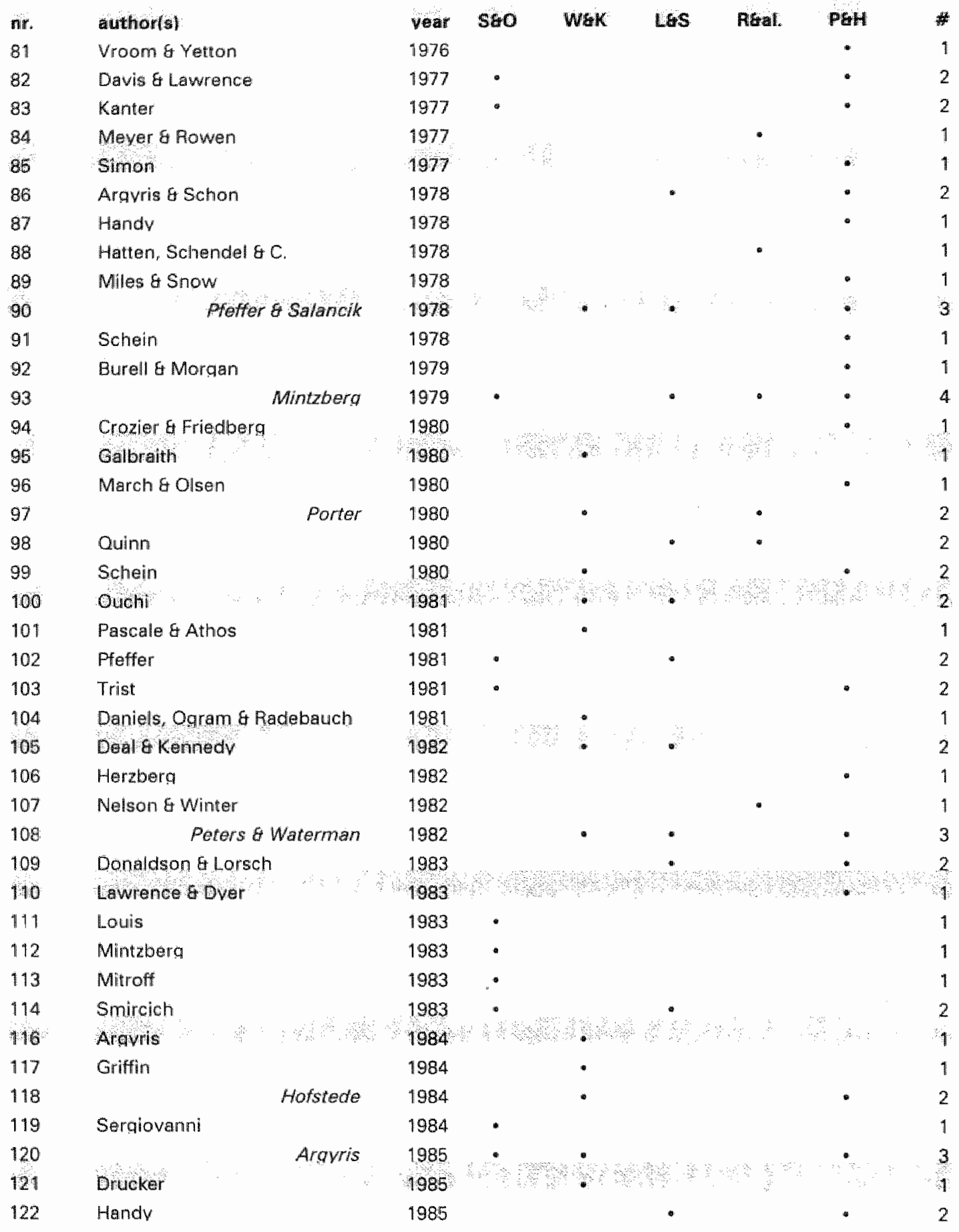


Table 5.1. Continued

\begin{tabular}{|c|c|c|c|c|c|c|c|}
\hline nt. & author $(s)$ & vear & 580 & wak & LGS & Rratal: & PGH \\
\hline 123 & Kanter & 1985 & & & & & • \\
\hline 124 & Kirpalani & 1985 & & - & & & \\
\hline 125 & Pettiarew & 1985 & & & - & & $\cdot$ \\
\hline 126 & Pinchot & 1985 & & - & & & \\
\hline 127 & Schein & 1985 & - & & & & $\cdot$ \\
\hline 128 & Weihrich & 1985 & & - & & & \\
\hline 129 & Williamson & 1985 & & & - & & \\
\hline 130 & Jensen & 1986 & & & & 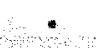 & \\
\hline 131 & Ronen & 1986 & & 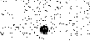 & & & \\
\hline 132 & Morgan & 1986 & & & & &  \\
\hline 133 & Trist & 1987 & & & & & $\cdot$ \\
\hline 134 & Vroom & 1987 & & & & &  \\
\hline 135 & Doz \& Prahalad & 1988 & & & & $\cdot$ & \\
\hline 136 & Hanna & 1988 & &  & 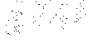 & & \\
\hline 137 & March & 1988 & & & - & & " \\
\hline 138 & Mintzberg \& Quinn & 1988 & & & - & & \\
\hline 139 & Quinn \& Cameron & 1988 & & - & & & \\
\hline 140 & Vroom \& jago & 1988 & & & & & 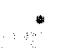 \\
\hline 149 & Peters & 1988 & & 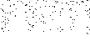 & 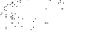 & 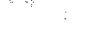 & : \\
\hline 142 & Bartlett \& Ghoshal & 1989 & & & & - & * \\
\hline 143 & Drucker & 1989 & & - & & & \\
\hline 144 & Mannan \& Freeman & 1989 & - & & - & - & $"$ \\
\hline 145 & Mintzberq & 1989 & & & & & $\therefore$ \\
\hline 146 & Kanter & 9989 & & 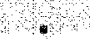 & 8 & & 4 \\
\hline 147 & Coleman & 1990 & & & 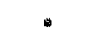 & & \\
\hline 148 & Lindenbera & 1990 & & & - & & \\
\hline 149 & Porter & 1990 & & - & & & \\
\hline 115 & DMaqaio \& Powell & 1991 & & & 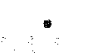 & & . \\
\hline 150 & Adler & 1991 & & $\therefore$ & & & \\
\hline 151 & Hofstede & 1991 & & & & & $\cdot$ \\
\hline 152 & Pettiarew \& Whipp & 1991 & & & & & $\cdot$ \\
\hline 153 & Hannan \& Carroll & 1992 & & & - & & $\cdot$ \\
\hline 154 & Mintzberg & 1992 & & $\cdot$ & & & \\
\hline 155 & Senqe & 1992 & & & & & 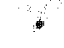 \\
\hline 156 & Aravris & 1993 & & & & & $\cdot$ \\
\hline 157 & Morqan & 1993 & & & & & - \\
\hline 158 & March & 1994 & & & & & " \\
\hline 159 & Miles E Snow & 1994 & & & & & $\cdot$ \\
\hline 160 & Peters & 1994 & & & & & 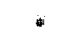 \\
\hline 161 & Kanter & 1995 & & & & & $\cdot$ \\
\hline 162 & Weick & 1995 & & & & & 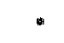 \\
\hline
\end{tabular}


The checkpoints described in section 4.5 will be used as a framework for evaluation. In addition to that, elements of each theory will be illustrated by citing relevant fragments from the original text.

The reason for those, sometimes large, quotations, is twofold. In the first place they illustrate what the authors meant to say in their own words. That is the best possible picture of important elements of the ideas, propositions, postulates, Weltanschaumng, style, idiosyncrasies, and other typical characteristics as are exposed by the author. It may be quite enlightening, for instance, to read what Weber wrote in his own life and times, in his own language.

The second reason lies in our own metatheoretical requirements. When observing, care must be taken to avoid premature interpretation. When theories are examined, the original text is the only genuine material available. Interpretation, even paraphrasing, involves the risk of kneading or twisting of what is originally proposed. It could do wrong to the intention of the author.

For those reasons, examples of the elements of knowledge development will be given as citations when they elucidate the intentions of the author. I will underline terms and passages directly relating to definitions, constructs, models, and the like. In addition I will comment on these citations and draw conclusions about the observed knowledge development.

The examples given are not intended to cover all instances of the mentioned aspects. The finding of some clear examples will suffice to obtain a systematic assessment.

Whenever possible however, I have tried to mention all important assertions from the books. It should be noted that the reports on the theoretical cases are not meant as ordinary reviews: this study has a unilateral focus on knowledge development and on some connected general aspects. Neither have I tried to make a judgement about 'good' or "bad" writers or theories. The selected cases just represent a sample over the last century, taken from acknowledged repertories. Some belong to the early work of authors (like the one of Blau and Scott, 1962). Other samples represent a mature product of a long tradition of research (like Hannan and Freeman's, 1989).

\subsection{Frederick W. Taylor}

\section{Bibliographical data}

Taylor, F.W., The Principles of Scientific Management, New York 1914. 


\section{Contextual points}

Taylor (1856 - 1915) came from a well-to-do family and was preparing for Harvard University when his study was interrupted due to a nervous breakdown. He then began a career as a workman. He accumulated a great experience in American industry, from the rank and file of workers to top management positions. Taylor conducted a great number of experiments about human labor. He also developed and patented numerous metalworking methods and machinery, which made him a very rich man. He was obsessed by the idea that better efficiency would improve societal conditions as a whole. After the civil war the American industry developed quickly. Growing demand often could not be met due to poor industrial practices (lack of standardization, insufficient quality) and problematical industrial relations. American mechanical engineers joined together in American Society of Mechanical Engineers (ASME), the American Society of Mechanical Engineers, set themselves up as experts to remedy these problems through rationalization. Taylor was among those who stretched technical solutions into the domain of human labor. This lead to a severely reduced, mechanistic 'model of man' in which the workman was considered as a mere production factor.

Predecessors of Taylor are, for instance, Adam Smith (1776), Charles Babbage (1832), and Henry Towne (1886). The ASME, in pursuit of recognition as a profession, was his scientific environment. Frank Gilbreth was a contemporary of Taylor, with a remarkable parallel career: he stopped his academic study to become a bricklayer and studied the trade in great detail, as Taylor did in metalworking. Gilbreth developed time and motion studies independent from Taylor. After they met in 1907, they cooperated (Weihrich and Koontz, 1994).

In order to underline the societal importance of his work, the author quotes president Theodore Roosevelt in his address to the governors at the White House (p. 5):

The conservation of our national aseunces is only

prebminary to the larger question of national

efficiency."

Taylor indicates two important problems. The first is the necessity to train managers. In the past 'Captains of industry are born, not made' (p. 8); in the future leaders of all levels must be trained. The second problem he identifies is the low level of productivity, caused by mistrust and antagonism between employers and employees. 'Soldiering' (intentional underperformance) is universal in the US and England. By applying appropriate means doubling of output is possible. The author considers soldiering as a main societal problem (p. 14):

"America and England hawe been recently agiteted over such projects as the terit, the control of the large corporations on the one hand, and of heredity power on whe other hand, and over watrous more or wess socialistic proposals for thation, atc.... and hardly a voice has been raised to call attention to this yasty. greater and mote important subject of 'soldiering'. 
which ... affects the wages, the prosperity, and the life of almost every working man, and also... the

prosperity of every industrial establishment in the nation... The writer has a great sympathy with those that are overworked, but on the whole a greater sympathy for those who are underpaid.

Taylor elaborates on soldiering, quoting from a paper from June 1903 (ASME). He sees three causes of the problem (p. 15):

"First, the fallacy, that ... an increase in output would result in ... throwing a large number of men out of work, Second, the deffective system of management, which makes it necessary ... to soldier ... in order to protect... [one's] own best interest, Third ...inefficient rule-of-thumb methods, ... in practicing which our workmen waste a large part of their effort."

By the end of the book he recommends his solutions to cure large societal problems (p. 144):

"Is not the realization of results such as these of far more importance than the sollution of most of the problems whicth are now agitating both the English and American peaples?

\author{
And is it not the duty of those who are acquainted with \\ these facts, to exert themselves to make the whole \\ community, realize this importance?"
}

\section{Contents and relevance}

The author expresses several basic positions. Three of these will be discussed here. The first one states that it is necessary to switch priorities between 'man' and 'system'. In the past man has been first, but in the future 'the system must be first' (p. 7):

"This in no sense, however, implies that great man is not needed. On the contrary...lbut the remedy of problems l lies in systematic management, rather than searching for some unusual or extraordinary man."

Second, the author does not reject the necessity of individual quality, but he considers a systematic way of management to be of the highest importance. This system must have a scientific basis, as is illustrated by his statement that "the best management is a true science, resting upon clearly defined laws, rules, and principles, ... '(p. 7 ).

Third, he believes that operational work and its scientific control should be separated (p. 26):

"... the workman who is best suited to actually doing the work is incapable of fully understanding this science, without the help and guidance of those who are working with or over him, either through lack of education or through insufficient mental capacity. '

In the situation that existed by the turn of the previous century, most workmen in the United States were first generation immigrants with little education. This may explain Taylor's opinion that is illustrated by the foregoing statement about the necessity to separate planning 
and control from operational work. Others must do the preparation and supervision, as well as the training of operators.

In the third place he argues that scientific research is able to describe, explain, and predict human effort in labor. This knowledge would solve the aforementioned problem (p. 119):

"There is another type of scientific investigation which has been referred to several times in this paper, and which should receive special attention, namely, the accurate study of the motives which influence men. At first it may appear that this is a matter for individual obserwation and iudgment, and is not, a proper subject for exact scientific experiments. It is true that the laws which result from experiments of this class, owing to the fact that the very complex organism - the human being - is being experimented with, are subject to a larger number of exceptions than is the cose with laws relating to material things. And yet laws of this kind, which apply to a large majority of men, unquestionebly exist, and when clearly defined are of great value as a guide in dealing with men. In developing these laws, accurate, carefuly planned and executed experiments, extending through a term of years, have been made, similar in a general way to the experiments upon various other elements which hawe been referred to in this paper."

This passage demonstrates Taylor"s metatheoretical belief in organizational laws and the possibility to obtain these by experiment.

The author's central contention is, that both employers and employees can maintain maximum prosperity by achieving excellence in business through cooperation and scientific management (p. 9):

'The principal object of management should be to secure the maximum prosperity for the emplover, coupled with the maximum prosperity for each employé.

The words 'maximum prosperity' are used, in their broad sense, to mean not only large dividends for the company or owner, but the development of every branch of the business to its highest state of excellence, so that the prosperity may be permanent. In the same way maximum prosperity far each employe means not only, hiaher wages than are usually received by men of his class, but of more importance still, it also means the development of each man to his state of maximum afficiency, so that he may be able to do, generetly speaking, the highest grade of work for which his natural abilities fit him, and it further means giving him, when possible, this class of work to do.

It would seem to be so self-evident.. but, a large pert of employers and employés are for war."

Apparently prosperity is meant to be more than its pure economic component. It also involves the edification of the worker.

The final sentence of the citation demonstrates Taylor"s opinion that the ideal situation is fusustrated by mutual mistrust. Piece rate systems, an essential part of scientilic management, have been abused by employers and sabotaged by workers (pp. 23, 24):

'It is, however, under piece work that the art of soldiering is thoroughly developed.... The employer is soon looked upon as an enemv, and the mutual confidence which should exist between a leader and his men, the enthusiasm, the feeling that they are all 
working, for the same end and will share in the results is entirelw lacking.

The feeting of artagonism under the ordinary piecework system becomes in many cases so marked on the part of the men that my proposition made by their employers, however reasonable, is looked upon with suspicion, and soldiering becomes such fixed habit that men will frequently take pains to restrict the product of machines which they are running when even a large increase in output would involve no more work on their part. .... As to the third cause for slow work, considerable space will later in this peper be devated to illustrating the great gain, both to employers and employees; which results from the substitution of scientific for rule-of-thumb methods in even the smallest details of the work of every trade.

Here the author stresses the fixed habit of restricting output by workers and the disbelief of employers in a scientific solution of the problem. But Taylor insists that minute scientific research of the labor process by motion and time study can overcome the controversy between laborers and employers. By contrast, the employers try to motivate workers by extra inducements rewarding their own successful initiatives. The author rejects this method. Instead, he argues, it is necessary to apply scientific management with incentives related to measured effort ( $p$ p. 32, 34).

Scientific management comprises standards as well as standard related incentive (p. 121):

These two elements, the task and the bonus (which, as has been pointed out in previous papers, can be applied in several ways), constitute two of the most importantelements of the mechanism of scientific management. They are especially important from the fact that they are, as it were, a climax, demanding before they can be used almost all of the other elements of the mechanism; such as a department, accurate time study, standardization of imethods and implements, a routing system, the training of functional foremen or teachers..."

But it goes much farther, as the author argues in this passage. From the study of the operating level, knowledge can also be obtained about managerial and preparatory work. From this tenet it can be concluded that Taylor"s research directly pertains to structure, as his work enables the design of accurate organization elements. His second main contention, the principle of shared specialized leadership, refers also to structure. This latter position of functional leadership was severely criticized by Fayol (1920) and later writers.

Although strategy was not yet an explicit issue, Taylor's attempts to cure the antagonism between capital and labor were of strategic importance. His work directly pertains to the design of structure.

Taylor's research typically took place at the large mechanical engineering plant. Several hundreds of workers were employed, mostly operators, in a hierarchical structure with hardly any facilitating or staff functions, as was common at the turn of the previous century. As said Taylor claims a wider applicability (p. 7):

the best management is true science, resting upon clearly defined laws, rules, and principles, as a foundation ... applicable to all kinds of human activities from simplest individual acts to the work of our great 
corporations, which call for the most elaborate cooperation"; ... "whenever these principles are correctly applied, results must follow that are truly
Estounding. ... It is hoped to be clear to other readers that the same principles will apply with equal force to all social activities."

\section{Process of knowledge development}

Taylor proposes two main theories: one about the scientific organization of labor to obtain maximum prosperity for both employers and employees, and one about functional management.

The first one is grounded on numerous experiments. They include the pig iron example, with 'Dutchman' Schmidt, who is asked to perform ever heavier daily tasks (p. 40), the art of shoveling ( $p .64)$, in which different kinds of shovels are used and their effect on productivity is examined, Gilbreth' study of brick laying (motion study, p. 77), the study of inspecting bearing balis with the aspects of quality control, tiredness, performance in relation to the length of the working day (p. 86), and the steel cutting study (p. 98), in which the relation between tool steel quality, speed of rotation, and other factors relating to productivity were investigated. In all these studies the complete cycle A through F was repeatedly and completely followed.

With respect to this theory, hypothesis, derivation and prescription are reported in the book. An example of the first element can be found on page 121 :

"The remarkable and almost uniformly good results from the correct application of the task and the bonus: must be seen to be appreciated.

These two elements, the task and the bonus which, as has beein pointed out in previous papers, can be applied in seweral waysl constitute two of the most important elements of the mechanism of scientific management."

Derivation leads to the necessity of minute observation of motions of the workers, together with the time involved (pp. 23,24):

"The enormous saving... of time and therefore increase in the outpul which it is possible to effect through eliminating unnecessary motions and substituting fast for slow and inefficient motions for the men working in

Prescription is found on page 122 :

"This involves not only fixing for each man his daily task but also paying him arge bonus, or premium, any of our trades can be fully realized only after one has personally seen the improvement which results. from a thorough mation and time study made by a competent man.

each time he succeeds in doing his task in the glven lime..."

In the book itself not all of the experiments concerning the first theory are reported in detail. For most of these, reference is made to other publications of the author himself or other 
researchers (Gilbreth). Therefore, in the pictorial model given hereafter, certain boxes will be dashed.

The second main theory has the form of a set of hypotheses, directly followed by a set of rules. It states that the operating level should be supervised by a number of functional bosses, in order to obtain an efficient organization. This would imply that every worker could have as much as eight direct supervisors. In this case, he defends his proposition mainly by reasoning. The following elements of knowledge development occur in the theory:

One of the many examples of hypothesis of the second theory can be found on page 122 :

"The necessity for systematically teaching workmen

how to work to the best advantage has been several times referred to.

An example of rules following from the second theory is (p. 122):

These instructions represent the combined work of severall men in the planning room, each of whom has his own specialty or function. One of them, for instance, is a specialist on the proper speeds and cutting tools to be used. He uses the slide-rules which have been above described as an aid, to guide him in obtaining proper speeds, etc. Another man analyzes the best and quickest motions to be made by the workman in setting the work up in the machine and removing it, etc. Still a third, through the time-study records which have been accumulated, makes out a timetable giving the proper speed for doing each element of the work.'

Contrary to his painstaking research into time and motion studies, his observation of the functional management doctrine was limited to his own experience as a manager. He was probably the only person capable of running a shop with eight supervisors directly commanding and teaching all workers on the operating level.

In his second theory, induction was virtually absent, the tenets being based on the belief of the author.

Assessment following the A-F-scheme

As stated, the first theory is about time and motion study and incentive systems, combined with propositions about selection and training of workers. This theory has sound hypotheses (p. 121), operationalized observables (pp. 23, 24), and prescriptions (p. 122) (boxes A, B, and E). Definiteness, precision, and coherence are correct.

Numerous experiments are referred to, like 'the art of shoveling' and the experiments with "Dutchman Schmidt'. Their set-up and their evoked observations are described in a verifiable way (pp. 40, 64) (from E to F, followed by C and D). This theory is fully elaborated (bold lines) and comprises the complete cycle $\mathrm{A}$ through $\mathrm{F}$, which means that it has a perfect systematic structure. Those elements not materially rendered in the book, but largely available 
from Taylor's preceding studies, have dotted lines around their boxes. It can be concluded that metatheoretical criteria are complied with to a large degree, and that Taylor indeed formulated a scientific theory, with a high degree of metatheoretical rigor. Validity has been tested. Its utility is apparent for all applications in which the amount, the nature, and the remuneration of labor are important. Although it is not in alignment with today"s psychological insights the theory seems to be in coherence with the psychological assumptions of 1900 .

The second theory refers to multiple (functional) leadership over operational workers. This theory, covering hypothesis and prescription, is not supported by other experience but the author's. Therefore, boxes A and E have thin lines. Lacking elements of knowledge development are represented by thin dotted lines.

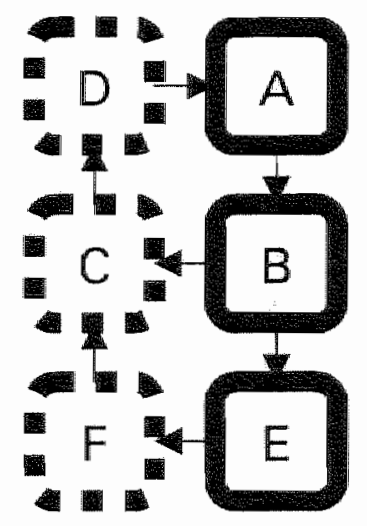

Model of the first theory

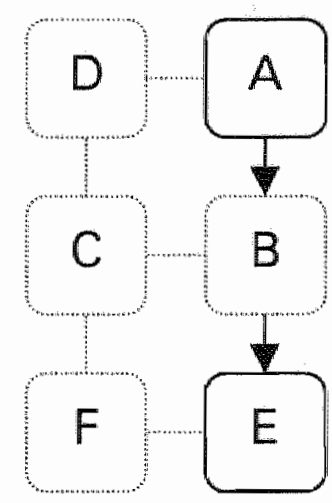

Model of the second theory

\section{Conclusion}

Taylor's theory on the organization of human labor leads to important rules that are useful for the design of organizational structure. Taylor's theories must be judged against the values of his time and age. They are a typical product of the turn of the 19 th to the 20 th century in the United States. In spite of the severe critique he met (sometimes on pollitical or ideological grounds) he had, and still has, an enormous influence on all researchers of management and organization. Drucker (1954) for instance, considers Taylor's work as perhaps America's most influential contribution to Western thinking since the American constitution.

Validity and utility are sound. As far as fecund elements are concerned, it must be noted that the author's conclusions concerning the organization of work (but only those based on the first theory) led to extremely valid and useful recommendations (rules for action), which still hold. 


\subsection{Henry Fayol}

\section{Bibliographical data}

Fayol, $\mathrm{H}_{\text {, }}$ Administration Industrielle et Générale: Prévoyance, Commandement, Coordination, Controle, Paris 1920 (Extrait du Bulletin de la Société de l'Industrie Minérale, 3 "livraison de 1916).

\section{Contextual points}

Fayol (1841-1925) was educated in the French tradition of the grandes écoles as a mining engineer. He fulfilled management functions from his thirties and was a general manager from 1888 to 1918 . Only in his seventies he started to publish his ideas on management. Contrary to Taylor, he proposed his ideas without pretense.

Fayol derived his principles from an enormous practical experience. He was a pioneer in nonmilitary management doctrine. He worked in the French philosophical-educational tradition, leading to an essay-like treatment of the subject (this will be seen again in Crozier's work of 1964). Concepts are derived from general hypothesis (based on general experience) and translated into rules for action. He makes no attempts to formulate propositions in a testable way.

His historical/social environment was that of the end of the 19 th century. At the time, the French education system at the highest technical level was concentrating on mathematics and its technical application. Management was supposed to be learned in practice. Fayol opposes to this bias and recommends the teaching of management as well. He considers this training to be easy enough, as the subject is common knowledge of every experienced manager.

Fayol contended that the art of management should be applied to the full domain of society. His original intention was to write about a range of subjects in this respect, but he did not complete his plans, as the third and fourth part of his series were never published (p. 5):

Ladministration joue dans le gouvermement des: affaires, de toutes les affaires, grandes ou petites, industrielles, commerciales, politiques, reliqueuses ou autres, une rôle tresimportant. Je me propose d'exposer ici més ides sur la manière dont ce róle dewrait btre rempli.

Man travail sera divise en quatre parties: 1re partie. - Nécessité et possibilité d'un enseignement administratif; $2^{\text {k }}$ partie. - Principes et éléments d"administration;

$3^{\text {m }}$ partie. - Observations et experiences personelles; 4 partie. - Lecons de la guerre.

Les deux premières parties, qui font l'abjet du present volume, soint le développement de la confểrence que j'ai failt au Cinquantenaire de la Saciété de l'Industrie minerale, à Saint.Etienne, en 1908. Les $3^{a}$ et $4^{e}$ parties feront l'objet d"un deuxième volume qui paraitra prochainement." 
The author stresses the necessity to train managers on the basis of an 'administrative doctrine" $($ pp. 21, 23):

'L'administration ne figure meme pas dans les programmes d'enseignement des ecoles supérieures de gếnie civill....

II importe done d'établir le plus tôt possible une doctrine administrative. Ce ne serait ni bien long m bien difficile si quelques grands chefs, se decideient à exposer leurs idées personnelles sur les principes qu“ils considèrent comme les plus propres à faciliter la marche des affaires et sur les movens les plus favorables à là réalisation des principes. La lumière sortirait bientôt de la comparaison et de la discussion. Mais la plupart des grands chefs n'ont ni le temps ni le goùt d'écrire ... II n'est heureusement pas nécessaire de gouverner une grande entreprise-ni de présenter une étude magistrale pour apporter un concours utile à la constitution d'une doctrine. La moindre observation bien faite a sa valeur, et, comme le nombre des observateurs possibles estillimite, on peut esperer que, le courant une foils établi, il ne starreter plus; il s'agit de determiner ce courant, d'ouvrir la discussion publique ; c'est ce que jessaye de faire en publiant ces études. ل'espere qu'une doctrine en sortira."

Here Fayol states that an 'administrative doctrine' needed to serve as teaching material for future managers could simply be compiled by writing down the many experiences of all grands chefs. He proposes to make a start, hoping that discussion and enhancement will follow in order to obtain the 'doctrine' sought.

\section{Contents and relevance}

In his Principes généraux d'administration, the author states his basic position, holding that management is essentially the organization of human resources (p. 25):

'La fonction administrative n'a pour organe et pour instrument que le corps sacial. Tandis que les autres fonctions mettent en jeu la matiere et les machines, la fonction administrative n'agit que sur le personne!. Lé santé et le bon fonctionnement du corps socilal dépendent d'un certain nombre de conditions que l'on qualifie à peu près indifféremment de primcipes, de lois ou de règles. J'emploierai de préference le mot principes en le dégtugeant de toute idée de rigidité. II n'y rien de riglide ni d'absolu en matière administrative; tout y est question de mesure. On n'a presque jamais a appliquer deux fols le meme príncipe dans des conditions identiques: ill faut tenir compte des circonstances diverses et changerntes, des hommes également divers, el changeants et do beaucoup d'autres élérments wariables."

In his opinion, management is an art, in which moderation is required. The unlimited number of principles and rules of management should be molded into any useful and applicable way, as long as they are confirmed by experience (p. 26):

'Aussi les principes sont-ils souples et susceptibles die s'edapter à tous les besoins. II s'agit de savoir s'en servir. Costi un art difficile qui exige de l'intelligence. de l'expérience, de la décision et de la mesure, Faite de tact et d'experience, la mesure est l'une des principales qualités de ladminilstrateur.... Le nombre des 
principes d'administration n'est pas limitê. Toute règle, tout moyen administratif qui fortifie le corps social ou en facilite le fonctionnement, prend place parmi les principes, aussi longtemps du moins que l'expérience le confirme dens cette haute dignité. Un changement dans l'état des choses peut déterminer le changement des règles auquei cet état avait donné naissance."

The author strongly rejected Taylor's theory of functional management, holding that every operator should have several direct supervisors that together form a staff. Fayol was a firm proponent of unity of command. He admits that supervision and training of the operating level requires strong support by a staff of experts. The discussion is interesting, as Fayol's view was supported by later evidence. Nevertheless he acknowledges Taylor's management acumen (p. 97):

Selon Taylor, il faut abandonner le type ordinaire d'organisation, qu'il designe non sans quelque dédain sous le nom de type militaire d"organisation, où les ouvriers reçoivent leurs ordres d"un seul homme, chef d'atelier ou chef d'equipe. ... II [Tiaylor] repose sur les deux idées suivantes:

1. La nécessité de rentorcer les chefs d'atelier et les contremaîtres par un Etat-Major :

2. La négation du primcipe de l"unité de

commandement, autant la première me paraît bonne. autant la seconde me parait fausse et dangereuse. ...
[Taylor was able to manage large organizations under the rule of functional multiple supervision.] ... Comment expliquer cette contradiction? ... Tous les jours, dans les affaires, et du haut en bas des hiérarchies, on a à concilier le fonctionnement de IEtat-Major avec le principe de lunité de commandement. Il y faut quelque habileté. Taylor devait en être richement pourvu.

So Fayol attributes the success of Taylor in his practicing of functional management to his personal managerial capabilities and his knack, that enabled him to overcome the fundamental flaw of this way of managing. As said Fayol vigorously rejects functional management as a general principle.

He was, however, a great admirer of Taylor as far as his scientific analysis of labor and mechanical engineering were concerned ( $p .98)$ :

'Mes reserves sur l'organisation scientifique ou administrative de Taylor ne m'empêchent point d'admirer linventeur des aciers i coupe rapide, le createur de procédes minutieux et precis des conditions dans lesquelles s'execute le travail de l'ouvrier, lindustriel ónergique et inqénieux qui après avoir fait des découvertes, n'a reculé devant aucun effort et aucum ennui pour les faire entrer dans le domaine de la pratique, el le publiciste infatigable qui a tenu a faire profiter le public de ses essais et de ses expériences. Nous pouwons souhaiter que l'exemple du grandingénieur américain soit suivi à cet égard par beaucoup de nos compatriotes:

Fayol's basic contentions are the following.

In all industrial enterprises, large or small, six types of activities exist: technical, commercial, financial, those concerning security, accounting, and management. 
Management is important in all business (large or small), be they industrial, commercial, political, religious or any other.

Management is foresight, organization, command, coordination and supervision.

A doctrine for management is needed.

Management should be part of the curriculum of leadership education.

Management is an art; it should be applied with moderation.

Rules concerning:

- unity of command,

- division of competencies between board members,

- research and other improvements,

Functional management as proposed by Taylor is wrong, as it violates the rule of unity of command.

There are 14 principles of management ( $A$, some leading to $E$, p. 26):

1. division of work (for expertise building and productivity),

2. authority (command and responsibility)

3. discipline (with good leadership as counterpart)

4. unity of command

5. unity of direction (one goal for all people involved)

6. general interest must supersede individual interests

7. remuneration is an important motivator (but there is no perfect system)

8. centralization or decentralization should be applied in accordance with the function at hand

9. lateral communication is acceptable as a shortcut between distant hierarchical lines

10.order (material and social)

11. equity (a combination of mildness and justice)

12. stability of tenure (management positions are more stable in successful business)

13. initiative should be accepted in some way, although it may wound superiors" pride

14. "esprit de corps" is important.

Structure was the central issue in this work. Strategy was not yet considered: the firm "s position was considered as a given fact.

Fayol claimed applicability to all sizes of business and non-profit organizations.

Process of knowledge development

As a start for hypothesizing the author defines a number of terms (pp. 7, 76, 89), One example is given here:

"Définition de l"administration. Six groupes

d'operations dans les entreprises: techniques.

commerciales, financières, de sécurité, de comptabilité et administratives. Administrer. c'est prévoir. organiser commander, coordonner et controler. "

In addition, definitions are given of organization and of staff. 
Fayol's hypotheses ("principles") consist of definitions of phenomena involved in management, and of statements about their supposed character and relationships. In their simplicity, no derivation as an intermediate step is considered necessary before rules can be formulated. At first sight, his organistic metaphor of the division of labor seems to be a scientific hypothesis, but it is only a manner of speech (p. 26, see above).

The author had a long-standing experience in management. Scientific observations were not reported.

He used metaphors that supported his 'principles'. He compared the organization with natural forms and their functions. Examples are the following (pp. 44, 84):

'Comme la 'division de travail', la centralisation est un fait d'ordrenaturel; celui-ci consiste en ce que dans tout organisme, animall ou social, les sensations convergent vers le cerveau ou la direction, ell que du cerveau ou de la direction partent les ordres qui metrent en mouvement toutes les parties de l'organisme:"

\begin{abstract}
... "La vie végétale été aussi l'accasion de nombreux rapprochements avec la via sociale. ... Les arbres "ne grandissent pas jusqu"au ciel"; les corps sociaux ont aussi leurs limites. ... Mais certain force, certaine puissance que l'arbre ne peut atteindre par son seul développement, peuvent résulter du groupement, de la juxteposition, de la foret. .
\end{abstract}

The author compares the brain to top management, from which orders to act are given. Trees do not grow into heaven; but a wood, a group of trees, might be able to do what a tree cannot perform.

The author seamlessly goes from hypothesis into prescriptions. On the subjects specified earlier (p. 26), rules for the manager are formulated.

Recommendations are also given for the division of competencies between members of the board (p. 84):

"Les directeurs généraux muitiples se partagent les attributions de la direction generale de manieres diverses.

"L.unité a, sur la pluralité, l'avantago de faciliter lunité devues, lunite draction, l'umité de commandement. Elle tend à prévaloir. Mais en ces sortes de matières, la valeur personnelle des hommes a une importance énorme quillemporte sur le systéme.

Dans tous les cas, la Direction génerale s"appule sur un Etat-Major:'

The author recommends the use of the organization chart as well (p. 110).

Fayol, as a manager, intervened all of his professional life. But his observations remained in the realm of broad lines and contemplation.

\section{Assessment following the $A-F$ - scheme}

The knowledge development as described is represented in the model depicted hereafter. Hypothesis (A) is well elaborated as far as definitions are concerned (pp. 7, 76, 89). This means that defmiteness and precision are properly dealt with (bold frame). However derivation is not 


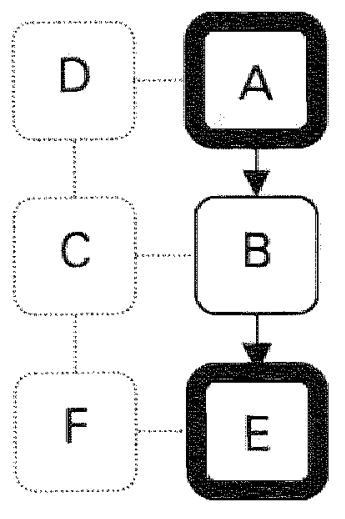

developed enough to obtain testable hypotheses (thin frame).

Knowledge is treated on the basis of long-standing observation (C), it is taken for granted and not elaborated into data that allow for induction (dotted line for $\mathrm{C}$ and $\mathrm{D}$ ). The prescriptions in $\mathrm{E}$ are most elaborated on (pp. 26, 84, 110), hence the bold frame. B is discussed in the attributes of the organization chart. F is not discussed.

Coherence is in accordance with the insights of those days (p. 26, about 'esprit de corps').

Metatheoretical requirements concerning the systematic structure that would enable testability are not met. By their absence this is not a scientific theory. The recommendations however are directly useful for practical application.

\section{Conclusion}

Fayol's principles typically follow from hypothesis, more or less directly followed by prescription. Fayol's pioneering work describing organizational principles was an important source of rules for the design of organizational structure. Its character however was not intended to be scientific. Fayol knew Taylor's work (p. 93). Next to his admiration for his technical achievements and his organizational studies he rejected the principle of functional management, as was discussed above.

A most fecund element in his work was the attempt to define management. 'He is the earliest known proponent of a theoretical analysis of managerial activities - an analysis that has withstood a half-century of critical discussion" (Pugh \& Hickson, 1997, p. 90).

\subsection{Max Weber}

\section{Bibliographical data}

Weber, M., Wirtschaft und Gesellschaft; Grundriss der verstehenden Soziologie, Kapitel I: Soziologische Grundbegriffe; Kapitel IX, 2. Abschnitt: Wesen, Voraussetzungen und Entfaltung der bürokratische Herrschaft, Tübingen 1976 (original text 1921).

\section{Contextual points}

Weber (1864 - 1920) was the son of a German lawyer and politician. He was a reserve officer of the German army and became a lawyer, but continued his studies of law and economy, obtaining a Ph.D. in 1899. He was a professor at Freiburg and Heidelberg, later at Vienna and Munich. He was founder of the Deutsche Demokratische Partei (in the political center) and member of the German delegation at Versailles after the first World War. 
Weber worked in the tumultuous years starting with the Bismarck episode and ending with the treaty of Versailles. It was a time of "... demise of "liberal" politics and culture ...; the ... steady" growth of socialism ...; a shift in socio-cultural sciences ... toward economic categories, concepts and explanations ...; and ... an uneasy concern over the prospects of ...

Kulturpessimismus." (Scaff, 1989, p. 11) Weber's scientific environment becomes clear from his reference to Karl Jaspers for the psychological concept of Verstehen. The author worked in the tradition of German philosophers like Simmel and Tönnies. He rejected Durkheim's search for "sociologicall laws". Instead, he stressed the necessity to relate human action to meaning. Weber considered himself a political economist, as becomes clear from his opening sentence in: Wissenschaft als Beruf, Gesammelte Aufsäze zur Wissenschaftslehre, Tubingen 1922.

\section{Contents and relevance}

In an opening statement about his basic posinion Weber defines sociology, thereby illustrating some essential properties of his scientific objectives. In his view it seeks deutend Verstehen (explaining by interpretation). Handeln (acting) comprises outward and inward doing, refraining and enduring; acting is only social insofar its meaning (Sinn) relates to others and is oriented towards the processes (Ablauf) involved. This is illustrated by the following passage ( $\mathrm{p}$. 1):

'Soziologie ... soll heißen; eine Wissenschaft, welche soziales Handeln deutend verstehen und dadurch in seinen Ablauf und seine Wirkumgen ursächlich erklaren will. "Handeln" soll dabei ein memschliches Verhalten leinerfei ob äußeres oder innerliches Tun, Unterlassen und Dulden) heisen, wenn und insofern als der oder

\begin{abstract}
die Handelnden mit ithm einen subjektiven Sinn verbinden. "Soziales" Handeln aber soll ein solches Handeln heißen, welches seinem vor dem oder den Handelnden gemeinten Sinn nach auf das Verhalten and erer bezogen wird und daran in seinem Ablauf orientiert ist."
\end{abstract}

"Meaning' is essential in his work. The scholar must construct it as a concept. It is said to be attributed in a subjective way to acting and it explains this acting as it is observed in sets of observed cases (p. 1):

\footnotetext{
"Sinn" ist hier ... in einer gegebenen Masse von Fällen won den Handelnden, oder ... in elinem begrifflich konstruierten reinen Typus von dem gedachten Handelnden subiektiv ge me in te Sinn. Micht ekwa ein
}

The citation demonstrates that Weber considers sociology to be a science like history, in the sense that it reports events and states and it explains these out of an assumption about the meaning of social actions of (groups of) individuals. In this sense hypothesis is borrowed from the historical narratives and at the same time they are used as explanations.

The concept of 'ideal type" is again related to 'meaning' and also to 'rationality' (pp. 2 - 4 ): 
"Fur die Ty pen bildende wissenschaftliche

Betrachtung werden nun alle irrationalen, affektuell bedingten, Sinnzusammenthänge des Sichverhaltens, die das Handeln beeinflussen, am übersehbarsten als "Ablenkungen" von einem konstruierten rein zweckrationalen Verlauf desselben erforscht und festgestellt ... Die Konstruktion eines streng zweckrationalen Handelns also dient in diesen Fällen der Soziologie, seiner evidenten Verständlichkeit und seiner - an de Rationaltät haftenden - Eindeutigkeit wegen, als Typus ("Idealtypus" ${ }^{\text {m }}$, um das reale, durch Irrationalitater aller Art (Affekte, Irrtümer)' beeinfluBte Handeln als "Abweichung" von dem bei rein rationalem Verhalten zul gewärtigenden Verlaufe zu verstehen. ... aus diesem methodischen

Zweckmaßigkeitsgrunde ist die Methode der "verstehende" Soziologie "rationalistisch"."

Important concepts of Weber are - next to ideal type - instrumental and substantive rationality, power, authority, rule, discipline.

Weber defends the following basic contentions.

1) His Weltanschauung entails that sociology should aim at "interpretative understanding" (deutend Verstehen) of social acting (visible as well as interpreted inward processes). It uses ideal types of (complexes and processes of) social acting, which are derived from the observed or interpreted ways of acting by omitting all irrational influences on the process. As irrational are considered those influences which cannot be attributed to instrumental or substantive rationality.

2) The statements concerning bureaucracy hereafter.

Structure is elaborated for large organizations. The author claims that bureaucratic organizations may be public as well as private. Strategy is not yet an issue. The work pertains mostly in a metatheoretical and indirect way to the design of structure.

\section{Process of knowledge development}

Four types of rationality are hypothesized (p. 12):

1) zweckrational: behavior selecting means to ends, instrumental rationality,

2) wertrational: behavior respective of values (moral, esthetic, religious), substantive rationality,

3) affectional, or emotional, rationality, and

4) traditional rationality.

For the study of sociological ideal types the first two are relevant.

Three types of Herrschaft are distinguished, indicating that the term may mean 'rule' as well as "authority" (p. 124), namely on the base of:
1) legal rule,
2) tradition,
3) charisma of the leader. 
The author introduces the concepts of Macht (power: obedience that can be coerced), Herrschaft (authority, based on legitimate rule: voluntary obedience for certain orders), and Disziplin (discipline: obedience through trained disposition), (p. 128):

'Macht bedeutet lede Chance, innerhalb einer sozialen Bezlehung den aigenen Wulle auch gegen Widerstreben durchzusetzen, gleichviel worauf die Chance beruht. Herrschaft ... die Chance, für einen
Befehl bestimmten Inhalts bei angebbaren Personen Gehorsam zu finden... Disziplin die Chance, kraft eingeübter Einstellung für einen Befehl... Gehorsam ... zu finden:

Bureaucracy is discussed in the section called Weser, Voraussetzungen und Entfaltung der Bürokratischen Herrschaft. The specific way of functioning of modern bureaucracy is described (pp. 551, 552):

"I. ... das Prinzip der festen, durch Regeln ...geordneten Kompetenzen, d.h. 1. eine feste Verteilung der... regelmäßigen Tätigkeiten als amtlicher Pflichten; -2 . Die ... erforderlichen Befehlsgewailten sind ebenfalls festverteilt und ... fest begrenzk; - 3. Für die Erfüllung der ... Pflichte... und Rechte ... ist planmäßige Vorsorge getroffen durch Anstellung von Personen mit einer generell geregelten Qualifikation. ...

Diese drei Momente konstituieren in der öffentlichrechtichen Herrschaft den Eestand einer bürokratischen "Behörde", in der privatwirtschaftichen den eines bürokiatischem "Betriobes"....

11. Es besteht das Prinzip der Amtshierarchie ... ein fest geordinetes System von Ueber- und Unterordnung der Behörden unter Beaufsichtigung der unteren durch die oberen, ...

IIV. Die ... Amtsführung beruht auf Schriftstücken ..., welche aufbewaht werden, und auf einem Stab won Subalternbeamten und Schreibern aller Art. ... IV. Die Amtstätigkeit ... setzt eine eingehende Fachschulung voraus.

V. ... die amtliche Tảtigkeit (nimmt) die gesamte Arbeitskraft des Beamten in Anspruch, unbeschadet des Umstandes, daß das Maß seiner pflichtmaigier Arbeitszeit auf dem Büro fest begrenzt sein kann. V. Die Amtsführung der Beamten erfolgt nach generellen. ... erlernbaren Regeln. ... [welchel ... eine besiondere Kunstllehre dar[stellen] ...'

In this passage the essentials of bureaucracy are described. It says that officials have ordered and fixed tasks and discretionary competencies; they have a defined qualification that is obtained by a professional education, and that the hierarchy is precisely defined. Next to that, all regulations are laid down and are maintained in written instructions, while the task of officials covers their total availability during working hours. From these hypotheses, consequences for the position of the officials are derived. The office is said to be a vocation requiring a special education, the official usually enjoys a distinct social esteem. He is officially appointed (not elected), and the tenure is nomally for life. There is a pecuniary remuneration, while his career follows a predetermined upward path, with steps distinct by certain 'proofs' (pp. 552 - 555).

Next the author formulates the social and economic presuppositions for the development of bureaucracy, as compared with other ways of functioning (p. 556). These conditions are: the development of a money economy, a sufficient volume in size and depth of the tasks to 
be fulfilled, and the necessity of getting things done in a "machine-like" manner". This is said to relate to a number of characteristics, among which precision, speed, univocality, knowledge of files, continuity, and discretion. Also important are unity and rigorous subordination. Weber concludes that material and personnel costs are lower in the bureaucratic organization (especially in the case of unity of command and the deployment of well-trained officials) as compared with organizational forms based on collegiate direction or on part-time or honorific service. The bureaucratic structure is associated with the concentration of capital equipment in the hands of the principal. Finally, a certain degree of economic and social leveling is in favor of its development.

Observation and induction are treated in a number of chapters between the two that are discussed above. Weber's approaches are those of a historian, using broad descriptions of social processes and constellations and transferring these directly into hypotheses that are descriptive and predictive at the same time. Curious is his building of ideal-types using assumed irrationality as a filter, and next using these ideal types to explain human social action.

Weber was a describer, more than he was a prescriber. However, rules for management and administration entail easily from his contentions. Such rules have been widely applied in public and commercial organizations ever since.

\section{Assessment following the $\mathrm{A}-\mathrm{F}$ - scheme}

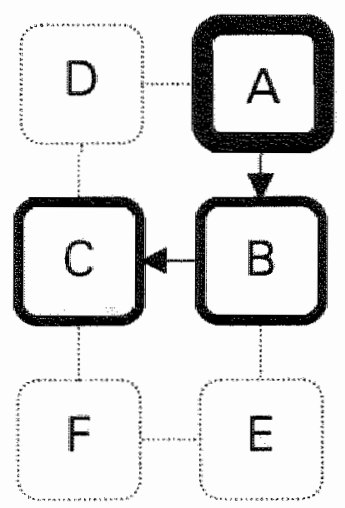

The way Weber developed his theory is summarized in the following diagram. Hypothesis (A) is the most elaborated. element, with sharp definitions (pp. 12, 124, 128), definiteness and precision and a precise conceptualization ( $\mathrm{p}$. 128). Derivation (B) is present in predictive models (p. 556). Observation (C) is done in a historiographic way. Typical for the ideal-type approach is the direct linking of $\mathrm{C}$ and $\mathrm{A}$, thereby skipping $\mathrm{D}$. Despite the elliptical character of the further reasoning, its inner logic is sound, as it has a well-chosen systematic structure. Metatheoretical requirements are met to a high degree within each box, but not in the entire system of knowledge by the lack of the intention to test validity. Many of the author's tenets are directly applicable to the design of organizational forms.

\section{Conclusion}

The author's scientific background has been described above. Fecund elements are his immense corpus of definitions, concepts and suggestions. Next to their great value as background knowledge for the design of structure, they have been (and still are) offering a wide area for research. Most writers on organization refer to his work. 


\subsection{Chester Barnard}

Bibliographical data

Barnard, C.I., The Functions of the Executive, Cambridge MA 1938 (20th printing 1971).

\section{Contextual points}

Barnard (1886 - 1961) went to Harvard where his study was cut off short of the bachelor's degree. It was followed by 40 years of service at AT\&T, and ended with the presidency of the New Jersey Bell Telephone Company. Parallel and afterwards he had many functions in the public interest, ranging from founder of the Bach Society of New Jersey to President of the Rockefeller Foundation.

The author was acquainted with Pareto and Mayo. The Hawthorne studies influenced his ideas as exposed hereafter, as did his rejection of the ideas of human rational behavior as held by Tayllor and Fayol. Instead, he was an early proponent of the concept of "bounded rationality".

Important influences from his historical/social environment were the great depression and the pre-war years that followed, with their social uncertainties. In chapter 1 the author underlines the importance of knowledge on formal organizations for society: 'social explanations nowadays neglect an important element of modern society, i.e., the large formal organization' (p. 3).

\section{Contents and relevance}

His metatheoretical hyporhesis about the population ecology of organizations as proposed later by a/o Hannan \& Freeman (1989) is striking. As Barnard states (pp. 5 - 6):

What are observied from day to clay are the successfull survivors among innumerbble fallures. ... the existence of a population does nor necessarily imply longevity, but merely the balancing of constantly recurring deaths by births... The survival of an organization depends upon the maintenance of an equilibrium of complex character in a continuously fluctuating environment of physical, biological, and social materials, elements, and forces, which calls for readjustment of processes internal to the organization."

More about his basic position is demonstrated by his conclusions in which three contemporary views can be discovered: 1) the informal organization, 2) a precursor of bounded rationality, and 3) the philosophy of language (pp. 286, 287):

'Informal organizations are found within all formal organizations and are essential to vitality:... Error of decision must be large because of the unbalance due to the difference in the precision of the perception as 
respects the physical, the biological, and the social enviromments. This is a general factor limiting successful cooppration. ... All knowledge is expressed in languages and symbolic systems. These are socially developed with meanings that ara socially determimed; and all finally accepted observetions of phenomena are coóperatively arrived at."

In chapter 2 Barnard discusses the question of free will versus determinism (p. 21). He contends that both free will and determinism will exist. The conditions under which one of these will prevail must be embodied in the theory. At the end the duality of man and the paradox of free will is restated (p. 296): 'free and unfree ... controlling and controlled ... seeking the particular but concerned with the whole ... finding leaders and denying their leadership ... this is the story of man in society told in these pages."

The author points at the shortcomings of reductionism, and the necessity to approach the subject of the executive process cautiously as it has to do with "... "feeling", "judgment", ... it transcends the capacity of merely intellectual methods... It is a matter of art rather than science, and is aesthetic rather than logical' (p. 239). He continues as follows:

"For example $\|$ am asked [by students] to what extent and how economic facts and general economic knowledge govern my decisions in an organization. It is only with difficuliy that I comprehend the question. ... Let the reader take a balance sheet or an income statement - the most unequivocally economic statement I know of - and ask someone who understands those specific statements to explain them. Then observe how little of that explanation is economic except the money walues that are assigned, and the arithmetic significance of these values."

It is important to note that as early as 1938 Barnard underlined the need for further research into organization. About his own theory and his hopes for a future scientific elaboration, he writtes (p. 292):

Whether the present essay is a contribution to the science hoped for remains to be determined by others. What has been presented is a hwoothetical scheme which att present explains roughly to me what I have observed in many years of practical work with organizations of various kinds and what I have constructed from the experience of others, supplemented ... by a little knowledge of the sacial sciences. It is not the work of a scientist or a scholar, but rather of an interested student of affairs.
... The test of it will come from its application to social phenomena as a whole ... I hope that the socilel scientist ... may attempt a pretiminary testing of it against the background of present knowledge. More concretely, I hope for a social anthropology. a sociology a social psychology an institutional economics, treatise on management, etc., written with the concepts of coopperative systenn....

From the citation it becomes clear that the author's contentions were mainly based on based on practical experience, as was the case with Fayol (section 5.3). 
Stating basic contentions he argues that human efforts are constrained by physical and biological limitations (p. 22). Cooperation would overcome these limitations. But at the same time the management processes, necessary for cooperation also have their limitations (p. 35). At the end of chapter $V$ a summary renders the basic contentions of the author so far (p. 59):

1. The individual human being possesses a limited power of choice. At the same time he is a resultant of, and is narrowly lmited by, the factors of the total situation....

2. Among the most important limiting factors in the situation of each individual are his own biological limitations. The most effective methoid of overcoming these limitations has been that of cooperation. This requires the adoption of a group, or non-personal, purpose....

3. Cooperation is a social aspect of the total situation and social factors arise from it. These factors may be in turn the limiting factors of any situation... conditions: (a) itts effectiveness; and (b) its efficiency.

5. The survival of cooperation, therefore, depends upon two interrelated and interdependent classes of pracesses: (a) those which relate to the system of cooperation as a whole in relation to the environment; and (b) those which relate to the creation or distribution of satisfactions among individuals.

6. The instability and fallures of cobperation arise from defects in each of these classes of processes separately and from defects in their combination. The functions of the executive are those of securing the effective adaptation of these processes."

4. The persistence of coopperation depends upon two

In this passage the functions of the executive are clearly explained.

In chapter VII the theory of formal organization is exposed (pp. 82 -95). He states that the continued existence of an organization requires both efficiency and effectivity; its vitality lies in the willingness of individuals to contribute their forces. This willingness requires the belief that the collective task can be fulfilled. An organizational unit must not necessarily know the 'general purpose of the complex, ... but it is essential that it know and accept an objective of its own, or it cannot function." (p. 137)

In this chapter we find more important basic contentions, for instance about the size of executive units (p. 112), when it is stated that "The size of executive units of organizations is limited generally by the same conditions that govern the size of unit organizations of other kinds."

The purpose of the organization must be accepted; which means that effective communication of the purpose is necessary. Organization is always an impersonal system of coordinated human efforts.

But next to the formal organization, informal organization too is said to be essential (p. 116):

"informall organization, although comprising the processes af society which are unconscious as contrasted to those of formal organization which are conscious, has two important classes of effects: (a) it establishes certain attitudes, understanding, customs, habits, institutions; and $(b)$ it creates the condition under which formal organization may arise." 
In this respect, he refers to Mayo (p. 121), with the remark that the study of informal organizations so far was restricted to the production level of ind ustrial organizations. Functions of informal organization are (p. 122): 1) communication, 2) maintenance of cohesiveness 'through regulating the willingness to serve', and 3) maintenance of the feeling of personal integrity.

The author's definition of authority is idiosyncratic (p. 163):

"Authority is the character of a communication forder) in a

formal organization by virtue of which it is accepted... as

governing the action he contributes."

This means that authority requires the willingness and ability to follow orders (p. 165): $(a)$ the order must be understood; $(b)$ at the time of his decision the subordinate must believe the order is not inconsistent with the purpose of the organization and with his personal interest as a whole, and $(c)$ he is able to comply. This is quite different from the usual notion of authority.

The executive functions, the central issue in this book, are described in chapter XV (p. 215). The author states that 'Executive work is not that of the organization, but the specialized work of maintaining the organization in operation."

This is the starting point of the author's further reasoning. He continues with what the executive function is not, plus a metaphor (p. 216):

The executive functions serve to maintain a system of coopperative effort. They are impersonal. The functions are not, as so frequently stated, to manage a group of persons. ... It is not even quite correct to say that the executive functions are to manage the system of coòperative efforts. As a whole it is managed by itself. not by the executive organization, which is a part of it. The functions with which we are concerned are like those of the nervous system, including the brain, in relation to the rest of the body."

Siructure is the central issue of the book, but Barnard addresses the subject indirectly, from the executive's perspective. In chapter XIV a theory of opportunism is proposed, in which the term strategic is introduced (p. 202). This notion, however, differs from its nowadays notion as it is used after Commons (1934), being the most scarce (physical or social) resource, the increased availability of which is necessary to attain new goals. The work pertains mostly to metatheory, and in an indirect way to the design of structure.

Important is his view on morale and responsibility (pp. $261-272$ ). For instance, on page 267:

"the point is that responsibility is the property of an individual by which whatever morality exists in him becomes effective in conduct.

Barnard's propositions can be summarized as follows. The formal organization is an important, yet neglected, explanans in the social sciences. It is a consciously designed cooperative system 
that must be kept in equilibrium by the executive, in order to survive. The equilibrium rests on the balance of contributions from its members and the inducements it provides to its members. The latter can have many forms, from wages to the gratification of belonging to a group. Essential functions of the executive are the designing of the organization, the selection of personnel, and the continued incorporation of members in the value system.

\section{Process of knowledge development}

Hypothesizing, Barnard globally indicates the meaning of formal organization (p. 4):

'For the present, formal organizations may be described rather than carefully defined. The more important of them are associations of cooperative efforts to which it is possible and customary to give definite names, that have officers or recognized leaders, that have reasons for existence that may be appropriately stated - such as governments, churches, universities, labor units, industrial corporations, symphony orchestras, football teams.'

At this point, the author avoids to formulate this notion in an exact way. But on page 73 , he presents a definition of formal organization as: "... a system of consciously coördinated activities or forces of two or more persons.'

A definition of effectiveness is given on page 55 :

3 effectiveness of coopperation is the accomplishment of the recognized objectives of cooperative action. The degree of accomplishment indicates the degree of effectiveness."

Next to these crisp definitions mixtures of definitions and hypothetical contentions can be found as well, like in this description of the term efficiency (p. 56):

$\checkmark$... efficiency relates to the satisfaction of individual motives. ... If the individual finds his motives being satisfied by what he does, he continues his coöperative effort; otherwise he does not... Thus, the efficiency of a cooperative system is its capacity to maintain itself by the individual satisfaction it affords.'

On page 23 he formulates the questions to be addressed:
\%. Why or when is cooperation effective?
II. What are the objects of coopperative processes?
III. What are the limitations of coopperation?

\author{
W. What are the causes of instability in coöperative \\ systems? \\ V. What effect has coopperation upon the ends sought
}

In general the author does not distinguish between hypothesis and rules. Two examples of the intermediate phase, namely derivation, can be found. The first is an exposition of inducements and incentives (p. 142):

- material inducements,

- personal non-material ones (like prestige), 
- desirable physical conditions,

- ideal benefactions (like pride of workmanship).

As examples of incentives are proposed:

- associational attractiveness (like the avoidance of racial hostility),

- conditions as habitual (the exclusion of 'foreign' attitudes),

- enlarged participation (be part of an organization that is considered important),

- the condition of communion (solidarity, comradeship).

The second is the summing up of the methods of persuasion (p. 149), namely coercion, rationalization of opportunity (propaganda), and inculcation of motives. Both derivations could be used to test hypotheses, but the author limits himself to an essay-like discussion ( $p, 292)$. Barnard had, like Fayol, a huge managerial experience. His observations were practical. His conclusions were the result of well-educated generalization, but lacked Taylor's empirical specificity.

Only two of the many precepts of Barnard will be given here. The first is a summing up of controlling factors in the communication system (p. 175):

"We may now consider the controlling factors in the character of the communication system as a system of objective authority:

(a) channels of communication should be definitely known,

(b) objective authority requires a definite formal channel of communication to every member. (c) the lines of communication must be direct and shoirt,

(d) no steps in the communication ine shoulld be skipped,

(e) persons serving as communication centers should have adequate competence'

The second example is about the essential executive functions (p. 217):

"I) to provide a system of communication (the first task and immediate origin of executive organization); ii) to promote the securing of essential efforts:

III) to formulate and defime purpose."

Point 1 is elaborated in a notable way (p. 224). It comprises 1) making the scheme of organization; 2) conduct personnel selection; 3) care for an informative executive organization (this is a matter of selecting and promoting those who "fit' into the organization by 'education, experience, age, sex, personal distinctions, prestige, race, nationality, faith, politics, and educational antecedents").

No observations provoked by the effects of intervention are reported in the book.

\section{Assessment following the $\mathrm{A}-\mathrm{F}$-scheme}

The weights of the different phases of knowledge development are depicted hereafter. The most elaborated element is hypothesis (A), done with definiteness and precision as reported at several places (pp. 55, 56, 73). Derivation (B, pp. 142, 149) and prescription (E, pp. 175, 224) are 




discussed, but both are limited to reasoned entaiment of $\mathrm{A}$, and in an abstract way, as may be expected in Barnard's essay.like treatment. Coherence is sought (p.292) and in accordance with the then knowedge. Scientific observation is absent, so validity cannot be tested. Utility for the design of organization is certainly present in many of Barnard's recommendations. All of these considerations lead to the representation as depicted in the model alongside. The theory has practical value for the design of structure. The fulfilment of metaheoretical requirements enabling subsequent testing is not sought.

\section{Conclusion}

Barnard's work typically offers rules based on well-reasoned hypothesis. As stated above, Bamard buit on Taylor and Fayol but without accepting all of their contentions. Fecund elements are abundant in Barnard's work. As an inspirator of Simon and many other prominent scholars, he has been one of the founding fathers of American organization science. "He seized upon the concept of an organization as a social system, elaborated it in original definitions of formal and informal organizations, worked out the ... difference between effectiveness and efficiency, incorporated noneconomic notions into a theory of incentives, and developed a controversial concept of authority" (Kenneth Andrews in his introduction to the 1968 edition). The author was far ahead with his propositions about bounded rationality, the informal organization, organizational ecology, and morale, as well as the recognition of symbols and language as organizational determinants.

\subsection{Fritz Roethlisberger and William J. Dickson}

Bibliographical data

Roethlisberger, F.J., and W.J. Dickson, Management and the Worker, Cambridge MA 1939

\section{Contextual points}

Roethlisberger (1898 - 1974) was an industrial psychologist, a Harvard professor, Dickson (b. 1904) a staff member of the Western Electric Company.

The book is written in the scientific environment of the human relations movement. Elton Mayo was the founder of the tradition and a supervisor of the research of Roethlisberger and Dickson. In an earlier research Mayo had found that better physical conditions, like the introduction of rest pauses, led to important improvement of workers' morale (Pugh \& Hickson, 1997, pp. 138 141). 
The management of Western Electric (the precursor of General Electric, with 29.000 employees in the 1920s) wanted to find out what factors influenced the output of human labor (p. vii, comments by C.G. Stoll of Western Electric Company):

'earlier research revealing considerable deficiency of intangible factors in the work situation ... of shop workers ... it seems clear that the knowledge acquired has been increasingly helpful in our efforts to create a better relationship between supervisors and workers. ... Which contributes naturally to proficiency and a high state of morale."

Mayo pointed at the difficulty of the research (pp. xii - xiv):

"It took courage and determination to persist with inquiries that often seemed doomed to inconclusiveness"; ... [the importance is stressed of] ... 'fundamental research in this field of human nature especially at this time "

He also expressed his worries about the global problems in this period (p. xiv):

'The spectacle of Europe, erstwhile mother of cultures, torm from end to end by strife that she can by no means resolve...In this gieneral situation if would seem that inquiries such as those ... have an urgent practical importance that is sacond to no other human undertaking.'

The research took place from 1927 until 1932 in Hawthorne near Chicago, in the years of 'the great depression'. The company's output was highest in 1929 ; afterwards layoffs were necessary. The risk of being dismissed was constantly on the employees" minds. Most of the workers observed had a low-grade education. Many were furst or second generation immigrants, some of them still holding foreign nationalities. The attitude of the company towards its personnel was generous, with a wide range of employee benefit programs and organized social activities. Special attention was given to create good relations between supervisors and operators.

\section{Contents and relevance}

As a part of their basic position, Roethlisberger and Dickson aim at scientific rigor (p. 5,389$)$ :

"to keep separate the facts observed and their uniformities from the methods, working bypothesses, theories, and conceptual schemes employed ... [only those theories or visions are mentioned which assisted the researchersil to find more facts or more adequate discrimination in fact ... observation, if it is to be at all scientific, must be guided by a working hypothesis which enables the observer to make active discriminations in the complete interplay of factors before him."

Clearly, scientific observation is at the basis of their study, while as little ex ante positions are taken as necessary. They also take care to avoid a basic problem in the observation of social 
phenomena: "the help of anthropologists is sought in order to avoid observation affecting the behavior of the observed". (p. 389)

Typical for this study is that basic contentions are virtually absent. All three stages of inquiry end with new questions. To this rule two exceptions can be found at the end of the book (Part V). The first is a statement about the equilibrium of an organization. It is said that an organization needs an external and an unternal equilibrium in order to exist. The external equilibrium would be a matter of being a successful competitor, while the internal equilibrium must be maintained by the management (p. 551). The second basic contention holds that management has three major human problems to deal with. These interrelated problems comprise the general problem of maintaining internal equilibrium of the plant, namely:

1. problems of change in social structure,

2. problems of control and communication,

3. problems in the adjustment of the individual to the structure (p. 578).

Fundamental contributions to structure are proposed, while strategy is still an abstraction, although the effect of the business and social environment is clearly recognized. The findings relate to small units, functioning within a large industrial organization, and have mostly an indirect character with respect to application.

\section{Process of knowledge development}

Unlike the other descriptions of theoretical cases in the study, this one will be reported in the order of conduct. The research followed four stages of inquiry, 'each stage representing a major change in working hypothesis and method' (p. 5), namely:

1) a preliminary exploration followed by an experiment on working conditions and employee efficiency in the "relay assembly test room' with five female operators,

2a) interviews with 20.000 employees of the Hawthorne plant to determining those aspects of their working environment that they either favored or disliked,

2b) an analysis of these interviews, presenting a theory of employee satisfaction or dissatisfaction,

3) the interviewing and observation of fourteen male operators in the "bank wiring observation room".

\section{The preliminary exploration}

A preliminary inquiry was conducted on the association between lighting and output (p. 14). During experiments the illumination level was changed over time, ranging upward from the normal level of 16 to 28 foot candle up to 70 ( $800 \mathrm{lux}$, the value recommended nowadays), and downward to 0.06 (moonlight level). Also 'placebo' alterations were enacted.

At the same time, in a separate room, 5 women operators were observed and regularly interviewed. In this way the number of variables could be restricted, and disturbing influences could be kept at a distance. A highly repetitive routine operation was chosen (p. 19). 
The results of the exploration were puzzling. Changes in output did not in any way reflect the changes in lighting conditions, the girls commented favorably on imaginary lighting improvements, and unfavorably on imaginary decreases of illumination. In general they gave answers they thought to be appropriate (pp. 15-17).

The hypothesis that better lighting alone would increase efficiency was rejected. Lighting appeared to be only one, and perhaps a minor, factor-influencing output. Many more factors had to be examined to find relevant answers to the question concerning physical conditions and output (pp. 18, 19).

\section{The first experiment}

In the first experiment the general hypothesis was stated that fatigue relieve will lead to an increase in output. Factors examined were rest pauses, and changes in daily and weekly working hours. The result was, that any particular change (for better or worse) led to a higher output. The output was higher than in the rest of the factory. The physical condition of the female workers involved was not influenced. The morale of the group improved as followed from more mutual help, more contacts after working hours, and a higher solidarity toward supervisors (pp. 20 - 85, $90-117,127)$.

Again, these results were puzzling (p. 86). Five hypothetical explanations were proposed:

1. the test room had better physical conditions from the beginning (this was rejected as differences were only slight),

2. the pauses and shorter working time had provided a relief from cumulative fatigue,

3. they reduced the monotony of work,

4. a change in the payment system during the experiment had a favorable effect,

5. improved output and attitude was due to the gradually changing method of supervision. These fatigue and monotony hypotheses were tested (pp. 90-117, 127). For hypotheses 2 and 3 the result was as follows:

"An analysis ... failed to support the hypothesis that relief from faticue or monotony accounted for the changes in output from periad to period. With respect to the monatony hypothesis no definite conclusion could be drawn. ... It was clearly understoad, howewer, that monotony is primarily a state of mind and cannot be assessed on the basis of output data alone."

The wage incentive hypothesis was tested by new experiments in the test rooms. First with alteration of payment system only, and next with all factors the same as in former test room. (p. 129).

The authors conclude that the experiment fell short of the experimental conditions (pp. 158 160). Keeping the factors unchanged appeared to be impossible.

Two 'warranted' conclusions remain: 1) there is no evidence that the increase of output in experiment number one could be attributed to the wage incentive factors, 2) the wage incentive factors are strongly dependent on their relations to other factors. 
When the effects of individual situations outside the factory and of interpersonal relations at work were tested ( $p .179$ ) it appeared that on the first factor no clear conclusion could be obtained except that personal social conditions influence output. As for the second: when in the interest of the experiment the method of supervision changed, a mutual cooperative attitude among supervisor and operators emerged in which output could increase easily. Conclusion: not the individual factors are important, but the social situation is.

At this point it should be noted that the method of this experiment was in agreement with a complete $\mathrm{A}$ - F cycle.

The management of Western Electric Company concluded that the results from a research point of view were negative. However, they saw practical opportunities: 1) regular rest pauses were introduced; 2) the understanding of many problems was improved as popular assumptions had been questioned; 3) employee-attitude was proved to be predominant, "it can open stores of latent energy under the right conditions'. They further decided that more research was needed on employee attitude and its related factors (p. 184).

Here we see the struggle between theoretical endeavor and practical life in its full magnitude. No explanations are found by the research, but the management takes action on suppositions that seem worthwhile.

\section{The second inquiry}

In order to improve the relations between workers and supervisors a second inquiry was stated (p. 189). Over 20000 interviews were conducted to identify satisfying and dissatisfying factors (primarily physical ones), together with the urgency and tone of the topics involved.

In Part III the implementation and results are described (pp. 373 - 376).

The answers obtained about physical conditions (including payment) again were not conclusive. They were contradictory and vague. The researchers supposed that they conveyed feelings and emotions and were carriers of social values. More research in small groups was considered to be necessary for adequate understanding of the functioning of employees under certain social conditions.

\section{The third investigation}

The third experiment took place in the 'bank wiring observation room'. Now 14 male operators were put apart in a test room with an 'observator'. The wage incentive system is one of the factors to be examined. The essential point there is the "bogey", the standard amount of output per day that is imposed on the workers (pp. 391, 409).

After some time, intermediate findings could be reported (p. 445). It appeared that each individual was restricting his output. The group standards of daily production were substantially lower than the bogey. Output records were distorted in terms of quantity of output as well as hours worked. The highest performers produced the highest quallity. 
This outcome led to new questions (p. 446): (a) why did every member of the group feel that a fairly uniform rate of output was necessary (the reasons given were not satisfactory); (b) why was the daily output per worker so different (this was not related to personal capacity); and (c) why did the top performer report even more output than he produced, while others systematically reported less than they did?

The explanation was the existence of the "informal organization" ( $p .508$ ). There were two distinct cliques, each with a different set of values, and a marked mutual consideration of one another.

After this discovery, assumptions about the function of the informal organization were made (p. 523):

'The social function of the bank wiremen performed a twofold function: (1) to protect the group from internall indiscretions, and $(2)$ to protect it from outside interference. ... pressure was brought to bear upon those individuals who deviated too much from the group's norm of acceptable conduct. From this point of view, it will be seen that that the great variety of activities ordinary labeled 'restriction of output ${ }^{*}$ represent attempts at sociall control and disciplne and as such are important integrating processes."

The assumption led to speculation about the occurrence of the informal organization (pp. 547, 548). On the basis of experimental evidence three hypotheses were rejected. Neither fear of being laid off, nor economic interest or faulty supervision was considered to explain workers" curious behavior with respect to the bogey. Finally, it was assumed that the conduct of the group would be induced by the different 'logics' of management and the workers, such as company rulles (based on the logic of efficiency) are often felt by the workers as 'annoying and seemingly' functioning only as subordinating or differentiating mechanisms."

The third round of investigation did not render any answers, but instead leaded to the conjecturing of new hypotheses with respect to the informal organization. These are described above under basic contentions.

At the end rules for management were formulated. They mainly refer to human relations and personnel management. The appointment of counselors ("a catalytic agent, ... carefully listening and observing') and a maintained interview relationship are recommended (pp. 590,604):

"by means of this sikill management should commit itself to the continuous process of studving human situations - both individual and group - and should run its affairs in terms of what it is conthually learning about its owni organization."

\section{Assessment following the $A-F$ - scheme}

The book contains at least three cycles of knowledge development, with a number of iterative sub-rotations. Characteristic accents of these cycles are depicted below. The boldness of the frames represents their degree of elaboration. The three main cycles of knowledge development are discussed hereafter. 
In the first (left) a series of cycles $A-B-E-F-C$ was followed with all of these elements are fully elaborated $(20-85)$. Derived rules had to be changed repeatedly (slanted arrow from $C$ to E). But at the end the findings were not only inconsistent with the hypotheses $(158-160)$, but also completely confusing, as any relationship between lighting conditions or fatigue relief and productivity failed to emerge. The causation by individual factors had to be rejected. The dotted arrow from $\mathrm{C}$ to $\mathrm{A}$ indicates a return to complete new conjecturing, the start of the second cycle. Now social factors had to be investigated (pp. 179, 184).

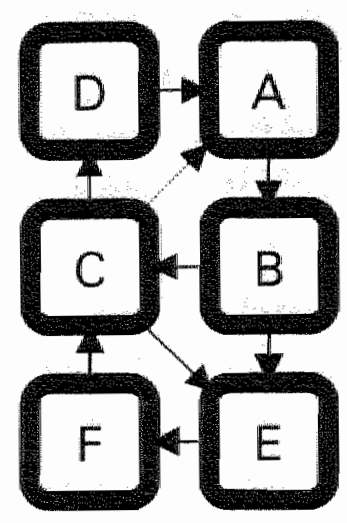

first set of cycles



second cycle

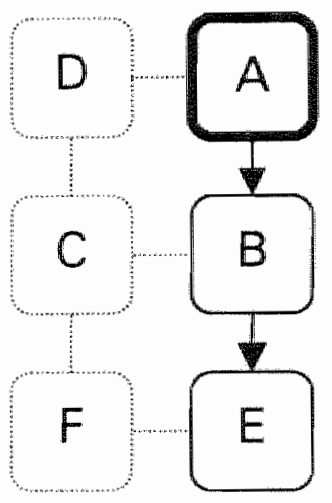

third cycle

This consideration led to the second stage (middle), starting with observation and ending with new attempts to find regularities. The large survey was meant to indicate relevant factors of satisfaction and dissatisfaction of workers. This inquiry (pp. 373 - 376) had the form of an exploration, with some preliminary hypothesis (A) embedded in questions (B), and a large number of observations (C), intended to conjecturing new hypothesis (D). Clear hypotheses could not be obtained, but it was concluded that observation should be focused on small groups. It was hypothesized that the incentive system with its ensuing satisfaction or dissatisfaction would influence output.

This hypothesis was the basis for the third project (depicted at the right). It started with the rather roughly defined hypothesis (p. 391), followed by derived consequence (p. 409). The project, the bank wirng experiment, included close observation of a small group. Conclusions were drawn on page 445 .

It ended up with the hypothesis about the importance of the informal organization. Again, observed reality did not correspond to the hypotheses. Instead, it led to a completely new discovery, namely the importance of informal organization (p. 523).

On its furn the hypothesis offered a starting point (A) for subsequent research (not depicted) in which some earlier hypotheses were rejected (pp. 547, 548), and in which rules were formulated 
(pp. 590,604). At all stages metatheoretical requirements, including definiteness, precision, and coherence were perfectly met (pp. 5, 389).

\section{Conclusion}

The work builds on earlier research of Mayo, but it largely transcends the scope of it.

The most fecund element of the work is the dismissal of wrong ideas about management and the worker and his motives. It was a pioneering research based on the human relations approach. It was also an important example for scientific research into human organization.

\subsection{Herbert Simon}

\section{Bibliographical data}

\section{Simon, H.A., Administrative Behavior: A Study of Decision-Making Processes in} Administrative Organization, New York 1947 (second edition 1957).

\section{Contextual points}

Simon (b. 1916), with a Ph.D. at the University of Chicago in 1943, was awarded with a Nobel laureate in economics in 1978 . He has publicized on a wide range of topics, from psychology, organization and administration, and computer science, to economics.

During the second World War already he publicized preliminary studies on the subject. The author was critical about the lack of research in administrative science, and tried to propose a new system of terms and concepts as a start for building theory.

Simon combined knowledge of psychology, economy, and administration into a metatheoretical framework. He referred to writers on government administration, but also, specifically, to Taylor for his methodological rigor and to Barnard for his propositions about the executive function.

\section{Contents and relevance}

The author's point of departure for this study is the search for tools for research into public administration. Existing studies would not properly describe "the flesh and bones" of organizations, nor would they have their recommendations properly derived from the evidence presented. The main purpose of the book is to formulate a vocabulary for the proper description of an administrative organization, its working and its looks (p. $x l v$ ):

.... so fair "there are no adequate lingluistic and conceptual tools for realistically and significantly describing even a simple administrative organization describing it, that is, in a way that will provide the basis 
for scientific andelysis of the effectiveness of its structure and operation. ... These conclusions do not constitute "theory" of administration, for except for a few docta by wey of hupothesis, no principles of administration are laid down. If any "theory" is involved, it is that decision-making is the heart of administration, and that the vocabutary of administrative theory must be derived from the logic and psychology of human choice."

The passage brings us at the core of Simon's endeavor. His intention is to advance the knowledge on administration by way of scientific research. An important metatheoretical credo goes as follows (p. 3):

In the study or organization, the operative emplovee must be at the focus of attention, for the success of the structure will be judged by his performance within it. Insight into the structure and function of an organization can best be gained by analyzing the manner in which the decisions and behavior of such emplovees are influenced within and by the organization."

In a discussion of received administrative theory, Simon criticizes the so-called 'proverbial principles". Some will be discussed in his book. One of these is the proposition stating that administrative efficiency is increased by the application of four principles, namely 1) dividing the total task of the organization in specialized groups, 2) a determinate hierarchy of authority, 3) a limited span of control, and 4) the grouping of workers according to purpose, process, clientele, or place. The author demonstrates with examples that these rules are ambiguous, and in some cases even conflicting (p. 20).

He concludes that received administrative theory is at an impasse (p. 35):

$\therefore$ all the rellevant diagnostic criteria [must] be identified; each ... situation [must] be analyzed [by] the full set of criteria; and... research [must] be instituted to determine how weights can be assigned to the several criteria when they are, as they usually will be, mutually incompatible.

A better approach is suggested (p. 36). Two questions have to be answered, the first one being how the administrative situation must be described in order to enable analysis, while the second would be about what weight must be given to the various criteria. The first question is addressed by following the yardstick of efficiency. It can be rephrased as: what are the limiting factors to a person's quality and quantity of output. These factors are said to be limits of skills, as well as restrictions in bodily and cognitive capacity. The author shares a view central to this study ( $\mathrm{p}$. 37):

Before a science can develop principles, it must possess concepts. ... These concepts, to be scientifically useful, must be operational; that is, their meanings must correspond to empirically observable facts and situations.'

The author stresses the need for experiment in administrative science (p. 43). As requirements to the efficient organization as stated by "principles" are contradictory, experiment is needed to 
establish the weight of the different criteria. But experiment is scarce in administrative science. Taylor is said to be one of the few who applied 'painstaking methods of science'. In chapter 71 will come back on Simon's vilew.

Simon states the objective and the limited scope of his book, and calls for more research (p. 44):

Certainly neither the practitioner of administration nor the theoretician can be satisfied with the poor analytic tools that the proverbs provide him.... As already indicated, the present volume will attempt only the first step in the reconstruction of administrative theory - the construction of an adequate vocabulary and analytic scheme. ... To be sure, the literature of administration has not been lacking in "theory", any more then it has in descriptive and empirical studies. What has been lacking has been a bridge between these wwo, so that theory could provide a guide to the design of "critical" experiments and studies, while experimental studies could provide a sharp test and corrective of theory.

Indeed we will see that the author's work is contained to our box 'A',

His epistemological discussion ends as follows. First, 'logical positivism will be accepted as a starting point'. Hence the distinction is made between factual propositions (concerning the observable world, either being true or false), and ethical meaning (how it 'ought to be', p. 45). Second, he concludes that in decision making there are value elements and factual elements. This distinction corresponds to two types of questions, namely those of policy and those of administration. They are also the distinction between ends and means (p. 59).

Ends may have a hierarchical order, in which the 'lower' ends are means tot higher ones. Conflicting ends exist, and require a preference scheme. This scheme, however, is usually lacking: 'the means-end hierarchy is seldom an integrated, completely connected chain' (p. 64). Finally he comes to the central theme, stating that 'the objective environment surrounding choice was examined.' ( $p$. 77) The theme is described as a set of alternative behaviors, each leading to definite anticipated consequences. The prime influence on choice is knowledge about the consequences of each selection of behavior. But this knowledge is imperfect. The second influence lies in 'the preferences of the behaving individual for one set of consequences as compared with another. The problem of choice is one of describing consequences, evaluating them, and connecting them with behavior alternatives.' Intermediate ends in a means-end chain serve as value-indices, so alternatives can be evaluated 'without a complete exploration of the final ends, or values, inhering in them." In this respect patterns of interpersonal behavior are important. In a competitive relationship, or when errors are made in the prediction of the behavior of the others, interpersonal behavior patterns are unstable. 'Finally some definitions have been laid down to distinguish various meanings of rationality: objective, subjective, conscious, deliberate, organizational, and personal.'

This exposition of limits and possibilities of human rationality is based on literature search. Limits of rationality derive from human inability to incorporate all relevant aspects of value, knowledge, and behavior into one single decision. Hence, the making of a choice among alternatives in fact demonstrates a stimulus-response pattern (p. 79).

The position of the author can be summarized as follows. Received theory on administration falls short of proper description of orgamizations, while evidence based recommendations are 
lacking. Not "theory", but some fundamental hypotheses are the conclusion of the book. The operating employee must be the focus in theory building. "Decision making is the heart of administration". But we know very little about the subject. Decision-making, like all human contributions to organizations, is limited by psychological, cognitive, and physical constraints of the individual. This means that "rationality" is limited, and that organizational choices follow a successive stimulus-response behavior rather than being the outcome of a rational selection from all possible options.

His basic contewtions include that purposive action is characteristic for the organization, that decisions about goal attainment are based on values (how it should be) and on facts (how it is), and that the final choice of behavior frequently is a compromise as not all requirements following from values and facts can be satisfied (p. 4, 5).

About organizational transaction the author states that the individual transfers some of his decisional autonomy to the organization. The latter takes decisions about the employee's function, his superiors, and other limits to his discretionary capacity (p. 8).

Next Simon gives three reasons for vertical specialization, namely: 1) to obtain coordination; 2) to concentrate expertise; and 3) to establish a structure "to assure legislative control over the administrator" (p.9).

The concept of influence is discussed on page 11 . It is said to be effected through authority (meaning that an individual behaves according to decisions of others without questioning), through organizational loyalty, through adherence to efficiency, by means of advice and information (less formal), and by training.

Further he states that an organization has three kinds of participant: entrepreneurs, employees, and customers. In order to survive the contracts between the first and the two other parties must remain mutually satisfactory (p. 16).

According to Simon, at least four types of unity of command exist, namely 1) everybody having only one superior, 2) each individual receiving orders from several superiors, but in case of conflict only one of these is to be obeyed, 3) for a number of specific areas authority being assigned to one superior, and 4) higher ranks having to be obeyed in all circumstances, the last order being the one to be followed (p. 140).

About the formal and informal organization, the author states ( $p .148$ ):

'no formall organization will operate effectively without an accompanying informal organization. ... A formal organization is a plan for the division of work and the allocation of authority. The organization plan gives to each member of the group his status and role in relation to the other members, but it specifies the content of his work and his decisional function only in wery general terms."

Here we hear Barnard's voice (section 4.5).

Authority is said to be a matter of behavior: "When the behaviors do not occur there is no authority, whatever may be the "paper" of the organization." Authority is defined as "all situations where suggestions are accepted without any critical review or consideration." authority has three functions: it enforces responsibility to those who wield it, it secures expertise, and it permits coordination (p. 151): 
Authority is only one of a number of forms of influence. Its distinguishing characteristic is that it does not seek to convince the subordinate, but only to obtain his acquiescence. In actual exercise, of course. authority is usually liberalty admixed with suggestion and persuasion. An important function of authority is to permit a decision to be made and carried out, even when agreenent cannot be reached:

The concept is close to Weber's 'Herrschaft'.

The design of a formal structure is discussed. It is said that the design rules are governed by principles of administration. The point is not elaborated any further.

The author's position regards all types of large organizations. In what follows, much emphasis is laid on public administration (p. 179 and further). In the discussion on efficiency, both commercial and public organizations are addressed ( $\mathrm{p} .197)$. All propositions pertain in an indirect and mostly metatheoretical way to the subject of structural design.

\section{Process of knowledge development}

An important hypothesis is the one about the individual having a limited ability to perform, and to make decisions. This is the phenomenon of limited rationality. The limits lie in insufficient cognitive capacities, in values that influence a person's choices, and in a lack of relevant knowledge about the job (p. 39).

A second important argued hypothesis is about the equilibrium of the organization. After Barnard (1938), members are supposed to contribute to their organization in exchange for inducements. If both sets of transactions are balanced the organization will persist. Different types of members of the organization (customers versus employees or entrepreneurs, superiors versus operators) have their own types of inducement. Various forms of organizations and their respective goals are discussed (pp. 110,122$)$ :

These inducements include the orcanization goal itself "conservation and growth of the organization, and incentives unrelated to these two.... The organization equilibrium is maintained by the control group, whose personal values may be of various kinds, but who assume the responsibility of meintaining the life of the organization in order that they may attain these values."

In the remainder of the book the topics introduced thus far are developed (pp. 125, 128, 135). Important concepts are authority, unity of command, formal and informal organization, communication, and efficiency.

Hypothesis on communication is formulated on page (p. 171):

"The specialization of decisionmaking functions is largely dependent upon the possibility of developing adequate channels of communication to and from decision centers. Generally the organization structure will include ... a formal system of communication ... but this will be supplemented by a rich network of informal communications based upon the social relationships that develop in the organization. Personal motives may lead organization members to try to divert the communications system to their own uses, and may ... also influence the reception given to those communications that are transmitted." 
Training is also mentioned as an important means for communication.

Assessment following the $A-F-$ scheme

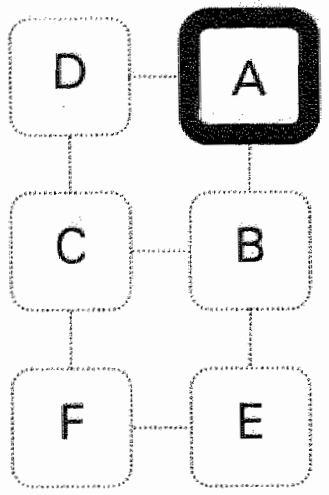

Simon's statements are all hypotheses (A). These include the formulation of problems (pp. xlv, 37, 43, 247), axioms (pp. 3, 39, 110 , 122, 171), definiteness and precision (pp. 44, 179), definitions (pp. 77 - 79), and concepts (pp. 11, 16, 140, 148, 151). Box A is extensively elaborated (boldest line). Coherence is demonstrated in the critical discussion about other basic theories (pp. $x l v, 110,122$ ). The other boxes (derivation, observation, induction, prescription and intervention) are empty. The author starts with terminological propositions and reflects on some background theories. From this point he argues toward his conclusions, carefully avoiding propositions outside the grounds specified. In the end, he modestly limits his tenets (p. 220).

Metatheoretical requirements, including systematic structure, are met to a high degree within box $A$, but derived qualities and subsequent testing are absent. The work is only indirectly useful for organizational design.

Conclusion

As stated, preliminary studies on the subject have been publicized during World War II already. The author draws substantially on Barnard's work. Simon derived propositions that are equally valid for government, business, and non-profit organizations. The dictum of 'limited', or "bounded", rationality was a fecund element that has not stopped to evoke new strains of research and theorizing.

He makes important recommendations for the ways further research should be conducted, as becomes clear from the following citation (p. 247).

\section{- Our study has not led us to anv definitive}

administrative principles. It thas, however, provided us with a framework for the analysis: and description of administrative situations, and with a set of factors that must be weighed in arriving at any valid proposal for administrative organization. It has shown us, further; that currently accepted "principles" of administration suffer from internal ambiguity and mutual contradiction.

What are the next steps that research must take? First. it must develop adequate case studies of existing administrative situations. It will do well to initiate these on small scale - dealing in minute detail with organizational units of moderate size. Only in this way can superficiallity be avoided. Second techniques must be developed and improved for measuring the success of particular administrative arrangements. Specifically, the assumption so often made in administrative studies, that an arrangement is effective because it exists, is a circular argument of the worst sort. Students of administration are possessed of no occult wision which permits them, by simply observing an administrative organization, to determine whether it is "working" or not. The only procedure of evaluation 
Finally, the valuable investigations already initiated of the "conditions" under which different administrative principles are validly applicable might well be extended with the use of the "decisional" framework described in this study"

Simon indicates here that the result of his work is not the 'principles' of administration, but a well-established starting point for further scientific study. He stresses the necessity of observing objective results against hypothesis.

\subsection{James March and Herbert Simon}

Bibliographical data

March, J.G. \& H.A. Simon, Organizations, New York 1958 (2nd edition Oxford 1993).

\section{Contextual points}

The book can be seen as a sequel to Simon's earlier work (1947).

Simon (b. 1916), with a Ph.D. at the University of Chicago in 1943 was awarded with a Nobel laureate in economics in 1978. He has publicized on a wide range of topics, from psychology, organization and administration, and computer science, to economics.

March (b. 1928) is professor of management and of political science at Stanford University. The authors felt the need to introduce decision making as an explanans in organization theory, against classical positions in economy concerning equilibria subject only to external conditions of the firm. This decisional behavior would be essentially determined by limitations of rationality. In addition to that they wished to bundle and classify the dispersed body of knowledge about organization.

They stressed the importance of valid organization theory for the understanding of society as a whole (p. 21).

\section{Contents and relevance}

In 1958 the authors express their basic position, writing that the original objective of the book was to make a "propositional inventory" of theory about organizations (p. 1). In the 2 nd edition of 1993 some comments are added, but not much progress seems to have been made (p. 1):

'... we are today probably not wiser than then. ... If there were any general pronouncements we would like to utter today, it would be that no events during this long period have shaken the foundations of organizations or organization theory so roughly as to make them unrecognizable, or ewan greatly distorted." 
Some accents have changed since then (p. 2), like 'the rhetoric, ideology, and reality of relations among ethnic and gender groups', and the interest in the technological context of organizations. There are, however, many new findings in organizational research.

The central concept is decision making, but "less [as] a theory of choice than a theory of attention', as not all goals can be attended at all times, 'nor their alternatives, nor the consequences of the alternatives." ( $\mathrm{p}$. 4). The book was a response to a classical view in economic organization theory in which the influence of decision was denied. Instead the authors defend an important role for this factor, with important consequences ( $p$. 16):

-... limitations on rationality introduce massive

unpredictability; ther are multiple equilibria, the time

to equilibrium is rather slow in relation to the changes in the context; external environments ane not really exogenous but are (partly) created by the arganization and its decisions."

March and Simon state that "This book is about the theory of formal organizations." (p. 20). New evidence is not intended, but testing will be discussed (p. 24). Steps toward testing of existing hypotheses will be proposed. First by restating hypotheses in order to make them testable, and second, in some cases, by proposing possibilities for testing.

The authors" basic position is the dictum of bounded rationality (p. 4). Their method is eclectic, at times integrating and specifying existing theories, at times picking from loose propositions, at times logically derivative. They try to integrate. Two problems are said to arise when bringing together 'this scattered and diverse body of writing': not much is said about organizations, but it is said in different languages, and 'there is in the literature a great disparity between hypotheses and evidence" (p. 24). "We have tried to steer a middle course between eclecticism and provincialism.' (p. 25)

A classification of organization literature is proposed (p. 23):
'1. executives' experiences
2. scientific management studies
3. studies on bureaucracy

\author{
4. studies of leadership and employee attitudes by \\ social psychologists \\ 5. contributions from political science \\ 6. economic theories of the firm ${ }^{2}$
}

After the examination of received theory, they summarize their findings as follows (p. 52):

'In the case of classical administrative science, the problems of making operational the definitions of key variables and of providing empirical verification for those propositions that can be made operational seem particularly pressing. ... In the course of [the further] discussion we hope to make clear why we consider classical organization theory to represient oniy a quite small part of the total theory relevant to organizational behavior."

In this respect, the authors identify five basic limitations in organization theory:

1. motivational assumptions are incomplete and consequently inaccurate,

2. there is little appreciation of intraorganizational forces, 
3. little consideration is given to the constraints when man must process information,

4. little attention is given to the role of cognition in task identification and classification as well as in decision,

5. little emphasis is laid upon program elaboration.

The discussion is an elaborated version of the one Simon proposed in 1947 (section 5.7). The authors explicitly reformulate a selection from received theory, with some salient propositions as their basic contentions. Again bounded rationality, the umportance of decisionmaking processes and the necessity of more and better scientific research are stressed. We will come to this point in the concluding section of this case report.

Another basic proposition states that man is more than a mere production factor. He has wants, motives and drives, but his knowledge and learning capacity is limited. The human organism is characterized in a psychological postulate (p. 30):

'... a choosing, decision-making, problem-solving organism that can only do one or a few things at a time, and that can attend to only a small part of the information recorded in its memory and presented by the environment:

From hypotheses about human behavior an important conclusion ensues (p. 101):

In particular, it should be obvious that supervisory actions based on the naive "machine' madel will result in behavior that the organization wishes to avoid.

This conclusion was, af course, one of the central hypotheses of Merton, Selzmick, and Gouldner in their writing on bureaucracy.

In addition, we have looked at three different modes of influence over individual motivations in an organization, paying particular attention to the congruence between individual attitudes and organizational demands reflected in the motivation to produce. Our analysis suggests that influence over the motivation to produce is a function of influence over (a) the evoking of action alternatives for the individual, (b) the consequences of evoked alternatives anticipated by the individual, and (c) the values attached to consequences by the individual. Each of these aspects is partu under the control of the organization but party also determined by extraorgenizational factors. The amount of organizational control, in turn, depends partly on the behawior of the organization (e.g., superwisory practices) and partly on factors largely outside its control (e.g. general economic conditions)."

A third basic position is the reformulated Barnard - Simon theory of organizational equilibrium (p. 104):

- an organization is a system of interrelated social behaviors of persons: the participants,

- each (group of) participants receives inducements from the organization, in return for which he makes contributions to the organization,

- each participant will remain in the organization as long as his inducements are sufficiently large when compared to his contributions (measured in his own value system, and compared to his alternative opportunities), 
- the contributions of the participants are the source from which the organization manufactures the inducements,

- hence, the organization is solvent - and will survive - as long as the contributions exceed the inducements sufficiently (Simon et al. 1950).

Some hypotheses are related to game theory. Three types of conflict are distinguished, namely, conflicts in individual decision-making, conflicts within an organization, and conflicts between organizations or groups (p. 132). Individual conflict would ensue from the incomparability of alternatives, from the unacceptability of alternatives, or from uncertainty about the consequences of alternatives. Both the organizational environment and the characteristics of the organization contribute to the amount of individual conflict within an organization. Similarly, intergroup conflict within an organization, the conditions under which it arises, and organizationall reactions are discussed ( $p, 155)$ :

Beceuse organizational conflict leads to such phenomena as bargaining and power struggles, the present chapter differs from the earlier chapters on motivational factors in organizational behavior. Here the motiwations are frequently made more explicit and the problem of conflict of interests is met lalbeit somewhat reluctantly by the arganization thead-on.
Thus, we have moved all the way from the avoidance of motivational factors in the scientific management movement to the central role of interpersonal conflict in game theory. We have fried to indicate at several points in our discussion that the interaction between motivational and cognitive factors is substantiall."

At the conclusion of the study the authors summarize their findings (p. 157):

\footnotetext{
... "we will have completed the main tasks we set ourselvies:
}

1. to eliminate, one by one, the artificialities of the clissical description of the employee as an instrument;

\section{It should be noted that propositions mentioned sch}

2. to replace this abstraction with a new one that recognizes that members of organizations have wants, motives, and drives, and are limited in their knowledge and in their capacities to learn and to solve problems." on received theory advanced by other scholars.

The work pertains to both structure and strategy, although instead of the term strategy the expression 'the organization's programs of a high hierarchical order' is used. The essence of it is metatheoretical, while its character is indirect with respect to the application as basis for design rules.

The authors apparently address the larger organization, but they recommend investigating such an organization by examining its small units.

\section{Process of knowledge development}

Important hypotheses include concepts like decision making as an object of study, bounded rationality, "satisficing' behavior, inducements from and contributions to organizations by its participants. 
Predictive models of bureaucracy are proposed. After Weber, the bureaucratic theories of Merton, Selznick and Gouldner attempted to explain unintended results of managerial control measures. Concepts are identified as variables and depicted in models with boxes, connected by arrows indicating their mutual dependency (p. 56).

Theories on (lack of) satisfaction and productivity are presented. As a next step they are translated into pictorial models and even in mathematical form (pp. 66-70). A speciall case is the motivation to produce. It is treated likewise with pictorial models (p. 71).

An attempt is made to operationalize propositions about participation, but this first step is not elaborated any further (p. 130).

An example of derivation through reasoning can be found on page 155:

"In this chapter we have indicated how conflict arises within an organization and what types of behavior result from conflict. We have discussed two quite distinct kinds of organizational conflict:
1. conflict that is essentially intraindividual, where organization members themselves heve difficulty making a choice:

2. conflict among hindividuals, where the members of the organization have choices that are mutually inconsistent.'

Here again, the derived consequences of hypothesis are obtained by logic, but not far enough to make testing possible.

It can be concluded that the authors do not go beyond hypothesis and the very begin of derivation. Observation, induction, prescription, and intervention are not addressed. Some empirical verification is pretended, but only as a check against general experience and the observation of others, as is illustrated by the following statement (p. 234):

'It would certainly be difficult, and probably superfluous, to summarize the content of a volume that is already a summary of a vast mass of theorizing and (to a far lesser extent) empirical werification of theories.'

\section{Assessment following the $\mathrm{A}-\mathrm{F}$ - scheme}

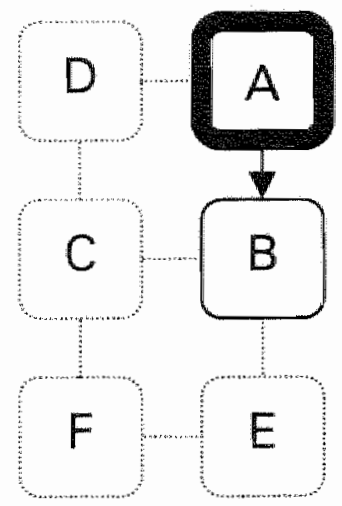

Hypothesis is elaborated in the formulation of axioms (p. 4, 30), domain delïmitation (definiteness, 20), and the definition of problems (precision, p. 24, 25). Formulation of hypothesis is based on these starting points. Examples are on page 101, 104,132, 155, and 157. A step into the field of derivation is made by the formulation of predictive models (pp. 56, 66 - 70, 71, 130), but testability is not attained.

Elaboration is extensive for ' $A$ ', but ' $B$ ' is only touched upon. Like in Simon's theory (section 5.7) great care has been taken to maintain coherence with other relevant theories (pp. 4, 23, 24-52).

Metatheoretical requirements, including systematic structure, are met to a high degree with the reservation that the work is mainly confined 
to hypothesis. Subsequent testing is lacking.

The usefulness for organizational design is indirect.

\section{Conclusion}

As mentioned above important predecessors are Weber, Merton, Selznick, and Gouldner. Simon's own work (1947) was a major base too, next to earlier research of March.

As Simon did in 1947, the authors emphasize the need for further research, and make concrete recommendations at this point (p. 234):

"... The cognitive aspects of organizational behavior are to date almost unexplored terrain.

At the same time, we have observed that the problems of testing empirically the propositions about organizational behavior that are set forth here raise a number of technical and methodological issues. ... We should like, ... , to cite four methodological questions that seem particularly important for research on organizational behavior.

1. The question of identification. Econometricians and others (Koopmens, 1950; Hood and Koopmans, 1953) have devoted considerable attention to the problem of testing theoretical models with empirical data. At several points we have noted that some of the models that we and others have presented in organization theory are substentially underidentified.

2. The question of inferring the program that an organzation unit uses from obserwation of behavior by members of the unit. A substantial amount of wark has been done on the methodology of program inference lCyert, Simon, and Trow, 1956; Newell, Shaw, and Simon, 1958).

3. The question of inferring the presence or absence, and strength, of influence relations among members of an organization. Some of the major problems involved in measuring influence have been discussed by us and by other researchers in the past few years (Simon, 1953a, March, 1955a, 1956, 1957; Dahl, 1957).

4. The question of the status of fileld research in general and the single case study of organizational behavior in particular in organizational research. We do not feell the area is well cleveloped and wish we could report some new contributions. Unfortunately, we cannot. As in the case of the substantive theory, the methodology of organization theory is uneven and invites further development."

Despite these brave intentions, advanced in 1958 , the edition of 1993 does not report much progress in the direction the authors pointed out.

The most fecund elements of the book are its elaborated repertory of organizational knowledge up to 1958, plus its main hypotheses like bounded rationality and organizational equilibrium, which have had a great impact on all subsequent thinking.

\subsection{Douglas McGregor}

Bibliographical data

McGregor, D., The Human Side of Enterprise, New York 1960. 


\section{Contextual points}

McGregor (1906 - 1964) was a social psychologist, working in the line of Herzberg and Lewin. In contrast to these precursors he was, in his own words, "not an experimentalist". The author belongs to the 'Human Relations"-school, together with Rensis Likert. He was president of Antioch College. His role as a top administrator of the institute influenced his ideas on organization. Later he became a professor of management at the M.I.T.

In the fifties it became apparent that the old-fashioned ideas of a 'mechanistic' organization were conflicting with expectations of younger employees, while much talent was spoiled by not fully exploiting human faculties. This problem typically set the historical/social agenda for the period.

On page 244 the author expresses a claim of general societal importance of his vision, when he states:

"..., if we can learn how to realize the potential for collaboration inherent in the human resources of industry, we will provide model for governments and nations which mankind sorely needs:"

\section{Contents and relevance}

The author takes a clear basic position in several issues. For instance he repeatedly stresses the need for new and improved theory (p. 244):

"Developments in physical science theory curing the first half of the twentieth century ... would still be inconceivable were it not for developments in scientific theory and man's inventive genius in exploiting them. Although the parallel may seem unreasonable to some, we are today in a period when the development of theory within the social sciences will permit innovations which are at present inconceivable Among these will be dramatic shanges in the organization and management of economic enterprise

But new evidence is not sought, as the author states (p. w): 'I am not an experimentalist." He formulates his intent as follows (pp. vi, vii):

"... we have not learned enough about the organization of tallent, about the creation of an organizational climate conductive to human growth.... This volume is an attempt to substantiate the thesis $\ldots$ that the theoretical assumptions management holds about controlling its human resources determine the whole character of the enterprisen:

McGregor criticizes the shortcomings of classical textbook theories of organization, with principles such as hierarchical structure, authority, and span of control (pp. 11, 15-17):

"Human behavior is predictable, but, as in physical science, accurate prediction hinges on the correctness of underlying theoretical assumptions. ... ITextbook theories] ... rest primarily on armchair speculation rather than on empirical research, ... traditional principles fall considerably short of being like the laws 
of physics. ... ; wrong models, like the military, have been used, the social enviroment has been ignored, underlying assumptions about human behavior are wrong:

More about science and non-science about organization is advanced on pages 3 to 6 :

The professional draws upon knowledge of science... He can draw upon a reasonable body of knowledge in the social gciences as an aid to achieving his managerilal objectives. ... Progress ... is associated with the ability to predict and control ... The frequent success of the outright charlatan in peddling unanagerial patent medicines also reflect the consciousness of inadequacy. ... the lack of associating personal experience and scientific findings has been a severe handicap in this field. ... it has permitted the quack and the charlatan to pedidle worthless gimmicks. and programs. ... The time is not far off when the competent manager ... will find it a necessity to be well enough wersed in the scientific disciplines relevant to his work to bie able to read the literature and judge the adequacy of scientific findings and claims. ... Every managerial act rests on assumptions, generalizations, and hypotheses - that is to say, on theory. Qur assumptions are frequently implicit, sometimes quite unconscious, often conflicting; nevertheless, they determine our predictions that if we do $a, b$ will occur. Theory and practice are inseparable."

So far, a range of metatheoretical contentions are proposed. Apparently this is not a scientific book. It refers to existing knowledge, as developed by Herzberg et al. (1959). However, it is not very specific as to the nature of this knowledge, or as to its links to his own position, as will be seen in the next section.

More basic contentions of the author lie in his juxtaposition of 'Theory X' against 'Theory $Y$ '. These have been discussed already at length in section 3.5 where they were used as examples of the formulation of rival hypothesis. But 'Theory $Y$ ' is not meant to be a set of testable suppositions. It is meant as a thetoric tool to beat the allegedly wrong opinion that man needs unit-of-command structures and one-to-one relationships in the organization, while he would escape responsibilities and is said to need coercion and direct control to make him work. This becomes clear in the following passage (p. 244):

\section{"... His not important that wangement accept the} assumption of Theory $Y$, These are gne man's interpretalons of current social science knowledge, and they will be modified - possibly supplanted - by now knowledge within a short time. It is important that management abandon limiting assumptions like those of Theory $X$. so that future imwentions with respect to the human side of enterprise will be more than minor changes in already obsolescent conceptions of organizad human effort.

Theoretical assumptions such as those of Theory $Y$ imply some conditions which are unrealizable in practice llike the perfect vacuum implied by physical theory). This is not a handicap; it is the stimulus to invention and discovery. ...

The ideas with respect to changed managerial strategies consistent with Theory $Y$ which have been discussed .... are no more than beginning steps toward management by integration and self-control. Once management becomes truly persuaded that it is seriously underestimating the potential represented by its human resources ... it will invest the time money, and effort not only to develop improved applications of such ideas ... but also to invent more effective ones. As always, however, invention will go hand in hand with new theory. 
The purpose of this wollume is not to entice management to choose sides over Theory $x$ or Theory $Y$. It is, rather, to encourage the realization that theary is important, to urge management to examine its assumptions and make them explicit. ..."

Theory $Y$ indirectly pertains to structure. The rejection of too strict one-to-one relationships and the introduction of network-like systems and cooperating teams as recommended affect the design of organizational structures. The essence of the work is metatheoretical.

\section{Process of knowledge development}

The book is a manifesto rather than a scientific work, as can be seen from McGregor's own concluding chapter. The elaborated metatheoretical introduction, suggesting the importance that McGregor attributes to science, ends with nothing but perswasive speculation.

Examples of hypothesis are his formulation of 'Theory X' (p. 33) and 'Theory $Y$ '. The latter is important enough to be cited in full (p. 47):

"1. The expenditure of physical and mental effort in work is as natural as play or pest. The average human being does not inherently dislike work. Depending upon controllable conditions, work may be a source of satisfaction land will be voluntary performed) or a source of punishment (and will be avoided if possible).

2. External control and the threat of punishment are not the only means for bringing about effort toward arganizational objectives. Man will exercise self-direction and self-control in the service of abjectives to which the is committed.

3. Commitment to objectives is a function of the rewards associated with their achievement. The most significan of such rewards, e.g., the satisfaction of ego and self-actualization needs, can be direct products of efforts directed toward organizational objectives.

4. The average human being learns, under proper conditions, not only to accept but to seek responsibility. Avoidance of responsibility, lack of ambition, and emphasis on security are generally consequences of experience, not inherent human characteristics.

5. The capacity to exercise a relatively high degree of imagination, ingenuity, and creativity in the solution of organizational problems is widely. not narrown, distributed in the population.

6. Under the conditions of modern industrial Mfe, the intellectur/ potentialities of the awerage human being are only partially utilized."

Instances of derivation occur when the author goes into the consequences of the hypotheses of Theory $X$ and $Y$, for instance for the staff-line relationships and the organizational structure. In conventional organization theory the chain of command is said to be directed at operations. Staff persomel provide services and advice; they have no authority, as this would wiolate the principle of unity-of-command. They are subordinated to the next higher line-official. However, in practice the influences between line and staffs would be more complicated, while the mutual climate is often troubled. Causes for the unsatisfactory situation are discussed. 
Theory $Y$ denies the conception of management: the role of line managers will become more like that of the teacher, consultant and colleague. The true leader would use the self-control of his subordinates at the expense of authoritative control.

McGregor comes to the following conclusion (p. 175):

The modern industrial organization is a vast complex of interdependent relationships, up, down, across, and even "diagonally". In fact, the interdependence is so great that arly collaborative team efforts can make the system work effectively. It is probable that one day we shall begin to draw arganization charts as a series of linked groups rather than as a hierarchical sitructure of individual "reporting" relationships."

Observation is restricted to the findings of other researchers. The author refers to Herzberg et al. (1959), who found that "opportunities for "self-actualization" are the essential requirements of job satisfaction and high performance." (55n)

He summarizes their findings:

'One group revolves around the need to develop in one's occupation as a source of personal growth. The second group operates as an essential base to the first and is associated with fair treatment in compensation. supervision, working conditions, and administrative practices. The fuifillment of the needs of the second group does not motivate... to high levels of job satisfaction and ... to extra performance on the job."

Other recent research is mentioned, but without specific sources given (pp. 185, 189):

'Research findings to date suggest, then, that it is more fruitful to consider leadership as a rellation between the leader and the situation than as a universal pattern of characteristics possessed by certain people. ${ }^{*}$

As the author is "not an experimentalist" induction from his own findings is absent. Anyhow, the general terms in which the findings of others are expressed would not allow for such induction.

Prescriprion can be found in chapters 5 to 10 . Management by integration and self-control is recommended. Performance appraisal is criticized. The Scanlon-plan system, participation, and the managerial climate are discussed.

Confidence between staff and line must be created. The appropriate role of staff is 'that of providing professional help to all levels of management'. The help has to be defined by the recipient; the central principle is self-control. The staff official cannot "maintain proper ethical standards of conduct if he is placed in a position, which involves conflicting obligations to his managerial "clients." (p. 173)

No intervention is reported. 


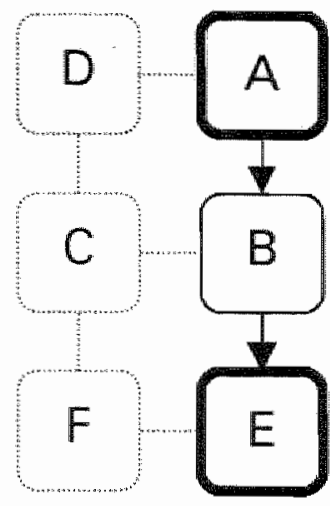

An important hypothesis is Theory Y (p. 47). Above the presence of derivation is noticed. This is done as a form of extension of hypothesizing by reasoning. Prescription has the form of general recommendations.

Mapping of the relative importance of the elements of knowledge development leads to the scheme as depicted. The degree of elaboration of hypothesis (A) and prescription (E) is moderate, while derivation (B) is just touched upon. Metatheoretical requirements are weakly met, for instance with respect to definiteness and precision ( 3 -6). A lack of coherence follows from the fact that many hypotheses of others are used without a clear explanation of the connection with the author's own tenets. By neglect of testing the theory is an exposition of principles, with ensuing rules. These are only indirectly useful for organizational design.

\section{Conclusion}

The work is a well-written manifesto defending human faculties beyond assumed narrowmindedness and supposed limitations. Its importance lies in its eloquent attack on a mechanistic view of human nature, as was still held by many managers of the post-war era. It contributed to further research into the domain of human relations. As said, McGregor built on Herzberg el al. (1959). Other hypothetical positions and research findings are referred to without specification.

\subsection{Tom Burns and George M. Stalker}

Bibliographical data

Burns, T. and G.M. Stalker, The Management of Innovation, London 1961

\section{Contextual points}

Burns' (b. 1913) early interests lay in urban sociology. Later he became a professor of sociology at the University of Edinburgh until his retirement in 1981 . Stalker, a psychologist, contributed to the Scottish study.

After World War II there was a need of post-war reconstruction of the British community in general, and the industry in particular. Given the policy of full employment a switch was necessary to change industry from wartime duties into market oriented activities. 
The approach belongs to the domain of field sociology and social anthropology, combined with industrial psychology. Reference is made to Marx, Tönnies, Weber, Simon, Barnard, and Roethlilisberger.

\section{Contents and relevance}

Two intriguing questions led to the research (p. 1,2). It was observed that a Lancashire factory, operating economically in a stable environment, was ruled smoothly. It seemed "Iubricated by a certain paternalism" by its London headquarters. No insecurity or stress was present. Why was it that the research and development departments were met with such suspicion and hostility?

By contrast, in an engineering concern with large development interests, functions were ill defined, causing insecurity and stress. "Cliques and cabals" were thriving. "Yet there was also the striking fact of the concern's commercial and technical success.' How could this paradox be explained?

In their basic position, scientific method is not pretended (pp. 12-14):

"All this is very far removed from any method of investigation which could possibly be called scientific. It does not share the principal advantage of anthropological field method, which lies in a lengthy period of residence in the community being studied. ...'

At times the formulation of basic contentions is not very clear (p. 231):

"According to the evidence supplied by these studies, and the unterpretation of it given here, both the organization of the internal interpretative system and the direction of the commercial, technical, and productive capacities of that system in the interests of the firm are conditional for their success on an apprectation of the rate of change affecting the tasks of the concern: i.e. of the number and importance of new technical and market circumstances confronting the firm from day to day. As the rate of change increases in the technical field, so does the number of accasions which demand quick and effective interoretation between people working in different parts of the system. As the rate of change increases in the market field, so does the need to multiply the points of contact between the concern and the markets it wishes to explore and develop. This last consideration weighs very heavily in deciding the success or failure of directional policy in technically progressive firmis."

The central tenet of the study is that two "ideal-types' of organization exist: the mechanistic and the organic type. The first is said to be suitable for stable conditions, while the second would be most appropriate for change. The mechanistic system is strictly hierarchical, with precisely defined positions and responsibilities. In the organic model no formal regulations about tasks and positions exist, every member has a status dependent on his specific knowledge, and is supposed to contribute to the goals of the concern as good as he can. The transition from the one to the other form, necessary under altering external conditions, is hampered by resistance to change, caused by political forces (the informal organization) and 
status conflicts. The qualities of top management greatly determine whether such changes may finally succeed.

Structure is the central issue of the book, but it is treated in its relation to deliberate strategic change from the wartime supply requirements to the postwar market-driven attitude. The research led to foremost metatheoretical propositions, indirectly pertaining to the complex of structure and strategy. The size of the companies addressed is unclear.

The book does not excel in specificity. It is said that the Scottish firms were smaller than those from England were, but the actual size is not given. From the context it may be assumed that rather small as well as rather large companies have been observed.

\section{Process of knowledge development}

The book is badly composed, the coherence between the different sections is unclear, and the exposition at places obscure. Reports on observations are intertwined with essay-like contemplation in which a number of other writers are cited (pp. 20 - 36). As a narrative it is enthusing and persuasive.

The essay-like interludes resemble the Weberian ideal-type approach, but lack this author's immense socio-historical base and precise formulations. In fact, Burns and Stalker only use their few cases as empirical background. Their essays therefore are foremost hypothetical. For instance, the development of society is elaborated (pp. 20-36). Marx and Tönnies are cited. There would exist a 'mutual, procreative impact of developments in material technology and social organization". In a lengthy narrative, the authors describe how in the 19 th century 'Invention was seen as the product of genius.' In this era technical development came about in a special social setting of scientists and interested amateurs, while an enormous amount of risk capital was available. These circumstances would have ended by the end of the century when Britain lost its leading position in Europe to Germany. In 1917 the Department of Scientific and Industrial Research was founded. Since then the British Government played an important role in the development of research.

The example demonstrates the distance and the difference in scope between hypothesis and observation in this study.

The authors go through a series of observational, inducing, and hypothesizing considerations. At the hyporhesizing phase, they begin with the proposition of definitions and concepts.

Referring to research by Roethlisberger and Dickson (1939), and by Burns (1958, p. 58), the informal organization is introduced. People in firms are said to have, next to their working organization, their informal interest groups (a 'political system") and a 'status structure'. 'This leads to conflicts over power and status. In unfamiliar circumstances these impede the effective introduction of new practices, like the adoption of the appropriate system of organization. The fear of people for a greater commitment in the new organization may be seen as another cause of resistance (pp. 6, 7). After a discussion referring to the work of, Taylor, Bendix, Barnard, Gouldner, Whyte, and many others the characteristics of Weber's bureaucratic system are elaborated (pp. 103-110). Barnard"s framework of organization (1938) and Simon's framework of decision (1947) are followed (p. 209). 
The eclectic introduction of terms and hypothesis does not lead to a derivation toward observable phenomena.

Important concepts in the study are the informa organization, technological and commercial innovation, and environmental change.

An inductive model is formulated on page 96. The model is based on empirical evidence from "the last chapter'. It says that the system of management is a dependent variable. Extrinsic factors are the rate of technical or market change (i.e. the appearance of novelties, requirements for products" of a kind not previously available or demanded'). Other independent variables are: '( $i)$ the relative strength of individual commitments to political and status-gaining ends, and (ii) the relative capacity of the directors of a concern to "lead' - i.e. to interpret the requirements of the external situation and to prescribe the extent of the personal commitments of individuals to the purposes and activities of the working organization.'

Observation is mixed with contemplating interludes. On page 154 we find an essay-like, rather messy description of Scottish and English firms, with anecdotal or idiosyncratic examples. Page 155 and 205 offer essays on the (difficult) relationship between the laboratory and the workshop and on the problems of power and status between scientists and managers. The important hypothesis is further elaborated into the characteristics of both systems. The first, mechanistic, model (appropriate for stable conditions) typically shows (p. 119):
(a) specialization of tasks;
(b) tasks aimed at means, not ends, of the concern as a whole,
(c) reconciliation of disengaged tasks by direct superiors,
(d) precise definitions of rights and competencies,
(e) the translation of these in formal responsibilities for each position.
(1) concentration of knowledge of actualities at the top, where the final coordination takes place,
(9) interaction between members mostly vertical,
(t) operations and working behavior governed by superiors' instructions,
(i) members must be loyal and obedient to the concern.
ij) local skills more important than general ones'

The second model is said to suit changing conditions (p. 121):
(a) special knowledge and skills contribute to the goal of the concern,
(b) tasks are "real" i,e. fitting into the common task of the concern.
(c) tasks are continually re-defined in interaction with others',
(d) no stift of responsibilities lposting elsewhere) to others,
(e) commitment to concern "beyond technical definition"
(f) 'a network siructure of control, authority, and communication',
(g) no knowledge monopolies at the top of the concern, specific knowledge may be located anywhere in the organization,
(h) communication rather lateral than vertical, 
(i) Communication embodying advice rather than instructions,

(1) commitments to the concern's task is more important than obedience,

(k) importance of expertise in the environment of the concern."

The methods of observation are described as follows (pp. 12-14):

[methods as] ... those common to ... field sociology and to social anthropology. ... gaining acquaintance. through conversation and observation, with the routines of behaviour current in the particular social system being studied, and trying hereafter to reach an appreciation of the codes of conduct which are supposed by the members of the swstem to underlie behaviour. All this emerged very slowly in the course of interviews, meetings, lunch-time conversations, and the like. At the same time we, as outside observers, have tried to construct some systematic explanatory description of what we have been told and have observed, a description which will be reasonably selfconsistent and al so understandable in terms of other explanatory descriptions of behaviour in other social systems ... Our usual procedure, after the first interview with the head of firm, was to conduct a series of interviews with as large number of persons as possible in managerial and superwisory positions. Such interviews lasted anything from one hour to whole working day."... After we had become acquainted with the general structure and functioning of the organization, we sought opportunities of observing how people dealt with each other, and also of pursuing, by further interviews, some of the problems of description and interpretation which by this time had appeared. In their simplest and most significant form, these problems were presented as discrepancies between the account of the same: functions or parts of the organization given us by different people concerned in them. Such discrepancies, in our experience, are always present, and provide the most direct introduction to the analysis of a situation or social system in soclological terms."

Observation amounts to 300 interviews, without pertinent concepts or accents prepared. In addition three forum discussions with representatives of interested parties and experts (pp. 12 14) were conducted. Some propositions about organization and innovation are based on discussions in three meetings with experts and government and industry representatives (pp. 92 - 95).

There are no prescribing or intervening elements in the study.

\section{Assessment following the $\mathrm{A}-\mathrm{F}$-scheme}

The process of knowledge development starts at $\mathrm{C}$, with the interviewing of managers. From this point, some regularities are sought, followed by elaborated hypothesis (A, pp. 6, 7, 20 $36,231)$. Hypotheses are not developed into testable statements. Ensuing observation is again conducted by interviewing $(92-95)$. From the observation, inductive modeling follows (pp. $96,119)$. The degree of elaboration in hypothesis and observation (C) is substantial. For derivation (B) it is virtually absent, while for induction (D) it is moderate, while it should be noted that the connections $B-C$ and $D-A$ are virtually lacking. This absence places the work in the ideal-type tradition, as is supported by Burns' view that 'A sense of the past and the very 


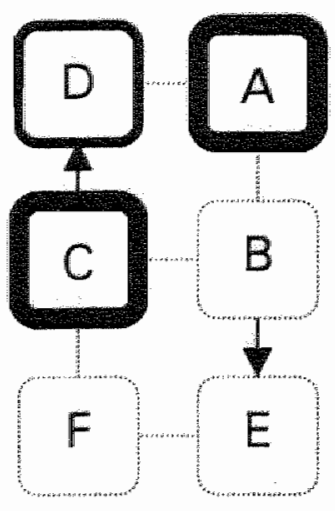

recent past is essential to ... perceive the here-and-now of industrial organizations' (quoted from Pugh\&Hickson, 1997, p. 49).

Definiteness and precision are not sought (pp. 12 - 14).

Metatheoretical requirements are met to a moderate degree, as formulations tend to be unclear. In its own way, systematic structure is present, but testability is not obtained. These considerations lead to the pictorial model alongside.

The theory has an important relevance for organizational design, albeit indirect.

\section{Conclusion}

The work is essentially an idea-generating book based on well-documented knowledge. Only much later many of the ideas of the authors were acknowledged in organizational research. An example is their treatment of the comparative effectiveness of central control versus systems of sub-enterprises. These may take the divisional form, or they may lead to distinct companies depending on a holding corporation (p. 224). In addition, the authors had an early awareness of the importance of concepts of language and meaning (p. 155). In the final paragraph we find the early recognition of the context-related character of organization studies (p. 262).

The use of earlier theories is reported in the preceding sections. Fecund elements are the idea of the working of the informal organization in a period of massive change, and the two idealtypes of structure, the organic and the mechanistic. Together with the earlier mentioned novelties these have been starting points for subsequent research.

\subsection{Peter Blau and W. Richard Scott}

\section{Bibliographical data}

Blau, P.M. \& W.R. Scott, Formal Organizations, A Comparative Approach, San Francisco 1962 (British edition 1963).

\section{Contextual points}

Blau (b. 1918) is a sociologist who after World War II emigrated to the US. He published some 15 book and numerous articles. Some years after the book he changed his functionalist sociological view, that he owed to his teachers Parsons and Merton (Merton, 1990, p. 37), into a structuralist paradigm. Scott (b. 1932) is a sociologist, professor at Stanford Graduate School of Business. Both Blau and Scott are academics that dedicated their professional life to the continuous improvement of sociological knowledge, especially on organization, by theorizing 
and through numerous empirical studies. As stated Blau became more and more a structuralist. The book builds on the tradition of Parsons, Merton, Weber, and Simon.

Blau's background as a victim of a dictatorial system may explain his interest in studying the formal organization in order to find sociological generalizations and to defend "the many against the few" (p. 14):

"We consider the study of formal organization to be capable of making the greatest contributions to the advancement of systematic sociology at this juncture. ... In contrast to communities or societies, formal organizations are characterized by explicit goals, an elaborate system of explicit rules and regulations, and a formal status structure with clearly marked lines of communication and authority. ... Since the most serious problem in the investigation of sociallife is to establish causal relations by disentangling the interplay among a large number of social forces, the fact that some of these are relatively fixed in a formall organization and only others vary simplifies the analysis. ... In sum, the comparative study of formal organizations offers great promise for advancing systematic knowledge about the organization of social life.... Since formalized organizations have become the dominant form of institution in modern societies, thorough knowledge of them is esisential for an understanding of contemporary sociallife. The centralization of power in the hands of management that organizational giants make possible, moreover, poses a challenge to democracies. An efficient administrative machinery vests tremendous power in the hands of the few... Acquiring knowledge about bureaucratic organizations is an important first step in meeting the threat they pose for democratic institurions.'

The citation demonstrates that the authors were convinced of the importance of organization study for obtaining knowledge about society. This would implicate not only scientific progress. It would also contribute to the defense of democratic values. The latter position is also reflected in the preface:

"If the most dramatic fact that sets our age apart from earlier ones is that we live today under the shadow of nuclear destruction, the most pervasive feature that distinguishes contemporary life is that it is dominated by large, complex and formal organizations. The ability to accomplish enormous tusks by organizing millions of people in formal organizations is a great strength. The danger of free men becoming cogs in bureacratic machinery is a great threat."

\section{Contents and relevance}

The metatheoretical basis of the authors is clearly expressed at different places $(p p, 8,10)$ :

"Theory is both the end product and the starting point of scientific research. On the one hand, the objective is ... to develop ... a set of interrelated verifiable generalizations that account for and predict the empirical phenomenon that can be observed. On the other hand, scientific research must be guided by a theoretical framework ... a system of interrelated concepts that suggest theoretically fruitful lines of empirical investigation. ... What do we mean by a scientific explanation? An observed fact is explained by reference to general principle, that is, by showing that the occurrence of this fact under the given 
circumstances can be predicted from the principle.... To explain a principle requires a more general proposition from which this and other similarly specific arinciples can be inferred. Not only testing but alsa even originating an explaniatory hypothesis requires information on a number of independent cases."

The position of the authors corresponds to the A - D - cycle of knowledge development as used in this study. In what follows it will be seen if the authors succeed in its application. In addition, there is an early awareness of the micro-macro problem in sociology (p. 13):

If the early socidologists were primerilly concerned with broad problems of social orginization and neglected questions of scientific evidence, later ones became preoccupled with refining methods for testing hypotheses, and were willing to sacrifice the sociological focus on organized social relations for nearness of research design. ... Recently, however, the gag käs been narrowed... [there is] an increasing emphasis on obtaining systematic data about social organization instead of collecting rigorous data only about individuals and merely impressionistic information about the sociall relations and shared beliefs that link them into a common structure. ... - a knowledge of simpler systems is needed before one can understand more complex ones - but only a first step. A host of problems of organizational life cannot be clarified on the basis of observations of small groups because they simply do not occur in these groups.... Research on formal organizations, on the other hand, provides opportunities for investigating these kinds of problems."

This means that the integration of the micro-study of small groups with the study of large organizations would be the best way to obtain sociological knowledge.

The objective of the book, its method, and the use of research are explained on page 25 . The authors use a comparative approach:

\section{The objective of this book is theoretical: to suggest} tentative generalizations that help to explain the structure and dynamics of organizations. The emphasis in this book, however, is on the andlysis of research tindings. Since valid generalizations must be both derived from and tested in empirical research, we shall be largely concerned with empirical studies rather than with general discussions of administrative principles or criticisms of the bureaucratic tendencies in American life."

About research in bureaucratization extensive literature search is reported, with some fundamental comment. The combined body of hypothesis is not re-stated in one wellformulated theory.

Some salient basic contentions can be found in the classification of organizations that is presented, based on cui bono. A distinction is made between 1) service organizations for clients who need help, 2) mutual benefit organizations for the good of members, 3) business concerns for the benefit of the owners, and 4) commonweal organizations that serve society at large, like an army. It is argued that each of these has its specific problems. In the first type, the crucial problem is how to provide professional services to clients (such as patients), who often are ignorant about their own interests (p. 51). In mutual-benefit associations the crucial issue is the maintaining of membership control (internal democracy). The main problem here 
is apathy and oligarchic control (p. 45). In business concerns (p. 49) the dominant problem lies in maintaining operating efficiency; human relations may be important in this respect (Kahn, 1950). Finally, in commonweal organizations the central issue is in the working of external democratic control.

Three problems are said to be dominant: power, promotion of extraordinary performances, and dealing with outcasts (pp. 54 - 55). In addition, two 'publics' are distinguished: public-incontact and public served. Publics of both types may be multiple (p. 59).

The authors' own research leads to the tenet that the more powerful the clientele group of welfare, the more time will be spent per case, the less bureaucratic procedures will be, and the more the tasks will be tuned to the specific problems. In addition, significant differences in attitudes are said to be associated with the four grades of professionalism (see hereafter).

The book is foremost metatheoretical. Its material conclusions rest on limited observation, namely two welfare organizations. From the theories on bureaucracy a number of indirect suggestions concerning the design of an organization structure can be borrowed.

Strategy is referred to in the discussions about the public that is directly involved with the organization and the societal environment at large, but primarily in the sense that the environment must be taken into account when the structure is chosen.

The theories developed mainly refer to the larger organization.

\section{Process of knowledge development}

The authors give a detailed account of their points of departure. Important elements of these are the following:

- the macro-micro problem is addressed (see above),

- the concept of bureaucracy, based on Weber, Simon, and Parsons, with adaptations by the authors, is applied, and,

- a distinction is made between professionals and bureaucrats (like in independent lawyers $v$. employed legal specialists). The first category would be controlled by peer group organizations; the second is subjected to the norms of the hierarchy.

In the book different lines of thought are followed. First, heawy emphasis is laid on existing theories, with some comment added (A). This leads to a firm hypothetical basis. Second, reference is made to empirical research of others. Next, theories are partialized and rough predictive models are proposed (B). Finally the two cases of the authors (C) are discussed. Hypothesis, based on existing theories, largely draws on Weber's (1947) concept of authority (see section 5.4). It means that directives issued by the agency holding authority are said to be voluntarily obeyed without the need for persuasion. Simon's view of bounded rationality is used too (Simon, 1957). In an organization the decisions each person takes have to be described, together with the influences to which he is subjected. But individuals' rationality is said to be fundamentally restricted. Therefore, the function of the organization is to overcome these limitations. Finally, the authors adopt Parson's (1960) scheme. In this view, all social 
systems must solve four basic problems": 1) mutual adaptation of the system and its external situation, 2) goal achievement, 3) integration of members to make a single entity, and, 4) latency: the maintenance over time of the system"s motivational and cultural patterns (pp. 38, $39)$.

Parson's argument is adopted that only within a certain level the superior can supervise the work of subordinates and assume responsibility for it. This is the case for instance when subordinates that are professionals take their own responsibilities (pp. 38, 39):

Indeed, it is not correct even to say that the execuitive delegates responsibility to professionals. The latter assume full responsibituty for technical decisions, and the executive must rely on their expert judgments in discharging his managerial responsibility, which is the area of his special competence

The authors refine these hypotheses. Weber's bureaucracy is said to be an 'ideal type', a construct, and not an empirical phenomenon. It is "an admixture of a conceptual scheme and a set of hypotheses' as it contains both definition (the determinant combination of characteristics) and a number of assumed relationships (e.g. 'specialization promotes expertness") between these characteristics.

The authors reject this confusion and recommend to use the definition and to test the hypotheses (p. 33). They point at other shortcomings of Weber (p. 34), like 1) his neglect of dysfunctional effects of bureaucracy, 2) his neglect of informal relations, and, 3) the implicit contradictions in his propositions.

They also adjust the hypotheses of Simon (p. 38), especially his neglect of a systematic analysis of non-formal interpersonal processes, and the reduction of all problems of social structure to sociopsychological problems.

Parson's view is rejected after examination (pp. 38, 39). It is argued that his abstract conceptions are devoid of propositions from which specific hypothesis can be derived. They claim that it is only a theoretical framework, not a substantive theory.

So far, the authors have molded received theory into a well-argued propositional base. In chapter 3 the hypotheses are expanded. The often-neglected relation between the organization and its public is discussed. It is assumed that organizational forms have effect on their relations with third parties involved, and vice versa.

Hypotheses concerning similarities and contrasts between professional and bureaucratic orientation are proposed ( $p .60)$ ). Professionalism is characterized by 1 ) governing principles based on a body of specialized knowledge, 2) specific expertise, 3) neutrality toward case, 4) status achieved by performance, 5) decisions not based on self-interest, and 6) control by a professional association. Bureaucracy is said to have the same properties, but now it is not the professional norms that dictate conduct but the directives of the formal organization, in other words it is not the colleagues but the hierarchy that determines norms and standards (p. 60 ):

".we shail discuss the orientation of officials. concentrating on the contrast between professional and bureaucratic orientations. White these orientations have relevance for many aspects of organizational life. they are of particular importance in service 
More hypotheses concern the role of the supervisor in these types of organization. Two types of supervisors' attitude are introduced, namely an excitable and a detached attitude. More detached supervisors have better performing units (This is corroborated by literature, p. 155 ). Another hypothesis reads (p. 159) '... an official who enjoys social integration among his peers will be more impersonal and detached in his relations with subordinates than one who does not.' This hypothesis will be rejected following the authors" research (p. 159).

For a case study of two welfare agencies four hypotheses are formulated. 1) The more professional an organization, the more outside- and client oriented it will be, and the more convinced it will be that superiors must be graduates. 2) Professional orientation is inversely related to organizational loyalty. 3) Professional orientation means a more critical opinion about the professionalism of the agency. 4) Professional orientation means a more critical opinion about the negative effects of formal procedures and regulations on the quality of the work. These statements are almost directly testable, so here we have a first step into derivation.

Another example of derivation from these and many other hypotheses is found in the distinction made between four types of social workers in the two cases, namely 1) professionals, with graduate training and the involvement of colleagues outside the agency as a reference group, 2) non-professionals with outside reference, 3) professionals oriented towards inside reference, and 4) bureaucrats, that are neither trained nor seeking outside reference ( $\mathrm{p}$. 67).

After the elaborated phase of hypothesis and some derivation, observation takes different: forms (p. 25):

"The major empirical sources to be used are: (11) reports of research on various organizations: (2) experiments and other studies from the literature having bearing upon some organizational problem; and (3) our own investigations, especially our research on two welfare agencies. The approach of this book, finally, is comparative. By "comparative' we mean that the importance of comparing different organizations for generalizing about them informs our thinking throughout the analysis. We cannot claim more than that, inasmuch as most research on this subject that has been reported in the literature consists of case studies. Indeed, in view of this situation, our attempt to be comparative may seem hezardous if not foolhardy. Nevertheless, we believe that the fruits to be attained by even partial success justify the risks involved. How do we propose to proceed with this comparative study. and from where shall the data come? First, it will be possible to attempt to make comparisons between severall of the case studies of formal organizations in the literature. Second, we shall draw on those studies that make internal comparisons, for example, of one department with another. Third, we can make use of the few studies that have attempted to make systematic comparisons of several organizations ...Finally, we shall draw extensivelly on our own separate studies of wo welfare agencles ... Since we shall have many occasions to refer tha these two studies in the following chapters, it sthould be noted that the fact that these organizations are public welfare 
The citation demonstrates the doubts of the researchers concerning the value of their observational approach. As often in organization studies desk research is feasible (literature research, reasoning), but observational material is hard to produce. In this case we have to be satisfied with two case studies.

Results from observation of the two subject cases of chapter 5 , concerning communication and consultation patterns (reciprocity, relation to self-confidence), are reported as follows (pp. 134, 139):

The central topic of this chapter was the significaince of the free flow of communication among colleagues. By providing social support, challenging stimulation, error correction, and a laissez-faire competition for respect among participants, the free flow of communication contributes to finding solutions to problems, ta making decisions, and to creative thinking. But the battleground of ideas generated by such a free flow makes coordination more difficult. Herarchical differentiation of status tends to block the free flow of communication in a group and thus to impede problem-salving, although some types of leadership have the opposite consequences, such as that of the discussion chairman who prevents suppression of minerity opinions.

A hierarchical organization, in part precisely because it restricts the fres flow of communication, improves coordination; indeed, it seems to be essential for effective coordination of group effort. This is the dilemma posed by hierarchical differentiation: while it is necessary for coordination, it blocks the communication processes that are vital for stimulating initiative and facilitating decision-making. Moreover. even if there were no formal hierarchy in the organization, communication among peers woulla be likely to give rise to informal differentiation of status, which also creates obstacles to communication. These considerations illustrate the dynamics of organizational life. Hierarchical structures channel communication processes; communication processes give rise to structural differentiation, and the emergent social structures in turn, redirect the communication processes. The existence of dilemmas that canmot be definitively and finally resolved is inherent in such dynamia processes."

As mentioned above, the hypothesis about hierarchy and peer relations is rejected (p. 159). Now the association is examined between the index of detachment (the ability to remain calm and not lose temper) and three measures of social integration among peers i.e., 1) feeling of integration among other supervisors, 2) number of received friendship choices from other supervisors in the department, 3) the same number from all supervisors. Result: "the hypothesis is clearly negated'.

Concluding remarks on chapter 6 are the following (p. 163):

"Emotional detachment, consistency, and hierarchical independence were found to be the supervisory characteristics most closely related to the ability to command the loyalty of subordinates. Authoritarian practices on the part of the supervisor, on the other hand, had no bearing on loyalty in the welfare agencies. Worker productivity was largely associated with factors that were related to lovalty perhaps 
because supervisors who had won the loval support of their subordinates were most successful in commanding willing compliance with their directives and in stimulating effort in their work group.

Authoritarian practices by the supervisor adversely affected work satisfaction, the willingness to assume responsibility, and the tendency to extend casework service to clients. But in contrast to the findings abtained in other types of organizations, authoritarian supervision did not lower productivity in the two welfare agencies. The supervisory attributes that exerted most influence on group solidiarity were hierarchical independence and consistency. Contrary to expectations, the supervisor's relations with his peers did not affect his approach to subordinates, probably because only a low level of peer-group solidarity existed among supervisors. Workers seemed
Iypically to derive their social support from cooperative relations with their peers, notably

from consulting one another. Superwisors, on the other hand, obtained theil social support not from working relations with other supervisors, but from loyal subordinates or from their relations with their superiors. The data suggest that a supervisor who expresses loyalty to his superior is less apt than another to command the loyally of his own subordinates "to be detached in his relations with subordinates and to exthibit hierarchical independence. If this suggestion is generally true, it would imply that a manager"s ability to command his subordinates" loyalty impedes their effectiveness as supervisors in theil own right. This implication. in turn, suggests that effective menagement can be expected to occur only on alternate levels in the herarchy"

The citation demonstrates that peculiar conclusions have emerged from the research. It would have been interesting to test the finding as a new hypothesis. To my knowledge it has not been done by the authors or other students afterwards.

Chapters 8 and 9 contain reflections of the authors on the basis of the preceding hypotheses and the findings of the two case studies.

\section{Assessment following the $A-F$ - scheme}

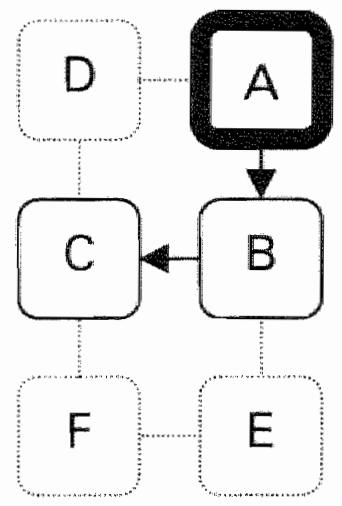

The authors start with the formulation of thorough metatheoretical propositions and a firm theoretical basis (pp. 8, 10, 13). Hypothesis is present in conjecturing (pp. 13, 38, 39, 45, 49, 51, $54-55,60,155$, 159), domain delimitation (p. 25), definitions (pp. 38, 39, 59, 60), leading to adjusted hypothesis of predecessors (pp. 34, 38). For the case studies derivation (B) has been conducted as derivable consequences are formulated (chapter 5, p. 67). Box C (observation) only for a minute part does share a common set of definitions, concepts, constructs, and models as used in A. Where concepts or classifications are defined (the cui bono distinction of organizations, and the concepts of the public-in-contact, and the public-served) some interesting corroborations emerge. But it is not made clear that these are valid outside the limited domain of public service organizations. Moreover, these concepts have no link to the research of others that is referred to. The connection is narrative, making coherence questionable. This all means that the intention of meeting meratheoretical 
requirements (p. 10), was only scarcely realized, meaning that validity cannot be tested. Utility for organizational design is indirect.

Requirements of definiteness and precision are well met in the introductory chapters (pp. 27, $32,33,42)$. The case descriptions are rudimentary (pp. $254-257$ ): they do not serve as digested empirical material as they fail to elucidate most of the phenomena that are relevant to the study. The observations used are from questionnaires. The degree of elaboration of hypothesis (A) is large, while derivation (B) and observation (C) are discussed but hardly elaborated.

Induction (D) is not explicitly discussed. Prescription (E) and intervention are no part of the study (F). It can be concluded that the essence of the study is hypothesis.

\section{Conclusion}

This book is an early work of both authors, who in later years provided more, and more substantial, contributions to the knowledge on organization. As stated, its main contribution is hypothesis. The introduction of the micro-macro problem in sociology (for a much later discussion on the subject see Coleman, 1990) is an important point. An interesting relationship to earlier work of others is the reference to Crozier (The French Bureaucratic System, 1962), a precursor of The Bureaucratic Phenomenon. Fecund elements are present in the attempt to take the environment of the organization into account, and the building blocks for a theory on bureaucratization in public service organizations. The study has been a basis for further research into organizations in general (as was done in a vast body of subsequent work by the authors themselves).

\subsection{Alfred D. Chandler}

Bibliographical data

Chandler, A.D., Strategy and Structure: Chapters in the History of the Industrial Enterprise, Cambridge MA 1962.

\section{Contextual points}

Chandler (b. 1918) is professor emeritus of business history at Harvard University. He is an economic historian, who centers his research on business history and, particularly, administration. In his work, he places four case studies in the historical context of the growth of large-scale enterprise in the United States.

The author indicates his scientific environment, discipline, and school in expressing his intention to conduct a historical, comparative study of different American businesses carrying 
out the same activity (p. 1). The central subject to be studied is the administration of such businesses.

\section{Contents and relevance}

The author's basic position, and the intent of the research follow from his research questions (p. 2): what structures were used 'to administer ... great enterprises? And who were its innovators?" He starts his study with the examination of the first adopters of the 'decentralized', multidivisional form, namely E.1. du Pont de Nemours \& Co., General Motors Corporation, Standard Oil Company of New Jersey, and Sears, Roebuck and Company. After the preliminary investigation, he argues that looking at just the four cases would neglect the effects of general social-economic developments affecting the strategic and structural decision (p. 17).

The following basic contentions resulted from the first four cases (p. 3). 1) The analysis required knowledge of each firm's administrative history. 2) Changes in structure related to the way of expansion. 3) These patterns of growth reflected changes in the overall. American economy. 4) Reorganizations reflected the then state of administrative art. Contentions 3) and 4) call for an examination of the history of U.S. business economy.

Therefore the historical setting is accounted for in a 'brief review of the growth of large-scale business enterprise in the United States"

The central thesis of the book is written on page 14 :

"The thesis deducted from the several propositions is then that structure follows strategy and that the most complex type of structure is the result of the concatenation of several basis strategies."

The author argues that expansion of volume led to an administrative office. Growth by geographical dispersion led to a departmental structure supervised by a headquarters. New emerging types of functions required a central office plus a departmental structure. Finally, new lines of product or continued, international growth led to the divisional structure with a general office.

The research pertains to both structure and strategy and their interrelatedness, in an indirect way. The size and type of organization addressed is clearly that of the large business corporation.

\section{Process of knowledge developinent}

The comparison of four companies in detail and of many more in general, as well as the use of decisions and actions as indicators for their history requires the careful and precise definition of terms and concepts as a part of the hypothesizing phase. Examples are (pp. 7 - 12):

- the industrial enterprise: a large private, profit-oriented business;

- administration: the executive action and orders as well as decisions about coordinating, appraising, and planning the work of the enterprise and about allocating its resources; 
- general office: where the administration of the firm as a whole takes place;

- division." a quasi-autonomous, fairly self-contained unit handling a major product line or a large geographical area;

- departmental headquarters: leading entity for a number of field units;

- field unit: 'runs a plant or works, a branch or district sales office, a purchasing office, an engineering or research laboratory, an accounting or other financial office, and the like."

On page 13 and 14 , the author continues with theory-related definitions:

The thesis that different organizational forms result from different types of growth can be stated more precisely th the plenning and carrying out of such growth is considered a strategy, and the organization devised to administer these enlarged activities and resources, a structure. Strategy cian be defined as the determination of the baistc long-term goals and

\begin{abstract}
objectives of an enterprise, and the adoption of courses of action and the allocation of resources necessary for carrying out these goals. ... Structure can be defined as the design of organization through which the enterprise is administered. ... It includes, first, the lines of authority and communication ... and ${ }_{n}$ second, the information and date that flow through these lines."
\end{abstract}

Many concepts, like 'central office', 'division', etc. are rather crudely defined. In practice these organizational elements may differ considerably between companies. The author is aware of this, and pointed to 'Fritz Redlich's more precise definitions' (chapter 6, note 1).

The author skips the phase of derivation. As a historian, he starts with the observation of states and events that have evolved in the past, beginning with the exposition of the general historical setting in the U.S. from 1850 until 1914 (pp. 19 - 27). He describes how, after the Civil War, demand for goods and services grew quickly. Technological progress offered new and better products and processes. Railroad development and huge concentrations of population enabled a strong economic growth, interrupted by the spell of recession in 1900 .

To give an idea of Chandler's case descriptions one of his expositions is paraphrased hereafter. He tells that Swift purchased cattle in the western plains. The entrepreneur adopted the new technology of refrigeration and supplied large quantities of meat to the cities of the East. 'Before the end of the 1890 's, Swift had created a huge vertically integrated industrial empire.' Other examples are (pp. 28-32) the introduction of electricity that led to industrial giants like General Electric and Westinghouse.

All these growing firms needed better forms of internal and external organization. First came horizontal combinations and consolidations (entrepreneurs flocking together). Next vertical forward and backward integration followed in order to safeguard the output and to have disposal of material resources. Most measures were aimed at the limitation of competition. But soon modern competitive thinking emerged. In their fourth annual report of 1901, the National Biscuit Company concluded that the control of competition did not work (p. 32):

'[so] we bent oul energies to impiroving the internal management of the business, to getting full benefit from purchasing our raw materials in large cuantities, to economizing the expenses of manufacture, to 
systematizing and rendering more effective our selling department, and above all things and before all things to improve the quality of our goods and the condition in which they should reach the customer. It became the settled policy of this Company to buv out no competition."

It should be noted that in this 'mission statement' all modern ideas on management are present already, except for the contemporary attention on human resource policy.

More historical observation is reported in chapters 2-5, in the description of the development over time of Du Pont, General Motors, Standard Oil, and Sears Roebuck. The author explains that the problems arising with growth lead to new types of structure.

Chandler describes the problems of organization building, and the new role of the manager, a type of person distinct from the entrepreneur. This official is said to have a difficult task to perform, as control of competition was still the central thought of the owners and of speculators who founded consolidated companies. Chandler induces that the line-and-staff structure was a solution for this problem (p. 37) after pointing at the example of Pennsylvania Railroad, who faced the organization problem already by 1880 and opted for this type of structure.

But in the first decades of the 20th century further growth and technical development, which enabled the introduction of new products, made this structure inefficient (p. 44):

'By placing an increasing intolerable strain on existing administrative structures, territorial expansion and to a much greater extent product diversification brought the multidivisional form:

This was Chandler's induced explanation of the multi-divisional form.

Further induction is reported in chapter 6 (p. 283). Two types of responses are said to be the problems of growth and complexity, namely 1) the adaptive response, and 2) the creative innovation (after Schumpeter).

The author argues that the multi-divisional form is the necessary form for the larger company at that stage of development of enterprise and society.

Chandler concludes as follows (p. 303):

'a company's strategy in time determined its strucure and that the common denominator of structure and strategy has been the application of the enterprise's resources to marker demand... Growth and shifts in the location of population technological $^{-}$

developments, and changes in consumer income, all affected the markets which the administrators applied these resources. ... If the need to use resources provided the dynamic force that changed structure and strategy, the nature of the inwestment in these resources helped to determine the course and direction of growth and of subsequent structural change. The type of investment, in turm, depended on the technology of production and the techiriques of marketing of the individual companies. original product line or fines. Finally, the rate of growth and the effectiveness in the use of the enterprise's resources rested on the ability and ingemuity of its administrators to build, adjust, and apply its personnel and facilities to broad population, technological, and income changes. ... The market, the nature of their resources and their entrepreneurial talents have, with relatively few exceptions, had far more effect on the history of large industrial firms in the United States than have antitrusit 
Lws, taxation, labor and welfare legislation. ... Then came second period of growth and a second rationalization of the use of the firm"s resources.... as it came to the limits of cost reduction through rational and systematic integration and use of its resources, its senior weutives began to seek new markets or new lines of business ... Thus four phases or chapters can be discerned in the history of the large American industrial enterprise: the initial expansion and accumulation of resources; the rationalization of the use of resqurces; the expansion into new markets and lines to help assure the continuing full use of resources; and finally the development of new structure to make possible continuing effective mobilization of resources to meet both changing short- term market demainds and long-term market trends. ... In very general terms, then, many of America"s largest industrial enterprises initially accumulated their resources in the years between the 1880 's and World War 1. During the first two decades of the twentieth century, these same firms built their initial administrative structures. For some, continued expansion, largely through diversification, began in the 1920's, but for most it came after the depression of the $1930^{\prime} \mathrm{s}$. Thus, although the pioneers in the fashioning of a new structural form to manage these expanded resources began their work in the 1920's, most enterprises carried out their maior structural reorganizations in the $1940^{*}$ s and $1950^{\prime} \mathrm{s}^{*}$

In the final part of the book, he explains why some industries were late in adopting the divisional structure. He hypothesizes on the causes of such delay (pp. 314, 315). He describes industries not accepting the new structure (by 1960) like the metal- and papersector, and those partly accepting it (processors of agricultural products and rubber). The latter instances show that the extent of divisional decentralization is associated with the degree of diversification. Finally, there are industries widely accepting the new structure, like electrical products and electronics, power machinery and automobiles, and chemicals.

\section{Assessment following the $\mathrm{A}-\mathrm{F}$ - scheme}

Observation (C) is based on a general economic-historical study supported by statistical data, reported in a narrative way. It leads to the induction of hypotheses about the line-and-staff structure (p.37) and the multi-divisional form (p. 44). A hypothesis on strategic response is also induced (p. 283), together with the four-stage hypothesis about the relation between structure and strategy in the development of a company (p. 303).

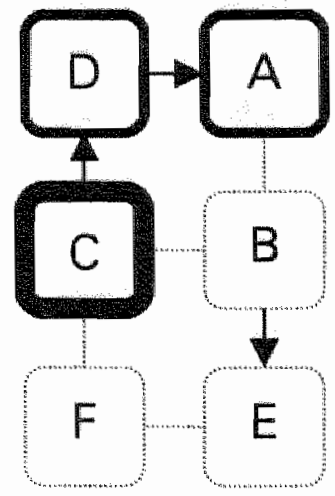
Hypothesis (A) mostly deals with definitions of terms and concepts (pp. 7 - 12), demonstrating adequate definiteness and precision. Derivation into testable statements is not sought. The highest degree of elaboration is in $\mathrm{C}$, while hypothesis (A) and induction (D) are only moderately elaborated.

Validation is not possible, but indirectly the theory is useful for the design of both structure and strategy. Coherence and systematic structure are those typical for the historiographical approach. Metatheoretical requirements are met to the same extent. This leads to the depiction alongside. 


\section{Conclusion}

For the greater part the study consists of historical observation and hypothesis. It resembles in some respect the work of Weber, as it is based on a economic-historical analysis, ending with hypothesis. But it is not ideal-typical as hypothesis is induced from observation. The author himself mentions Schumpeter as one of his predecessors. Chandler's main tenets, broadly formulated as they are, have had and still have an important impact on later research into strategy and structure. His explanation of the recurrent influence among structure and strategy does not cease to fuel a continuing scientific debate.

\subsection{Richard M. Cyert and James G. March}

Bibliographical data

Cyert, R.M., and J.G. March, A Behavioral Theory of the Firm, Englewood Cliffs NJ 1963.

\section{Contextual points}

Cyert (b. 1921) and March (b. 1928) are both professors at Stanford University, California. The scientific environment of the book is the school of Simon (1947) and March and Simon (1958). The authors say to aim at the expanding of narrow approaches (like the classical economic theory of the firm) by adding elements of social-economic behavior in organizations. The accent on operations research-like methods with mathematical models of economic and social phenomena is typical for the book.

The historical/social environment of the period was characterized by a number of new theoretical views. The authors state: "In theory it seems reasonable to conclude that the basic theory used to develop models of price and output determination may be useful as a basis for models of other decisions made by (or in) complex organizations." (p. 266) On onganization there were new theories like those of Crozier on bureaucracy, Blau and Scott on formal organizations, Chandler on economic history, and Burns and Stalker on innovation.

\section{Contents and relevance}

Throughout the book, the authors advance several important metatheoretical propositions that express their position, and also the intent of the research. Some examples follow (pp. $1,2,3)$ :

"This book is about the business firm and the way it makes economic decisions. We propose to make detailed observations of the procedures by which firms make decisions and to use these observations as a basis for a theory of decision making within business organizations. ... Our articies of faith are simple. We believe that in order to understand contemporary economic decision making, we need to supplement the 
study of market factors with an examination of the internal poeration of the firm - to study the effects of orgamizationel structure and conventional practice on the development of gods, the formation of expectations, and the execution of choices. The rationale for such a belief is also simple. The modern "representitive firm" is a large, complex organization. .... Within the firm, information is genierated and processed, decisions are made, results are evaluated, and procedures are changed.... The modern firm has some contro over the market; it has discretion within the market; it sees the market through an organizational filter. ... The insistence on empirical content follows naturally from the emphasis on identifying the actual process of decision... We were constrained to secure research access to a number of firms under conditions that protected the competitive position of the firm without interfering with the disclosure needs of a research study.... We did not want the theory to be limited to descriptive models of specific firms making specific decisions. We required a set of explanatory concepts that would serve as a framework for analysis and further research."

Here we come across some fundamentals. The first is the tradition of Simon (decision and choice as explanantia in addition to the economics of the market). The second is the need for an empirical base of theory. The third point is essential. As shall be seen later, many of the books in the sample of our study claim that observation and its inducement are of vital interest, but only a few are able to report on empirical content, simply because organizations are reluctant, to say the least, to disclose their inner practices. Cyert and March intend to find empirical evidence for their propositions and to cope with problems of business privacy. The research focus of the authors is reiterated on page 19:

'Our conception of the task we face is that of constructing a theory that takes (1) the firm as a basic unit, (2) the prediction of firm behawior with respect to such decisions as price, output, and resource allocation as its objectives, and (3) an explicit emphasis on the actual process of organizational decision making as its basic research commitment

They explain why classical economics falls short of the explanation of the viability of the individual firm (p. 16):

(1) It [classical economic theory] deals with a particular set of decisions (e.g., price, production that are vilewed as functions of a few "catch-all" variables le.g. demand, costs\}.
(2) The theory uses aggregation as a tactic; it attempts to specify total market supply and demand curves.

(3) There is no attention to, or interest in, the actual processes by which individual firms reach decisions"

About organization theory it is said that only those organization theories 'that emphasize the empirical study of behavior in organizations are relevant to our present purpose." That leaves the authors with three fields of interest: 1) the sociological theories that would especially be concerned with bureaucracy, 2y the social-psychological theories (centered on efficiency), and 3) the administrative theories, focused on problems of the executive (p. 16).

Next a conclusion about the application of the different types of theory is advanced (p. 18): 
'Thus, existing organization theory prowides only very partial basis for a new theory of the firm. The sociological and social psychological approaches thave emphasized questions that are only marginally relevant to either the objectives of conventional theories of the firm or the objective of predicting individual firm behavior. The decision-making approach has developed a substantial theory of dacisionmaking processes in an orgianizationat context, but has not applied the theory to the specific environmental conditions in which the business firm operates nor applies the theory in detail to the particular dacision variables that characterize the firm's operation."

Further in the book two more metatheoretical views are exposed (pp. 251,252). The notion of 'organizational slack' is introduced, meaning that the objective of the firm shifts from 'the best interest of stockholders' to "the self-interest seeking of managers". And one of the models (see hereafter) reflects "The basic behavioral assumption in all of economics', namely that people seek their own self-interest. Under severe competition the model reduces to the profitmaximizing hypothesis.

The final result of the research is held against all of these metatheoretical intentions. On page 297 it reads:

'We have tried to suggest some possibilities of recent work on a behavioral theory of the firm. The implications for descriptive economics, for studies on noneconomic organizations, and for normative analvsis are not always easy to see at this stage. They are even harder to validate. In the area of the descriptive analysis iff the firm, we can claim some modest validation. We think a behavioral theory of the firm has a major contribution to make to the understanding and prediction of decision making within economic organizations and we have tried to present the theoretical constructs, models, and empirical observations upon which that belief is based. Beyond the area of positive theories of business decision makingl. we believe the concepts of a behavioral theory of the firm mey hawe some potential relevance. The rough ideas in this volume are offered to indicate possible directions for further empirical and analyucal work."

So positive results are a modest validation of a theory describing the firm. Building blocks for the further construction of a behavioral theory of the firm are also obtained, together with indications for further research in this freld.

A basic contention of the authors is that modern business organization is a large, complex system, in which choice is determined by rules and organizational learning continually alters goalls and procedures.

Other basic contentions are embodied in the outcomes of a logical/mathematical duopolistic model. An example from one of these models reads as follow (p. 148):

The department store model is a specific application of the general model described in this book. The evidence supports the specific model and thereby presents corrobaratiwe evidence for the general model. We would not argue that the evidence is conclusive. It is not. It is, however, consistent with the model. The model lends itself to further elaboration and testing and the world is full of firms for further empirical study." 
The passage shows the accuracy of formulation of the authors. As a bottom line the authors declare (p. 266):

In theory it seems reasonable to conclude that the basic theory used to develop models of price and output determination may be usefull as a basis for models of other decisions made by (or in) complex organizations:

Structure and strategy are both addressed indirectly through the derived behavioral rules concerning choice and decision making. The final hypothesis based on the outcomes of the modeling procedure pertains to all types of commercial organizations. The study has mostly metatheoretical value.

\section{Process of knowledge development}

The authors go through a repeated A - D-cycle. The first starts with a number of basic assumptions, as described above under metatheory. As a start the entailing research strategy is explained (p. 2):

1. 1. Focus on a small number of key econonic decisions made by the firm. ...

2. Develop process-oriented models of the firm.

3. Liak models of the firm as closely as possible to empirical observations of both the decision output and the process structure of actual business organizations....

4. Develop a theory with generality beyond the specific firms studied...."

A discussion of the existing body of economic theory on firm behavior follows (p. 4). It is said that formal economic models of the firm describe its behavior in terms of the choice of factors used (costs) and outputs produced (results) in order to maximize profits. Generally perfect competition and the existence of one single economic equilibrium are assumed. These models are said to be restrained to a coarse reduction of reality. Deficiencies of these theories would be that firms not only seek profit maximization. Moreover, they lack perfect knowledge, and are not individual actors but a cooperation of actors (p. 8). Three research questions follow (p. 19):

1. which are the 'organizational objectives of a business firm", beyond one, supposedly single, organizational goal, and what are the effects of structure and of planning, budgeting, the change of objectives,

2. as far as "decision strategies' are concerned: what are the discretionary powers of the firm over market determinants, and what rules are followed?, and,

3. about "decision making with strategies": what information does the market offer, how is the information processed?

The term 'organizational slack' is introduced (p. 36). It is defined as the surplus of inducements the individuals receive over the minimum required to make them stay as members 
(in classical theory slack is typically zero). On page 43 , a summary of assumptions about organizational goals is given:

1. goals emerge from a bargaining process among participants in the organization; as the dominant coalition changes, goals change too, (mostly gradually, so a short term goal may be established),

2. five major types of goals can be distinguished in the modern business firm: those concerning production, inventory, sales, market share, and profit,

3. conflict is never fully resolved because of the sequential and decentralized process of goal setting, and because of organizational slack.

An important point in the study is the use of predictive models, with emphasis is on decision making processes, and the use of pictorial and computer models (p. 2):

"The emphasis on studying actual decision processes: implies a description of the firm's decision in terms of a specific series of steps used to reach that decision. The process is specified by drawing a llow diagram and executing a computer program that simulates the process in some detail. We wanted to study the actual making of decisions and reproduce the behavior as fully as possible within the confines of theoretical manageability."

This is a perfect example of a predictive model.

Existing research into organizational expectation is reported on page 44 to 47 . It is said that in many theories the assumption is made that firms make a selection out of all possible alternatives, and that they possess all information necessary to make a choice. This view is examined by experiment. Four case studies of decision-making processes and "two experimental studies of organizational communication' are reported as the result of induction (pp. $78-82$ ).

1. an organizational coalition does not require either consistency or completeness in information,

2. there is no constant level of search into the determinants of choices,

3. 'Resource allocation within the firm reflects only' gross comparisons of marginal advantages and alternatives.'

4. 'Computations of anticipated consequences used by the organizations seem to be quite simple.'

5. 'Expectations are by no means independent of such things as hopes, wishes, and the internal bargaining needs of subunits in the organization.'

6. 'Communication in a complex organization includes considerable biasing, but also considerable bias correction.'

This first A - D round produces the basis for the next one. On page 84 , derivation of a model of organizational choice in two steps is described.

'In this chapter we suggest first ... a partial model of organizational choice and second how an examination of the actual decision procedures ... leads to a more complete model. For, as we shall see ... organizational 
cholce is heavily conditioned by the rules within it

occurs. These ruies, in turm, rethect prganizational learning processes by which the firm adapts to its environment."

A partial model is proposed. For each of the items a calculation rule is formulated, together with instructions for stepping to a next item (pp. $84-88$ ):

". For cast competitor"s Gehavior.

2. Forecast demand.

3. Estimate costs.

4. Specify objectives.

5. Evaluate plans.
6. Re-examine costs.

7. Re-examine demand.

8. Re-examine objectives.

9. Select alternative:

The model is further elaborated for a duopoly, formed by an ex-monopolist and a spin-off (the 'splinter', p. 88). A series of mathematical relations or estimating rules for and among variables are formulated, like:

"Our assumption is that the splinter will simply use the


information from the past two periods. Thus,

Comparison with observed figures takes place (p. 93). It is concluded that the outcomes of the logical/mathematical duopolistic model show a close fit with the history of Continental Can and American Can over the period 1915 - 1965.

The second A - D-loop ends with new induction. Novel elements in the model as compared to conventional theory are formulated. It is said that the model describes the decision process of organizations. It would depend on a theory of search and on one of choice. The organizational goal may change as a result of experience; the same goes for forecasts. Organizational bias is part of the model, and also is 'slack' (p. 97).

Now the authors are ready for their third round. Deficiencies of the model used so far are described (p. 98), such as the assumption that the price is fixed. In addition, only one single goal is considered, while feedback and organizational learning are only present in a limited sense. The following summary is made (p. 113):

"... We can describe a skeleton of our basic theory of organtizational choice and control. We assurne: ... multiple, changing, acceptable lavel goals. ... a... sequential consideration of altermatives.... The organization seeks to avoid uncertainty by following regular procedures and a policy of reacting to feedback rather than forecasting the environment. ... [and]... uses standard operating procedures and rules of thumb to make and implement choices.

Next goals, expectations, and choice in the new theory are elaborated (p. 115). Goals are said to have two sets of variables: the selection of what is important, and the aspiration level per sub-goal. Expectations are inferred from available information. "Choice takes place in response 
to a problem, uses standard operating rules, and involves identifying an alternative that is acceptable from the point of view of evoked goals."

Four major relational concepts are formulated (p. 116):1) the quasi resolution of conflict, 2) uncertainty avoidance, 3) problem-invoked search, and 4) organizational learning.

This all leads to the third-level predictive model (p. 128) in which a detailed elaboration in mathematical and pictorial. form of a price - output model is embodied. In an empirical test the fit is claimed to be good.

As a conclusion of the book, a general model of price and output is presented. The following summary is given (p. 182):

The fact that many of the parameters that are apparently important can be seen as the product of a learning process suggests that one next step in the development of the model is the introduction of additional higher-level learning mechanisms. This conclusion is reinforced by the identification of two basis learning parameters in the model as being especially important to the profitability of the firm represented by the model."

This is an interesting point, as it anticipates on future emphasis on learning processes in organization.

As an encore, a model of rational organizational behavior by O.E. Williamson is presented (p. 237). In the model 'organizational slack' specifically means the surplus of staff costs over the minimum as determined by classical theory (excess of personnel and inducements). The contribution can be seen as a building block of Williamson's later transaction cost theory.

Prescription and intervention are not discussed.

Assessment following the $\mathrm{A}-\mathrm{F}$ - scheme

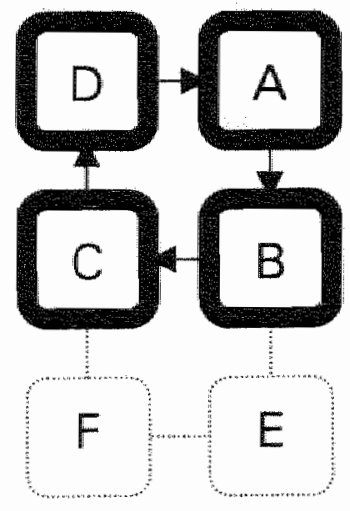

Three complete loops

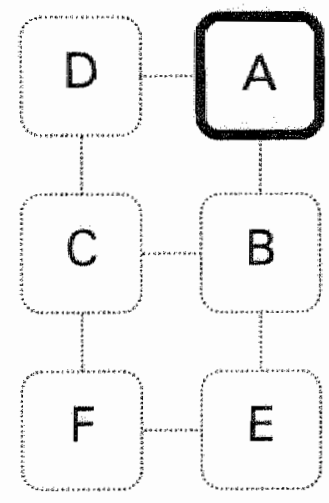

Fourth position 
Three times the A - D-loop is run through. The first round defines the scope and the metatheoretical base (pp. 1-3, 16, 18). Hypothesis (A) encompasses definitions of concepts (precision, 36), research questions (definiteness, 19), and conjectures (p. 43). Hypotheses are developed into predictive models (B, pp. 2,148$)$, and tested in observation $(C)$ by means of case studies and experiment (pp. $78-82$ ). Induction (D) leads to new hypothesizing as the start of a next round (pp. 78-82).

In the second round another predictive, partial model is proposed ( $\mathrm{B}, \mathrm{pp} .84,88)$ en elaborated in detail, followed by observation again (C, p. 93). It is tested against two case studies (,$p$ 97). On the basis of the outcome (D, p 98) deficiencies of the model are corrected and the third round of knowledge development can start (A, pp. 113, 115). This round involves new hypotheses, again represented in a predictive model (B, p. 128) that are tested again. In the fourth round, an improved hypothesis of the behavior of the firm is formulated (p. 182). This all demonstrates an appropriate systematic structure. The link with earlier theories is dealt with in a coherent manner.

As stated above, prescription and intervention are not discussed.

The example embodies a well-developed theory with all phases of knowledge development largely elaborated, especially observation (C) and hypothesis (A). Metatheoretical requirements are fully met, including definiteness, precision, coherence, systematic structure, and metatheoretical rigor. Validity is tested. The theory has indirect utility for organizational design.

\section{Conclusion}

The book contains many fecund elements. It has become one of the most cited set of ideas on organization theory and a connerstone of further research, drawing on a rigorous methodology. An early Williamson contributed a chapter to the book with a young shoot of transaction costs economics, while the concept of learning was introduced as an organizational determinant. Simon is an important predecessor with his concept of bounded rationality. The authors further draw on Crozier, Blau and Scott, Chandler, and Burns and Stalker.

\subsection{Michel Crozier}

\section{Bibliographical data}

Crozier, M.; The Bureaucratic Phenomenon, Chicago 1964 (translated by the author from Le phénomène bureaucratique: Essai sur les tendances bureaucratiques des systèmes d'organisation modernes et sur leurs relations en France avec le système social et culturel, Paris 1963). 


\section{Contextual points}

Crozier"s (b. 1922) personal background is one of a French student at the Haute Ecole de Commerce who after his study (1949) conducted a research into labor unions in the United States. Only then he realized his affinity to the sociological approach. He is a professor emeritus at the university of Paris-Nanterre and at Harvard University. He retired from working at the C.N.R.S (national center for social studies) and nowadays runs a consultancy. The author places himself in the sociological tradition of Parsons and Merton and connects to March \& Simon, and also to Blau \& Scott. His working in the US enabled him to bridge the gap between two cultures and to be listened to by an Anglo-Saxon audience.

His research focus is on the sociology of organizations, and especially on French bureaucracy. His writings reflect the typical French system of education, holding that already at the bycee students are trained in the writing of philosophical essays (see also Fayol). His approach is contemplative, rather than positivist.

The research leading to the publication was done in the early sixties, when new ideas emerged on the power concept as well as on bureaucracy in relation to organization theory.

In the historical/social environment of the period, the human relation school had lost most of its luster, as predictions from their theories were not corroborated by observation.

\section{Contents and relevance}

Crozier's own ambition goes well beyond the limits of organization theory: he wants to develop a theory of bureaucracy that fits both into a general theory of organization as well as in a general theory of cultural systems (pp. 2 - 7).

The author expresses his preference for the case method in the exploratory phase of social science. He defends his basic position as follows (pp. 4,7,8):

"Ail theory ... originates in a partial and insufficient contact with reality, but this is ... masked in the social sciences because of the seperation between empirical research and theoretical problems."

This basic position implies a clear defense of linking observation and hypothesis in social theory.

Crozier also points out that research in which value-systems and personality-characteristics are observed, the results of which are subjected to statistical tests, only can yield a static image, and are unable to account for the dynamics of organizational action (p. 7). Therefore he prefers a clinical approach. Further he takes a functionalist standpoint:

We do, in fact, maintain that that a functionalist perspective constitutes a necessary phase of all sociological research .. (while in this) .. discipline the majority of .. problems are still at an exploratory stage.

After the description of his research, followed by a mixture of description, analysis and hypothesizing ( . 150), Crozier seeks a firm theoretical basis. He rejects the rationality of 
Taylor ('a man is just a hand') and the ethical human relations approach of Mayo and Roethlisberger ('a man is just a heart'). He is convinced, following Parsons (1960), that the power concept must become central to organization theory. Thereby he will draw on March and Simon (1951).

One of the basic contentions of the author is, that the following findings from interviews are consistent with supposed characteristics of a highly formalized organization (p. 110):

- strict impersonal rules, fixation in roles, and the seniority system weaken the hierarchical line; this preserves the personal independence of workers, but at the same time it blocks the way to solve problems (vicious circles),

- the confinement to certain strata and occupations increases the force of group pressure, which replaces the weakening hierarchical power,

- as a result, human relations become more affective than instrumental,

- change is difficult to initiate and can only be effected by external crises, and usually through outside agents ("authoritarian reformers"),

- new power relationships develop around the trenches of the regulatory system (for instance: personnel dealing with uncertain events -the occurrences that escape regulation- have power, they protect their position by keeping their tricks of the trade a secret and oppose the progress of knowledge that might resolve uncertainty).

On page 80 the author concludes from the research that 'among all occupational categories a subculture exists that is in opposition to the goals of the organization'. Groups demand more autonomy on one hand, but stick to the security of regulations on the other. Abstract principles are stated as a defense while practical behavior may be based on completely different considerations.

By the end of the book, more basic contention can be found (p. 187):

Bureaucratic patterns of action, such as the

impersonality of the rules and the centralization of decision making, have been so stablized that they have become part of the organization"s seff. reinforcing equilibria."

And a most important one, at about the bottom line (p. 194) reads that all the restrictions and limitations that counteract the growth of bureaucracy indicate that vicious circles can be broken. But this action would always have the form of a crisis, usually induced by external forces.

Pertinence lo structure and strategy follows from the central issue of the study, namely that organizational processes are supposed to be driven by power. This means that internal as well as external dymamics (both structure and strategy) are addressed. The implications are indirect, and mostly metatheoretical.

Apparently the size and type of organization referred to is the large, monolithic one. 


\section{Process of knowledge development}

The research consists of two elaborate case studies. The first concerns a clerical organization with 4500 employees. It is a public agency, assigned to the authorization and payment of allowances to one and a half million customers. At the time of study (mid-fifties) the annual. growth rate of the number of clients is 10 percent. The case study is exploratory and a preparation for the second one.

The author gives three distinct connotations of the central concept of bureaucracy (p. 3): the bureaucratic government, the Weberian ideal-type, and what he calls the vulgar sense. His focus will be on the latter, pejorative side of the term, evoking 'the slowness, the ponderousness, the routine, the complication of procedures, and the maladapted responses of "bureaucratic" organizations to the needs which they should satisfy, and the frustrations which their members, clients, or subjects consequently endure.' In this respect he adopts Merton's term "dysfunction'. So while postponing the definition of this subject, he sets limits to its domain.

In the phase of hypothesis the author intentionally avoids a predetermined definition of the term bureaucracy. He first wants to explore the subject, and give a definition afterwards (pp. 2 - 7).

Another important starting point of the research that was mentioned shortly already is the following:

"Our work corresponds, in fact, to an indispensable phase of scientific development, that which could be termed the exploratory phase. ... The elaboration can be effected only by developing systems of hypotheses sill close to the concrete, but going beyond the affirmation of banall interdependencies and appearing sollid and significant enough to be tested in a later phasie.

Hxpotheses are tested throughout the course of such elaboration; but these are descriptive hypotheses which permit only an understanding, and in part a measurement, of the diverse systems of relations. constituting the phenomenon under analysis in the particular case studied. They are directly valid only for the case under investigation and the lessons they fumish do not constilute laws, but only examples. examples of models of systems of relations in action. These examples, however, can teach us more about the functioning of sacial systems of the same order and of even vaster systems than laws which a premature rigor has kept from being adequately comprehensive.

To resolwe upon a clinical approach may seem regressive after certain earlier ambitions of the social siciences. However, this seems to us indispensw for all those problems which touch upon the sociology of institutions and the sociology of action. There are no shortcuts possible. Gerieral statistical relations, which can be perceived the opinion level, are fragmentary and undifferentiated; they can testify to accomplished changles, but not to the process of change, nor to the laws of action, nor even to the general direction of the evolution. Only models of functioning at an operational levell can help us progress. This is what a clinical approach can offer us. In the case under discussion, that of the "bureaucratic" aspects of the functioning of

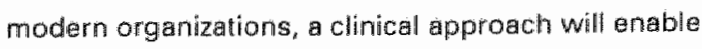
us to insert a greater number of givens into the traditional schema borrowed from Weber, whose ideal type, in our opinion, corresponds to an inadequate description. The clinical approach will, above all, 
enable us to advance from a static fragmentary image to an integrated image of the model, all of whose elements are interdependent.

Finaly, in adopting the clinical approach, we have experimented whith a play of relations between empirical research and theoretical reflection that the reader may find surprising. ... We have sought to bridge this gap lbetween hypothesizing and induced abservationl and to use the confrontetion between the wwo modes of thought as a stimulus for each of them.

Here again we see a clear defense of exploratory research that tries to link preliminary theory to observation. Moreover, Weber is referred to as provider of a conceptual scheme.

The first case study (the "Agency") is based on the foregoing hypotheses. Two lines of inquiry are followed. The purpose of the first is to give a description of the process, the organization, personnel regulations and other characteristics of the work and its crew. Due to the strictly formalistic character of the organization, this was the easy part. Every member of the Agency acknowledged all detaills concerning their place, competence, limits and possibilities, as well of those of colleagues, bosses and subordinates.

The second line of investigation was about work satisfaction (p. 23). From the interviews about work satisfaction Crozier concludes that the workload is high. The growth of the clientele is not met by an adequate increase in capacity, for reasons of parsimony. The work is monotonous and the workers (mostly young women) are subject to nervous tensions. At the time conventional wisdom held these inconveniences to be the consequence of "inhuman technology". But Crozier demonstrates that the real cause lies in the relations between people and groups. The workload itself is high, but can be met. Many of the girls (especially those who have a weak position on the labor market) take pride in mastering the simple work. But opinions about colleagues, superiors and union representatives are negative, and being a "fonctionnaire' (civil servant) is no ground for pride, it is even denied by the lower ranks. There are no friendships between colleagues. Supervisors have no power in this ower-regulated environment, as the complete formalization leaves no room for discretionary competence.

The first case leads to derivation, observation and induction. At this point of the book however, the first of a series of recurrent methodological flaws appears. On pages 17 to 21 not only the formal features of the organization are described (the first line of inquiry), but these are mixed with contentions about causes and effects of this highly formalistic and impersonal system. These contentions are partially grounded, partially speculative, but in either case have no bearing on the observed phenomena. In fact, derivation and induction do not link observation and hypothesis.

The final conclusions from the first case are (p. 50):

- workers and supervisors do not participate in the goal of the organization (hostile feelings, no involvement),

- yet, a satisfactory basis pattern of adjustment exits ('a grumbling way of achieving'),

- people seem extremely isolated, no stable cliques (except for the work team of four),

- no conflicts between groups are allowed, emerging problems are directly settled by higherups. 
From the first case, hypotheses are drawn that are the basis for the second inquiry. The author goes on as follows (p. 51):

"It is still to early to discuss the interrelationships of these four different features of organizational behavior and their meaning for a tentative theory of bureaucratic strains. But we should like, at this stage, to make the first attempt at a synthesis by trying to show how this description may hellp us to understand the patterns of human relationships that lead to the development and the maintenance of routine:

The author can't wait to come to some conclusions. On page 54, as an introduction to the second case study, he states to have obtained now a general descriptive scheme. This would allow for the explanation of a number of administrative practices and behavior patterns usually associated with routinism. According to the author, this routinism would ensue from the social control as described. It should be noted that the hypothesis could equally well have been obtained from general observations of bureaucratic organizations.

What follows is a well-reasoned hypothesis about routinization as a consequence of extreme formalization (p.51):

"In other words, why do people build organizations where impersonal rules and routine will bind individual behavior to such an extent? Why do they build bureaucracies? Anticipating our future analysis, we should like to suggest that they are trying to evade face-to-face relationships and situations of personal dependency whose authoritarian tone they cannot bear."

The second case is about a large state monopoly (the French tobacco industry, p. 58). It consists of 30 comparable manufacturing establishments and is part of the French government. The research is done in two stages. The first is an in-depth study of three plants in the Paris area. The second a more general survey of the 30 plants throughout the country.

Every production plant of the State Monopoly is subject to the same set of detailed regulations. They are subsidiaries of a ministry in Paris, where high-ranked civil servants take all policy decisions. The production divisions are supposed to manufacture the products against minimal cost. As a Parisian fonctionnaire put it: we do the thinking, they do the work.

Every plant has the same organization chart. The top consists of a director (general manager), an assistant director (deputy), a comptroller, and a technical engineer. Production workers (most of them female) are supervised by foremen, who are subordinate to the director and his assistant.

New, improved problem formulation and its constructs follow. Crozier states that 'Because of the special conditions we have just summarized, we shall now be able to investigate new problems whose importance will be seen to be crucial - the problem of power relationships and the problem of individual and group strategy within the organizational system" (p. 58). Three concepts are to be observed, namely work load, mechanization, and seniority rule. The technical engineer directs maintenance workers (men). He and the comptroller are subordinates of the director and his assistant. 
The director and his assistant are polytechniciens, a caste of engineers educated at the famous technological university (one of the grandes écoles of France). The director's low workload allows him to pursue gentlemen's activities outside the work (personal research, lecturing, consultative positions). He is in his fifties, has little power (everything is internally formalized, no external problems exist) and he has no further career prospects. His assistant is much younger and is frequently transferred from one plant to another in order to be trained to become a director. He is doing most of the managerial work. Like all personnel in the line of command his discretional power is futile because of the complete rigidity of the over-ruled system.

The technical engineer has a lower technical education. Therefore, his status in the top is low. However, as the direct supervisor of the maintenance workers he holds an essential position. This can be explained as follows. The single objective of the organization is to realize a set volume of products. The only uncertain factor in the over-regulated system is a machine failure. Such an event endangers the position of the production workers, who are held responsible and risk loss of income, and in severe cases it may jeopardize the reputation of top management. By consequence, maintenance workers have a key position. Only they know how to perform repairs. It is one of the few things for which no rules exist. Quick repair is essential, but no one has any grip on the work of the maintenance workers and the priorities they give. Only their direct boss, the technical engineer, is knowledgeable at this point. He is careful not to reveal his guild's secrets, since these embody his personal power base.

Further inquiry is done by personal interviewing a great number of employees. The workload is fixed by formal, compulsory standards. The question 'can standards easily/difficult/not be met' gets significantly different answers from the workers themselves, their colleagues, the maintenance men, union representatives, and higher management. The order of affirmative answers ('standards are easy to be met") is the same in al» plants. In a typical case, the positive answer is given by $46 \%$ of the workers themselves, $30 \%$ by their colleagues, $57 \%$ by maintenance workers, $67 \%$ by supervisors and $36 \%$ by trade-union delegates. But between factories there is a significant difference. Pessimism about meeting the standards by production workers is higher when expressed by people with a higher seniority, more prestige and deeper roots in the tradition of the organization (family links). Crozier concludes that these respondents show an acquired attitude, and that their answers are related to opinions about other characteristics of the organization, like seniority.

Seniority rule is the second subject of research. As a part of the organizational regulation, the ministry and the unions have agreed on a system of job allocation and promotion that leaves no room for surprise. Discretionary power of the local management is eliminated. So recruitment is based on strict admittance rules for each occupation, and promotion is a matter of seniority only. Shifts of personnel between the different strata or occupational categories are virtually nonexistent.

The principle of seniority is disapproved by $20 \%$ of the production workers, $5 \%$ of union representatives, $33 \%$ of maintenance personnel and $70 \%$ of the supervisors. Acceptance of the seniority principle appears to be concomitant with a negative attitude towards the production 
standards and towards plant modernization. Those who are in favor of the seniority principle reject every departure from the existing situation (p. 67).

In the book, all of these findings are reported in a verbose form, with a mix-up of analysis and new hypothesis (pp. 68 - 79). Necessarily, the results of the research are rendered here in $a$ very condensed form.

Finally, Crozier designates these phenomena as 'quite fixed bureaucratical givens'. It should be noted that at this point he has not even defined the term bureaucracy (p. 80 ).

On page 111 , a summary of the interviews is given. The findings correspond with the observations stated earlier:

- strict impersonal rules, fixation in roles, and the seniority system weaken the hierarchical line; these conditions preserve the personal independence of workers, but at the same time they block the way to solve problems,

- the confinement to certain strata and occupations increases the force of group pressure, which replaces the weakening hierarchical power,

- as a result, human relations become more affective than instrumental,

- change is difificult to initiate and can only be effected through outside agents,

- new power relationships develop around the loopholes of the regulatory system.

Next the problem is reiterated. It is said that the analysis of conflicts in the top and the way people adjust to their situation results in the observations already described before. One type of conflict occurs in almost all of the plants. The technical engineer is member of the management team but at the same time subordinate to the director and his assistant. He has expert power but is not accepted as an equal party by the polytechniciens. A typical statement of the technical engineer about his bosses is 'they are arrogant but they know nothing'. Again, Crozier points to the only unpredictable event in the life of the State Monopoly, namely the breakdown of production facilities.

The dependence on the power of the maintenance branch is absent in other countries.

Therefore, Crozier attributes this phenomenon to the French bureaucratic system. And he repeats his view on the cause (p. 142). Next he tries to project his empirical findings on the power-uncertainty model. He concludes that in dynamic and complex organizations the management will enforce social controls in order to let these be the outcome of internal power struggles. Second, that a dynamic equilibrium is more favorable to change since the pressure to eliminate uncertainty will not be held in check by the resistance of well-entrenched groups ( $\mathrm{p}$. 171).

On page 175 a chapter starts on the bureaucratic system of organization. The paradox of Michels" 'iron law of oligarchy' is introduced, holding that democratic social action is possible only through bureaucratic organization, and bureaucracy is destructive of democratic values. Next, Crozier starts to "re-read his data" in an attempt to show that a bureaucratic system is restricted in its development, and that the evolution toward large-scale organizations is not inescapable provided men can break out of bureaucratic "vicious circles". 
On page 180, an investigation follows of the limitations of bureaucracy with respect to the following aspects:

- the achievement of conformity,

- the basic elements of bureaucratic vicious circles,

- impersonal rules,

- centralization of decisions,

- strata isolation and group pressure, and

- the development of parallel power relations.

On page 187 we get a definition at last, hidden in the verbose text: 'A bureaucratic organization is an organization that cannot correct his behavior by learning from errors".

Assessment following the $\mathrm{A}-\mathrm{F}$ - scherne

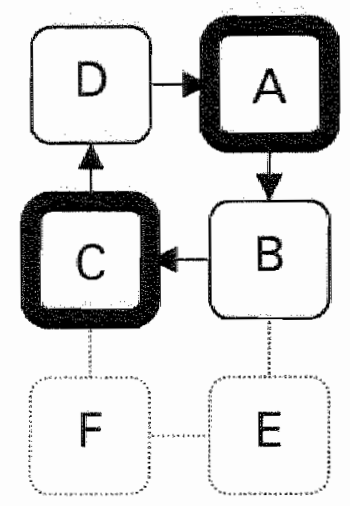

Three cycles

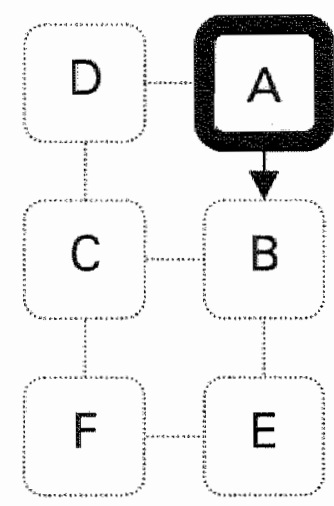

The fourth cycle

Crozier is a conscientious methodologist who does not hesitate to take the reader along his travel through the repeated switching of hypothesis and observation. He frequently oscillates between contemplation and description. In doing so he may repeat himself occasionally. The author runs through the A-B-C-D-loop three times, starting with an exploratory case, then investigating the second case twice.

As a start, a definution (part of hypothesis, A) of bureaucracy is discussed, but not chosen (2 8). The author prefers a clinical approach, in which observation and hypothesizing are intertwined ( $p$. 4, 7,8). A first case study is conducted in two rounds. It ends with findings that are well-formulated hypotheses (A) for further inquiry (pp. 50, 51). But preciseness, and definiteness suffer from too many, too ambiguous terms and concepts.

In the second case study (the third round of research) these hypotheses are tested in interviews, with a positive result (p. 111). The study ends with a set of final hypotheses (pp. 175-180). 
The research has an appropriate systematic structure. Coherence is amply dealt with in the references and discussions of the works of Weber, Blau and Scott, and March and Simon (pp. $3,110,150$ ). Observation (C) and hypothesis (A) are the most elaborated elements of knowledge development. This is in accordance with the clinical approach that has been chosen. The author's research remains in the realm of narration, meaning that derivation (B) and induction (D) are not treated in a way that enables a scientific connection of $\mathrm{C}-\mathrm{A}$, or $\mathrm{A}-\mathrm{C}$. He does not enter the E-F trajectory. This means that definiteness and precision remain sacrificed in favor of unprejudiced observation.

As stated derivation and induction are just touched upon. His critique on Weber (p. 7) would have been better grounded if $\mathrm{B}$ and $\mathrm{D}$ would have been discussed more elaborately and with more precise formulations. It now seems that his approach is akin to the ideal-type method. Metaiheoretical requirements are moderately met in $\mathrm{A}$ and $\mathrm{C}$.

The theory has indirect utility for organizational design.

\section{Conclusion}

One of the fecund elements in his work is the role the author assumes as an advocate of the case-method. The cases, in spite of, or perhaps thanks to, their odor of bureaucratic degeneration, are in fact excellent examples. But at the same time his work reveals the limitations of the method: in the later stages of research more precision, coherence, and definiteness of concepts and models would have enhanced the result of the research. It now tends to remain narration, coming close to the ideal-type approach.

His work has enabled further research on a more specific basis (rigorous definitions, constructs, and models), in order to come to grounded rules of organizational design. Nevertheless, the descriptive power of his work gives an impression of the causes of failure of structures and strategies.

The study is related to earlier work of Weber, Parsons, Merton and March and Simon. In the final chapter of part three Crozier depicts the limits of bureaucratic growth. He describes a number of mechanisms that help us to understand the dynamics of internal organizational behavior.

\subsection{Daniel Katz and Robert Kahn}

Bibliographical data

Katz, D. and R.L. Kahn, The Social Psychology of Organizations, New York 1966. 


\section{Contextual points}

At the time of the study Katz (1903-1998) and Kahn (b. 1918) worked at the Department of Psychology and the Survey Research Center, University of Michigan.

The authors characterize the scientific environment and discipline of the study by saying that they want to bridge the gap between social psychology (not extending its social vision beyond small groups), and sociology (neglecting individual behavior). The open-system approach, borrowed from the physical sciences, is said to be an approved and powerful model for organization ever since: Von Bertalanffy (1956) was the predecessor of this approach who described the general properties of the open system, while the work of Jaques (1951), Lewin (1952), Thompson (1967), and that of Lawrence and Lorsch (1967) is on related ground. Rensis Likert launched the research program they work on in 1947.

\section{Contents and relevance}

In the book a clear basic position is taken. The intent of the research would be to bridge the gap between the psychological and the sociological approach of organization (p. 12):

"Psychologists have been ... unwilling and unable to deal with facts of social organization and social structure. ... The older sociol ogical theories reflect a limitation complementary to the theories of psychology. ... (they) treat the.... collective level without reference to individual characteristics or to the attributes of transactions between individuals. They are concerned with the products of such interaction but not with the process. ... This book proposes that the resolution of such theoretical difficulties can best be achieved by means of agen-system theory:

It is said that the system concept helps to develop knowledge on organization (p. 14):

"Tho social aclentigt whishes to understand human organizations, to describe what is essential in their form, aspects, and functions. He wishes to explain their aycles of growth and decline, or predict their effect and effectiveness. Perhaps he wishes as well to test and apply such knowledge by introducing purposeful changes into organizations:

In this citation one can find descriptive and explanatory hypothesizing (A), as well as testing through observation (C), based on the effects (F) of intervention (E).

The authors criticize the common-sense approach, for two reasons. First, organizations cannot be known by their name alone. There are questions to be answered like: what is an organization, what are its boundaries, what behavior belongs to it and what lies outside it, who are the individuals to be studied, and which part of this behavior is relevant?

Second, they are more than "the epitome of the purposes of its designer, its leaders, or its key members', as in organizations numerous latent functions occur (p. 15).

A better approach is proposed (p. 16): 
"It would be much better theoreticdly, however, to start with the concepts which do not call for identfying the purooses of the desianers and then correcting for them when they do not seem to be futflled. The theoretical concepts stould begh with the insut. outaut, and functioning of the organization as system...

By the end of the book, a metatheoretical conclusion is drawn (p, 452):

In some respects open-system theory is not a theory at all: it does not pretend to the specific sequences of cause and effect, the specific hypotheses and tests of hypotheses which are the basic elements of a theory. Open-systems theory is rather a framework, a metatheory, a model in the broadest sense of that overused term. Open-system theory is an approach and canceptual language for understending and describing many kinds and levels of phenomene. It is used to describe and explain the behavior of living orgenisms and combinations of organisms, but is applicable to any dynamic, recurrent process, any patterned sequence of events."

This conclusion is at the same time the central basic contention of the book. The authors claim that open-system theory offers a vigorous model for describing and understanding organizations. In the model events of social behavior are linked together in a model that resembles physical and biological energy-translorming systems. The organization should not be treated as a closed system, as its transactions with the environment determine its propensity to survive. However, the modell it is not a theory but a meta-theory, a 'model in the broadest sense".

Both structure and strategy are addressed, as they are affected by social-psychological phenomena and the open-systems model. The theory refers to all types and sizes of organizations. The study has an indirect pertinence to design and has a large metarheoretical content.

\section{Process of knowledge development}

As said, the theory proposed is in fact a metatheory (the open systems model) in which previous research of others is embedded. The book is a collection of hypotheses. The following examples of knowledge development are rendered hereafter.

The correspondence of the main variable among physical and organizational system models is discussed (pp. 17 - 18). The authors argue that in physical system analysis energy and energy transformation are the central concepts. In its organizational counterpart this 'energy' is what is transformed in the throughput through the processes maintained by the organization, thereby creating extra value of the output over the input. This is not to be measured only in terms of money, it encompasses all purposes of the business. The authors state that the applicability of this natural-sciences model to the social science, together with its constructs and characteristics, require a detailed examination.

Common characteristics of open systems are hypothesized (pp. 19-25). They are: 
- importation of energy,

- the through-put: work gets done in the system,

- the output: products are exported,

- systems are cycles of events, while the relatedness of parts can be observed ("it is events rather than things which are structured, so that social structure is a dynamic rather than a static concept"),

- negative entropy (the system does not necessarily collapse as long as the input-output balance of energy is positive),

- the information input, the negative feedback and the process of coding,

- the system has a dynamic homeostasis, the system preserves its character,

- differentiation,

- equifinality (the final situation can be reached through different paths).

Some consequences of this view are stated on pages $26-29$ :

- organizations have to adapt to environmental changes,

- concentrating on the internal functioning of the organization may be wrong,

- the organization is not a closed system.

Characteristics of social organizations are defined (p. 69):

- social systems have structure, but it is a structure of events, so functioning is inseparable from structure,

- next to production inputs, maintenance inputs are important,

- social systems are designed for a wide range of objectives, they are not bound to the typical growth curves of natural systems, and they require control mechanisms to assure good functioning:

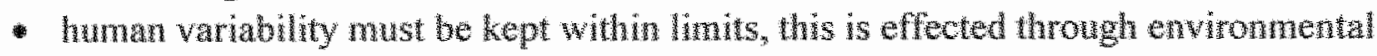
pressures, shared values, and rule enforcement,

- the integration process is complicated by the differen dynamics of the organizational subsystems whike biological or physical ones; sochal systems have no physical boundries.

Hyorheses on the development of organizational structures are advanced (p. 109). It is clamed that the classic models of Taylor, Weber and Guhck do not deal adexaley whth transachions between organization and enviroment. The oper-system theory is sad to be superior to lhese.

Next, thee stages of organizational development are presented. At the first stage a certain population develops a systen of task fulfmment and producton in order to cope with environmental problems. At the second stage a structure of axthority emerges to provide nangement and maintenance. Finaly, wrther development of suppotive structures at the organzational boundaries (procurement, disposal, extemal relations)' takes place. Each of these subsystems (prodwction, maintenance, and adaptive-political action) would develop its own dyamics, such as the economic dynamics for the production function. 
In chapter 5, a typology of organizations is presented (p. 147). "... a typology ... is proposed, based upon genotypic (first-order) and second-order factors". Genotype is said to be based on the four functions described above, but now acting in the societal system as a whole. So there are production firms with production dynamics, schools and churches, with the typical maintenance dynamics, adaptive behavior like research laboratories and universities, and organizations with managerial-political behavior, like the state, or labor unions.

Examples of the second-order characteristics are given as well.

In chapter 6, several components of organizational effectiveness are hypothesized (p. 170), such as efficiency (ratio of energy output to energy input), potential versus actual efficiency, and profit, the latter being strongly related to efficiency.

The concept of role is elaborated on page 197:

"The concept of role is proposed as the major means for linking the individual and organizational levels of research and theory; it is at once the building block of social systems and the summation of the requirements with which such systems confront their members as individuals. Each person in an organization is linked to some set of other members by virtue of the functional requirements of the system which are hevily implemented through the expectations those members have of thim; he is the focal person for that set. An organization can be viewed as consisting of number of such sets, one for each person in the orgarization. The process by which the expectations of members of a role set arelinked to the behavior of the focal person or that set is described in terms of role episodes. The role episode in turm consists of a sequence of events involving members of a role set and the focal person."

Power and authority are discussed in a descriptive way. Next a belief in the virtues of hierarchy is expressed (pp. 221,222). The necessity and means for exerting influence within the organization is stated.

We are led by these analyses to an attitude of great respect for the formal, hierarchical organization. It is an instrument of great effectiveness; it offers gireat economies over unorganized effort; it achieves great unity and compliance."

It should be noted that the authors recognize the virtue of the bureaucratic system, in contrast to a/o Crozier.

On the pages 257 and 258 we find a descriptive discussion of communication, plus one more hyporhesis, reading that '... social systems can be defined as restricted communication networks; unrestricted communication "mply noise and inefficiency.' After a description of certain types and characteristics of communication, "the hypothesis is offered that communication and information subsystems are often located disadvantageously in organizations, both in terms of accessibility to top leaders and in terms of contamination of the information-getting process."

A description of policy formulation and decision making is given in chapter 10 (p. 282). After a general description, March and Simon are cited with their concept of bounded rationality. The authors give a summary on page 298 , stating that 'organizational decision can be 
characterized" by 1) level of generality or abstraction, 2) the amount of organizational space involved, and 3) its duration. These conditions lead to two types of organizational decision, namely goal identification, and strategy formulation. Criteria to be applied in feedback processes, like cost accounting, profitability and growth, must be constructed.

In chapter 11 leadership is discussed, with reference to various sources (p. 334). It is defined as 'any act of influence on a matter of organizational relevance". The need for leadership is said to lie in four facts, namely 1) incompleteness of organizational design, 2) changing external conditions, 3) inter dynamics of the organization, and 4) the "nature of human membership in organizations".

The psychological basis of organizational effectiveness is discussed on page 338 with reference to research by $\mathrm{Katz}$ (1964) and by Likert (1961).

Four motive patterns are proposed as characteristic of the organizations and as capable of producing the required behaviors. These are said to include 'legal compliance, instrumental satisfaction, self-expression, and internalization of organizational goals.'

When discussing organizational change, the authors refer to research of Lewin (1952), Jaques (1951), Trist (1951) and others (p. 449). As a summary seven approaches to organizational change are mentioned, "with their characteristic strengths and weaknesses", namely supply of information, individual counseling and therapy, peer group influence, sensitivity training, group therapy in organizations, feedback, and systemic change.

So far, all reported statements from the book are hypothetical. Although concepts such as input, throughput, output, energy, transformation, exchange, and equifinality are designated, they are not operationalized.

As can be seen from this list of subjects, the authors try to incorporate a great number of concepts and mechanisms relating to organization into a large conceptual system.

Assessment following the A-F-scheme

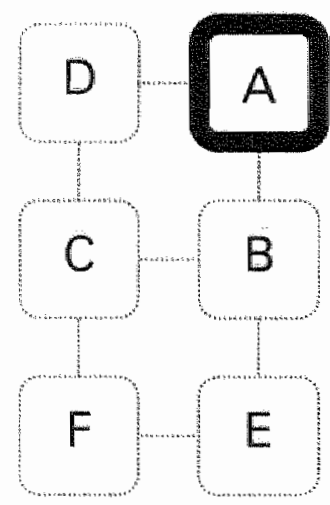

The book is a collection of hypotheses (A), many of them epistemical, like on pages $19-25,69,147,170$. Also concepts are defined (p. 197), with definiteness and precision. Hypotheses directly referring to observables can be found on pages 257,258 , and 282 . The summary on page 298 can be allso considered as a compounded hypothesis. The remainder of the book is a catalogue of selected received theory that demonstrates a considerable degree of coherence.

The work has two distinct parts. One is concerned with the opensystem concept. The other part discusses the social psychology of organizations. No link between the two parts seems to exist, apart from the claim that an organization should not be regarded as a closed system. The social-psychological section partially contains descriptive hypotheses on organization. Some of these refer to research findings of others that are elaborated into grounded hypotheses. 
It must be concluded that the book does not go beyond hypothesis with a large degree of elaboration, while the above mentioned metatheoretical requirements within this box are duly met.

\section{Conclusion}

The book draws on earlier work of Bertalanffy and of predecessors of social psychology as mentioned. The fecundity of this work lies in the open-systems concept and the integration of various theories within it. That way the study has opened new ways to the development of organizational knowledge.

\subsection{Paul R. Lawrence and Jay W. Lorsch}

\section{Bibliographical data}

Lawrence, P.R., \& J.W. Lorsch, Organization and Environment: Managing Differentiation and Integration, Boston 1967.

\section{Contextual points}

Lawrence (b. 1922) is a professor emeritus in Organizational Behavior at the Harvard Business School. Lorsch (b. 1932) is a professor at the same school in the same discipline.

The authors conducted a series of studies together with many collaborators (Allan, Davis, Kotter, Lane, and Morse) into the structure and functioning of organizations using the organization and environment approach (Pugh and Hickson, 1997, p. 50). Important predecessors are Woodward and Burns \& Stalker.

They characterize the scientific and social environment of their period as follows:

'A grroundswell of opinion is developing these days among some applied behavioral scientists and managers that the time is ripe for an infusion of more systematic and scientific tectiniques into the intuitive art the experienced manager practices as he designs and plans complex organizations."

\section{Contents and relevance}

The authors state their basic position, by challenging the claim that there would be 'one best way to organize in all situations' (p. 3):

'Managers must find answers to such questions as: What type of organization will best coordinate our sales effort? How much control and direction should we give our research scientists? ... What can we do to achieve better coordination between sales and plant personnel on delivery schedules? Will changes in our 
This is the problem they want to discuss. In addition, in order to find answers to the problems (p. 5), they opt for parsimony in theory building: "as few (concepts) as you may, as many (concepts) as you must". Shortcomings of existing theory are mentioned (pp. 12, 13). Early authors are said to ignore feelings and emotions connected with the achievement of collaboration, and neglect of interpersonal skills required. Recent contributors would undervalue the inevitability of conflict that is due to differentiation.

The authors" central question of research is whether different environmental conditions call for different characteristics and behavior patterns of the organization. They specify the question in their own words as follows (pp. 14, 16):

1. How are the environmental demands facing various organizations different, and how do environmental demands relate to the internal functioning of effective organizations?

2. Is it true that organizations in certain or stable environments make more exclusive use of the formal hierarchy to achieve integration, and, if so, why? Because less integration is required, or because in a certain environment these decisions can be made more effectively at higher organizational levels or by fewer paople?
$3_{3}$ Is the same degree of differentiation in orientation and in departmental structure found in organizations in different industrial environments?

4. If greater differentiation among functional departments is required in different industries, does this influence the problems of integrating the organization's parts? Does it influence the organizational means of achieving integration?

5.

A comparative research approach in two stages is set up. The authors made a study of competing organizations in each of several industries. "In this way they attempted to learn how the effective organization in a particular industry differed from its less successful competitor, and also to learn how effective organizations performing in different industries differed from one another.

The work was carried out in two distinct, but related, phases. The first was a detailed study of a number of firms operating in one industry. The second phase was a study of a highly effective organization (by conventional economic and commercial standards) and a less effective competitor in each of two other industries' (p. 19).

Research methods are explained (pp. 20, 21):

To gather out information on internal organizational functioning we used both questionnaites and interviews, which were given to beween 30 and 50 upper-level and middle-level managers in each organization... Data on the three industrial environments in which the companies operated were also gathered by means of both interviews and questionnaires. For this purpose, however, information was solicited from only the top executives in each arganization (e.g. the president, division or product 
The relationship between organizational and environmental variables was studied in three industries: plastics ( 6 organizations), containers ( 2 organizations), and food ( 2 organizations) (p. 21). A start was made with the plastics industry. Findings from the research were used to study the other two industries. Then a comparison was made of all 10 organizations and new hypotheses were formulated.

At the end of the book the authors muse about further implications of their findings, but in this process they drift more and more apart from their research base (pp. 221 - 245). Remarks are made on:

- matrix organization,

- educational approaches (learn to apply confrontation to solve conflicts),

- choice of management practices,

- the design of multi-industry and multinational companies,

- implications for growth and change,

- the viable organization of the future, and

- leadership and multi-organizations.

As one more basic contention the authors state that "The] division of labor among departments and the need for unified effort lead to a state of differentiation and integration within any organization.' (p. 8)

Their summarized basic contentions are the following:

- three environmental features (market, state of science, and state of production technology) impose organizational demands on the departments of marketing and sales, research, and production, respectively,

- in order for an organization to be successful, differentiation of the departmental managers (in cognitive and emotional orientation) is indispensable, in order to cope with the uncertainties involved,

- from this mental differentiation a lack of integration will ensue unless integration measures are effectuated,

- the adequacy of internal differentiation and the effectiveness of integrational measures determine the level of performance of the organization.

These contentions lead to a contingency theory of organization.

Design rules for structure follow directly from the theory, as is shown in the following example (p. 213):

'Our research indicates that the clear-cut and formal differentiation of organizational units, when based on significant task arid environmental differences, contributes to good performance. By contrast one common organizational error is to combine two distinctlv different tasks in a single organizational unit. 
Conclusions about strategy can allso be drawn from the findings. The pertinence is direct. The organization addressed in the theory is the not too small industrial company.

\section{Process of knowledge development}

Basic hypothesizing and the formulation of definitions are done in the first chapter. Different orientations on integration are said to lead to differences in 1) particular goals, 2) time frame perception, 3) interpersonal attitudes, and 4), the degree of formality of structure (pp. 9-11). Case companies are plotted in those four dimensions. Definitions of differentiation and integration are given.

On page 12 four types of conflict resolving are identified. They are characterized by 1) hierarchy, 2) assigned integrating agents, 3) control and scheduling procedures, and 4) individual managers outside official channels.

Hereafter the two stages of knowledge development will be discussed one after the other. The first round of research concerns the 6 firms in the plastics industry (pp. 23, 24).

The object of this study are six organizations (parts of larger corporations), firms that produce and sell plastic materials in the form of powder, pellets, and sheets. These materials are used by customers ranging from small firms making toys, to large companies in the automobile industry. Each product is developed for its specific purpose, on the basis of polymer technology. Once a product and its manufacturing process are developed production is semiautomatic with relatively few operating personnel.

About competition and uncertainty it is stated that the dominant competitive issue is the development of new products and processes. Life cycles are short. Relevant scientific knowledge is crucial. But there are a number of uncertainties involved, with questions such as how must clients" requirements be translated into chemical formulae, will our research be successful, what are competitors cloing, etc. (pp. 24, 25).

This brings the authors to a definition of environment, with the unconventional inclusion of the physical machinery of the company itself (p. 27):

"While what we call "environment' is fairly selfevident as applied to research and marketing, the use of this term in relation to production requires some explanation, Contrary to conventional usage, we have chosen to conceive of the plysical machinery, the nonhuman aspect of production, as parit of its environment. Production executives must draw information from this equipment's performance and analyze it im terms of costs, yields, and quality, just as
Whey must also draw information from outside the physical boundaries of the furm about newiy available equipment and alternative processes. It is this information and knowledge from all these sources that we are interested in characterizing as certain or uncertain. Readers who find this awkward may prefer to think in terms of 'the production task' rather than of the "techno-economic envirorment"."

Derivation required the operationalization of performance standards and ranking ( $p p .39-42$ ). As the companies involved were unwilling to disclose financial results performance had to be established indirectly. 
Based on the hypotheses and their operationalization, observation took place (pp. 31 - 36). The four units (fundamental research, applied research, sales, production) were measured on the three dimensions: formality of structure (high / low), interpersonal orientation (relationship or task oriented), and time orientation (short/long). This analysis showed significant differences between the four.

Goal orientation was also measured (p. 37). It appeared that all sales personnel were primarily concerned with customer problems, and that all manufacturing personnel focused on cost reduction. In some cases research was directed at the development of new products, while in the other cases it emphasized short-term concerns like process improvement or cost reduction.

Induction was the next phase of inquiry (p. 42):

'From these interviews, the top managers" subjective appraisals, and the empirical evidence available, we felt iustified in dividing these six organizations into the three broad categories of performance that we have indicated. With this general understanding of how these organizations were succeeding in dealing with the plastics industry environment, we can now examine their internal functioning to learm if their state of differentiation was related to effective performance.

This is a fine example of inducing general traits from ordered observation. The authors conclude that the high performers deviate significantly less frequent than the two other categories. This means that the departments of high performers have the right way to deal with uncertainty (p. 43). More observation follows. The counterpart of differentiation is integration. Each organization requires its own type of integration measure, depending on the degree and type of differentiation among departments (p. 46). All six examined companies had a group of "integrators' as liaison officers between departments. The quality of integration was measured through a questionnaire with a 7-point scale, varying from 'serious problems' to 'full unity is obtained".

High performers combine high differentiation with high-quality integration. This presents a paradox, as is explained in the following citation (p. 53):

"But this finding still leaves us with a curious contradiction. If, as we have found, differentiation and integration work at cross purposes within each organization, how can two organizations achieve high degrees of both? The best approach to explaining this apparent paradox becomes evident if we consider how arganizations might go about achieving both of these: states. If organizations thave groups of highly differentiated managers who are able to work together effectively, these managers must have strong capacities to deal with interdepartmental conflicts. A high degree of differentiation implies that managers
Will view problems differently and that conflicts will inevitably arise about how best to proceed. Effective integration, however, means that these conflicts must be resolved to the approximate satisfaction of all parties and to the general good of the enterprise. This provides an important clue to how two of these organizations met the environmental requirements for high differentiation and high integration. Ihese two organizations differed from the others in the procedures and practices used to reach interdepartmental decisions and to resolve conflict. We now want to explore these differences." 
This result ends the iterative approach of the first stage of research. At the same time it offers ideas on new hypotheses that are the starting point the second stage. Two new research questions follow (p. 54):

1) what factorsis whin the organizational system determine whether managers deal effectively with interdepartmental conflict?', and

2) are these determinants ... more likely to be present in the organizations that erre both highly differentiated and highly integrated than in the other four orgamizations?

... We limited our inquiry to the single most crucial competitive issue of the plastics industry - product and process innovation."

The authors observe that effective integrators have intermediate opinions on significant characteristics between those they must attune (p. 59):

In essence, if the integrators thought and behaved in ways that were not too dissimilar to those of each of the departments with which they had to work, they would be better able to communicate with all these deparments and thus to help solve interdepartmental disagreements. If the integrators adopted points of view and behavioral patterns thet were too similar to those of any one functional department, the others would see them as understanding only the problems of that particular unit and not as responsive to the problems of other units."

Next to the foregoing determinants, 5 others are found to be significant ( $p .80)$. The effectiveness of integrators also would rest on:

- their influence resting on technical competence,

- the perceiving of their rewards in relation to total performance of the organization,

- their influence throughout the organization,

- their influence being centered at the right level,

- their preference for confrontation as a means for conflict resolution.

Based on the findings of this in-depth study of the plastics industry newly induced hypotheses could be formulated (pp. 84, 85). In what follows, the researchers intend 1) to examine differences in differentiation, integration, and conflict resolution in various industrial environments, and, 2) to see if in other industries the same determinants for performance apply.

To this end, next to the six plastics manufacturers four more other are chosen. Two are from the standardized container industry, and two from the packaged food industry. In both instances a high and a low performer are chosen. The authors state (p. 85):

In this second phase of the study, then, we looked for two environments that were different from plastics and also different from each other in at least two of these attributes. One important consideration was to select industries with slower rates of environmental change.
Which might be more typical of present industrial conditions and less typical of future ones. This comparison, we hoped, would teach us something about the organizational impact of increasing rates of technological and market change. We therefore sought 
one industry whose rates of growth and change were very slow, and where innovation was not the major competitive factor. For the second environment we wanted an industry where the rates of growth and change seemed to be moderate. While innovation would still be the major issue, we sought an industry in which the capacity to deal with only one part of the environment would be dominant factor in the organization's success."

This statement embodies an attempt to refine the findings of the first phase. The required differentiation per type of industry is hypothesized on the base of the foregoing research ( $\mathrm{p}$. 95). Departments in the container industry have the same degree of uncertainty, so there is no need for structural and interpersonal differentiation between them. In plastics and food companies differentiation between research and production departments needs to be substantial. In the plastics companies differentiation between sales and research must be substantial as well, like in food between sales and production.

Contrary to expectation management in all three industries gave the same appraisal of the required intensity of integration. However, the level where integration is dealt with is low in plastics and food (near to the available knowledge), while in containers top management takes care of integration (p.96). As expected, the more difference in certainty, the more differentiation was observed between pairs of departments of high performers, in other words 'the high-performing organizations had units whose members' ways of thinking and organizational practices were consistent with the demands of their particular part of their environment." This was not the case for the low performers (p. 104).

A mext phase of induction is attained (p. 108):

"The findings reported in this chapter, suggest that the states of differentiation and integration in effective organizations will differ, depending on the demands of the particular environment. In a more diverse and dynamic field, such as the plastics industry, effective organizations have to be highly differentiated and highly integrated. In a more stable and less diverse environment, like the container industry, effective organizations have to be less differentiated, but they must still achieve a high degree of integration.

From these findings we begin to get a partial answer to our basic research question of what organizational characteristics fit different environmental conditions. These differences in states of differentiation and integration are, however, only-part of the answer, because these two states are antagonistic.

..the devices and practices used to resolve conflict and achieve integration might differ among the organizations in these three enviconments. The way these methods and practices varied among these organizations throws further light on our central research question. It is to these differences that we now turn.'

Next, conflict resolution in the container firms is examined (pp. 110-117). Three hypothesized determinants of effective conflict resolution were measured:

1) the relative influence in the process of the various departments,

2) the total influence of all members of the organization,

3) the management level most influential in conflict resolution. 
It appeared that in the high-performing organization influence was more concentrated at top level, while the influence of 'everybody' was less. One production manager of the low performer commented: "It doesn't work with so many cooks in the stew.'

A fourth factor induced was that top management of the high performer was considered to be highly knowledgeable and competent, as appeared from 'unsolicited comments in interview after interview' (p. 119). A fifth factor was the mode of conflict resolution: the high performer more often resolved conflict through confrontation. The authors conclude as follows (p. 122):

From the foregoing comparison we can understand how the high-performing organization was able to achieve better integration (aithough the same state of differentiation) than its less effective competitor. The more successful company, had a better balance of influence between its sales and production units than the low performer. The pattern of thiererchical influence in the high-performing organization was allso more consistent with the environmental demands than that in the low performer. Executives at the rop of the high performing organization had both the influence and the knowledge necessary to resolve conflicts, which was not the case in the low performer. We also found that the influence of the top managers in the highperforming organization was at least partially derived from their expertise and knowledge. While to some extent this may have been true in the case of the upper-level managers, in the low-performing organization it clearly was not true for the members of the integrating unit. As a result of their lack of influence and incomplete knowledge, these integrators were not effective in helping to resolve interdepartmental conflict. This suggests that in a stable environment when there is little differentiation among departments, special integrating units are not only redundant, but may actually add confusion. Finally, we found that in the high-performing organization managers were relying more on confrontation and problem-solving behavior as a way of handling conflict than were the managers in the other organization."

It must be noted that these far-reaching conclusions are not in balance with the minute empirical base, consisting of the comparison of only two companies.

Finally, the research into food firms is reported (p. 124). Here, methods of conflict resolution are:

- personal integrators (effect on performance is not reported),

- dominance of influence of marketing and research over production (more typical in high performer),

- total influence of all members (higher in high performer),

- distribution of influence over levels (the more equal, the better performance),

- mode of conflict resolution (preference of confrontation goes together with low performance).

Conclusions are given on page 131. Again, it should be kept in mind that in containers and in food only two organizations were examined, a 'good' and a 'bad' one.

"With more effective methods for dealing with conflict, the highwperforming organizations tended to achieve the required states of differentiation and integration to a greater degree than their less effective competitors and the evidence indicated that this contributed to higher performance. This finding suggests an answer 
to the major question of this study - What kinds of organizations are most effective under different environmental conditions? To be effective, an organization must approach its environmentally requilired states of differentiation and integration. To achieve these states, it has to meet most of the determinants of effective conflict resolution, so that the managers in the organization can effectively settle the differences that result from their specialized points of view."

All findings so far are summarized systematically in a table on page 138. Based on all findings so far, a contingency theory of organizations is formulated ( $\mathrm{p} .156)$ :

"From this comparison we have seen that it is possible to understand the differences in the internal states and processes of these three effective organizations on the basis of the differences in their external environments. This, along with the comparison between the high performers and the other organizations in each erivironment, has provided us with some important leads as to what characteristics oraanizations must have in order to cope effectively with different envilronmental demandis.. These findings suggest a contingency theary of organization which recognizes their systemic nature. The basic assumption underlying such a theory, which the findings of this study strongly support, is that organizational variables are im a complex interrelationship with one another and with conditions in the environment.

In this study we have found an important relationsihip among external variables the certainty and diversily of the environment, and the strategic environmental issulel, internal states of differentiation and integration. and the procass of conflict resolution. If an organization"s internal states and processes are consistent with external demands, the findings of this study suggest that it will be effective in dealing with its environment. ... our findings have also indicated that the states of differentiation and integration are inversely related. ... The more diverse the environment, and the more differentiated the organization, the more elaborate the integrating devices. The process of conflict resolution in the effective organization is also related to these organizational and environmental variables. The locus of influence to resolve conflict is at a level where the required knowledge about the environment is available. The more unpredictable and uncertein the parts of the enwironment, the lower in the organizational hierarchy this tends to be.... This contingency theory of organizations suggests the major relationships that managers should thirk about as they design and plan organizations to deal with specific environmental conditions. It clearly indicates that managers can no longer be concerned about the one best way to organize.... We shall now examine in mare detail the implications of these findings, not only for the desian and planning of organizations, but also for gaining a clearer perspective on current organizational theory."

So the authors now expand their theory by drawing on other existing sources of knowledge. In chapter 7 (p. 159) 'classical' and 'human relations' theory are elaborated. In chapter 8 ( $p .185$ ) they point at the flood of studies on human behavior in organizations, too much to be covered in digests and reviews. A better theory that synthesizes the diverse findings is asked for, but "this present chapter cannot fill this need, but we hope to make a contribution ...' The authors refer to different themes of theoretical predecessors, like those addressing environment and task (Chandler, 1962), conflict resolution, and individual predispositions (Vroom, 1960). 
The authors" formulation of a contingency theory has the form of as a set of design rules ( $\mathrm{p}$. 209):

1. establish for each department: 'what business are we in?'

2. examine the attributes of the chosen environment,

3. establish the obviously important personal predispositions of personnel,

4. test the fit of internal attributes, like structure and orientation, with 2 and 3.

The goodness of this fit is a determinant for success.

The building of a complex, multi-unit organization requires an effective integrating unit and good conflict resolution practices. This would lead to a good overall performance.

The theory is said to be a model, but its elements are measurable and can be put into action ( $\mathrm{p}$. 210). It is interesting to read the authors' position on knowledge development:

'The resulting model does simplify the complex reallities of modern organizations, as any model should, but it lends itself to further elaboration as needed. Each variable has been conceptualized and operationalized. at least cruclely, for measurement, From our study and those discussed above we have derived some knowledge about the relationship aimong these variables. More research can and must be done on all aspects of the modell. ... it does reflect the findings of a number of modern arganizational studies. It clearly points the way to a more sophisticated model that will not only reduce the confusion in organization theory. but will also have considerable implications for the design and management of complex organizations. If such a model, as it evolves and improves, comes into any generall usage, it will have impact beyond the boundaries of the specific organizations where it is applied.'

\section{Assessment following the $\mathrm{A}-\mathrm{F}-$ scheme}
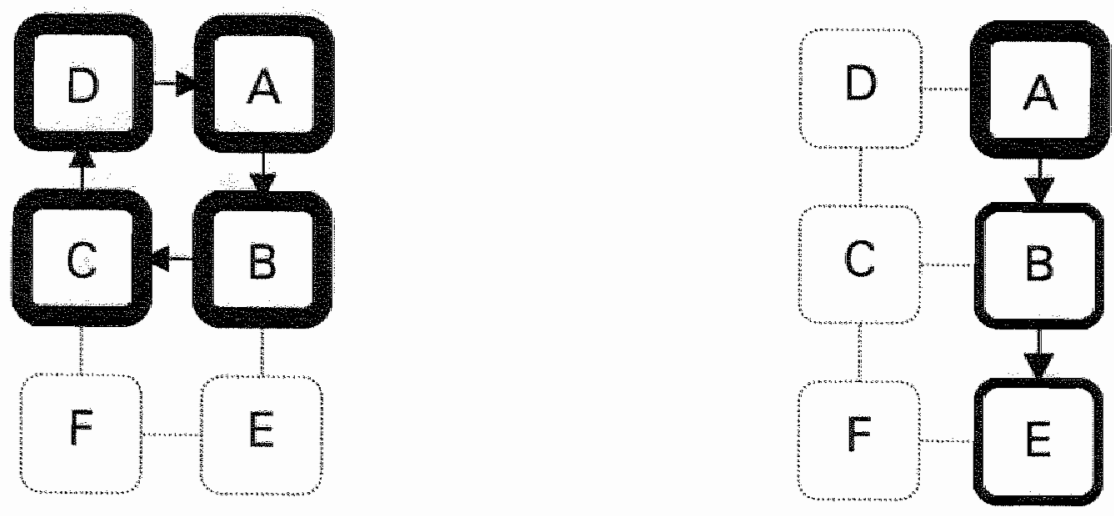

First stages of research

Final stage of research

Hypothesis (A) is exposed in the formulation of problems (pp. 14, 16) and definitions (pp. 9 $11,12,27$ ), which meet requirements of definiteness and precision. Derivation (B) is present 
in the plotting of companies (p. 12, a predictive model). The first stage of the research is an orientation, starting with operationalization (pp. $39-42$ ). In connection, observation (C) is reported (pp. $31-37$ ), followed by induction (p. 42). The orientation ends with a new research question (p. 53), the start of further inquiry. New hypotheses are formulated (pp. 54, 84, 85). In the next stage the cycle is run through again, with ever more precise elements of knowledge development (examples are hypothesizing, pp. 104, 110-117, and induction, p. 108). Based on all findings so far, a contingency theory of organizations is formulated (p. 156). Finally, in combination with other theory, design rules are rendered (p. 209).

The first rounds of knowledge development encompass the complete cycle of largely' elaborated hypothesis (A), derivation (B), observation (C), and induction (D). The final round elaborates moderately upon derivation and prescription. Coherence is demonstrated on page 9. Metatheoretical requirements are duly met, due to the systematic stmucture of the theory. This is a theory that has been developed in a most elaborate way, with strict adherence to metatheoretical requirements, including validation. Furthermore it is useful for organizational design.

\section{Conclusion}

Relation to earlier theory follows from the authors' reference to predecessors, like Fayol, Gulick, Mooney, and Urwick (p. 9). Two earlier studies in the field of contingency research are those of Joan Woodward (1958) and Burns and Stalker (1961, p. 15). These 'suggested that the certainty of information and knowledge about events in the environment was one external dimension that impacted on the organizational variables in which we were interested." The study involves many fecund elements. The book has triggered a host of subsequent research in the 'organization and environment' field. Moreover its research approach was an example for later students of organization. It is one of the most cited books in organization theory.

\subsection{James D. Thompson}

\section{Bibliographical data}

Thompson, J.D., Organizations in Action: Social Science Bases of Administrative Theory, New York 1967.

\section{Contextual points}

Thompson (1920 - 1973) was a sociologist, who did research work at business schools. From the following citation the scientific environment of the research becomes clear ( $\mathrm{p}$. 10): 
$\therefore$ We witl conceive of complex organizations aps open systems, hence indeterminate and faced with uncertainty, but at the same time as subject to ciriterif of rationality and thence determinatedness and certainty:

Apparently the author will try to reconcile the conflicting factors of certainty and uncertainty. Much of preceding theory, like the work of Simon, Crozier, and Cyert and March, as well as the concept of open systems was integrated in his work. Thompson tried to put these together in a large framework of propositions. The author describes the historical/sacietal environment of the study as follows (p. 162):

Modern societies must ... struggle with questions of developing and allocating human capacities for the adrinistration of complex organizations."

\section{Contents and relevance}

The author makes clear assertions about his basic position and about the intent of the research. He argues that recent research into complex organizations reveals common elements, "but more importantly suggests [new] ways of conceiving of variables... these tend to go unnoticed' as there is conversation with disciplines, 'while organizations are multidisciplinary phenomena.' ( $\mathrm{p}$. wii). The central purpose of the book is said to be the identification of 'a framework which may link at important points several of the now important approaches to the understanding of complex organizations.... a broad if still shallow field' (p. viii). The author sets limits to the domain of the study (p. viii):

1. only "instrumental organizations which induce or coerce participation" are discussed (no voluntary organizations will be discussed, such as religious or ideological associations),

2. only concepts and ideas of theories are used, not there ultimate origins, meaning that "schools in caricature" (p. 5) are referred to,

3. only fruitful concepts from theories are used,

4. some of these will be extended or modified for the purpose of the study.

Another important basic position of the author is about causes and effects (p. 85). Four instances are discussed. Causes leading to the desired outcomes may be known, assumed, or unnoticed. People's belief about their knowing of these cause/effect relations may be complete or incomplete. Now four combinations ensue.

Thompson's study has an eclectic character. The focus of research will shift (p. ix). First the behavior of organizations will be studied, so organizations will be considered as 'actors'. In Part 1 this 'shorthand convention' will be used, while in Part 2 the fact will be discussed that the organization can only act as the result of action of members.

The basic meta-hypothesis of Part 1 will be that organizations must be rational in order to produce results but that uncertainty challenges this rationality. Uncertainty follows mainly from specific technologies and environmental conditions, so organizations with similarities in 
both characteristics should exhibit the same kind of behavior. This leads to the basic contention that 'patterned variations in problems posed by technologies and environments should result in systematic differences in organizational action.' (p. 1)

The author borrows certain essentials from closed-system theories in a rough form

("caricatures", 5), namely scientific management, administrative management, and, finally the principles of bureaucracy. He states that variables unknown or neglected in closed-system theory, like unpredictable behavior or informal norms, lead to the image of the organization as a spontaneously developing entity. A better model would look at the organization as interacting with its partly unpredictable environment. Both ideas entail a vision of the organization as an instrument of adaptation and survival (p. 6).

The work is focused entirely on structure. It pertains mainly to the large, bureaucratic commercial organization. Although the work has a strong metatheoretical content, its rules can be directly used for the design of structure.

\section{Process of knowledge development}

Examples of hypothesis are the following. It is said that the technical level will try to consider itself as a closed system, while the institutional level has to acknowledge its open-system orientation. The managerial level has to function as intermediary between those two (p. 12). Other tenets are about rationality in technology-based organizations (pp. 14-18). Technical rationality would have two components: effectivity and efficiency. Differences in organizations in which technology is dominant will reflect their specific technological requirements. Three varieties of technologies are distinguished: the long-linked type (the mass production assembly line), the mediating type (such as banks), and the intensive technology, wherein a range of specialized, customized interventions are carried out on the objects, upon necessity (the repair shop, or the general hospital). In these three types environmental factors can be 'sealed off' in a decreasing order as technical perfection dictates what must be done. Propositions about ways to neutralize remaining outside influences are made on pages $19-24$ :

1. buffering (stocks of materials and finished products),

2. smoothing input and output transactions (filling 'troughs' with 'peaks', for example by using pricing policies),

3. anticipation and adaptation with regard to environmental fluctuations (forecasting),

4. rationing (meaning that not all demand is automatically accepted).

Next, definitions and assertions concerning the domain of action are proposed (pp. 25-26). Technologies used by a company always require the input of other companies and the transfer of outputs to third parties. The same inputs or outputs may be used by, or bought from others (dispersed) or they may be concentrated toward one buyer or seller. This delimits the domain of action. The term task environment is limited to the domain that is "relevant to goal setting and its attainment' (p. 27). This has to so with customers, suppliers, competitors, and regulators. It is argued that domains only exist insofar the organization and its surrounding actors share expectations about the limits of each other"s role (pp. 28 - 37). 
Other propositions concern power and dependency of organizations in view of their task environment (p. 38). In order to maximize rationality, organizations would seek power and minimize dependency over other parties. They do so by maintaining alternatives, and by seeking prestige. If alternatives are absent, power is sought by contracting, co-opting (collusion), or coalescing (joint ventures).

Hypothesizing about organizational design, the author states that in order to maximize rationality, organizations try to incorporate those activities, which would be crucial contingencies if left to the environment. For long-link technologies this is realized by vertical integration, for mediating technologies it means enlarging their clientele, and for intensive technologies it ensues from 'incorporating the object worked on'. So patients must stay in the hospital during crucial treatments, and students are part of the university system, not mere 'customers' (pp. $39-43$ ).

This evokes the problem of balancing the capacity (p. 44). Enlarging domains as described above, especially in diversified companies, would lead to imbalances of capacity in various operating units. On its turn it would lead to growth attempts until 'the least-reducible component is fully occupied', and to the enlargement of the domain by diversification. Limitations to such growth may be set by legislation.

An important hypothesis is induced by the 'disaster example'. When a disaster strikes, a 'synthetic' organization will manage rescue, while the distribution of relieve resources emerges spontaneously. This is effective (the job is done), but not efficient, because "the synthetic organization must simultaneously establish its structure and carry on operations.... Our basic assumption is that structure is a fundamental vehicle by which organizations achieve bounded rationality." (p. 51)

Interdependence would have three varieties (p. 54):

1. pooled: if one part fails, all are jeopardized by the consequences,

2. sequential: one part relies for inputs on outputs of another part (not symmetrical),

3. reciprocal: several parts cannot function well if one of the others don't.

In this order coordination will be nore difficult, as higher costs will be involved.

On page 64 a recapitulation of a first round of hypothesizing is given. Three types of interdependence stemming from technological requirements within organizations would exist, each with its appropriate method of coordination. Structure is meant to facilitate the exercise of the appropriate coordinating processes. Organizations group positions to minimize coordination costs, first by combining reciprocally interdependent positions, then sequentially interdependent ones, and finally grouping positions homogeneously to facilitate standardization. Because first groupings do not entirely handle interdependence, organizations link the groups involved into higher-order groups, thus introducing hierarchy. Organizations assign remaining problems of coordination to committees or to task forces or project teams. More hypothesis follows in chapter 7 , with the identification of the variables involved in the assessment of organization (p. 84). Desirability is said to be determined by culture and has always many dimensions (wealth, health). Choices have to be made, and at times or in different situations the outcome may vary. As a result goal getting will be between 'crystallized' and 'ambiguous'. When people believe they know about all cause/effect relations 
they will apply efficiency tests; but when technical knowledge fails or standards of desirability are ambiguous, they will fall back on effectiveness measures. In the most ambiguous case reference groups will be used to assess the outcomes (p. 87).

In the second part of the book the influence of human behavior must be added to the concept of the acting organization (p. 99). Two questions arise, namely, how do individuals contribute to the uncertainty to which organizations are exposed, and, how do individuals make decisions if, after accounting for all constraints, choices are left? The latter question regards the problem of discretion.

A discussion of the effects of human behavior on the organization follows (pp. 101-131). Next, discretionary decisions ensue (pp. 132 - 143):

'Although the pyramid headed by an all-powerful individual has been a symbol of organizations, such omnipotence is possible only in simple situations where perfected technologies and bland task environments make computational decision processes feasible.

The view challenges the unquestioned acceptance of the hierarchical pyramid. In more complex cases judgment prevails and control would be vested in a dominant coalition. Conflicts may arise if outside forces are numerous and divergent, and where many different professions occupy the dominant coalition.

Chapter 11 is a discussion about the administrative process, the conclusions of which are summarized in the following citation (pp. $144-158$ ):

"The besic function of administration appears to be coalignment, not merely of people (in coralitions) but of institutionalized action - of technology and task environment into a viable domain, and of organizational design and structure appropriate to it. Administration, when it works well, keeps the prganization at the nexus of the several negessary streams of action."

More hypotheses are summarized on pages 159 and 160. 'Uncertainty appears as the fundamental problem for complex organizations, and coping with uncertainty, as the essence of the administrative process."

Finally, variable aspects of organizations in action are discussed (p. 161):

"The fact that we expect all organizations to seek the same state - self-control - does not mean that we expect all of them to attain it in the same wax, with identical design, structures, or behavior. It is essential that we find universals; but equally essential to find patterns in variations.

At warious points, therefore, we have asserted that the desigm, structure, or behavior of organizations will vary systematically with differences in technologies. If our understanding of organizations is to grow we must compare organizations with different technologieg. But to do 50 we must Larn lo categorize technologies with some precision. The old categories of business. medical, educational or governmental organizations simply are inadequate for the development of theory. In a variety of ways we have also assertsd that the design, structure, and behavior of organizations will reflect wariations in task environments: and if that is true we must learn to make sustematic comparisons of organizations in terms of their task environments. To 
This is a clear instance of preparation to derivation. It is only a preliminary step that says how derivation should be done. However, it seems strong enough in itself as a basis for design rules.

Other rules are embodied in a recapitulation of organizational rationality and structure. These show some generic descriptions from which rules for the design of structure entail (p. 81). They read that "... adjustment to constraints and contingencies not controlled by the organization is the crucial problem for boundary-spanning components.' To exercise bounded rationality segments facing the same type of environmental problems are clustered. For units that only need combined scheduling, hierarchy is created, while those that are mutually interdependent are clustered into self-sufficient units (decentralization). Finally there would be unique incidental tasks executed by task forces of specialists. These are put together in homogeneous groups ("for housekeeping reasons").

Thompson has more remarks to make on operationalization (p. 163):

'Unless questions are asked about technologies and task environments, concepts adequate for the analysis of these dimensions are not likely to be developed or refined. But without refinement of the rather crude concepts we have been using, we are not going to get very far in testing hypotheses or in asking more sophisticated questions. Both theoretical development and empirical inwastigation hinge on the adecuacy of conceots. The propositions offered in this volume have been stated in the form whlch allows them to be negated if incorrect; when certain enpirical conditions are fownd, we sey, certein other empirical things will also be found. Testable form is not enough, however. We must have operations which will enable us to say that in fact the specified conditions do or do not exist. Here again, operationalization must proceed hand in hand with conceptual refinement.

Hopefully our propositions seem plausible and important, but it is unlikely that many will be treated as hypotheses for extensive testing, for in the process of the necessary conceptual refinement, more specificand subtle hypotheses will be generated. Our hope and intention has not been to state eternal truths but to focus theoretical and empiricall attention on organizational action by stating as forcefully as possible the need to study organizations in toto and, for that purpose, the significance of the open-system approach and the certainty/uncertainty dimension.'

\section{Assessment following the $A-F-$ scheme}

Core elements in the book are uncertainty, contingency, the open-systems model, bounded rationality, satisfycing behavior, efficiency, effectiveness, and dominant coalitions. Combining a number of existing theories, a large set of propositions is meticulously formulated. As the author indicates himself, they are yet to be operationalized. The approach is systematic and design-oriented. This means that the hypothesis phase (A) is elaborated on to a high degree in conjecturing (pp. 12,14,18,19-24,28-37,38,44,51,132,144-161), and in definitions (pp. 25, 26, 27, 54, 64, 84, 87, 99), meaning that requirements of definiteness and precision are 


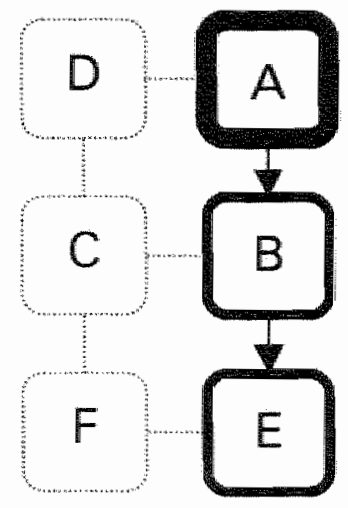

duly met. A step into derivation $(B)$ is made on page 163 where operationalization is discussed. Box $\mathrm{E}$ (prescription) can be found in the first part of theorizing (p. 81).

Although the author indicates that more precise derivation is yet to be done, its degree of elaboration in the study goes well beyond a simple description. The same goes for prescription, which is specific enough to be useful in the design of structure. In summary, the theory is to be considered as having a systematic structure. As will be clear from the foregoing, metatheoretical requirements are met within the boxes concerned. As a total system of knowledge development however it lacks the connection with observation and, hence, the possibility of validation.

\section{Conclusion}

The theory holds useful rules for the design of organizational structure, based on an eclectical set of existing theories, logically derived into prescriptions. Thompson uses the views of predecessors as building blocks, sometimes with subtle difference (p. 5). Simon (1957) stressed the elusiveness of rationality while Crozier (1964) made clear that bureaucracy was a means to cope with external uncertainty. Cyert and March (1963), and March and Simon (1993) elaborated a new vision that captures both, seemingly contradictory, models, stating that organizations both search and learn, as well as decide; they face complexity and uncertainty and cope by seeking satisfycing, not maximizing, strategies ( $p$. 9). Further the author draws on Parsons' three levels of control and on rules for departmentalization come from Gulick and Urwick (1937). Fecund elements are a large body of recommendations for further research that conclude the book. Most important among these are the author"s remarks on future operationalization as cited above (p. 163).

\subsection{Oliver E. Williamson}

\section{Bibliographical data}

Williamson, O.E., Markets and Hierarchies, New York 1975 (pbk. edition 1983).

\section{Contextual points}

Williamson (b. 1932) began his career as an economist, working as a project engineer for the American government. Later he took degrees at Stanford and at Camegie-Mellon (Ph.D.). He is now professor of Business, Economics, and Law at the University of California, Berkeley. 
His current research topics are the new science of organization, bureaucracy, and transaction cost politics.

The scientific environment, discipline, and school of this work can be characterized as part of the transaction costs economics, applied to institutional forms. Williamson is an economist rejecting the frictionless model, which is based on the assumption that participants in economic transaction are rational actors that are completely informed on relevant factors. At the time of the study, new explanations were sought for firm and market structures.

\section{Contents and relevance}

The author advances a number of basic propositions. Essential elements are his juxtaposition of markets versus hierarchies. He dismisses the view of frictionless transactions; instead he stresses the importance of transaction costs. Two of his other postulates are bounded rationality, and what he describes as 'human nature as we know it'. Originally the study was focused on the field of industrial economics, but he expanded his view to organization theory (ix in the 1983 edition):

"I am gratified, however, that organization theorists have recognized that the book deals with a number of issues relevant to them. This is because Markets and
Hierarchies makes contact with human nature as we knowit.

The citation demonstrates that the author's view on human nature is an important element of his theory on organization. This point will be discussed later in more detail.

In Williamson"s work metatheory and theory itself are difficult to distinguish. The following elements can be considered to be his basic contentions:

- the transaction is the ultimate unit of economic analysis (borrowed from Commons, 1934),

- received microeconomic theory fails to explain market faillures,

- bounded rationality and opportunism ('guile') are important determinants of economic behavior,

- market failure is caused by bounded rationality, together with the coincidence of uncertainty and of transactions that occur once or sporadic,

- organizations exist in order to minimize transaction cost,

- in case of market failure internal organization solves the problems caused by bounded rationality (by specializing), as well as those caused by opportunism and sporadic transactions (by managerial control), by uncertainty (by coordinating contingencies), and those caused by information impactedness (by internal auditing),

- people in an organization are less calculative to one another than to outsiders ("atmosphere").

The typical tenet about 'human nature as we know it" is important enough to be cited in full ( $p$. 255): 
"The assumption that individuals behave in a selfinterested way is so commonplace to economics that it would seem scarcely to warrant separate attention.

Qpportunism, however, is more tham simple self: interest seeking. it is self-interest seeking with guile: rgents who are skilled at dissembling realize tranisactional advantages. Economic man, assessed with respect to his transactional characteristics, is thus a more subtle and devious creature than the usual selfinterest seeking assumption reweals.

Opportunism can involve either data distartion or the making of self-disbelleved promises. Data distortion is possible, of course, only if an information impactedness condition obtains. Symmetrically. information impactedness by itself would pose no transactional problem if individuals could be relied on candidly to reveal the information to which they heve selective (low cost) access. It is the proclivity of individuals to distort to their advantage the data to which the have preferred access which poses the contractual problem. Ceteris paribus, forms of organization which serve to check these distortion tendencies, possibly by reducing the information disparities between the parties through auditing, will be favored. Internal organization may obtain for this reason."

Apparently man is reduced here more drastically than, for instance, in Taylor's alleged-and much loathed-view that "man is just a hand".

Pertimence to structure and strategy follows from the author's deduction of different organizational structures, each type of which is depending on specific situations. $\mathrm{He}$ distinguishes the U-form (unitary), the H-form (holding company), the multidivisional or Mform, and the mixed or X-form. Strategy is addressed in that his approach touches upon the problem of outsourcing wersus in-house production. "The theory has direct implication on structure, but indirect on strategy. It theory refers to all kinds and sizes of organization.

\section{Process of knowledge development}

The author"s metatheoretical defense of transaction costs economics goes as follows (pp. 248, 249):

"The foregoing treatment of market.s, hierarchies, ... is more microanalytic than previous economic studies of these matters. ... The organizational failures approach to economic organization emphasizes that it is transactions rather than technology that mainly determine the efficacy of exchange by one mode organization as compared with another. Were it that complex, contingent claims comtracts could be written. negotiated, and enforced at low cost or that incomplete or shortherm contracts did not pose hazards, market medioted exchange among relatively small and specialized autonomous traders would he pervasive.
The shift of transactions from autonomous market contracting to hierarchy is principally explained by the transactional economies that attend such assignments. First, the parties to the exchanges in question are assumed to be engaged in cecurrent contracting. Ono time or occasional exchanges are not matters for which the organizational fallures framework is especially gemane. Second, the choice between market and hierarchy needs to he addressed in terms of particular types of markets and particular internal organizing modes." 
Shortcomings of received microtheory are explained. This model is said to be too abstract to represent the real behavior of firms (p. 250):

First, it is assumed that the firm operates on its production function, which shows the niaximum output of product that can be realized from each feasible combination of factor inputs (mainly labor and capitall. Failure to operate on the production function would imply wasteful use of inputs; this is assumed away. Second, given factor prices, it is assumed that the firm chooses the least-zost factor combinations for each possible level of output. The total cost curve, from which average and margina cost curves are derived, is constructed in this way. ... That many interesting problems of firms and markets are suppressed or bypassed by reducing the firm to a production function to which a profit maximization obiective hals been assigned should come, perhaps, as no surorise:"

Next shortcomings of the structure - conduct - performance paradigm are exposed. Its main flaw is said to be that the already too abstract model is applied to the industry as a whole. This is contradictory to the fact that only individual firms can act (p. 251):

The industrial organization tradition that has developed around the structure - conduct performance paradigm employs the received microtheory model of the firm as a building block, but the principal unit of analysis is the industry. The influence of market structure and of interfirm conduct on economic performance occupies the center stage. The resulting study off firm and market activities is even less microanalytic than are the models of received microtheory referred to above. However useful this approach has been for many purposes, it is necessarily limited in others.'

Finally, shortcomings of the property rights tradition are discussed. The Coase theorem if bargaining costs can be neglected, allocative efficiency will ensue, whatever the assignment of property rights" may be trivial, but in many instances bargaining costs (transaction costs) are said to be substantial (p. 252):

My analysis differs in that transaction costs are expressiv traced to the human and environmental factors that appear in the organizational failures framework."

A summary of the distinctive features of markets and hierarchies follows (pp. 252, 253):

\begin{abstract}
"The principal features of the markets and hierarchies analysis developed in this book are:

1. It makes evident what it is transactions rather than technology thet undertie the interesting issues of umicrosconomic organization.
\end{abstract}

2. A comparative institutional attitude is maintained: markets and hierarchies are regarded as alternative contracting modes.
3. It makes explicit provision for rudimentary attributes of human nature (bounded rationality and opportunism/ and relates these to a sel of environmental factors /complexity/uncertainty and small numbers) in the context of an organizational fablures framework.

4. It is much more microanalytic than previous treatments, focusing as it does on the transactional details of recurrent contracting under altermative 
modes of organization. Reducing, as it does, to a study of contracting means that the contracting expertise of lawyers developed in other contexts can be drawn upon.

5. However useful the fiction of frictionless is for some purposes, it is an impediment to the study of the efficiency properties of alternative modes of economic organization. The frictionless fiction is accordingly abandoned.

6. Organization form, which is concerned with the decomposition principles of hierarchy, is introduced as an intermal organizational counterpart to the familiar market structure measures of industrial orgamization.

7. New questions or a different slant on old questions is afforded across a wide range of issues . including peer growp organization, the employment relation, vertical integration, conglomerate organization, technological progress, dominant firms, and oligopoly.

8. The appraach is comparatively value -free - it is biased neither for nor against unfettered market modes of organizalion.

9. Supplying a satisfying exchange relation is made part of the economic problem by introducing the notion of atmosphere. The disregard for attitudinal interaction effects, among transactions and within groups, that is associated with quid pro quo modes of analysis in which separability is implicitly assumed is thereby avoided."

"Atmosphere' is the term used for the attitudes between group members, which would be less competitive than their posture toward market parties (p. 254). It is illustrated by the citation below (p. 258).

In the foregoing the most important instances of hypothesizing are presented. Some more hypotheses are elaborated from basic ones. One is about the dismissal of purely economic human behavior and the fiction of technical separability (p. 256):

The usual assumption in economics, implicit if not explicit, is thatindividuals regard their relation to the system in a strictly neutral, dispassionate manner. Subject only to the condition that transactions are technologically separable, each transaction can be priced separately and metered independently 1 submit. however, that technological separability is merely a necessary and not a sufficient condition for transactions to be regarded independanty.

Another speculation is about people not acting in a purely economic way (pp. 257, 258):

'It is interesting to speculate why individuals do not regard all makket transactions neutrally. Though I do not pretend that it is a complete explanation, / submit that one of the reasons for this is that individuals are generally not schizophrenic with respect to their economic and noneconomic identities. Individuals who experience nonmetered externalities in noneconomic contexts and reach nonmarket accommodetions thereto bring the attitudes and experiences which evolve in these nonmailket circumstances to the workplace as well. Rather than regard transactions in strictly quid pro quo terms, with each account to be setrled separately, they look instead for a favorable balance among a related set of transactions."

These citations demonstrate once more that the study is a complex of postulates, assertions and other suppositions.

A comprehensive summary as given by the author follows (p. 258): 
Bounded rationalify. Hierarchy extends the bounds on rationality by permitting the specialization of decisionmaking and aconomizing on communcation expense. Opportwoism. Hierarchy permis additional incentive and control techniques to he brought to bear in a more selective manner, thereby serving to curb smallnumbers opportunism.

Uncertainty. Hierarchy permits interdependent units to adapt to uinforeseen contíngencies in a coordinated way and furthermore serves 10 'absorb' uncertainty.

small numbers Hierarchy permits small-numbers bargaining indeterminecies to be resalved by fiat. Information mpactedness. Hierarchy extends the constitutional powers to perform an audit, thereby narrowing (prospectively at least) the information gap that obtains between attonomous agents.
Atmosphere. As compared with market modes of exchange, hierarchy provides, for some purposes at least, a less calculative exchange atmosphere. These are the advantages of hilerarchy. In circumstances where market exchange would occur between small numbers of traders under conditions of uncertainty hierarchical exchange is apt to be favored. But two caveats should be noted.

First, hierarchy experiences both size and transactional limits - for the reasons given in Chapter 7. Second, the advantages indicated are merely potential. For this potential to be realized requires that appropriate principles for decomposing thierarchies be followed and the requisite incentive and control apparatus supplied.

Derivation plays a modest role in the study. Prescription is obtained with recommendations for the various forms and degrees of governance, but more in order to illustrate the assertions than to the extent of practical application. Observation, induction, and intervention are not discussed.

\section{Assessment following the $\mathrm{A}-\mathrm{F}$ - scheme}

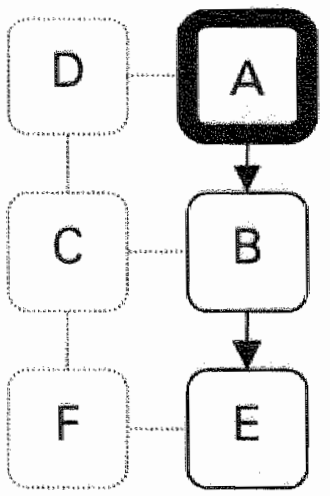

In hypothesizing (A) axioms are important (p. 255). After a long part of introductory considerations the central conjectures are formulated (pp. 249-258). The degree of elaboration of hypothesis is large. As stated, deriwalion (B), and prescription (E) are briefly discussed but not elaborated.

Metatheoretical requirements are duly met within box $\mathrm{A}$ with an as appropriate quality of definiteness and precision. The theory is in coherence with theories of predecessors. As a total it lacks means for validation. It has indirect utility for the design of structure, and, to a lesser degree, of strategy.

\section{Conclusion}

The theory is mainly restricted to hypothesis. The author elaborates upon the work of important predecessors like Hayek (1945), Coase (1937), Barnard (1938), and March and Simon (1958). Fecund elements are in the bridging between micro- and macroeconomics on one side and various schools of organization theory on the other. This way Williamson has 
offered new ways to develop explanations of structure and strategy. He has had a great influence on subsequent research into structure and strategy.

\subsection{Jeffrey Pfeffer and Gerald R. Salancik}

\section{Bibliographical data}

Pfeffer, J. and G.R. Salancik, The External Control of Organizations, New York, 1978.

\section{Contextual points}

Pfeffer (b. 1946) is a professor of organizational behavior at Stanford University. He is a social psychologist. Salancik, after a start in journalism, became a social psychologist. He was a professor at the Carnegy-Mellon University in Pittsburgh.

The scientific environment of the authors is the school that seeks to understand the organization from its social interrelationships. This view leads to the resource dependence perspective.

After the oil crisis concern grew over political-environmental problems facing the organization. The authors considered the subject to be neglected, despite some lip service given to it. It was their motive to start the research project.

\section{Contents and relevance}

The authors indicate their basic position in a number of statements. Core elements are the 'enacted' environment, the interdependencies between organization and environment and the ensuing constraints. They seek explanation and design rules (pp. xi, 1):

\footnotetext{
"This book is about how organizational environments affect and constraim organizations and how

organizations respond to external constraints. it is also a guide to designing and managing organizations that are externally constrained. ... Our intent is simple - to provoke additional thought, research attention, and
}

\author{
concern for the ideas of resource interdependence, \\ external social constraint, and organizetional \\ adaptation. ... The central thesis of this book is that to \\ understand the behavior of an organization you must \\ understand the context of that behavior - that is, the \\ ecology of the organization."
}

The basic contention of the study holds that in order to survive an organization needs access to resources. This would require the ability to coping with environmental conditions and actors. It is management's most important task to continually deall with the environment in a successful way. The essence of survival of the organization is being able to acquire and maintain resources. "To acquire resources, organizations must inevitably interact with their social environment' (p. 2). Important propositions about how to cope with uncertainty are presented 
on pages $42-45$. It is said that examples indicate that the organization seeks uncertainty reduction by attempting to 'interstructure the behavior" of the organization and third parties. "Social controll involves a process in which both the influenced and the focal organization act to affect the conditions gowerning the influence process."

The following is a summary of tenets on interdependency (p. 53):

When the rite exchange between organizational entities is asvmmetrical, some net power accrues to the less dependeint organization. This power may be employed in attempting to influence or constrain the behavior of the other more dependent organization. To summarize the preceding discussion, the potentibal for one organization's influencing another derives from its discretionary control over resources needed by that other and the other's dependence on the resources or access to alternative sources."

It should be noted that here the power concept appears and that this power is based on the control of resources.

On the final pages of the book views of the human relations school are criticized.

Strategy is the essential subject of the book. The implications of the theory are direct. The work has also metatheoretical pertinence.

The study refers to the larger organization.

\section{Process of knowledge development}

In the hypothesizing phase the authors propose that within the entire surrounding system of an organization, the part of it directly interreacting with the focal organization can be distinguished. In this respect it is claimed that what really matters is the external system as it is perceived, or enacted, by the focal organization (p. 63). Concepts are borrowed from Emery and Trist (1965). The authors distinguish four types of environment, namely 1) the placid random and 2) the placid clustered environment, both of which only slowly change. Next to these there would be 3) the disturbed-reactive environment (such as during the industrial revolution) and, 4) the turbulent field in which stability has been lost.

An important definition is the one about the term control (p. 260). A member's control over the organization is said to be its ability to controlling some resource, the criticality of this resource, the inability of the organization to find aiternatives, the visibility of the actions involved, and the organization's lack of control over resources critical to the member.

To establish the line between organization and environment a boundary definition is proposed (p. 32):

"The organization's boundary, then, can be defined in terms of its influence over activities compared to the influence of other social actors over the same activities of the same participants. When the focal organization's influence is greatest, we can say that those activities are included within its boundaries. Since organizations are quasimarkets for influence and control, it is altogether appropriate to define boundaries in terms of the relative influence and control over activities." 
Here again control over resources is the determinant concept.

Management's role is hypothesized as follows (p. 37):

The task of organizational management, as developed from this view of organizations, is the management of the coalition to ensure continued support and survival of the arganization. This task, which is problematic because of the reality of conflicting and competing demands, is necossary because of the organization's interdependence with other participants and organizations outside of its boundaries - i.e., because of its need for activities that are not completaly within its control."

A definition of interdependence can be found on page 40. This quality would exist 'whenever one actor does not entirely control all of the conditions necessary for the achievement of ... [actions or their outcomes]."

The essence of the resource-based view comes forward when critical factors of dependency are discussed (p. 45). These would depend on three questions, namely 1) how important is the resource controlled by the environment for the focal organization's survival, 2) what degree of discretion has the third party over this resource, and 3) do substitutes exist for the resource. In chapter 4 the effectivity of the organization is discussed (p. 62). Now the term model is coming into play:

'how does an organization become effective? ... Without an adequate model of the world, effective action is certainly unlikely.... the first step in effective management is being able to percelve the environment accurately and to understand the factors that determine how the organization defines its world."

Some more citations demonstrate the development of knowledge the authors follow. A belief is expressed when they state that "It is our impression that organizations are becoming more interconnected and that the cause of this ... is most often government action' (like wage and price controls) (p. 70).

A concept mentioned already is the one of the enacted environment. The authors follow Weick $(1969$, p. 27) who argues that the concept of environment is meaningless without the 'individuals who enact it in planning the activities of the organization.' Organizational environments are said to be notions enacted by a process of perception, attention and interpretation, influenced "... by organizational structures, information systems, and the distribution of power and control ...' (p. 260). In this respect one of the questions is about the kind of information that is collected from the environment. It is remarked that subunits of the organization have the tendency to present "their" part of the environment as most important (pp. $72-77$ ). As the environment is only known as interpretation of what different departments observe, the information is always late. Other problems are misreading interdependence (production officers neglecting governmental requirements), misreading as a result of the selective perception, commitment to the past caused by resistance to change, and the conflicting demands that are put forward by different external actors (pp. 78-83). The authors summarized these hypotheses as follows (p. 89): 
The enactment process, ... is largely determined by the existing organizational and informational structure of the organization.. But, enactment does suggest that more attention be devoted to the management of information acquisition activities and to the determinants of enactment arvd attentional processes in organizations.

Organizations may misread interdependence, misinterpret demands, remain committed to pest practices, or fail to see the various conflicts in demands. While attention is inevitably retrospective... it is possible to develop procedures for assessment that may overcome some of the problems commonly encountered in designing organizational actions. The outlined procedure for assessing organizational effectiveness represents both a model of organizational behavior and a prescription for managing organizations to ensure their contimued survival."

They point at the alleged flaws in other approaches, in which too much causality is said to be attributed to the actions of individuals (pp. 6, 10). The authors defend that the "context" (environment) of the organization has more impact than individuals have, including leaders. But leadership is not entirely devoid of discretionary power, as is argued on page 252 :

"However, there is an astonishing lack of attention to developing models of administration and administrative effect on organizational structure and action. Sociological analyses tend to dismiss the administrator as unimportant and substitute $a$ perspective of environmental determinism; industrial and organizational psychologists teind to concentrate on lower levels of management and on the supervisory component of administrative behavior. Reading the psychological literature, one might conclude that leadership was all important.

... Change comes through administrative succession because managers can, in fact, alter things. Such change is partially predictable, however, by the environmental context because administrators also operate within constraints, many of which come from the organization's context."

This statement means that the authors steer a middle course between free will and determinism. It reveals an important point of the authors' Weltanschaung.

The authors seem to demonstrate derivation in using the word model in some of their propositions. On a closer look this is not the term as meant in the definition of the predictive model in our chapter 3. Instead, it is used as a term for a set of propositions.

Observation in the book has two forms. First, some examples are used from the practical experience of the authors themselves. They concern two empirical cases. The first is about Israeli managers who were asked to indicate their willingness to accept a relatively low return on investments in special development areas. The government, playing the double role as purchaser of the goods produced by the firms as well as the main source of finance, pursued such developments. It turned out that the more the firms were dependent, the lower the return they would accept (p. 55). The second case is about the complying of U.S. defense contractors with aflirmative action. It appeared that the larger the firm and the more dependent it was on the government, the more it emphasized its willingness to employ female MBA graduates ( $p$. 56). Both cases are mainly anecdotal and serve in the book as examples of the thesis reading: 
'The effective organization, then, is the organization which satisfies the demands of those in its environment from whom it requires support for its continued existence.' (p. 59).

On pages $115-131$ some examples of research are given. The authors want to prove that the main reason for vertical integration is dependence reduction. The frequency of vertical mergers is examined. Indeed it appears that mergers significantly often occur between parties with many mutual transactions. This finding is explained as a support for their thesis. Next (pp. 131 - 139) they seek sources from literature. Research into the growth of companies and their profitability shows that concentration does not enhance profitability but increases stability ( $p$. 139):

"Organizational growth and large size enhances the survival capacity of organizations, providing them with more power with respect to their environments and with more parties interested in their continuation. Size was found to be positively related to stability but unrelated to profitability. The evidence is consistent with the argument thet firms grow and merge, a specific form of growth "to manage environmentel dependence, but it is not consistent with many of the other arguments advanced to account for the behavior."

These findings raise the interesting question: what has been proved? Mergers are the outcome of decisions based on arguments that may be right or wrong. As long as the manifold and various intentions of those making decisions are not examined, not much can be said about the common ground for integration. Maybe the management sought reduction of dependency as a means for higher profitability. That it did not work out that way is no proof of the absence of their intention. This research and the interpretation of its outcomes only hold if one believes that decision-makers 'unconsciously' have other intentions than they know of, or that they are like puppets on a string, whose efforts are futile in withstanding an inescapable fate. But this is contradictory to the authors' own mixed view on this matter, as becomes apparent in the citation given above about the content of free will in leaders' behavior (p. 252).

The phase of prescription contains a rule in the form of a pictorial model (p. 87) that is rendered hereafter in an abridged version (figure 5.1).

More examples of rules are found on pages 110 and 113, in a summary of proposed rules for complying with external demands.

\footnotetext{
"Alternative sources of supply, alternative resources, or diversification may be sought to diminish the criticality of a particular exchange relationship. Or the control that others have over the exchange can be attacked
} through the use of lawn, norms, or strategies of absorotion and regulation such as merger cooptation. and the exchange of personne:" 


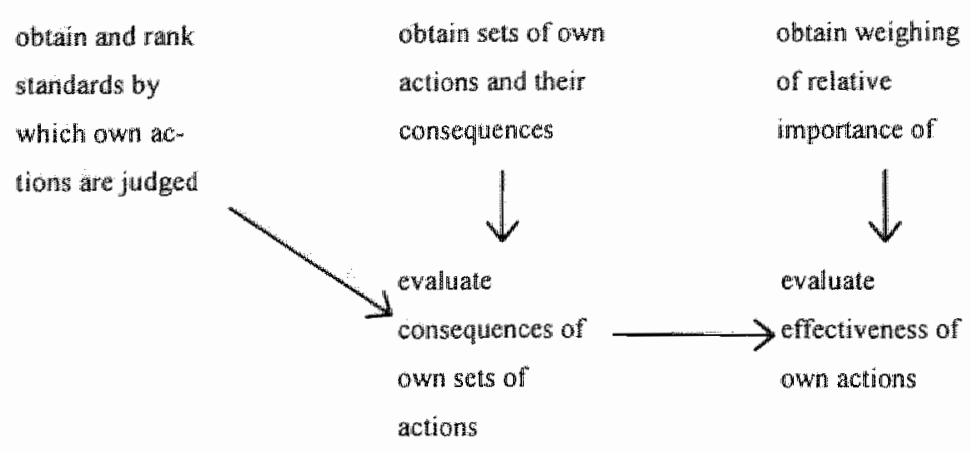

Figure 5.1. Abridged version of a pictorial model of rules by Pfeffer \& Salancik (1987)

The techniques involved in avoiding influence are said to include the restriction of information, "so that those making the demands do not know what others are receiving, conflicting external organizations can be balancing against each other, demands may be managed by attending to them sequentially, limited discretion can be claimed, and laws or norms can be sought, limiting the discretion of more powerful external organizations.'

A possible response to dependence from third parties is to absorb them. This may have the form of backward or forward vertical integration (mitigating the dependence from sellers or buyers), horizontal integration (reducing competition), or diversification (seek other, less problematic, interrelations).

These propositions have been tested as described above in the section on observation.

In chapter 7, a new round of knowledge development starts (pp. 143, 160). Shared norms among organizations and joint ventures are hypothesized. A model of joint venture occurrence is proposed to be explained by uncertainty reduction, "[the] results [of which] suggest that joint ventures are being used, even more than merger, to coordinate interdependence and reduce competitive uncertainty.' More propositions follow about shared board memberships, trade associations and cartels (p. 161). A discussion on political action of the organization, based on literature search, follows, with a summary (p. 224):

'Organizations are also likely to become involved in political activity when governmental intervention begins to affect their economic well-being and certainty.... Rather than taking the environment as a given to which the organization then adapts, it is considerably more realistic to consider the environment as an outcome of a process that involves both adaptation to the environment and attempts to change that environment.

Organizational efforts have been made to establish favorable environments through regulation as well as through other forms of political activity. Furthermore, organizations act to achieve social legitimacy and occasionally achieve this legitimacy through a process inwolving identification with other legitimate social 
actors. Whille the basic theoretical position we have developed in the earlier chapters has not been explicitly applied to test typotheses relating to these dimensions of organizational activity, the case evidence and data presented do indicate the possibitity that these organizational actions can also be explained by the situration of interdependence. theertainty and resource munificence confronting the organizations:

At this point it becomes clear that the authors themselves consider their position as rather weakly corroborated.

On page 258 the resource dependent perspective is reiterated:

"Survival of the organization is partially explained by" the ability to cope with environmental contingencies; regotiating exchanges to ensture the continuation of meeded resources is the focus of much organizational action."

Some more hypotheses are summarized hereafter. 'Organizations interacting with one another' are involved in a dynamic sequence of actions and reactions leading to variations in control and discretion.' (p. 260). Setting the agenda is said to be an important phenomenon, as subunits of the organization will try to mold environment so as to make it important for the dominant coalition, thus enforcing their own position ( $p .261$ ). Ways to cope with competing internal and external demands would complicate the task of management, therefore influence and constraint are avoided by secrecy, denying legitimacy, seeking other dependencies through diversification, and manipulating information (p. 261). Power may be sought by associating with parts of the environment. This however means that the "... organization must surrender some of its own autonomy.' (p. 261). The authors indicate that not all questions are answered as yet. Remaining white spots are the use of secrecy, the limitation of discretion, and the specification of the demands of external actors. In other words: "The question is how context affects organizations.' (p. 262).

Other rival views are criticized (pp. 257, 262):

'most current writers' are criticized for giving only token consideration to enwironmental forces as determinants of management's actions; "We take the wiew of externally controlled organizations much more seriously. This chapter will recapitulate the arguments derived from that perspective and then explore the role of manggement, the design of organizations, the design of organizational enviromments, and the likely future of organizational structures. In many instances, our theoretical orientation leads to expectations and recommendations discrepant with the dominant literature. While we have no particular stylle of management to promote and no appealing phrases like "human relations", "Buman resources" or "participation" to use to summarize oup thoughts, we would suggest that the ideas developed are likely to be more empirically verifiable and more descriptive of the actual operation of interacting social actors.... It is clear that the erwironment, the context of the organization, is more important than many writers have implied by restricting their attention to the effects of uncertainty on decentralized decision making."

To end this rendering of the authors' second round of hypothesis, some more of their summarized assertions are cited in their own words (p. 259): 
"Lorganizetional boundaries are]" ... defined by the organization"s control over participants relative to the control of other social entities.... Control is the ability to inifiate or terminate action at one siscretion."; an grgenization is constituted by the set of interlacked activities it controls. ... Qrganizations, in addition to being coalitions of interest, are markets in which influence and control are transacted. ... Participants attempt to exchange their own resources, thetr performances, for more control over the collective effort, and then, they use that control to initiate actions for their own interasts. In organizations as in other social systems, power organizes around critical and scarce resources. ... Power is ... determined by the definition of social reality created by participants as well as by their control over resources."

More hypotheses are elaborated. A description of the symbolic role of management is given (pp. 263,265). Managers are said to be symbols of the organization. Their influence, however, would be overestimated. In case of conflict they may be replaced as a tactical step that does not reduce the organization's discretionary power. Although not omnipotent, the manager has an important role as perceiver of external demands and adapter of the organization accordingly. The role of choice in decision making is frequently overrated: once relevant information is available, the choice of action may be obvious. In their discretionary role ( $p$. 266) "Managerial action focuses on altering the system of constraints and dependencies confronting the organization.' Here again, the information-processing task is critical: the accuracy of his model of reality is of vital importance.

Next, the chief executive is revisited (p. 275). The observable diffusion of ownership of companies would enable management to institutionalize its power. Diversification has the same effect. These forms of centralization necessitate the easy replacement of executives when environmental conditions change, or for the intentional sharing of organizational power. However, the ultimate solution (a system of representative democracy) seems unsuitable for the organization in general (p. 287):

"We suspect that is is mainly when the problems confronted by formal organizations become and acdaptations to changing social contexts that structural similarities to political organizations emerge."

increasingly the management of conflicting demands

In the final sections of the book more rules are given (p. 268). Important tasks of management are said to be the scanning of the environment, loosening dependencies, and coping with conflicting demands. The first task would require the bringing together of relevant, but dispersed, information gathered by different (and often conflicting) departments. Panels of experts using special query-techniques, like the Delphi method, can do this. The second problem may be solved by diversification and mergers, while the third can be helped by differentiation, such as the formation of loosely coupled subunits, each dealing with a part of the environment, and by the use of slack resources.

Apparently, rules follow from their starting points. These rules apply to structure as well as to strategy. 




Hypothesis (A) starts with a clear exposition of the domain of study (definiteness), the method of research and the results sought ( $\mathrm{pp} . \mathrm{xi}$, 1,2). Conjectures are formulated (pp. 37, 42-45, 53, 63, 89, 143, $160,252-265$ ), as are definitions (pp. 32, 40, 260), and concepts ( $\mathrm{p}$. 27 ), showing an adequate precision. Derivation (B) and obserwation (C) are hardly worked out. In these parts, clear formulations of definitions, concepts and models are difficult to find between the stimulating propositions. They only appear in a comprehensive way in the final part. Attempts to corroborate certain hypotheses with industrial statistics suffer from this lack of order. Here we come across a questionable point: the statistical assaying produces a positive significance of the hypotheses, but the rival hypotheses the authors tacitly reject might be 'proved' by the same experiment as well. This means that the validity test used to support hypothesis is inadequate and insufficient. Hypothesis (A) is largely elaborated, derivation (B) is virtually absent, while prescription in the form of rules ( $\mathrm{pp} .87$, $110,113,268$ ) is only moderately elaborated. Coherence is present in the linking with the work of predecessors (p. 23). Metatheoretical requirements are well met in A, but scarcely so in the other parts of the study.

\section{Conclusion}

The rules proposed by the authors are directly useful for the design of strategy, and indirectly for structure.

The authors (p. 23) draw on earlier work by Katz and Kahn (1966). Some definitions (p. 36) are borrowed from Cyert and March (1963).

"The organization is a coalition of groups and interests."

... "Because organizations are coalitions, management faces the necessity of coping with competing and confliticting demends."

Fecund elements of the study lie in the authors" passionate defense of well-elaborated environmental, socio-political research. This has been a stimulus for further thinking.

\subsection{Henry Mintzberg}

Bibliographical data

Mintzberg, H., The Structuring of Organizations: A Synthesis of the Research, Englewood Cliffs NJ, 1979. 


\section{Contextual points}

Mintzberg (b. 1938) is a professor of policy at McGill University in Montreal, Canada and a professor of management at INSEAD in France. After his training as an engineer he obtained a Ph.D. from Sloan School of Management at the M.J.T.

By the end of the seventies many results of research into organization were available. In this scientific environment the author attempted to combine all available knowledge in a series of five books covering the theory of management policy. He considered the case study tradition as unfit for escaping lower-rank descriptions, while the 'principles' approach 'lost touch with descriptive reality'.

Typical for the historical/social environment of the period is, that in those years the fears of the eighties were yet unknown.

\section{Contents and relevance}

The basic position follows from the author's remarks on research. He expresses the intent of the research in his foreword (pp. $i$-vii):

"specifically descriptive theory [is sought] based on empirical research ... theory that is "middle range". ... between ... case study tradition, which never sougltht ... conceptual interpretation of its lower-rank (concrete) descriptions, and ... principle tradition, whose highrange abstractions lost louch with the descriptive reallity:

In received theory a flaw is observed and explained (p. 12):

Most of the contemporary literature fails to relate the description of structure with that of the functioning of the organization.... The blame for this flaw can be placed largely on research "from a distance": research that records the perceptions of executives on questionnaires instead of their real behavior, research of a cross-sectional nature that takes measures in too diverse an array af organizations .... None of this research has been able to come to grips with the complex flows that take place in organizations."

In view of our quest for grounded theory here the author makes an important point. He dismisses case study research and the outcome of large-scale surveys. The end of our assessment will see if he has found ways to obtain better theory.

The author has chosen to take the functioning of the organization as the origin for his research (Part I).

A most remarkable metatheoretical point in this work is the Pythagorean hermeneutics. The number of five seems to have something special (p. 300):

There is order in the world, ... a sense of union or harmony that grows out of the natural clustering of elements, whether they be stars, ants, or the characteristics of organizations. ... In fact, the recurrence of the number "five in our discussion seems not to be coincidental, for it turns out that there 
It seems that Mintzberg wants to replace the observational methods he just dismissed by betting on some metaphysical order.

A strong position is taken about the five forces that would be typical for each of the elements in the organization (p. 302). The author argues that the top wants to centralize, the technostructure wants to standardize, the support staff seeks collaboration, and the middle line tries to balkanize, while the operating core exerts a pull to professionalize.

As a pentagonal capping stone on this metatheoretical building, essentials are recapitulated and some applications are proposed by the end (p. 468). The author states that a theory should rigorously reflect reality, and must be simple to comprehend, "like $\mathrm{E}=\mathrm{MC}^{2}$ ".

As said, one of the salient basic contentions in the book is that most literature fails to relate the description of structure with that of the functioning of the organization.

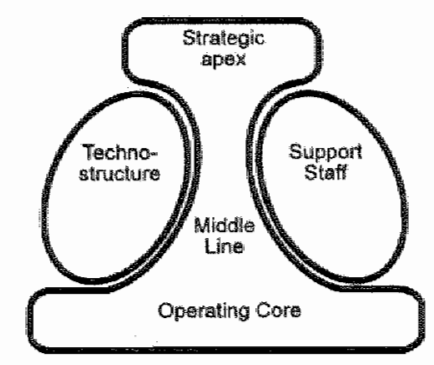

The Five Basic Parts of Organizations:

Figure 5.2. Quoted from Mintzberg (1979, p. 20, figure 2 - 1)

Other contentions hold that stable organizationall structures would have adopted one out of five distinct forms: the simple structure, the machine bureaucracy, the professional bureaucracy, the divisionalized form, and the adhocracy. Five forces are said to push structures toward these equilibria or may cause transitions from one form to another, each of which originates in one of the five distinct parts every structure has. These parts are the operating core, the strategic apex, the middle line, the technostructure and the support staff. This is depicted in the wellknown figure cited above (figure 5.2).

The work was meant to be part of a series, centered on the forming of strategy (p. $x i$ ). This book deals with structure, being considered to be a question preceding strategy.

It does not exclusively refer to any particular size or rype of organization. Its implications are hypothetical, and, as they are mostly descriptive, they pertain indirectly to our field of interest. 
Most of the propositions in the book are hypothetical. Hereafter, a number of examples will be given.

A definition of structure is given on page 2, reading "The structure of an organization can be defined as the sum total of the ways in which it divides its labor into distinct tasks and then achieves coordination among them.'

Hypothesizing follows (p. 3) when it is stated that there are five coordinating mechanisms as they are generally accepted, namely "mutual adjustment, direct supervision, standardization of work processes, of work outputs, and standardization of work skills'. As discussed above, it is stated that in the organization five basic parts could be distinguished (p. 18): the operating core (those who do the basic work), the strategic apex (the very top), the connection between the two (the middle line), and next to this middle line, on one side, the technostructure (controllers, strategic and operational planners, personnel trainers), and at the other side the support staff, providing services varying from research to the cafeteria. The model is depicted above in its well-known form.

Elements of Thompson's (1967) research are introduced on page 21. Thompson (see section $5.17)$ distinguishes three types of interdependencies between organizational units, namely pooled, sequential, and reciprocal interdependencies. He states that coping with uncertainty is the essence of the administrative process. Therefore specialized units deal with outside agencies. In the book the author repeatedly refers to Thompson, but at no point it becomes clear what exactly is used as a building block for his own theory.

A discussion follows about the organization as a system of flows between the five parts of the organization (p. 35):

1) the flow of authority,

2) the regulatory flow (of operating work, of control, of staff information),

3) the informal communication flow,

4) the system of work constellations,

5) the system of ad hoc decision processes.

1t should be noted that 4) and 5) are not so much flows as well as systems, or structures. Apparently some effort is required to mould logical concepts into rigid frames of thought.

In the chapters 4,5 , and 6 the design of positions is discussed. The contentions are based on exemplary references to research. At this point of the book, a mixture of hypothesis and design rules is advanced. Job specialization is discussed with its counterpart job enrichment. Behavior formalization is discussed with reference to studies of Pugh et al. (1963, p. 64). The degree of bureaucracy of a structure is defined as the extent to which 'its behavior is predetermined, ... in effect standardized', corresponding to Weber's description as discussed by Gerth and Mills (1958). Burns and Stalker's (1961) organic structure is juxtaposed to a formalized one. Dysfunctions of highly formalized structures are discussed with reference to Crozier (1964). Training and indoctrination are said to be important adjustment mechanisms in areas as diverse as unskilled work and high level professionalism. 
In chapter 7 (p. 104) unit grouping is dealt with in a descriptive way. In chapter 8 unit size is said to be based on two basic hypotheses: "the greater the use of standardization for coordination, the larger the size of the work unit', and: 'the greater the reliance on mutual adjustment ..., the smaller the size of the work unit' (pp. 139-141).

Design of lateral linkages is described in chapters 9 and 10. Planning and control systems and liaison devices are discussed. Five devices for lateral coordination are introduced: the liaison man, the task force, the standing committee, the integrating managers, and the matrix structure. All are discussed with dispersed reference to other research. The specific occurrence of certain liaison devises - relative to a continuum from pure functional to pure market structure - is depicted in a model (similar to Galbraith, 1973).

In vertical and horizontal decentralization the concept of power transfer is essential. An unusual definition is given (p. 181):

"When all the power for decision making rests at a dispersed among many individuals, we shall call the single point in the organization ... we shall call the structure decentralized."

structure centralizedi: to the extent thet the power is

If this dispersal goes down the line of authority it will be called vertical. If it goes to nonmanagers beside the line of formal authority, it is horizontal decentralization. Instances of the horizontal form are power attributed to the analysts, to the experts, and to certain or all members of the organization.

In part III design parameters are put into context by seeking their relationship with contingency factors, because 'most of the contemporary research has focused on this very issue.' (p. 215). Rules for the effective structuring of organizations are based on research of Burns and Stalker (see section 5.10), Lawrence and Lorsch (see section 5.16), Woodward (1958) and Khandwalla (1971). A model for structural design is proposed (figure 12-3), starting with 11 independent (contingency) variables, like organizational age, technical system, environmental diversity, passing through 4 intermediate ones (like diversity of the work), onto 9 dependent (structural) variables (like unit grouping, liaison devices, decentralization). But in the end the author rejects the contingency-perspective model because all variables may affect one another, while assumed linear relationships usually are in fact $U$-shaped. He criticizes research that uses variables 'that cannot be measured in the organization"s own terms.' By using perceptual measures such as executives" perceptions reality can be distorted (p. 224). These considerations make the author start from scratch again by proposing a number of hypotheses. The first refer to age and size of the organization (p. 227). Five hypotheses are stated, with exemplary reference to research:
11 The older the organization, the more formalized its behavior,
2) Structure reflects the age of founding of the indiustry.

3) The larger the organization, the more elaborate its structure (more specialized, more differentiated, a more devaloped administration). 
4) The larger the organization, the larger the size of its average unit,
5) The larger the organization, the more formalized its behavior."

On page 241, an important point is made. After a discussion of stages of the structural development of organizations (from simple and small to large and differentiated) the following conclusion is drawn (p. 248):

"... structures do not seem to change cantinuously or in linear patterns; it sems to be more accurate to describe them as passing through distinct transitions. fundamental changes in the ways their work is divided and coordinated."

This hypothesis is also known as the quantum leap proposition (Miller and Friesen 1984). Next, more hypotheses are formulated, now about the technical system, with reference to Woodward (pp. 249, 266):

"6) The more regulating the technical system, the more formalized the operating work and the more bureaturatic the structure of the operating core,

7) The more sophisticated the technicall system, the more elaborate the administrative structure, specifically the larger and more professional the support staff, the greater the selective decentralization (to that staff), and the greater the use of liaison devices (to coordinate the work of the staff).
8) (266) The automation of the operating core transforms a bureaucratic administrative structure into an organic one....

To conclude our discussion ... although it may have its greatest influence on the structure of the operating core, ... it has also fundamental, if sellective, influence on the structure of the middle level as weil. $A$ regulating technical system bureaucratizes the operating core; a sophisticated one elaborates the support staff structure: and an automated one debureaucratizes the structure above the operating core:

Four types of environment are proposed. They would correspond to the cells in a two-by-two matrix (p. 286). A stable environment in combination with a complex process would imply a decentralized/bureaucratic structure, while in combination with a simple process a centralized/bureaucratic structure would ensue. In a dynamic environment, a simple process corresponds to a decentralized/organic structure, but if the process were complex, a centralized/organic structure would be necessary.

About the environment the following hypotheses are formulated (p. 267):

9) The more dynamic the environment, the more organic the structure,

10) The more complex the environment, the more decentralized the structure.
11) The more diversiffed the organization's markets, the greater the propensity to split it into marketbased units (given favorable economies of scale),

12) Extreme hostility in its emvironment drives any organization to centralize its structure temporarily. 

organization to decentralize selectively to

These hypotheses are said to be very important, sometimes overruling the first eight (p. 287). It should be noted that these firm statements, although credible, only draw on intuition. Finally three more hypotheses are given:

"14) The greater the external control of the organization, the more centralized and formalized its structure,
15) The power needs of the members tend to generate structuires that are excessively centrallized,

16) Fashion favors the structure of the day land of the culturel, even when inappropriate."

The author concludes that the economic environment has the most impact on the apex. Factors of age and size are most pronounced in the middle of the structure, while the technical system is the prime factor affecting the operating core (p. 296). Furthermore it has become clear that the effects of different contingency factors on the same design parameter, as well as the interrelationships between design parameters and among contingency factors, cannot be determined by the knowledge gathered so far. This means that clusters of contingency factors and design parameters must be sought that together may determine the occurrence of certain structures (p. 297).

Part IV is about structural configurations. In Part III the hypotheses stood alone, sometimes even were contradicting (p. 15). Now synthesis is in order. Five natural clusters, or "configurations", emerge, namely (p. 301):

1) the simple structure,

2) the machine bureaucracy,

3) the professional bureaucracy,

4) the divisional form, and,

5) the adhocracy.

The author describes the adhocracy form as follows (p. 432):

'In Adhocracy, we have a fifth distinct structural

configuration: highly organic structure, with little

formalization of behavior: high horizontal job

specialization based on formal training: a tendency to group the specialists in functional units for

housekeeping purposes but to deploy them on small market-based project teams to do their work; a relliance on the liaison devices 10 encourage mutual adjustment - the key coordinating mechanism - within and between these feams; and selective decentralization to and within these teams, which are located at various places in the organization and involve various mixtures of line managers and staff and operating experts.' 
Most of the examples of propositions reported so far have a hypothetical character. Many of these hypotheses however, have a derivative flavor. They are being gradually transformed into design parameters, as the author calls them.

An example of a descriptive proposition with a rule-like character is the following (p. 429):

\section{'A Structure at the Edge of Chif Our discussion has} led to "damned if you do, damned if you don"t" conclusion. The pure (conglomerate) Divisionalized Form emerges as a structural configuration symbolically perched on the edge of the cliff, at the and of a long path. Ahead, it is one step away from disintegration - breaking up into separate organizations on the rocks below. Behind it is the way back to a more stable integration, perhaps a hybrid structure with Machine Bureaucracy at some intermediate spot along the path. And wer hovering above is the eagle, attracted by its position on the edge of the cliff and waiting for the chance to pull the Divisionalized Form up to more centralized social controt, on another. perhaps more dangerous, cliff. The edge of the cliff is ar uncomfortable place to be - maybe even a temporary one that must inc vitably lead to disintegration on the rocks below, a trip to that cilf above, or a return to a safer resting place on the path behind.
In other words, we conclude that the Divisionalized Form has the narrowest range of all the structural configurations. It has no real environment of its own: at best it piggybacks on the Machine Bureaucracy in the simple, stable environment, and therefore always feels drawn back to that integrated structural form. The pure Divisionalized Form may prove inherently unstable, in a social context a legitimate tendency but not a legitimate structure. The economic advantages it offers over independent organizations reflect fundamental inefficiencies in capital markets and stockholder control systems that should themselves be corrected. And it creates fundamental social problems. Perhaps there is justification only in its intermediate forms - by-product or related product. It is, after all, the interdependencies among its activities that give an organization its justification, its reason to "organize." Perhaps the pure Divisionalized Form, with so few of these interdependencies, really is an "ideal type" - one to be approached but never reached."

The recommended rule in this case is ambiguous: 'damned if you do, damned if you don't'. A warning is given: the divisionalized structure would be unstable. It is a prediction and a predicament at the same time.

About the simple structure some research findings on its conditions and limitations are discussed (p. 305). The machine bureaucracy is said to have an obsession with control. Research findings of its pros and cons are summarized on page 314. The professional bureaucracy would have an appeal for contemporary men and women by its democratic character and its provision of disseminated power and autonomy. This would allow professionals "to perfect their skills, free of interference" (p. 371). Some disadvantages are exposed.

On page 468 the five forces are reiterated. The configurations as 'pure types' are discussed, and their use when describing hybrids and transitional phenomena is described. Surprisingly, a sixth configuration pops up: the missionary type.

Some final remarks on the development of knowledge must be made. The author righteously criticizes the use of non-measurable variables, but he himself does not always avoid the trap. 
Striking is his ambiguity between free choice and determinism: throughout the work he focuses on design, while at the same time he describes structure as the outcome of a "natural" process.

Some contentions (like those proposing that all aspects come in five) are irrelevant: they only serve to suggest that some occult principle would lurk behind the design rules derived. There is a tendency towards "Platonism" throughout the work.

\section{Assessment following the $\mathrm{A}-\mathrm{F}-$ scheme}



The work is focused on hypothesis (pp. 300, 302, 468). Theory itself is obtained eclectically in a most elaborate and coherent way. Hypothesizing (A) includes the formulation of problems (pp. 8 - 12), conjectures (pp. 3, 35, $139-141,227,248,249,266,267,287,296$, 297), and definitions (pp. 18 - 21, 181, 286, 301, 432). Requirements of definiteness and precision are met. Descriptive propositions with a rule-like character are only seemingly derived, because derivation (p. 429) and prescription are not elaborated in themselves. Instead, they are but description otherwise formulated. The approach is systematic, but it lacks the metatheoretical rigor necessary for validation. This leads to the model that is depicted alongside.

The rules are useful for the design of organizational structure.

\section{Conclusion}

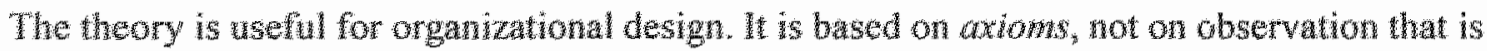
ordered. Is is not work out into construts and indwetve models that woud lead to growded

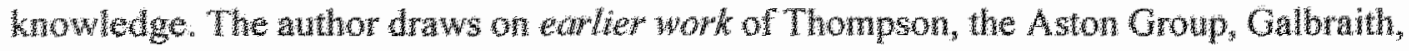
Crozier, Buns and Stake, Lawrence and Lorsch, Woodward and Kandwalla. Mis hypotheses conbune earher steps in the development of structuat knowedge nade by Taylor, Fayol,

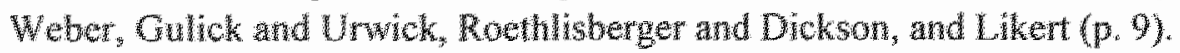

The "thesis of fve stable structural foms" was a fecund idea as it inspired huther reflection

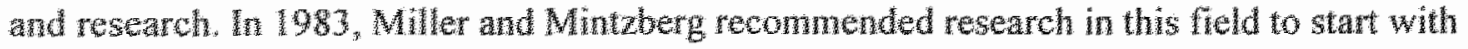

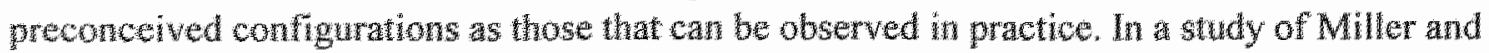



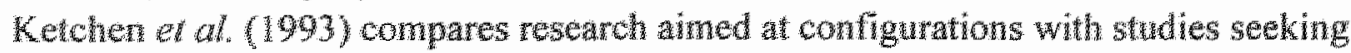
regunaties that hold across all organzatons. 


\subsection{Michael Porter}

\section{Bibliographical data}

\section{Porter, M. E., Competitive Strategy: Techniques for Analyzing Industries and}

Competitors, New York 1980.

\section{Contextual points}

Porter (b. 1947) holds a BS degree in aerospace and in mechanical engineering. He obtained at MBA and a Ph. D. in business economics at Harvard Business School.

The author"s approach is typically design-oriented; the book reads like an engineering textbook.

The historicalsocial environment of the period was characterizes by the beginning of global competition. The first signals of Japan's advance were picked up.

\section{Contents and relevance}

The point of departure of the author, and the intent of his research are expressed in the Preface (ix), when he states that competitive strategy is of primary importance to management and requires 'subtle understanding... Yet the strategy field has offered few analytical techniques for gaining this understanding, and those that have emerged lack breath and comprehensiveness."

The intended audience of the book is "practitioners who need to develop strategy for particular businesses and for scholars to understand competition better". (pp, $x, x v)$

He describes shortcomings of usual strategy approaches, and indicates the importance of an explicit process of strategy formulation (p. xiii). The author adds that strategy problems are widely addressed, but mostly by asking the right questions in an orderly way, not by answering them. And although his book is relating to the solution of practical problems by practitioners, the author also wants to contribute to scientific progress ( $p p . x w i$ ):

"The book is not written from the viewpoint of the scholar or in the style of my more academically oriented work, but it is hoped that scholars will nevertheless be interested in the conceptual approach, the extensions to the theory of industrial organization, and the many case examples."

An important basic contention is advanced on page 3:

'The essence of formulating competitive strategy is relating a company to its environment. ... The intensily of competition in an industry is meither a matter nor bad luck. Father, competition in an industry is rooted in its underlying economic structure and goes well beyond the behavior of current competitors. The state of competition in an industry depends on five basic competitive forces, ..." 
The working of these forces is explained in the model that is cited hereafter (figure 5.3).

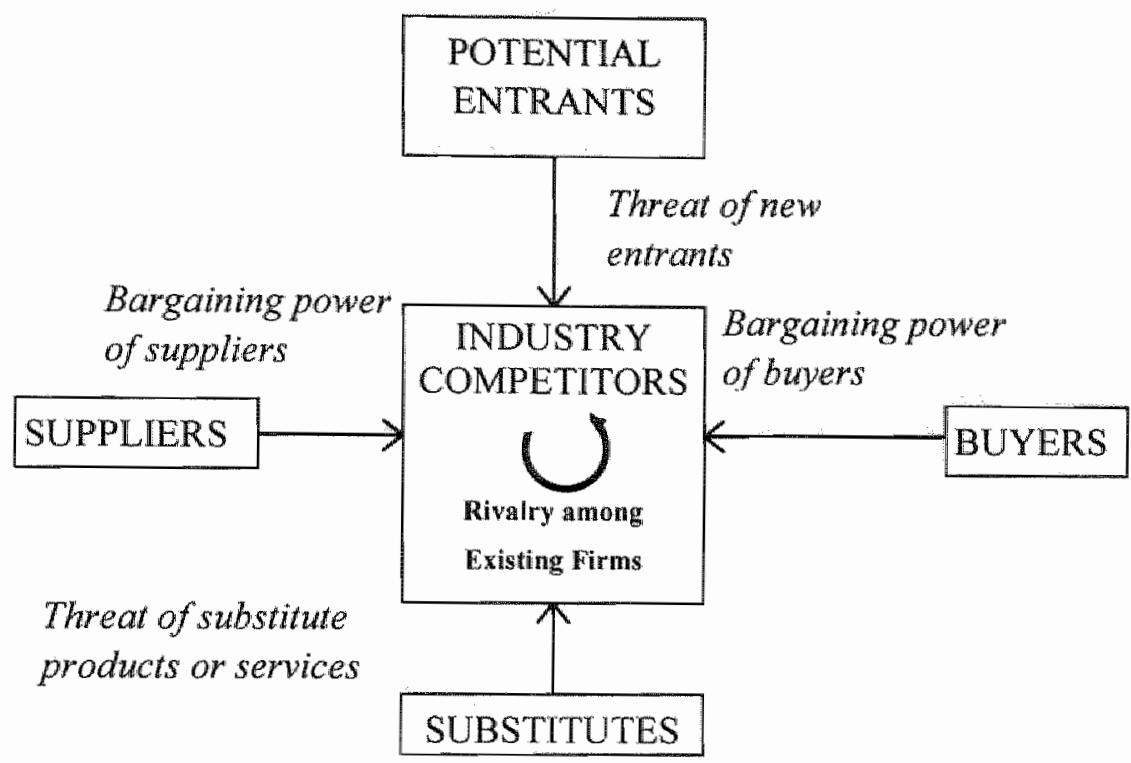

Figure 5.3. Quoted from Porter (1980, p. 3)

The book is pertaining to strategy, and to the competing company of all sizes. Its implications are direct.

\section{Process of knowledge development}

An important hypothesis is elaborated on the pages 5 and 6 :

Let us adopt the working hypothesis of an industry as the group of firms producing products that are close substitutes for each other. This hypothesis will be [eviewed] ... after the concept of structural analysis has been introduced ... (competition will drive the rate of return until perfect competition is arrived at .... The strength of the competitive forces in an industry determine the degree to which [the] inflow of invesiment occurs and drives down the retuin ... The five competitive forces ... reflect the fact that competition in an industry goes well beyond the established plavers. Customers, suppliers, sulothtutes, and potential entrants are all "competitor"s" to firms in the industry... Competition in this broader sense might be termed extended rivalry. All five competitive forces jointly determine the intensity of industry competition and profitability, and the strongest force or forces are governing .... strategy formulation.'

It should be noted that competition in Porter's view goes beyond the domain of rival suppliers. 
On page 34 three generic competitive strategies are stated and elaborated, namely 'overall cost leadership", which means offering a product that is simple to manufacture and at a low price, 'differentiation' (having a distinct design or brand image, dealer network, service system, etc.), and "focus", in which case the firm concentrates on a specific segment within the industry. Competitor analysis is discussed, with extensive checklists (p. 47). Examples of questions to be answered are: "Who should we pick a fight with ...?"; What are the meaning and the seriousness of a competitor"s move? and 'What areas should we avoid ...' because of competitor's disastrous retaliation?

In the same way, in the chapters $4-6$ other topics are discussed, like the analysis of market signals, competitive moves, and strategy toward buyers and suppliers.

Elements of industry evolution are hypothesized on page 158. Basic concepts are said to be the product life cycle ('The hypothesis is that an industry passes through a number of phases or stages - introduction, growth, maturity, and decline - ...'), and evolutionary processes and their key relationships. Next a description of the generic strategic industry environment is proposed (p. 189). Characteristics of fragmented, emerging, mature, or declining industries are given, while remarks on global competition are made. In the appendix the author proposes a number of portfolio techniques. These include the growth/market share matrix with its 'stars', 'cash cows', 'dogs", and "question marks', as well as the three dimensional 'Company position/Industry attractiveness Screen', indicating businesses to 'build, hold, or harvest' Limitations of both are that they 'offer little but a basic consistency check'.

In these sections again, hypothesis (A) and their derived concepts (B) come together.

An example of derivation is present on pages $7-33$, where predictive theory is elaborated, introducing a number of concepts, summarized in table 5.2 on the next page.

In chapter 7 a presentation is given of more definitions, concepts, and models concerning strategic industry analysis ( $p, 126)$. Dimensions of competitive strategy are said to range from specialization, through channel selection, to relationship to government. The concept of the 'strategic group' is introduced ('the group of firms in an industry following the same or a similar strategy along the strategic dimensions.') Fünally, the relation between strategic groups and profitability is discussed, while various checklists and mapping models are presented.

The author announced that he intended to offer rules for analyzing competition and for formulating a competitive strategy (p. xiv). These rules would be developed by discussing three subjects, the first of which contains the underpinning of the framework for analysis. This framework is based on the five competitive forces that were discussed above.

These rules pertain to the governing positioning, influencing the balance, exploiting change, diversification, and the use of structural analysis. The link to data is explained in Appendix B. Here we come across an important methodological point: Porter's rigorous formulations do not fail to follow the A - B - E line.

On page 399 , remarks and rules concerning strategic decisions are advanced. Subjects discussed are strategic benefits and costs of vertical integration, particular strategic issues in 
forward and backward integration, and long-term contracts and the economics of integration. Next to these subjects illusions in vertical integration decisions are discussed, as well as elements of capacity expansion. Rules are proposed for preemptive strategies and entries in new businesses through internal growth, or via acquisition.

1. THREAT OF ENTRY

1.1. BARRIERS TO ENTRY

1.1.1. Economies of scale

1.1.2. Product differentiation

1.1.3. Capital requirements

1.1.4. Switching costs

1.1.5. Access to distribution channels

1.1.6. Cost advantages independent of scalle

1.1.7. Government policy

1.2. EXPECTED RETALIATION

1.3. THE ENTRY DETERRING PRICE

1.4. PROPERTIES OF ENTRY BARRIERS

1.5. EXPERIENCE AND SCALE AS ENTRY BARRIERS

2. NTENSITY OF RIVALRY AMONG EXISTING COMPETITORS

2.1.1. Numerous or equally balanced competitors

2.1.2. Slow industry growth

2.1.3. High fixed or storage costs

2.1.4. Lack of differentiation or switching costs

2.1.5. Capacity augmented in large increments

2.1.6. Diverse competitors

2.1.7. High strategy stakes

2.1.8. High exit barriers

2.2. SHIFTINO RIVALRY

2.3. EXIT BARRIERS AND ENTRY BARRIERS

3. Pressure from substitute products

4. Bargaining power over buyers

4. 1. AETERING BUYING POWER

5. Bargaining power over suppliers

5.1. GOVERNMENT AS A FORCE IN INDUSTRY COMPETTTION

Table 5.2. Important economic and technical characteristics after Porter, as an example of derivation $(1980$, pp. 7 - 33)

Appendix $B$ includes suggestions on practical questions, like "how to define an industry or" business", "how to use public sources of information', and "how to obtain data from field intervilews". 




This is a design theory, descriptive and prescriptive. Essential concepts are the five forces and their derivatives. Many models are presented depicting concepts and their relationships. The method is solid and comprehensive. Hypothesis (A) involves problem definition (definiteness, $i x, x i i i$ ), conjecturing (the five forces model, 5, 6, 158), and conceptualization (precision, p. 47). Derivation (B, pp. 7 - 33) operationalizes the variables effective in rules and prescription (E) are those rules (pp. 29, 399, appendix B). All these elements are extensively elaborated, demonstrating a high degree of precision and systematic structure. A link toward testability and induction is not reported, nor is intervention. This involves a limitation of metatheoretical completeness. Validity testing is not sought. The utility of the theory for the design of strategy is considerable.

Conclusion

Porter refers to earlier work of other writers Andrews (1971) and Christensen (1973, xvi, note). The most fecund element of the book is the great advancement made in bridging the gap between various well-accepted strategic hypothesis and available observable business data. This leads to effective rules for the formulation of a concrete strategic plan.

\subsection{Tom J. Peters and Robert H. Waterman}

Bibliographical data

Peters, T.J., \& R.H. Waterman, In Search of Excellence: Lessons from America's Best-Run Companies, New York, 1982.

\section{Contextual points}

Peters (b. 1942) and Waterman (b. 1936) are both experienced consultants and lecturers with a MBA degree from Harvard. After publication of the book Peters lectured all over the world, while Waterman continued his consultancy work.

The authors" ideas are mainly based on a practitioner's view. They show most affinity to the schools of Institutionalism and of Culture.

The historical/social environment of the period, as well as claims of societal importance, are clearly exposed in the book. In the early eighties, American companies faced serious problems, partially due to severe international competition, especially from the Japanese. The authors 
tried to write a compelling and stimulating book, showing how well some companies did, and trying to explain this excellency. They were apparently disappointed with the failure of existing organization theory and tried to provide new insight.

\section{Contents and relevance}

Some important basic opinions are expressed (p. 20). The "rational model" is rejected since it is subject to 'professionalism', and has a 'numerative' and 'rationalist' character. It would 'seek[s] detached, analytical justifications for all decisions', and is said to be 'right enough to be dangerously wrong'. On page 89 , they make a promise, saying that 'to understand the relationship between performance of the excellent companies and the eight attributes, we need new theory. And that is what we intend to provide."

But they have reservations about their own theory, stating that its rightness will be difficult to discern (p. 100):

[it is not] ... 'easilly accessible, [in] a fairly early and messy state of development, largely obscure, and tied to the reall world only by implication."

The latter point makes no serious problem, as it applies to all theories. For the other points, we must acknowledge the author's honesty.

A point of philosophical interest is the presence of paradox. First Peters and Waterman focus on the contradictions that are built into human nature. This point is important enough for a complete citation (p. 100):

The excellent companies have learned how to manage paradox...

1. We like to think of ourselves as winners, but our talents are normally distributed]. ... We are not as good as we like to believe, but rubbing our noses daily in that reality doesn't do us a bit of good ...

2. While we hawe a very limited capacity to process information explicitly with our left brair, our unconscious mind (the right brain) is very powerful in being able to accumulate a vast storehouse of patterns. 3. While we are all creatures of our environment - very sensitive and responsive to extienall rewards and punishments - we are also strongly driven from wittin self-motwated.

4. We desper tely need meaning in our lives and will sacrifice a great deal to institutions that will provide meaning for us. Yet, we simultaneously need independence, to feel as though we are in charge of our destinies, and to have the abillity to stick out.

5. For all the focus on salfointerest rationality in management theory, organizational participants spend a majority of their working time doing things that are not in thoir self-interest.

It should be noted that these assertions exemplify the typical eloquence and rhetoric flavor of the book. Concepts as those mentioned here are not elaborated into more detail. 
More paradoxes abound in the work. In a review by Van de Ven (1963, p. 623) eight more are collected, like 'Small is beautiful in order to get or stay big', there is need for both flexibility and rigidity at the same time, the firm must diversify but also 'stick to the knitting", and so on. The authors conclude that most received theory "is not loose enough to consider the relative lack of structure and the need for a wholly new management logic to ensure continuous adaptation in large enterprises" (p. 107). But at the end of the book the promised alternative for current, allegedly inadequate theory is not given.

Their basic contentions are the following.

Excellent companies would have learned to manage paradox. They maintain eight

characteristics, or rules:

1. action is more important than too much analyzing,

2. keep in close contact with the customer,

3. encourage innovative entrepreneurship of employees,

4. consider personnel as the most important factor,

5. express and maintain company values,

6. do not enter unrelated businesses,

7. keep a simple organization and a lean staff,

8. maintain the right balance between centralization and decentralization.

In the study, both structure and strategy are addressed, with direct implication. The work pertains to large companies, as it based on the evidence of 43 important and well-run American companies. The industries observed are high technology, consumer goods, general industry, service, and project management.

\section{Process of knowledge development}

In the first round of theory development existing theories are checked and their valid elements combined. In the second round observation is used to derive theoretical generalizations and hence to formulate recommendations. No attempts are made to devise constructs and to operationalize these. As a consequence, metered quantities (financial data) cannot be linked to the terms of description or prescription.

The authors discuss a number of schools in organization theory. They follow W.R. Scott's classification in 'Theoretical Perspectives' (Meyer et al., 1987), who distinguishes 1) WeberTaylor, 2) Mayo-McGregor-Barnard-Selznick, 3) Chandler-Lawrence-Lorsch, and 4) WeickMarch. The authors select certain ideas, aspects and accents as valid while rejecting others. Criteria for the selection are not disclosed but seem to be intuitively linked to the eight principles. More salient is their opposition: "It was a eulogy to intuition, and a counterblast against all the scientific management and operational research that had dominated management thinking until them.' (Pocket MBA of The Economist, 1994)

The authors defend that lessons from 'best run' companies can be applied to other ones, and that by the use of these lessons the impact of economic difficulties will be eased and foreign competitors will be defeated. 
A general assessment of the excellent companies by the authors is summarized on page 13:

'th short, the excellent companies were, above all, brilliant on the basics. Tools didn't substitute for thinking. Intellect didn't overpower wisidom. Analysis didn't impede action. Rather, these companies worked hard to keep things simple in a complex world. They persisted. They insisted on top quality. They fawned on their customers. They listened to their employees and treated them like adults. They allowed their innowative product and service "champloms" long tethers. "They allowed some chaos in return for quick action and regular experimentation."

Again, this description is hard to be linked to concrete observables. Eight principles of excellence are hypothesized (pp. 63, 74, 170, 208, 242, 280 - 285, 293, 324). They are summarized here, together with the wordings of the authors:

\section{M bias for action - do it, try it, don't analyze the} problem to death.] 'You more likely act yourself into feeling, than feel yourself into action".

2. [Close to the cusiomer.] 'If you can't understand the customers, you won't understand the business.... The answer on how much service is enough or what kind of quality is right lies in the marketplace:

\section{3. [Autonomy and entrepreneurship.] "Innovation} success is a numbers game.... Make sure you generate a reasonable number of mistakes".

\section{Productivity through people. The excellent} companies treat their employees - not technology - as the root source of quality and productivity gains.)

Respect for the individual is a central bellief. The key to a people orientation is trust ... [and] a great number of people programs .

\section{Itands-on, walwe driven - MBWA (management by} wandering around). I If asked to provide an all-purpose bit of advice, we might be tempted to reply, Figure out your value system. Decide what your company stands for ... Set and demand standards of excellence. ...

Anybody who accepts mediocrity in school, in job, in life - is a guy who compromises. And when the leader compromises, the whole damn organization compromises:
6. [Stick to the knitting.] Never acquire a business you don't know how to run... The qualitative guiding value and the handsion approach are at war with diversification. Diversification dilutes the guiding qualitative theme - in part because the acquired firm undoubtedly thas different shared values, but also because themes such as quality tend to lose meaning when the organization strays far afiell'.

7. [Simple form, lean staff.] 'Most acronyms stink, Not KISS - Keep It Simple, Stupid! One of the key attributes of the excellent companies is that they heve realized the importance of keeping things simple despite averwhelming gemuine pressures to complicate things".

8. [Simultaneous loose-tight properties - both centralized and decentralized.] "Autonomy is a product of discipline. The discipline (a few shared values) provides the framework. It gives people confidance tto experiment) stemming from stable expectations about what really counts. The rules' in the wellitun companiles have a positive cast. They deall with quality. service, unnowation, and experimentation. They focus on expanding and building, the opposite of restraining. The value set is for all seasons"

Derivation of the hypotheses is absent. They are cast in the same formulation as the tenets. Observation is the first phase of knowledge development. Peters and Waterman applied the case method to selected companies, collecting information from financial reports and from 
interviews with top management. The variables used to measure performance of companies are compounded asset growth, compound equity growth, average ratio of market to book value, average return on total capital, average return on equity, and average return on sales. All were observed over a 20-year period.

\section{Assessment following the $A-\mathbb{F}$ - scheme}

Existing theories are challenged. This stage of problem definition belongs to box $\mathrm{A}$, hypothesis (p. 20). As stated, eight principles of excellence are hypothesized (pp. 63, 74, 170, 208, 242, $280-285,293,324)$. The philosophical problem of paradox (p. 100, and many other instances) is stressed. This is hypothesis in itself. Conjecturing involves the eight characteristics of excellent companies, which are at the same time proposed as rules (E). Observation is largely elaborated, with its number of 43 case studies. The definition of excellence is expressed in historical financial figures. Future success is found to be related to research and the quality of management, among other factors. In


general, definiteness and precision are weak.

Induction (D) is only seemingly present. Observation (C) served to identify the successful firms, but the hypotheses were not induced from these observations in a scientific way. Prescription is the direct application of hyporhesis. Many of these rules are contradictory. The authors state themselves state that their use is not easy in view of the many paradoxes.

No intervention $(\mathbb{F})$ is reported as part of the study. According to Van de Ven (1983) "The data presented to develop and support the eight characteristics would, by most scientific standards, not be admissible evidence of valid knowledge. But this is not a theory-testing effort; it is a rich display of idea generation and synthesis that may lead to the creation of a new theory.' So validation is not in order. The degree of elaboration of hypothesis and prescription is moderate. Observation is most elaborated. The utility is indirect: the criteria for excellence may serve as conceptual guidelines for organizational research as a base for desigm. In summary: this theory is not rich in metatheoretical rigor.

Conclusion

The relation to earlier work of others was explained above in the section contextual points. The theory in itself has been refuted shortly after its presentation, as some of the excellent companies, even those still satisfying the eight criteria, came into serious problems. Both writers put their own book into perspective when writing their next. In "Thriving on Chaos" (1985), Peters' opening sentence reads: 'There are no excellent companies'. And Waterman calls his 'The Renewal Factor' (1.987) 'a more balanced book'. 
But the book has fecund elements in the recommendations about further theorizing. As a means for inspiration for managers and workers, the book has had great rhetoric value. It sold five million copies.

The identification of the paradox problem is certainly a step forward towards better organizational theory. It should be noted however, that the identification of paradox should not be the end of research, but its very beginning.

\subsection{Paul J. DiMaggio and Walter W. Powell}

\section{Bibliographical data}

DiMaggio, P.J., and W.W. Powell, The Iron Cage Revisited: Institutional Isomorphism and Collective Rationality in Organizational Fields, in: Powell, W.W. \& P.J. DiMaggio, The New Institutionalism in Organizational Analysis, Chicago, 1991 (first printed version in American Sociological Review 48 April 1983).

\section{Contextual points}

At the time of publication, both authors were professors of sociology. DiMaggio (b. 1914) was at Yale University. Powell (b. 1952) taught for 11 years at the University of Arizona but was recently appointed as a professor at Stanford University.

The scientific environment or school of this study is the one of organizational sociology and institutionalism. The study must be seen in the historical/social environment of academic research in the eighties.

\section{Contents and relevance}

The authors' basic position and the intent of their research follow from the basic question for which explanation is sought. They wonder why there is such a startling homogeneity of organizational forms and practices. Moreover, they argue that the causes of bureaucratization and rationalization have changed (pp. $63-64)$ :

\footnotetext{
'Organizations are still becoming more homogeneous, and bureauciracy remains the common organizational form. Today, however, structural change in organizations seems less and less driven by

competition or by the need for efficiency. Instead, we
} contend, bureaucratization and other forms of organizational change occur as the result of processes that make organizations more simillar without necessarilw making them more efficient."

This position is called institutionalism. About 75 studies are cited to illustrate and support it. The authors criticize functionalist as well as Marxist explanation (p. 78). Sociological 
functionalism and Marxism contend that elites force organizations to become isomorphic. In their view this is paradoxical as it assumes that societies or elites are all rational, while most organizations are non-rational. The natural selection hypothesis is questioned as well (pp. 78 79). This view asserts that less fit organizational forms are supposed to be weeded out. "Such arguments, as we have contended, are difficult to mesh with organizational realities."

They defend the advantages of an explanation based on institutional isomorphism per se (pp. $79-80)$ :

- this mey explain why elites often get their way. while at the same time organizational life remains irrational, power is frustrated and innovation is lacking;
- it may offer a perspective on "the political struggle for organizational power and survival that is missing from ... population ecology':

- it may help social policy in the fields in which the state works through private organizations."

The basic contention of the work is that organizations tend to develop similar organizational forms and practices, to a degree depending on organizational and environmental conditions. The hypotheses are pertaining to both strategy and structure. It is the larger organization that is addressed. Their implication for design is indirect, while the nature of their assertions is hypothetical.

\section{Process of knowledge development}

As stated, the authors draw on a great number of other theories. Examples are Giddens (1979, structuration theory), Woodward 1965, Child and Kieser 1981, Hannan and Freeman (1977, organizational ecology), White et al. 1976, DiMaggio 1983, Selznick 1957, Meyer and Rowan 1977, Schelling 1978, Tolbert and Zucker 1983, Meyer et al. 1985, Carroll and Delacroix 1982, Freeman 1982, Hawley (1968, on isomorphism), Meyer 1983b, and Fennell 1980 (on the distinction between competitive and institutional isomorphism). Kanter (1972) is examined (isomorphism as an outcome of outside pressures) as well as March and Olsen (1976), together with Cyert and March (1963), and Katz (1975).

The phase of hypothesis comprises several definitions (pp. 64-65, 8In):

'By orgarizational freld' we mean those organizations that, in the aggregate, constitute recognized areat of institutional life: key suppliers, resource and product consumers, regulatory agencies, and other organizations that produce similar services or products... The field idea comprehends both comnectedness and structural equivalence. .... connectedness: the existence of transactions lformal and informall tying organizations to one another a clique: a set of organizations strongly connected to one another structural equivalence: similarity of position in a network structure organizational change: change in formal structure, organizational culture, goals, program, or mission" 
The concept of isomorphism is introduced after Hawley $(1968, p .66)$ as " a constraining process that forces one unit in a population to resemble other units that face the same set of environmental conditions".

Three mechanisms of institutional isomorphic change are proposed (pp. 67-72), namely the coercive mechanism (coming from political influence for reasons of legitimacy), the mimetic one (stemming from standard responses to uncertainty), and the normative one (associated with professionalization). Coercive isomorphism results from formal and informal pressures from other organizations or cultural expectations. These influences may come from authorities, affirmative action, and from nonprofit-organizations paying taxes. Structures tend to become isomorphic in the process of coping.

Mimetic processes are said to produce 'When organizational technologies are poorly understood ..., when goals are ambiguous, or when the environment creates symbolic uncertainty'. In this case organizations may model themselves on other organizations." Structures or other characteristics of successfully innovating competitors may be copied under influence of stakeholders or consultants. Public authorities may adopt 'market-like' attitudes. Normative pressures would stem from professional organizations that may try to standardize working practices. They may do this in order "to establish a cognitive base and legitimization for their occupational autonomy". Important sources of this effect are the formal education of the professionals based on the cognitive base of university specialists. It may also come from the growth and elaboration of professional organizations. This has effect the on the filtering of recruits, so "... Jewish naval officers, women stockbrokers, or black insurance executives are likely to be subjected to pervasive on-the-job socialization."

A number of 'predictors of isomorphic change' are proposed. The first series is at the organizational level (pp. $74-76$ ):

"Hypothesis A-1. The greater the dependence of an organization on another organization, the more similar it will become to that organization in structure, climate. and behavioral focus.

Hypothesis A-2. The greater the centralization of organization A's resource supply, the greater the extent to which organization A will change isomorphically to resemble the organizations an which it depends for resources.

Hypothesis A-3. The more uncertain the relatianship between means and ends, the greater the extent to which an organization will model itself after organizations it perceives as successful.
Hypothesis A-4. The more ambiguous the goals of an orgarization, the greater the extent to which the organization will model itself after organizations it percerves as successful.

Hypothesis A.5. The greater the reliance on acadomic credentials in choosing manegerial and staff personnel, the greater the extent to which an organization will becomo khe other organizations in its field.

Hypothesis A-6. The greater the participation of organizational managers in trade and professional associations, the more likely the organization will be. or wifl become, like other organizations in its field.' 
It should be noted that the authors make their statements in an orderly and systematic way, in contrast to many books on organization theory.

The second series of hypotheses are supposed to be relevant for the field level (pp. $76-77$ ):

'Hypothasis B-1. The greater the extent to which an organizational field is dependent upon a single for several similarf source (s) of suppont for wital resources; the higher the level of isomorphism.

Hypothesis B-2. The greater the extent to which the organizations in a field transact with agencies of the state, the greater the axtent af isomorphism in the field as a whole.

Hypothesis B-3. The fewer the number of visible arternative organizational models in a field, the faster the rate of isomorphism in that field.
Hypothesis B-4. The greater the extent to which technologies are uncertain or goals are ambiguous within a field, the greater the rate of isomorphic change.

Hypothesis B-5. The greater the extent of professionalization in a field, the greater the amount of institutional isomorphic change.

Hypothesis B-6. The greater the extent of structuration in a field, the greater the degree of isomorphism."

More concepts are introduced, namely isomorphism, organizational field, connectedness, and structural equivalence (p. 65):

"The structure of an organizational field camnot be determined a priori but must be decided on the basis of empirical investigations. Fields only exist to the extent that they are institutionally defined. The process of institutional definition, of "structuration", consists of four perts:

- an increase in the extent of interaction among organizations in the field.

- The emergence of sharply defined interocaanizational structures of domination and patterns of coalition.
- an increase of the information load with which organizations in a field must contend, and

- the development of a mutuial awaremess among participarats in a set of organizations that they are involved in a common enterprise. (DiMaggio 1983)

Once disparate organizations in the same line of business are structured into an actual field las we argue, by competition, the state, or the professionsl. powerful forces omerge that lead them to become more similar to one another." 


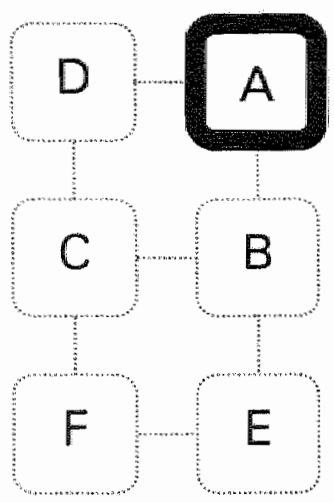

Hypothesizing (A) is reported in problem formulation (63-64), conjecturing (pp. $67-72,74-80$ ), definitions (pp. 64-65, $81 \mathrm{n}$ ), and conceprualization (p. 65).

The study is limited to a set of well-argued hypotheses. Hypothesis is largely elaborated, with adequate defmireness and precision. Other elements of knowledge development are not reported. Hence, validity is not testable. Coherence is present in the discussion about related theories. Metatheoretical rigor is present within box A. The utility for organizational design is minute.

\section{Conclusion}

There is a close relationship to earlier work of authors like Weber, Giddens, Hannan \& Freeman, and Hawley. A valuable point is in the assessment of a large volume of relevant literature. Paradoxes are found and examined, and a new set of hypotheses ensues. The authors" hypothesis represents a fecund element as they offer a basis for a host of interesting subsequent studies, varying from hypothetical reflections to directly derived quantitative research.

\subsection{Geert Hofstede}

Bibliographical data

Hofstede, G., Culture's Consequences, Beverly Hills CA, 1984.

\section{Contextual points}

The author is a social psychologist. Hofstede (b. 1928) has degrees in mechanical engineering (Delft University) and psychology. He worked as a manager in the textile industry before entering IBM Europe, where he conducted his famous survey among 116,000 employees worldwide. He continued his research after becoming a professor at IMEDE. At the time of this study, Hofstede was the number fifteen most cited social scientist.

The author borrowed hypotheses from ethology (Eibl-Eibesfelt, 1976) and human ecology (Hawley, 1968). 
In the historical/social enwronment of the beginning of the eighties Japanese industrial supremacy loomed ahead (for this point see also Peters \& Waterman, section 5.22).

Understanding of this phenomenon was urgent. One line of research was directed at cultural determinants of societies. At that moment, Hofstede's research was finalized and encountered great interest.

\section{Contents and relevance}

The author's basic position and the intent of the research become clear from the summary of the book on page 11:

This book explores the differences in thinking and social action that exist between members of 40 different modern nations. It argues that people carry "Mental programs" which are developed in the family in early childhood and reinforced in schools and orgenizations, and that these mental programs contain a component of national culture. ... Crass-cultural studies usually lack ... a theory of the key variable. culture itself.' 'Cu/ture's Consequences aims at being specific about the elements of which culture is composed. If identifies four main dimensions allong which dominant value systems in the 40 countries can be ordered and which affect human thinking. organizations, and institutions in predictable ways. The fact that the survey data were collected twice over a four-year interval allows an analysis of value developments aver this period:..."

The central basic contention is that organizations are culture-bound. Culture can be ordered along four dimensions, which affect human thinking, organizations, and institutions in a predictable way. Four constructs (dimensions) would determine the characteristics of culture, namely power-distance, uncertainty-avoidance, individualism, and masculinity. The theory is not directly useful for the design of structwe and strategy, but it provides a basis for the building of knowledge about these subjects. This is especially the case for personnel management. Inportant for structure are indications for authority mechanisms, need for and effects of formal rules, preparedness to take responsibility, usefulness of techniques like management-by objectives, and empowerment. Four strategy considerations are presented for the choice between outsourcing or integrated operation in certain areas. The work has implications for the prediction of national competitiveness as well.

The research seems to be foremost applicable to larger organizations.

\section{Process of knowledge development}

Hypothesizing starts with a tenet borrowed from Durkheim (1977). On page 16 Hofstede states that 'The transfer of collective mental programs is a social phenomenon which ... we should try to explain socially and not reduce it to something else like race." Other important sources are Mulder (1977) and the Aston Group (1976), leading to the hypothesis of the first dimension: power distance (p. 65): 
'According to Mulder's Power Distance Reduction theory, subordinates will try to reduce the power distance between themseives and their bosses and bosses will try to maintain or enlarge it. The present study, however, suggests that the level of power distance at which both tendencies will find their equilibrium is societally determined. it can be expressed in a Power Distance Index $(\mathrm{PDI}$ "... "the Power Distance dimension is assaciated with the "concentration of authority" dimension in the Aston siudies of organization structures."

The second thypothesized dimension is uncertainty avoidance. Its operationalized indicators are rule orientation, employment stability, and stress. (p. 110).

The third dimension is individualism (p. 148):

"It is reflected in the way people live together - for example, in nuclear families, extended families, or tribes; and it has all kinds of walue implications.... Sociology has provided us with a variety of distinctions associated with the individualism dimension, of which the best known is probably Tönnies" Geneinschat (low individualism) versus Gesellschaft thigh individualism!."

The fourth dimension is masculinity. Masculinity has femininity as its opposite pole (p. 176):

"... the issue is whether the biollogical differences between the sexes should or should nat have implications for their roles in social activities. ... The predominant socialization pattern is for men to be more essertive and for women to be more nurturing. In organizations, there is a relationship between the perceived goals of the organization and the career possibilities for men and women; business organizations have "masculime" goals and tend to promote men; hospitals have more 'feminine' goals and, at least on the nursing side, tend to promote women.... A review of survey data on the impartance of work goals shows near consistency on men scoring advancement and earnings as more important, women

\section{interpersonal aspects, rendering service and the} physical environment as more important. ... The factor score of the 40 countries an this factor has been used as the basis for a country Masculinity Index (MAS) which measures to what extent lthel respondents in a country (of both sexes) tend to endorse goals usually more popular among men thigh MASL Jor among women (low MAS). .. MAS is correllited, together with low uncertainty avoldence, with need for achidevement as measured by McClelland ... From all these data, air integrated picture has been developed of the masculinity and feminimity societal norms, the ir likely origins, and their consequences for society all large, for ideoliogy, and for organizations."

As a final phase of hypothesis, the four dimensions are integrated. Different sources produce highly correlated data (p. 211):

\section{The combination of PDI and UAl affects in particular} organization structures and functioning throwgh the implicit models of the ideal organization which people carry. It also affects which theories of organization will gain popularity in a country. The interaction of UAl and MAS is shown to relate to the dominant motivation pattern, thereby refuting the universality of the American motivation theories of McClelland and Maslow. ... This chapter summarizes the significant correlations that were found between the [IBM] indices and non-[IEM] data: data from narrow surveys, from 
An example of operationalization can be found on page 13 :

"Mertal programs can be found at the universal, the collective, and the individual level. They must be operationalized in order to be measured; four different strategies of operationalization are discussed. Values are distinguished into values as the desired and values as the desirable. Culture is defined as collective programming of the mind. The word is reserved for describing entire societies; for groups within societies, 'subculture is used."

\section{A description of observation is found on page 11}

The data used for the empirical part of the research were extracted from an existing bank of paper-and. pencil survey results collected within subsidiaries of one large multinational business organization in 40 countries, and covering among others mary questions about values. The survey was held twice, around 1968 and around 1972, producing a total of over 116,000

Induction is discussed too, for instance (p. 11):

The four main dimensions on which country cuitures differ were revealed by theoretical reasoning and statistical analysic. They were labeled Power Distance, questionnaires; respondents can be matched by occupation, age, and sex. Additional data were collected among managers participating in international management development courses and unirelated to the first multinational business organization.

Uncertainty Avoidance, Individualism, and Masculinity. Each of the 40 countries could be given score on these four dimensions:

It is also found when independent variables are selected (p. 39):

The ecological dimensions of Power Distance and Uncertainty Avoidance were found through an eclectic analysis of data, based on theoretical reasoning and corralation analysis. In these two dimensions, work god importance data had not been used. The processing of these needed all extra step: first, scores had to be standardized across goals In order eliminate acquiescence. Then they were subject to ecological factor analyses of occupation scores and of country scores; the country analysis led to the identification of the ecological dimensions of Individualism and Masculinity."

Another instance of induction obtains when related explanations of uncertainty avoidance are examined (p. 110):

"The most important correlations are with national anxiety level, as found in national medical statistics by Lynn, and negatively with need for achievement, as measured ... by McClelland [196】].
These and ten other cross-mational survey studies allow the composition of a coherent picture of the UAl syndrome as related to anxiety, need for security, and dependence upon experts. The country UAI scores are 
then correlated with seven national geographic, economic, and demographic indicators; the correlates differ strongly for wealthy and for poor countries; the one consistent correlate is faster aconomic arowth with hilgher UA:"

Finally, trends over time are induced (p. 232).

Assessment following the $A-F$ - scheme

The report on the research starts with a general discussion about the problem and a flawless exposition of its methodological approach (chapter 1, pp. 13-38). Preliminary and metatheoretical hypothesis (A) includes problem formulation, definitions, and conceptualization. Here flawless definiteness and precision are found. In operationalizarion



First stage of research



Second stage of research

(B) the operationalized concepts for the large-scale surveys $\left(60^{\circ}\right.$ 'core question' and 64 'recommended questions', divided over four categories, $43-47$ ). The subsequent observation (C) includes the design of the surveys, detailed definition of the variables, and their processing (48-61). Induction (D) includes the conjecturing and inductive modeling based on the four essential constructs (chapters $3-6$ ).

The modeling leads to the second stage of research (chapter 7) that is described above. The funal conclusion ends the study with a new, strong hypothetical position (A).

Coherence is aptly dealt with, for instance on page 65 .

The research processes are reported in great detail, even in this abridged version of the research report, and adhere flawlessly to metatheoretical requirements.

The method used demonstrates the validity of the theory. The theory is useful for organizational structure or strategy in an indirect way as it offers guidelines for decisions on the matter. 
The first round of research took place in two stages (around 1968 and 1972) at IBM. It encompassed $\mathrm{A}-\mathrm{B}-\mathrm{C}-\mathrm{D}-\mathrm{A}$. The second was done at IMEDE and comprised $\mathrm{C}-\mathrm{D}-\mathrm{A}$.

\section{Conclusion}

The theory is based on one of the most substantive research projects in the history of organizational science. It covers the complete $\mathrm{A}-\mathrm{B}-\mathrm{C}-\mathrm{D}$ - cycle of knowledge development.

The relation to earlier work has been discussed above. Fecund elements of the study are its consequences for policy and research (p. 252):

'The main finding is that organizations arre culture.

bound. ... even the theories developed to explain behavior in organizations reflect the national culture of their author, and so do the methods and techniques that are suggestad for the management of organizations. The consequences of this cultural relativity are described for a number of areas: motivation, leadership, and decision-making. Management By Objectives, planning and control, organization design, Management Development and Organization Development, humanization of work, industrial democracy, compeny ownetship and control, and, finally, the reaction of the local enviromment to organizations."

The four constructs and the corroborated regularities have proved to be fruitful bases for further research. For later discussions, see Van de Vijver \& Leung (1997).

\subsection{Chris Argyris}

\section{Bibliographical data}

Argyris, C., Strategic Change and Defensive Routines, Marshfield MA, 1985.

\section{Contextual points}

Argyris (b. 1923) is a psychologist. He began his career at Yale University and was a professor of education and organizational behavior at Harvard University. His writings focus on the personal development of people and their potential to contribute to organizations. From the beginning his work has been devoted to the humanizing of organizational conditions, in the interest of workers in the organizations and of the organization itself.

The author's scientific enviromment and discipline belong to the tradition of human relations. This school begins with Mayo. Organizational learning is considered to be essential. The book is a teaching manual, not a theoretical exposition. 
From the Preface it becomes clear that puzzling observations invoked his research $(i x)$ : (1) why do plans for strategic change fail so often, despite acceptance and good intentions of key individuals, and (2) why can expected defensive reactions of those involved not be prevented or overcome?' The author wants to corroborate the following explanation of this phenomenon (p.xi):

We may be socialized to deal with threat that is counterproductive to genuine solutions. ... We are taught to act counterproductively in the name of being humane, thoughrful and civilized, Moreover, the processes that the human mind uses to help us meke. sense of the world may be the same ones that help us to get in rrouble:

On page xii the author's intention of the book is said to applying his theoretical ideas to strategy implementation. He wants to make suggestions about how to formulate and introduce strategic plans in such a way that resistance is prevented or neutralized.

The author gives his vision on good theory ( $p$. xiii):

When concrete advice can be connected to abstract theory, then we have the best of both worids. The analogy that comes to mind is the aerial camera. The higher up the airplane can fly, the more comprehensive the picture can be. The good camera produces comprehensiveness without losing specificity. Agood photograph shows details with clarity."

These apt words on theory should not be misunderstood. Their implied promise to develop general assertions for testable use is not kept. The book has quite another objective, namely the overcoming of resistance against the implementation of strategic plans.

Two common types of strategy formulation are discussed on page 2. One starts with rigorous empirical analysis, based on theories of the firm. The second is 'the collecting, discussing, and massaging of the data by the top management group that administers the organization. Both evoke feelings of threat, which lead to defensive routines. "Change in dealing with threat ... is the name of the ... game." (p. 3)

The expected audiences of the book are all that want to design and (help to) implement difficult and innovative strategies (Introduction). The author hopes to develop a useful theory (p. 125):

'... the focus of Part 11 is how to identify, reduce, or better wet, prevent defensive routines... The theory. methods, and competencies that I present hold for dealing with any type of defensive routine."

Here it becomes clear that the theory is not about strategy formulation, but about the problems of its implementation. 
The basic contention of the book is that people in organizations unconsciously maintain defensive, self-reinforcing routines impeding change. This phenomenon is said to be the result of childhood learning. Those trying to implement changes are subject to the same mechanism. By demonstrating the presence of these mechanisms in reasoning routines, and by introducing a learning process, resistance to change can be mitigated.

The study pertains to the implementation of strategy. It is not meant to contribute to cognitive improvement of the design of strategic plans. In that sense it could be characterized as indirect.

\section{Process of knowledge development}

Some examples of hypothesizing are given hereafter. The first is about reasoning and designing to deal with threat. Earlier research would have indicated that in cases of potentially threatening information, a specific way of reasoning is followed (pp. 37, 76):

\begin{abstract}
In the world of management strategy, individuals often divide reasoning into saft and hard, sulbjective and objective. Defensive reasoning is often considered to be soft and subjective. This division is usually made by the more analytically and tough-minded executives as well as strategy professionals. The point is that this is
\end{abstract}

\author{
not a valid division: indeed, it may be a defensive \\ routine. \\ Thus, the key features of defensive reasoning are the \\ unawareness of the inferences made, the lack of \\ testing those inferences publicly, combined with the \\ certainty that none of this is happening. Defensive \\ reasoning is inflexible and unchangeable. ..."
}

The author now proposes 'Model \Theory in use' (p. 82). It consists of three boxes: governing values, leading to action strategies, leading to consequences.

'Igoverning wallus are]:

- Maximize winning end minimize losing.

- Minimize negatiwe feetings,

- Maximize rationality".

[action strategles are:]

- Advocate your position in order to control and win.

- Unilaterally save face - own and others" [consequences are]

- Miscommunication.

- Mistrust,

- Protectiveness,

- Self-fulfilling prophecies,

- Self-sealing processes.

- Escalating error."

After its examination, this theory will be dismissed and replaced by 'Model II Theory in use' (see hereafter).

A hypothesis about causes of defensive routines is formulated on page 91: 'We, as a society, hold a theory in use that is basically oriented toward unilateral control, winning not losing, and face saving. "This would lead to defensive reasoning, characterized by the use of soft data and reasoning that is not publicly testable.

The author describes received microtheory of implementation (p. 96): 
The advice in the literature uses what might be called a microtheory of implementation.

If the readers understand what is written, th they wish to implement the advice, Hthey are free to implement the advice.

Ther they can implement the advice effectively."

But this position has its flaws, and the causes of the flaws are supposed (p. 101):

I have observed cases in which managers understood the analysis but did not suppors it. However, they covered up their true feelings by bypassing the issues. and thereby activating defensive routines. ... I believe the gaps [in theories] go unnoticed [because] the writers are as human as the rest of Us. They also are influenced by the same defensiwe reasoning when dealing with defensive routines as is taught to all of us in early life.

On page 5, three case studies are presented, leading to three conclusions: 1) not motives (which are usually positive), but reasoning should be studied, 2) problems with defensive routines may be based on the reasoning behind them, and 3) the 'focus on the reasoning process gives us an effective lever for changing the status quo."

This is an example of observation, followed by induction.

One more example of it can be found on the pages 101-121, where four case studies are discussed, together with their summary (p. 123):

'.... the two most powerful sources for help to deal with defensive routines around strategy formulation and implementation - namely, the strategy implementation literature and consultants - tend to reinforce unintentionally the causes of the defensive routines.... It is fair to conclude that there exists a worldwide set of loops, beginning with individuals and moving to groups, intergroups, organizations, and finally the liarger culture, that creates, reinforces, and sanctions the use of defensive routines and bypass routines to deal with threatl wherever it occurs."

That would mean that the solution is the problem. But the author has the same problem as well (p.129):

'... there is a dillemma that I face as an author. How do I describe what action to take? I do not want to repeat the error that the authors made in the strategy literature reviewed in Chapter 4. Inamely, adopting the same defensive routines as those resisting strategic plansl.....

I have made several choices to try to deal with the problem. First, I use transcripts from tapes recordings or notes from observations (ailong with interviews) to provide the most directly observable data available. I also connect these data to my concepts. In doing so, I hope to make public my reasoning processes so that you can judge for yourselt whet his going on. Second, I include examples in which the people involved in changing the organization were facing the same problem I face in this book. ... Lpresent the reasoning behind their solutions as well as the sollutions.

Third, I present transcriptions and observations of how the consultants fared when they met with fop managernent, including the latter's reactions and how the former dealt with the reactions. 
Fourth, whenever I an focusing on what actions people take, I point ow what I believe were errors as well as correct responses. Whenever I identify errors present othor strategies that might have been more eftective. Ildentify patterns of effective actions that emerge and state the theory as well as the rules that underlie them.'

In chapter 9, a second "model/theory", as opposed to the first, is presented. The author assumes a seemingly functionalist position (p. 260). 'Model II Theory in use' is presented, having again three boxes: governing values, leading to action strategies, leading to consequences.

"[governing values are:]

- Valid (confirmable) information,

- Free and informed choice.

- Internal commitment to the choice";

[action strategies are]:

- Advocate youl position and combine this with inquiry and public lesting.

- Minimize unilateral face saving: [consequences are]:

- Reduction of self-fulfilling, self-sealing, errorescalating processes,

- Effective problem solving.

Both the Model I and II 'Theory in use' as described above are in fact sequences of the A - C type: hypothesis, followed by observation. Derivation and testing are not discussed.

The matter discussed is not easy to grab, as "solutions" tend to worsen problems or to invoke new ones. To illustrate this point, one more example of observation and induction will be cited in full. It is discussed in chapter 8 (p. 233):

"In this chepter, I tell the story of how the senior consultant of a team, skiled in deating with technical planning issues and defensive routines "was able to hellp a group begin to axamine undiscussable routines that hed formed around an important technical issue. The story is told in three phases. The first one will be faimiliar to line executives and to planning professionals because it is the story of the first feedback session. The purpose was not simply to inform the clients but also to engage them in questioning, reinterpreting, and if necessary, redesigning their work activities. This, in turn, might facilitate the second purpose: to create a culture within the top group to question themselwes, to discuss any defensive routines, and eventually to ask tough questions of any new strategic plan..

In the second phase, we see how the consultant, with the help of the clients, mekes explicit some importent business errors. While exploring the business errors, the consultant was abte to help the clients express some of their fears. ... This leads to phase three in which the CEO was identified as one factor and, in turn. the immediate reports were also identified as an important factor.

By the end of the three phases, the consultant has helped, lusing an incremental process of inquiry, to surface business errors and defensive routines that had led to errors, and further defensive routines that had helped to cover up the errors. The story ends with the clients and consultant ready to deal with the technical issues and defensive routines.... They are positioned to learn how to detect and correct errors, meaning they, as individuals and as an organization, would have been helped to learn how to learn and perform more effectively." 
For those familiar with consultancy work this all sounds quite normal. It is common practice for managers and consultants to exhume the real causes of trouble behind the appearances, and then to tackle them.

The C - A-jump of the cycle of knowledge development can be seen on page 231:

In the relationships where the defensive routines are addressed, the clients, even thase who are conflict awoiders, often choose to repeat the feedback sessions with their immediate reports. It is at this point that new problems arise. Subordinates may appear to discuss diagnoses more easily than to plan action steps because they may have differences with their superiors and are hesitant to express them. We now have a new condition of threat. The rules that we have just described to deal with threat would apply in this case. Once the differences are worked through, then this enlarged group could begin to redesign the planning process. The consultants could provide their views, but the more important value added would be to help tha clients redesign the process. One way to begin this taskik is to have the clients select a difficult and important strategic question. The clients and consultants could work jointly on formulating a new strategy. Periodically, they could reflect on their experience to redesign the planning process. The redesign would be examined by this group and other relevant plavers for possible errors and gaps. Finally, the consultants may help the clients generate a process by which the new plannirg process is monitored so they can redesign it as conditions warrant."

Rules are present where consistency is recommended to obtain participation (p. 261):

"It is inconsistent to encourage others to inquire, to become vulnerable, when your governing values are to be in unilateral control and to win and not lose. The recipients will soon sense that they are being manipulated and act accordingly. '

On the next page productive reasoning is recommended as a rule (p. 262). It is said to comprise the use of hard data (not just figures but also tape recordings to understand defensive routines and other errors), "explicit premises, explicit inferences, and publicly testable conclusions." The final chapter gives a summary and implications of the hypotheses advanced so far (p.337). Examples of the wicked world are described, like the behavior of newspaper people stretching or bending the truth in order to get an interesting story, without consideration for the reputation or feelings of individuals.

\section{Assessment following the $\mathrm{A}-\mathrm{F}-$ scheme}

The author claims to provide a theory (p. 125). Hypothesis (A) includes conjecturing (pp. 76, $82,91,96,101$, and, after preliminary observation, chapter 9). Observation (C) is the core of the book. It includes case studies (pp. $101-123$ ). The outcome of these studies is discussed, but no better hypotheses are obtained by induction. Instead, new rules (intervention, E) are formulated (pp. 261, 262). All three applicable elements of knowledge development $(A, C, E)$ are moderately elaborated. As stated the book is a teaching and learning manual. It is a 




problems of change.

verbatim representation of events that can only be used effectively in classroom simulations where participants learn by experience to change their behavior. The book does not seek theory as used in our terminology, in spite of it claims to connect 'concrete advice ... to abstract theory' (p. xiii). Definiteness, precision, coherence, systematic structure, and metatheoretical rigor are not intended.

\section{Conclusion}

Argyris draws on the findings of the human relations school. His book is, as stated, a teaching manual that does not seek the advancement of knowledge, but the training of those involved in

\subsection{Christopher A. Bartlett and Sumantra Ghoshal}

\section{Bibliographical data}

Bartlett, C.A., and S. Ghoshal, Managing Across Borders: The Transnational Solution, Boston MA, 1989.

\section{Contextual points}

Both authors have a consultancy as well as a scholarly MBA background. Today Ghoshal (b. 1948) holds the Robert P. Baughman Chair of Strategic Leadership at the London Business School. Bartlett (b. 1943) held the Class of 1966 Chair of Business Administration at Harvard Business School. The historical/social environment of the period is characterized by the changes in worldwide competition from the eighties on, which made hitherto common organization practices unsuccessful. The research findings are claimed to have broader application than originally intended and would 'have lessons for managers in all large organizations' ( $p . x$ ).

The authors apply the case study approach supplemented with interviews and a large-scale survey. In the book, they seek usefulness for managers but also value for academic colleagues, by extending the research (p. xi):

"While case resesirch ... constituted the core of our study and formed the basis of our observations and conclusions, we were also cancerned with the broader validity and generality of these findings. Therefore, we carried out some intensive and extensive surveys to complement the clinical studies. 
Points of basic importance are found at a number of places.

The study originated after observation of anomalies and failures in traditionally structured global companies. As the authors state most managers understand their strategic task when operating globally, but their problem is "the development of organizational capability to implement the new and more complex global strategies (p. $x$ )'. 'Provocative questions" induced the research, for instance (p. 3):

"Why became Matsushita in consumer electronics a world player in 20 years, while Phillips had difficulties 10 adjust, and General Electric (GE) was forced to sell its business? The same questions arise about the detergent markets concerning Unilever, Procter and Gamble (P\&G) and KAO, and again in telecommunication switching when comparing Ericsson, NEC and ATET:

The source of curiosity is elaborated in the appendix (p. 214). There were found 'wide differences in strategic and organizational response to threats and opportunities by companies from different parts of the world in the same business, [with a predominant] ... importance of their cultural background (corporate or family-owned, strong management structure vs. flexible).'

The book has three parts, each addressing a specific research topic, namely (p. 17): 1) Why the transnational: how existing capabilities affect ability to respond; this part discusses 'the development of conceptual arguments',2) What is the transnational, a particularly descriptive part, and 3) How to manage the transnational company, a part in which prescriptive propositions are advanced.

Basic contentions of the study can be summarized in the following points:

1. the orucial question is not: how to formulate a global strategy, but: how to develop the organizational capability to implement global strategies,

2. every business, function and task in a multinational company (MNC) requires a specific structural solution for each location,

3. one system for all subsidiaries (whether Japanese centralization, American formalization or European socialization) is an impediment for global success,

4. characteristics of the successful 'Transnational' are:

4.1. assets and capabilities: dispersed, interdependent, and specialized,

4.2. overseas operations: nationally differentiated, contributions integrated,

4.3. knowledge development: jointly and shared globally,

5. not a matrix structure but 'a matrix in the minds of managers' should be aimed at.

Next to these points the transnational company must be able to overcome the contradictions in simultaneously achieving I) global efficiency, 2) national responsiveness, and 3) the ability to develop and exploit worldwide-based knowledge (p. 57).

The study pertains to both structure and strategy, not as objects to be designed, but as a reference for choosing the right decision making procedures. This means that it has indirect 
usefulnews for design. It regards the large, globally operating company as follows from the citation of page $x$ above. It has axiomatic pertinence as well.

\section{Process of knowledge development}

The study has three cycles of knowledge development, corresponding with the three parts of the book. The cycles will be discussed here in the same order and indicated as Part, II, and III. The first question the authors ask themselves is how existing capabilities of companies affect their ability to cope with globalization. In this respect three types of international posture are hypothesized, namely the multinational, the global, and the international one (pp.13-15). The multinational posture focuses on a strong local presence and responsiveness, while the global mission is based on cost advantages based on global-scale operations. The international posture would emphasize on diffusing and adapting the parent company's knowledge. These contentions are based on narratives of success and failure (pp. 4 - 13). Some putative determinants are proposed, like global efficiency, specialization of manufacturing, and developments in consumer needs and tastes (toward homogenization). Other factors would be national responsiveness, ability to cope with national governments, and the development of worldwide innovations.

The following is an essential hypothesis (p. 17):

In essence, the transnational is a new management

mentality. The most fundamental objective of this

book, thenefore, is to describe, ilustrate, and advocate

the transmationad mentality ...

This position would mean that the authors look after a mentality more than a structure, or a strategy, of the globally operating organization.

On pages $20-25$ supposedly fitting characteristics in different industries in the seventies are discussed. Nine companies belonging to three different industries are examined.

Responsiveness is primarily associated with the Branded Packaged Products, efficiency with Consumer Electronics, transfer of knowledge with Telecommunications Switching. After plotting each of the nine companies onto a $3 \times 3$ 'as is' versus "should be' matrix, the authors conclude that Unilever, Matsushita and NEC fit best in their respective cells. Next, developments and new requirements since 1980 are discussed (pp. 25 - 33).

The linkage between environment, strategy, and structure is demonstrated with other narrative examples (p. 53). The authors explain that by a global strategy Matsushita defeated Philips with its multinational structure and strategy, and vanquished over GE with its international posture. At Unilever and Philips efforts to centralize product development are said to have failed by the strong inherited norms of decentralization. But circumstances change: today Matsushita's divisional structure is causing problems, as markets require systems solutions instead of stand-alone products, the development of which would be impeded by divisional competition. 
Conclusion about change are drawn (pp. 54-55):

*... changes in strategy or ... organizational ... structure, [necessary] ... to regaim fift ... are extremely difficult to achieve, since both structure and strategy are products of a company's unique and ingrained administrative heritage. ... In conceptual terms, we have described industries as gradually evolving to a similar transnational form. In operative terms, however companies face very different specific challenges. Similarly, differences in administrative heritages make the adaptation process very different, even for those companies competing in the same business.
Over time, through trial and error, the companies are developing certain similarities. Fundamentaly, they are evolving a common wision about mangging across borders. This vision recognizes the importance of adiministrative heritage both as an asset to protect and as a constraint to overcome. Another centrall belief is that the first sted loward developing the multidimensional strategic competencies needed in transnational businesses is to build organizational capabilities. Such a management mentality, mora than any particular organizational form or strategic posture. is at the heart of what we call the transmational organization.'

Here we find the proposition referred to above. It would be the right mentality more than any particular structure or strategy that is required for global success. The hyporhesis concerns the emergence of a new posture, next to the three proposed above. It is the 'Transnational' company that is said to be able to combine the best qualities of the others. In table 5.3 their summary is quoted.

\begin{tabular}{|c|c|c|c|c|}
\hline $\begin{array}{l}\text { arganizational } \\
\text { characteristics }\end{array}$ & Multinational & Global & International & Transnational \\
\hline assets and capablines & $\begin{array}{l}\text { decentralized and } \\
\text { nationally self- } \\
\text { sufficient }\end{array}$ & $\begin{array}{l}\text { sentralized and globally } \\
\text { scaled }\end{array}$ & $\begin{array}{l}\text { source of competence } \\
\text { centrallized only }\end{array}$ & $\begin{array}{l}\text { dispersed, } \\
\text { inter dependent, } \\
\text { specialized }\end{array}$ \\
\hline role of overseas & exploiting national & ämplementung pärent & adapt and leverage & nationally \\
\hline operations & opportunities & strategies & company competencies & $\begin{array}{l}\text { differentiated } \\
\text { contributhons } \\
\text { integrated }\end{array}$ \\
\hline $\begin{array}{r}\text { knowledge development } \\
\text { and doffusion }\end{array}$ & within each unit & $\begin{array}{l}\text { controlled from the } \\
\text { center }\end{array}$ & $\begin{array}{l}\text { centrally developed, } \\
\text { globally transfered }\end{array}$ & $\begin{array}{l}\text { knowledge developed } \\
\text { jointly nof storted } \\
\text { gloubally }\end{array}$ \\
\hline
\end{tabular}

Table 5.3. Organizational characteristics for different structures, quoted from Bartlett \& Ghoshal (1989, p. 55) 
On page 65, a hypothesis about an internally consistent organization system is proposed. For its central importance to the book, it is cited above in its original form.

On pages $66-71$ examples are given of the difficulties encountered on the way to this ideal scheme. These will be elaborated in Part II.

Observation includes the interviewing of 236 managers in 9 companies with many national subsidiaries all over the world. Globalization strategy and responsiveness to global demands were investigated (p. 217). The results are reported in a historiographical way when the administrative heritage of the nine case studies is described (pp. 35-40):

'companies [may be] ... captives of their past ... In deciling how to mainage their worldwide operations, most managers we studied focused intently on where they were going. They seldorn asked themselves where they were coming from, although this question often turned out to be crucial. Companies had lo

\author{
respond to mew environmental demands in the context \\ of their existing organizational capabilities as shaped \\ by various historical and structural factors. This \\ administrative heritage represented both a major asset \\ and a powerful impediment in the change process.'
}

Induction is found at various places. For instance, on page 16, three major conclusions are drawn:

1. after a period in which a company could prosper by maintaining its 'strategic fit', during the eighties it became necessary 'to develop global competitiveness, multinational flexibility, and worldwide learning capability simultaneously',

2. this is primarily an organizational challenge, requiring a new organizational model; this transnational model has some characteristics distinct from tradition,

3. such organizational capability is not easy to build and to manage; it demands "a great deal of management attention and effort".

Another example of induction is the conclusion about the 'shapers of administrative heritage' (pp. 41-48). These are said to be 1) the role of leaders, 2) the impact of national culture, and 3) the influence of organizational history.

Some more induced findings from Part I of the research are the following. On page 97 the need for differentiation and integration is discussed, based on an example from Unilever. In a series of diagrams clepicting the need for national differentiation and responsiveness on one axis, and the need for global coordination and integration on the other, every business (from chemicals through packaged foods), function (from research through sales) and task (from product policy through promotion) is plotted. These functions will appear to hold a quite different position on the map, indicating that the adequate structural solution for chemicals, detergents, personal products and packaged foods is completely different. "The uniform treatment of foreign subsidiaries is a major impediment in building the flexibility a worldwide company requires today" (p. 97).

Part II of the research is focused upon the characteristics of the Transnational. New hypotheses are formulated and discussed in interviews. Data from case studies are obtained. A conclusion 
is drawn about General Electric's' downfall in color-TV's. A comparison with Philips and Matsushita is made (pp. $78-81$ ):

"Again and again, GE tried to redefine its source of competitive advantage to fit shifting industry demands. and with each change in strategic direction, it restructured. ... As the GE example illustrated, managers who attempt to bring about change through drastic reconfiguration, with little consideration for the existing organization, found the exercise frustratingly unsuccessful. Although companies like Philips and Matsushita experienced great difficulty in reconciling external demands with the reallity of their administrative heritage, their more subtle, gradual, and consistent changes in structure were more successful."

Some observations that follow are about the roles of national subsidiaries (p. 105).

Transnational managers are said to use organizational assets worldwide. They would break out of the 'headquarters hierarchy syndrome' if necessary, therewith overcoming past priorities and idiosyncratic rules if these do not match global demands. A national organization may function either as a strategic leader, a contributor, an implementer, or as a "black hole'. More lessons from case studies are reported on pages 115 - 134. It is said that building and managing the diverse roles and simultaneous processes needed for transnationalization is not easy. Various perspectives and capabilities at widely dispersed locations must be "flexibly linked and leveraged".

Part II of the research comprised a number of questionnaire surveys in three companies. They showed the dependence of the researcher on the cooperation of the company (p. 218):

In the second phase of the research project, we conducted a multiple-indicator, multirespondent mailed questionnaire survey of headquarters and subsidiary managers in the consumer electronics business of Philips and Matsushita Electric, and the public switching business of NEC. This was a purely convenience sample, because these thre compenies were the only ones that agreed to host the survey."

The latter remark demonstrates the dependency of organization research on the cooperation of the subject companies. This may bias results, for instance when 'bad' performers have a greater tendency to withdraw from the research than the better ones. The sample had to be restricted to 10 wholly owned subsidiaries of Philips and Matsushita each, and 5 of NEC. Moreover, a similar problem is reported on page 227 . It is stated that from 438 mailed questionnaires to chairpersons or CEO's of multinational companies in North-America and Europe, 66 were returned complete and used for further processing. It is unclear why no Japanese companies have been contacted.

An example of the method of observation as used in this questionnaire is found in the Appendix, where variables and measwres are discussed (p. 227):

[the questionnaire] ... "required the CEO of the company or another manager who was responsible for overall assessmemt of the company's international operations to rate, on a scale of 1 (llow) to 5 high), each of the company's foreign subsidiaries on its ability to create and dopt innovations, and its overall performance relative to corporate expectations.

Besides these performance indicators, two other sets 
of variables were measured. The first pertained to the subsidiary environmental context: the intensity of competition, the extent of regulation, and the level of technological dynamism. The second pertained to the subsidiary's orcanizational context: the levell of local resources and slack, the extent of centralization formalization and normative integration (socialization) in the headquarters' relations with the subsidiary, and the intensity of the communication between the two. Our objective was primarily to measure differences among the subsidiaries within the companies."

The research of Part II is aimed at the development of suitable instruments for Part III. A large-scale survey is conducted to test ideas more rigorously. It focuses on innovations and the way these are handled. Three types are distinguished, namely 1) the "local" way with local development and adoption, 2) the global manner, with local implementation of centrally produced innovation, and 3) the transnational method in which creation, adoption and diffusion of innovations takes place by and between units. Effects of different attributes are measured, like local resources, local autonomy, shared goals and values, and communication density in the triangle headquarters-focal subsidiary-other subsidiaries (p. 219).

Induced findings of Part II are reported on page 222. Case results are supported by the new data: normative integration and communication (with headquarters, and in and between units) have effect on realization of innovations. But not all hypotheses are confirmed: local autonomy has no measurable effect on effective innovation.

For Matsushita and Philips three groups of local units with specific characteristics are distinguished. First, there are creators of innovations, who do not adopt nor diffuse. These have 'higher levels of local autonomy and significantly lower levels of slack resources, normative integration, intrasubsidiary communication, and headquarters-subsidiary communication compared to subsidiaries in the other two groups". Second, there are creators and adopters, who do not diffuse. They have 'significantly lower levels of local autonomy compared to subsidiaries in the other two categories". Finally there are those that simultaneously create, adopt and diffuse. This group has "the highest levels of normative integration, as well as the most dense communication, both within the subsidiary and also with the headquarters'. (p.226)

In Part III again examples from cases are used. The stories are in itself interesting enough, but the emerging induced propositions seem to not transcend 'conventional wisdom' (pp. 137 156). Rules are given for offsetting organizational biases, like strategic, organizational, and cultural barriers. Recommendations are proposed for building new management perspectives and capabilities, such as building legitimacy, providing access, and ensuring influence. And finally advice is given about maintaining a dynamic balance, which means building foundations, and managing misfit. This is said to be top management responsibility: ' $\mathrm{By}$ legitimizing the diversity of a truly multidimensional organization, management creates the core of an organization flexible enough to respond to environmental change and strong enough to compete on the basis of multiple strategic capabilities.'

Next it is recommended to manage complexity by developing flexible coordination. It is said that there is no one-best way of international coordination, like Japanese centralization, American formalization or European socialization. With the latter is meant the 
careful recruitment and acculturation of key decision-makers. The best solution is the creation of an internal market (provided that 'horse trading' is avoided), and the mixing of the three ways 'according to the nature of the task and the strategic roles of the units being coordinated.' (pp. $157-173$ )

Another recommended rule is the building of commitment. This is said to include the building of a shared vision (clarity, continuity, and consistency of purpose), together with the developing of individual understanding and acceptance (in recruitment, training, and career management). There should be a matrix, not as a formalized structure but in the minds of managers (p. 175).

After an elaboration of these suggestions, a biological analogy is proposed (p. 201):

'Formal structure defines an organization's basic anatomy; systems and information flows shape its physialogy; and culture and values shape its psychology. Change strategies that work through only one of these elements are less effective than that address all three.'

The metaphor serves apparently as a rhetoric support for the recommendations proposed so far. A 'Universal Solution" does not exist. The authors" recipe reads: "it all depends", every case has to be solved in its own way. The reader is left with some 'don'ts', but without any positive recommendations, as the authors confirm (p. 209):

In a sense, the question is misleading, since the transnational is less a structural classification than a broad organizational concept or philosophy, manifested in organizational capability and management mentality. ... Thus companies as diverse as NEC and Procter \& Gamble, Ericsson and Philips, or Matsushita and Unilever developed the organizational capabilities and characteristics that we call transnational. Because of maior differences in industry environments and administrative heritages, they faced quite different strategic tasks and organizational challenges. Nonetheless, these and many other companies shared a new set of bellefs about how to manage organizations whose operations transcended national boundaries. Management not only recognized the importance of the complex and changeable external forces affecting operations, but tried to reflect those characteristics interinally through the development of an organization with multidimensional perspectives, dispersed and differenliated organizational capabilities, and a flexible managemant process able to coordinate the conflicting, yet interdependent, interests."

Hypotheses are reiterated at the end of Part III (pp. 207, 208):

"Rather than assign joint responsibility for everything, as the classic matrix structure suggests, top management in the transnational retains the clarity of Iine authority, but pays a great deal of attention to the allocation of responsibilities. ... Some decisions will tend to be made on a global basis, often at the corporate center (most often research priorities and financing decisions, for examplei); others will be the appropriate responsibility of local management (typically sales and service tess and labor relations, for instancel. But for some issues, multiple perspectives are important and shared responsibility is necessiary.... The transmational appears to be a complex organization, with roles and responsibilities 
differentiated by business, by function, and even by

task. But at least they are clearly defined, not subject to the constant overlapping and shared responsibility that create so much tension and confusion in the global matrix. Coordination and control in the transnational organization are accomplished as much thirough the
Socialization of its members as through formal systems. This approach greatly simplifies the decisionmaking process, takes a huge burden off top management, and unclogs the company's overloaded communication channels, all-important benefits."

Here some skepticism is justified. Again, the reader is left in confusion. Despite implied promise no clear recommendations ensue, the authors are sitting on the fence and do not commit themselves to a clear prescription. Rules about the design of a structure must discriminate between different circumstances and conditions, prescribing in what case what option should be selected. But by saying "it all depends" nothing is said. In the end the authors propose that socialization, not the system, should be the solution. That is what they called earlier "a matrix in the minds". It must be concluded that the research has not produced an answer to the questions that evoked it.

Methodological problems are discussed in great detail. For instance, the authors report that the high intercorrelation among variables in the questionnaire restricted the inferences that can be drawn. Therefore a complementing analysis was made (pp. 228 - 229).

Comparing the results from different lines of research (p. 237) makes a triangulation. The authors conclude that "the findings broadly converge, but there are significant differences across the different methodologies... Our conclusions, therefore, are informed by each finding but represent the beliefs that we came to at the end of the study rather than the specific observations or statistical associations that were revealed in a particular part of it'. The partial inconsistency of the various lines of inquiry may explain the turn the research took from a highly scientific approach intended to find rules based on observation toward 'beliefs'. These are not based on corroboration but on being 'informed'.

Assessment following the $A-F-$ scheme



Part I and II



Part III 
Hypothesis (A) includes the conjecture of three international postures of companies, whose characteristics are defined $(13-15)$. A central hypothesis throughout the book is that the right mentality is more important than a selected structure or strategy. Derivation (B) follows, with the presentation of a predictive model (25 - 33). Induction (D) from the nine case studies leads to renewed hypothesis (pp. 16,41-48). New hypotheses follow, including the introduction of a fourth posture (pp. $54-55$ ). This all leads to a more elaborated predictive model on page 65. On the base of these preliminaries observation (C, described on page 227) starts, with a large series of interviews and a survey in three companies. Three independent variables for success (constructs) are examined (p. 219). Then back to hypothesis: one of the hypotheses is rejected. The answers obtained serve as a guideline for the third round of inquiry. In the third round observation is based on case studies again. At this stage the researchers fall back to a less scientific approach. Prescription (rules, pp. $137-175$ ) follows, but finally only negative recommendations ('don'ts') remain (p. 209). Despite the attempt to apply a rigorous method with supplementing inquiries (pp. 228 -229) and 'triangulation' (p. 237) no clear answers are found to the questions that evoked the research. This is an honest conclusion drawn by the authors themselves.

Many of the reported results are derived from case study observations and interviews in two loops (A)-(B)-C-D-A (left model). Here hypothesis (A), observation (C) and induction (D) are moderately elaborated. On one specific issue in the globalization process (innovation) an indepth survey is conducted (A-B-C-D-A, right model). From the knowledge as developed, rules are derived in the form of recommendations. In this loop $\mathrm{C}, \mathrm{D}$, and $\mathrm{A}$ are well elaborated, but derivation (B) is only slightly so. Instead an attempt is made to formulate recommendations (E).

The results from the third cycle refer to a part of the basic concepts only (partial reduction), but permit more specific tests of statements. Some of the hypotheses are partially confirmed, some others remain undecided, while some of them are refuted. It is clear from the attempts that many popular management notions are not easy to be operationalized.

Defimiteness (the pertinence to the transnational company), and precision (p. 226) are duly met. Coherence with the work of Porter and Prahalad is present. There is a considerable degree of systematic structure and metatheoretical rigor.

A flaw is the non-response of companies in the three phases of research. Non-response might be associated with poor performance, in which case the conclusions are severely jeopardized. Testing has been sought, and has led to conclusions about the only partial validity of the hypotheses. The theory does not end with $u$ seful recommendations pertaining to organizational design, but many of the findings are helpful when contemplating global structure and strategy of a business firm.

\section{Conclusion}

The book is a report on a well-elaborated theory. Its essence is the attempt to induce hypothesis from well-designed observation. Fecund elements are the perspectives offered by the large-scale survey. Problems to be solved will be theoretical (the operationalization of 
concepts) and practical (obtaining the cooperation of companies). For the research Porter and Prahalad are mentioned as predecessors.

\subsection{Rosabeth Moss Kanter}

\section{Bibliographical data}

Kanter, R. M., When giants learn to dance, New York, 1989.

\section{Contextual points}

The author is a professor of Business Administration at Harvard Business School. She is known for her investigations of gender issues in corporate life.

The study has a case study approach leading to a joumalistic report. The author (b. 1943) is a sociologist, 'working in the tradition of Max Weber' (Pugh and Hickson 1997, p. 105). Societal importance of this study is apparent from her concern about America's loss of entrepreneurial quality in the eighties. A basic vision underlying the study is that a revolution is taking place (p. 9):

'It is a revolution that I call 'post-entrepreneurial', because it takes entrepreneurship a sitep further, applying entrepreneurial principles to the traditional corporation, creating a marriage between entrepreneurjal creativity and corporate discipline. cooperation, and tamwork... One of the major questions about the current management revolution is whether it can reach the larger, older elephantlike American corporations that so desperately need revitalization. ... But does all change have to be via "creative destruction"? Does it come only from new entrants, or only from outside the industry? Or can even old companies mald themselves into new forms, accelerating innovation within a corporate structure?

The final sentence of this citation also expresses the core question of the study.

Kanter expresses her hope for America, and the importance of business life for the society as a whole: 'In studying and helping business-people with their professional balancing acts, I hope also to help America. The fate of America lies in the success of its businesses.' (p. 13) The American problem of the eighties lies in the entrepreneurial optimism of the start of the decade, followed by the disarray at its end. The author quotes from Commerce Secretary Peterson who wrote that the country has 'let its infrastructure crumble, its foreign markets decline, its productivity dwindle, its savings evaporate, and its budgets and borrowing burgeon.' 'The book ends with recommendations for America (pp. 365 - 372), eloquent pep talk ending in a rhetoric apex. 
In the book many metaphors are used, like 'elephants", and 'cowboys'. On example is on page 9:

"I have been trying to anticipate tomorrow's problems and tomorrow's needs in the cacophony of today by listening to people and companies ... As greater innovation has taken place in response to the challenges of a changing economy, the notes of change I hear have grown in wolume to sound more and more like a far-reaching revolution in business manggement."

The basic position, and the intent of the research become clear on page 10 and 12 where the author expresses her hope to producing useful knowledge from the past (p. 10), that is applicable and valid for the future (p. 12). These passages will be revisited in the next section. A basic contention is that to win the global corporate games ('Olympics') "postentrepreneurial' management is needed. Four F's have to be adhered to. One has to be Focused, Fast, Friendly, and Flexible. As Pugh and Hickson (1997, p. 109) point out this comes down to three principles, namely 1) minimize obligations and maximize options, keep fixed costs low, and use variable means to achieve goals, 2) derive power through influence and alliances, rather than full control and total ownership, and 3) keep things moving by encouraging a continuous regrouping of people, functions, and products in order to produce innovative combinations.

The study pertains to both structure and strategy, mostly addressing the question how to achieve desired structures and strategies. Its implications therefore are indirect. Rules to be applied have an abstract or ambiguous character, for instance when it is recommended to solve unsolved paradoxes.

The size and type of the organization addressed is apparently the large, globally operating business company.

Process of knowledge development

Above reference was made to passages on pages 10 and 12 . These read as follows:

"... I decided to write a book that would use the present to explore the future.... There is ample evidence, which / cite throughout, that my findings are widely applicable and that the trends l observed are reflected in national surveys and statistical compllations.... There is a question, of course, of how much I can generalize across wery diverse industries and company situations. As an advocate of 'contingency theor $x^{\prime}$ - the 'it depends' wiew that relates management choices to the particular business environment - I worried about violating my own principles by looking for commonalities in so many different business situations. Then I realized that I was discussing broad trends and broded strategies that hold true across many industries; however, the specific ways the strategies are interpreted and used clearly depend on each company"s history ervironment, and current situation. 
On page 11 the author describes her working method. It includes:

- listening to executives and other corporate members,

- observing and contributing to innovations,

- investigating disturbances and imbalances,

- investigating strategies and ways of implementation,

- examining new dilemmas resulting from new practices.

Like in Peters and Waterman (1982) paradoxes are said to need reconciliation (pp. 21 - 31). The author recommends to remain 'lean and mean' through restructuring and yet be a great company to work for, to innovate and yet "stick to the knitting". Moreover, it would be necessary at the same time to push for faster execution and to take more time for planning the future. Finally one must create autonomous business units yet centralize to capture efficiencies. "The great corporate balancing act is to cut back and grow, to trim down and build, and to accomplish more, and do it in new areas, with fewer resources". The term "post-entrepreneurial." enters on page 32 :

'Something new is required, something that marries the entrepreneurial spirit to discipline and teamwork. something that helps loosely managed companies get
Q little tighter and tightly controlled companies to loosen up-apost-entrepreneurial response:

Hereafter a number of examples of hypotheses are given.

Resources are said to become less scarce. Examples of these resources are physical space, computer power, and small-scale technologies. Barriers disappear by privatization, deregulation, and removal of tariff barriers. Social boundaries are easier to overcome: 'know one's place' is less common (p. 17).

The central problem would be to 'learn to balance dreams and discipline' in other words 'balancing the broomsticks' (p. 18).

Sports are proposed as a metaphor of management (p. 20). Hitting the ball every time is not enough; "responsibility for the whole team is required". The company game is like Alice's croquet; uncertainty is the rule and luck plays an important role:

'... Winning requires fester action, more creative maneuvering, more flexibility, and closer partnerships with employees and customers than was usual in the traditional corporate bureaucracy. It requires more agile, limber management that pursues opportunity without being bogged down by cumbersome structures or weighty procedures that impedie action. Corporate giants, in short, must learn how to dance."

Core characteristics of the post-entrepreneurial mode are supposed (pp. $52-53$ ):

1) restructuring to find synergies among pieces of the business, both old ones and acquired ones; 2) opening their boundaries to form strategic alliances with suppliers, customers, and venture partners; 3/ and developing explicit programs of investment and coaching to stimulate and guide the creation of new ventures from within.' 
Hypothesized threats to current productivity would be confusion, misinformation problems, loss of energy, loss of key resources through bureaucracy, loss of initiative, and loss of management's credibility. Examples of companies suffering from these problems are given (p. 62).

A typothesis based on research of others can be found on page 74. It is said that "in-house competition is a value subtracter', as appears from studies by Kohn and by Blau (1964). Other research would show that inside cooperation to fight outside competition would yield maximum productivity.

A concluding hypothesis contains the unavoidable paradox (pp. 88 - 89):

Instead of creating cowboy competition, winners and losers, conquerors and colonized, or rivals for the same tidbits of power, post-entrepreneurial corporations will raise performance standards by building commitment to shared goals and enhancing the ability to work together... But whille commitment comes from certainty and security, restructuring causes uncertainty and insecurity. This realization entails a major corporate bälancing act ..."

This statement is an example of Kanter's rich rhetoric.

Some tenets have a truism-like flavor (p. 100):

"The sitructure that is "right" in theory, the "right" combination of parts, is still not enough to produce synergy. A business mix that is glood from a strategic analysis standpoint brings benefit in practice only if the

\author{
relationships and processes are established to ensure \\ cooperation and communication - with managers in \\ every area committed to contributing value to one \\ another."
}

A propositions about cooperation with other companies is made, with the mnemonic 'PALS' (pooling, allying and linking, p. 117). In the cowboy era, good fences made good neighbors; nowadays cooperation is to be preferred.

Types of alliances are (pp. $123-140$ ):

- alliances to provide the same service to a number of partners,

- joint ventures to realize opportunities,

- stakeholder alliances (with suppliers, customers, employee organizations).

The cooperation of Digital with suppliers is described in detail.

Six Is (ingredients) are necessary in this respect (a mnemonic again, 172): the feeling that it is important, commitment to investments, mutual interdependency, integration, shared and equal information, and the institutionalization of the partnership.

A final hypothesis about the post-entrepreneurial corporation is given on page 200 :

While focused and disciplined in its pursuit of mainstream business success, the post-entrepreneurial

corporation is also flexible enough to have new ideas ready and organized enough to get new ideas moving fast."

Again this proposition implies paradox. 
It is said that tensions will arise between mainstream and 'newstream' groups. Differences will ensue in atmosphere, in perks, in procedures and standards, in liberty, in risk, and in rewards (pp. $214-222$ ).

The study remains in the domain of common language. Derivation of testable consequences from hypothesis or predictive modeling is absent. So observation is the next phase of knowledge development.

The method of observation is explained on pages 11 and 12 . Over eighty companies were examined. They comprise of 25 larger ones (among which Pacific Telesis, Digital Equipment, Apple Computer, CBS Publishing, Ford, Navistar, Eastman Kodak, and Western and Delta Airlines) in which consultancy projects "or extensive interviews and observations at repeated intervals' were conducted. In-depth interviews were held with managers from 30 other, smaller companies during a project on innovation.

Desk research was conducted as well (p. 12). 'I also read literally hundreds of reports of academic research and scholarly commentary (although in this book I cite only those from which I draw specific data or ideas).

Some examples of observation are the following. The first are observed developments in the American industry over the eighties (pp. 23 - 30). As is illustrated with the help of statistics a growing number of opportunities exist. At the same time there is a growth of competition, and a proliferation of activities. Moreover resources become constrained, while automatically rising income and certainty of employment is disappearing.

Of the companies examined, Kodak and Apple are used as example (p. 33). Both would combine 'the power of the giant with the agility of the dancer', although they differ considerably. Kodak has an old technology, is East coast based, and is a mature company. Apple is characterized by a new technology, is located at the West coast, and is young. The observation of Kodak leads to a historiographic narrative of its recent history, based on publicized data and in-depth interviews (pp. 33-41). Kodak's return on equity slipped from $20.9 \%$ in 1973 to $7.5 \%$ in 1983 , and it lost its leading position to Fuji (photo and film) and Xerox (copiers). Innovation was too slow; in 1983 new top management was appointed that made painful changes. Cost reductions took place, 24,000 jobs were eliminated, and top management ranks were reduced by $25 \%$. The company was restructured (the two divisions were transformed into five 'entrepreneurial' business units), and important changes of policy and culture were made. Certain activities were contracted out, lifetime employment was abandoned. The company sought acquisitions and alliances with clients and suppliers. Entrepreneurship was encouraged and bureaucratic procedures removed. "By 1987, Kodak's return on equity had rebounded to 19 percent".

The recent history of Apple is observed as well (pp. 43 - 51). It is told that Apple started as an official company in 1975 that went public in 1980. In 1983 chairman and cofounder Steve Jobs hired John Sculley as its chief executive. Apple is described as 'a corporation made up of a generation, unencumbered by the traditions of corporate America' (my emphasis). In 1983 and 1984 severe financial problems came up, together with conflicts between whimsical Jobs and other top officials. The culture was free with hardly any lines of authority, 'an organization 
composed of visionary idealists who wanted to change the way people thought about and lived life'. Despite the financial problems the company lifestyle was still exuberant. Conflicts between product divisions sharpened. In 1985 Apple had to report a quarterly loss for the first time. Remedies were taken in 1985 (p. 48). Steve Jobs left the company and Sculley took a number of measures such as restructuring to enforce synergy (four product divisions were combined into one), and the creation of alliances with suppliers and customers. Furthemore he sought ways to maintain the flow of new ideas to new products and ventures ('spinouts' were created to form a "federation' with the "mothership").

In 1988 results are that Apple is approaching $\$ 4$ billion in sales, it is able to trim costs and reposition itself and grow, all at the same time. The problem now is that as people work 12 and 14-hour workdays it is difficult to find time for the family or to pursue other personal goals. Career options have changed. One no longer is climbing the corporate ladder but one has to grow one"s own business as a contractor or partner (p. 51).

An induced conclusion is the following (p. 42):

"As Kodak learns how to 'do more with less' in order to compete effectively in the global corporate Olympics. the lives of Kodak's people change in significant ways.

The paychecks they take home bear numbers calculated in a new way, intended to reflect not just what their job eintitles them to but what their contribution is; their own efforts count tor mare. But as few people in a smaller Kodak attempt to take more responsibility in an enwironment with more complex external ties, they are inevitably working harder. A leaner organization makes more people feel stretched thin. An organization with more opportunities to contribute - and to get rewarded for it - makes more people feel like devoting more time to work, thus affecting their personal lives. But perhaps the most profound change for Kodak people is in their career expectations, Job losses have shaken the faith of managers and professionals in the security of the corporate ladder, a ladder which now has fewer rungs on it anyway. At the same time, the new venture process has opened up amother, less corventional avenue for carear growth - becoming corporate entrepreneur.

While proud of the company"s recent performance, top executives are quick to point out how much remainsto be done."

Another induced conclusion is that the "horizontal dimension" of the organization should be made more effective. Process is said to be more important than structure (pp. 115 - 16). Many more induction efforts can be found. Unfortunately, entailing more vigorous new propositions fail to be obtained. All remains in the realm of educated, but still conventional knowledge. An example is the discussion of synergy failure in case of cooperation among companies (p. 61). It is said that the failure is caused by the resistance of managers of acquired companies, by reduced motivation, and because too much energy is given to the acquired activities at the expense of existing business. Furthermore, overloading the management system would be an impediment. This all is conventional wisdom, a good start for research but not an impressive end of it:

Hereafter, some examples of rules are given. 
One is a statement about entering into new businesses (pp. 175-176). "One of the best fitness exercises for companies trying to win the global Olympics is stretching in new directions.' But this requires another 'balancing act': care for mainstream profitable business must be combining with efforts for new ones. New markets and products are volatile and uncertain, with unexpected competition and rapid obsolescence.

'Newstreams' (a neologism to distinguish new activities from the mainstream) should be dealt with like IBM did in the personal computer market. A 'Tiger Team' did it, far away from headquarters, in a leveraged buy-out structure, with "skunk works' admitting "maverick" inventors to develop new products ( $\mathrm{pp}, 176-182$ ).

A concluding rule on page 223 reads that corporations must teach more people to be an entrepreneur. Traditional hierarchy, bureaucracy, corporate identification, and career dependence will become less important. The power of ideas will surpass the power of office. Another rule is the final tenet of chapter 8 (p. 225):

- Earlier, I delineated the circumstances under which mainstreams cause newstreams to dry up. But it is clear that newstreams also have an infuence on the mainstream business, an imfluence above and beyond ary success in generating new sources of revenue. When newstreams exist beside mainstreams, and when corporate citizens swim in both directions, then the creative boat-rocking spirit of the newstream spills over to infect the mainstream. Unleashing the power of innowation is one more step toward loosening the power of corporate hierarchy and bullding the postw entrepreneurial corporation."

On page 344 'focus' is explained, with a summary of strategic recommendations:

'Driven by an imperative to make sure that all activities "add value, post-antrepreneurial companies decentralize some functions, putting them close to the business unit those functions support; they contract out for some services, turning to suppliers that are specielists in that area and reducing the need for the company to manage activities largely unrelated to their core business competence; and they convert some

Some recommendations are vague (p. 349):

The management challenge, then, is to select only those relationships that are sufficiently important that they will be entered into with full commitment and with a willingness to invest the resources and make the intermal changes that successful external partnerships service departments into "buslinesses' that compete with external suppliers to sell their wares both inside and outside the compary. Such organizational changes allow post-entrepreneurial companies to do more with less, because their staffs arre smaller, their fixed costs are lower, resources are available closer to the site of the business action, and all departments are more clearly focused on their contributions to the business ."

entail-the shating of information, the linking of systems $s_{r}$ and the establishment of agreements for governing the partnership. The 'six l's' of successful alliances ... [and so on $]^{*}$ 




Metatheoretical questions about the limits of generalization are exposed. In the same passage hypothesis (A), including the delimitation and the core question of the study (definiteness, pp. 9 12 ), is discussed. Here we find the problem of many organization theorists in a nutshell. How can the future be induced from the past, and how can conclusions from particular observation be extended to a more general field of application? Contingency theory is no theory unless it specifies propositions over the various categories of occurrence. In this study the specific answers are not produced. Coherence is present in the author's intention to reconcile paradoxes like those of Peters and Waterman (pp. $21-31$ ).

On several pages (pp. 17, 18, 52, 53, 62, 88, 89) more hypotheses are formulated. Many of these are trivial or paradoxical, with imprecise terms. This implies a lack of precision. Paradox remains throughout the book (pp. 100, 200).

Observation (C) includes desk study and numerous interviews and the findings in consultancy assignments (pp. 11, 12). Derivation (B) from hypothesis before observation is not reported. Two case studies are the main source of observation. Some new hypotheses are induced from these cases (pp. 115,116). As instances of intervention (E) follow (pp. 175 - 182, 223, 225, 344, 349). Most of these are too vague to be of particular interest, some are paradoxical again.

Narrative reports, eloquence, and mnemonic puns suggest that the book's main purpose is to convince. Hypothesis, observation and prescription are elaborated to a large degree, but without any scientific bearing. Induction is discussed but not elaborated, while derivation and intervention are absent. With its weak systematic structure it must be concluded that in this theory metatheoretical requirements are not met.

Validity is not tested. Utility for organizational design is absent.

\section{Conclusion}

Porter, Blau, and Quinn are mentioned as providers of ideas. The scientific value of this stimulating book does not lie the proposed knowledge itself but in the interesting questions that are posed. A fecund element is the reiterated warning against the perils of bureaucracy. This might lead to a more in-depth research into the question how exactly the paradoxical requirements of modern management can be reconciled. For instance, "success" in the absence of 'power' seems to be the philosopher's stone. 


\subsection{Michael T. Hannan and John Freeman}

\section{Bibliographical data}

Hannan, M.T., and J. Freeman, Organizational Ecology, Cambridge MA, 1989.

Contextual points

Hannan is a professor of sociology at Stanford University. Freeman (b. 1945) is a professor at the Haas School of Business, University of California, Berkeley.

The book is written in the scientific discipline of organization ecology. In this school, sociology is a science linking theory building, methodical elaboration, and empirical observation, in the tradition of Coleman. Next to the authors, Carroll is a co-founder of the approach.

During the seventies organizational sociologists became more and more dissatisfied with received theories on organization. They started attempts to bring back organization problems in the mainstream of sociological thinking.

\section{Contents and relevance}

The authors emphasize a number of philosophical aspects, which are important enough to be reported here in some detail. They state that their own work has four typical metatheoretical features (p. xiv). First, sociology, not bioecology is the focus. Second, dynamics, especially those shaping entry and exit rates of individuals in populations are the central object of study. Third, entire populations of organizations over their entire life span are studied. Finally, theory, models and empirical research will be tightly linked. A goal statement of the study is formulated in the preface (p. $x i)$ and in the final chapter (p. 331):

\footnotetext{
The ecology of organizations is an approach to the macrosociology of organizations that builds on general acological and evolutionary models of change in populations and connmunities of organizations. The goal of this perspective is to understand the forces that shape the structure of organizations over long time
}

\author{
spans. ... [Theory] ... treated organizations as rational, \\ flexible, and speedy adapters to changing \\ environmental circumstances. But in reality. \\ organizations were stuck with internal political \\ contests, constraint by sunk costs, and by \\ "anthroponorphical images of organizations." "
}

Basic contentions of the work are that ecological models of an adapted biotic type can describe the behavior of organizational populations. This is supported by the use of different sets of mathematical models and parameter estimations that all lead to similar conclusions. The outcome of this position implies limitations of the space of discretion for personal actors. An anthropomorphic image of the organization is rejected. 
Both structure and strategy are addressed indirectly, as the probable limits of viability of organizations are determined. As for design, only boundary conditions are offered. The study pertains to all types of organizations that operate in a competing environment.

\section{Process of knowledge development}

The essence of the methodology and its motivation is discussed in the introduction (p. xiii):

Since invoking selection processes in the social sciences violates an implicit taboo, as we discuss in Chapter 2 , it is worth noting our motivations. We did not seek to use biological theory to explain organizational change; nor did we propose to develop metaphors between bilitic populations and organizational populations. Rather, we wanted to explain a variety of sociological phenoment that could not be explained satisfactorily with existing social science theories. We relied on models from population bilology because these models appeared to clarify the social processes of interest. This was very much a

\begin{abstract}
"modeling strategy". As we explained initially, in describing our use of Lotka-Volterra modals; "No known population lof animals, or of organizations) grows exactly in the manner specified by this mathematical model. ... What the equations do is to model the growth path af populations that exist on finite resources in a closed system. Neither protozoa nor bureaucracies behave exactly as the model stipulates. The model is an abstraction that will lead to insight whenever the stated conditions are approximated".
\end{abstract}

The term model as used here is used as an abstraction of the theory the authors have in mind. They want to think of organizations as open systems dependent upon external opportunities and constraints and internal strengths and weaknesses. One of the many conceivable ways such forces affect birth, life, and death of systems is represented by certain mathematical models, such as those developed by Lotka and Volterra. They use this type of models as a means to go from theory toward observation. That means that they use predictive modeling, as was described in chapter 3.6 of this thesis.

Some more important basic points are advanced in chapter 2 (pp. $29-33$ ). The isolation of organization theory from sociology is attributed to five causes, namely 1) the "status attainment approach', that seemed to ignore the organizations that employ people, 2) cross-sectional analysis, impeded by its static nature, 3) the anthropomorphic imagery of organizations, 4) the overemphasis on managers' importance, and 5) the neglect of inertial forces.

The authors point at shortcomings of contemporary approaches, such as Marxism or neoinstitutionalism (pp. 33 - 35). These would neglect efficiency as one of the rationales.

They do not deny the influence of the manager. But they argue that this influence is limited by control systems and behavioral norms, and moreover so by scarcity of resources, by competition patterns, and by limited rationality (pp. 40 - 44).

Hannan and Freeman consider the organization as an important object of knowledge in sociology that is generally underestimated as a societal object and as a focus of research. In contrast, they argue, most sociological theory is about individuals, interest groups, and classes. They emphasize the necessity of studying the organization as a social constituent. In addition, 
they stress the importance of examining the dynamics within populations ( $\mathrm{p} .7)$. They specify the explanation sought:

'... an ecology of organizations seeks 10 understand how social conditions affect the rates at which new organizations and new organizational forms arise, the rates at which organizations change forms, and the rate at which organizations die out. "

An elaboration of existing theoretical strands is proposed (p. 11). At least three broad points of view would exist. First, there are selection theories: young organizations may be innovative and can adapt easily, but large and powerful ones 'rarely change strategy and structure quickly enough to keep up with the demands of uncertain, changing environments.' The second are adaptation theories: the largest and oldest, most powerful organizations 'have superior capacities for adapting to environmental circumstances", as they have the resources to maintain special units for coping. Third, there are random transformation theories. In this view organizational change is supposed to be at random and is "only loosely coupled with the desires of organizationall leaders and with the demands ... of the environment." The authors consider ecological analysis appropriate "when organizations are subject to strong inertial pressures and face changeable, uncertain environments.' (p. 13). This approach has three levels of complexity (p. 14), namely 1) the level of 'demography of organizations', that considers rates of founding, merger, and disbanding within one population, 2) the level of 'population ecology of organizations", whose models describe how vital rates are affected by the presence of other populations, and 3) the level of 'community ecology of organizations', in which a set of interacting populations (such as populations of firms, labor unions, and regulators) are examined. The unit of observation is the individual organization. Studied events are founding, disbanding and merger (p. 15).

In chapter 2 , the authors compare their positions to those of other writers on organization in more detail (pp. 35 - 40). Their own axioms and positions include the rejection of social Darwinism. They claim that efficiency is only one of the relevant dimensions. They adopt the view of punctuated equilibrium, not that of gradualism. They dismiss the objection that population ecology is only applicable for large organizations. Finally they deny that population ecology would imply determinism. Instead it is said to be probabilistic. "In no sense we think that the history of organizational populations is preordained to unfold in fixed ways. Quite the opposite: the ecological approach treats processes of change as contingent but also as random.' The authors follow a strict order in their development of knowledge. In the hypothesizing phase, concepts are defined. For instance, in the authors' scheme, the actors are populations of organizations. Populations are said to have members with 'a common standing with respect to processes and interest', mostly being 'a common dependence on the material and social environment'. To obtain testable predictions populations must be identified a priori. Therefore a related assumptions must be made about the characteristics or the boundaries of populations. The meaningfulness of such identification must be made clear too (pp. 45, $53-55$ ): 


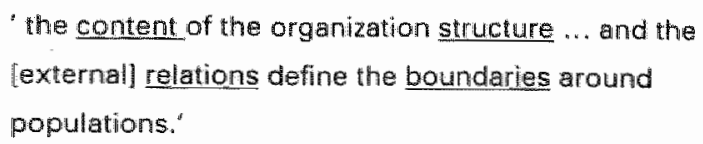

But this position requires further examination, as is shown by the example of the semiconductor industry at Silicon Valley. The question might arise "is this industry really so sharply differentiated from the broader electronics industry?"

The authors propose that the distinction is more associated with the difference between the tightly controlled, formalistic vacuum tubes industry that was not able to make an entry in the art-like, uncertain business of semiconductors:



Other grounds mentioned for distinction are the closure of social networks, successful collective action, and institutional processes. An example of the latter is the legal acknowledgment of state intervention to support workers" claims made by unions, through the Wagner Act of 1935.

But boundaries may erode as well by changing norms and de-institutionalization, such as the relaxation of rules forbidding the combination of banking, insurance, and stockbroker activities (pp. 57 - 59). Other examples are '( 1 ) strong segregation processes limit diversity, and (2) elimination of boundaries necessarily increases diversity of forms.' (p. 61) So far the process of knowledge development seems flawless. But when it comes to operationalization, the finale of these high-pitched reflections is slightly mundane, and criticized as well (p.63):

We have relied on the conventional wisdom of participants and observers.... For example, consider our analysis of restaurants, ... We began by .... self:designation in advertising in the Yellow Pages. We came up with 33 forms. ... But we were less interested in the precise form mare than in the underlying differences in specialism with respect to segments of the market. ... [so] ... we classified the 33 forms into specialist and generalist types and conducted our analysis of the dynamics of niche width using this distinction. ... Some critics have questioned whether collapsing forms [im this way] is warranted. ... the critics are at least party right ...'

Other important hypothetical propositions are the following ones (pp. 88-90):

We derived the proposition that organizational mortality rates decline with size. .. We proposed earlier that inertia be defined in terms of speed of adjustment relative to the temporal pattern of key environmental changes.... The complexity of organizational arrangements may also effect the strength of inertial forces.... Although slow response does not necessarily imply a lower rate of attempting structural changes, it 
seams likely that this is the terdertey. ... Complex

systems have slow response fimes not because they ar any slower than sinpler sytems in detecting erivironmentel threats and opportunities but because the process of adiustmant takes longer... The carouty to respond quickly to new opportunities presumably corripetes with the cepacity lo perform reliably and accountw bly ... Such dynamics may difute the importance of reliability and accountability in organizational selection. For all these reasons, it is not sufficient to assume that selection processes may favor organizations with high inertie and to process as though observed populations contain onily such organizations."

About the intrinsic growth rate an unconventional view is proposed stemming from the assumed theoretical position. In biology species with "r-strategies" and those with " $K$ strategies 'can be discerned. In business parallel strategies apply, the former relying on intrinsic competitiwe force (first mover, innovator), the latter on winning under conditions of scarce resources (efficient producer). However, a first mover is said not to be necessarily characterized by individual flexibility (p. 120):

"Populations of $r$-strategist organizations flourish under conditions of rapid technological change not because the member organizations have the capacity for flexible response to widely varying conditions; rather they flourish because the speed with which they cian be constructed allows a founding rate that is high enough to offset high mortality rates. Indered, individual mortality rates of $r$-strategists are typically much higher than those of individual $K$-strategists at ewery stage in the development of an industry."

Examples of operationalization also appear in chapter 7 (p. 147). The starting event is defined as 'the appearance of a functioning organization'. Ending may occur as 'disbanding, absorption by another organization, merger, and radical change of form", the exact moment of which will be specifically defined for each study.

A predictive model of adaptation under environmental challenge is discussed in a very complex passage - rife with speculation - which is exemplary for many parts of chapter 4 . The authors propose that as a result of the overcoming of starting problems, the lowering of costs by learning, and the growth of fixed patterns of behavior, "structural inertia increases monotonically with age, and organizational mortality rates decrease with age' (pp. 81 - 83).

Important model assumptions follow in chapter 5.

Organizations would have to cope with environments that are heterogeneous and may change over time. This leads to the logistic model of population growth, expressed in terms of the carrying capacity $K$, while $N$ denotes the size of the population, and $r$ is the intrinsic growth rate (pp. $95-100)$ :

$$
\frac{d N}{d t}=N\left(\frac{K-N}{K}\right)
$$


Next, this basic model is elaborated and further developed (p. 101). Competition is introduced, in which case two populations share the same resource. Now the breeding ground for one party is reduced by the other with a term $\alpha N_{i}$. In this expression $\alpha$ denotes the competition coefficient and $N_{i}$ the size of the competitor's population. Finally the general form for $I$ populations is derived.

'A population's niche width is the variance of its resource utilization' (p. 105):

$$
R_{w_{i}}=-\sum_{r=1} u_{r} \log u_{r}
$$

The authors give the following explanation of this formula (p. 105):

We wse this approach in measuring niche width. For example, we measure the niche width of semiconductor manufacturing firms in terms of the fraction of the industry's mix of products that a firm produces... Similarly, we characterize a labor union by the number of occupational and industrial categories that it claims to organize."

Both a narrow and a broad niche width are said to have advantages and disadvantages. $A$ tension exists between being a jack-of-all-trades and a specialist.

Continuing the building of the model, the authors argue that environments may have temporal and spatial variations. Spatial distributions may be solid, or they may consist of small patches of different types ('fine-grained'). Temporal variations may be seen as waves over time ( $\mathrm{p}$. 106).

In total, a number of mathematical models are discussed (pp. 179-198). Models describing organizational histories are those concerning survival, hazard, conditional survival, and instantaneous transition. Various models for transition rates are discussed, like exponential and log-logistic ones. Counting process models are described, and estimating and testing procedures are proposed.

At this stage, various models are built, employed, and tested. Four questions exist, namely 1) how does founding rate depend on density, 2) does it also depend on the number of recent foundings, 3) do these effects persist when environmental effects are included, and 4) does competition between firms affect the founding process.

Although some models fit better than others did, the effects presumed exist and are not dependent on the choice of model or parameters (p. 243):

"Have ertiries into populations of labor unions, semiconductor firms, and newspaper publishers been subject to similar processes of density dependence? In a general sense the answer appears to be yes. For all three kinds of organizations, rates of founding depend on density. For unions and newspaper publisthers the founding rates rise with increasing density to a point and then decline with further increases in density. For semiconductor firms this non-monotonic pattern characterizes only the subsidiary firms. The entry rates 
of independent firms do not behave as if they have encountered a carrying capacity. We should note that because of imprecise founding dates, we were forced to rely on aggregate analyses of entry processes in the semiconductor analysis. The small number of time points available makes this a risky procedure. We should also note that we are studying entries into the semiconductor business, not foundings. In this sense, the semiconductor study may very well produce different results because the phenomenon under investigation is conceptually different. Both labor unions and semiconductor firms display competition between forms, and in both studies the competition is asymmetric. The number of industrial unions has strong negative effects on the founding tate of craft unions, but the number of craft unions has no effect on the founding rate of industrial unions. Among semiconductor firms, the density of subsidiary firms has strong competitive effects on the entry rate of independent firms, but not the reverse."

A number of other tests follow. Age dependence in failure rates (p. 244), the population ecology of organization mortality (p. 271), and the dynamics of niche width (p. 310) are discussed. The authors induce an important result (pp. 329, 331 ):

"Our model of niche width and mortality appears to work reasonably well for semiconductor firms as well as for restaurants. Iwo more different organizational forms would be hard to imagine. The differences between the restaurant and semiconductor studies are substantial. ... individual restaurants are on average small organizations, and they are run by sole proprietors for the most part. Semiconductor companies are sometimes billion-dollar enterprises, but they are sometimes as small as all but the smallest restaurants. The owners af both kinds of organizations intend them to be profitable, but the technologies used to generate their products stand at the apposite extremes of sophistication. In a comparison of these two studies, "high technology" meets "low technolog $\gamma^{\prime \prime}$ :

After the long travel through this complicated imaginary landscape of conjectures and parameters it appears that all's well that ends well. The theory is corroborated whatever type of predictive model is applied.

\section{Assessment following the $A-F$ - scheme}

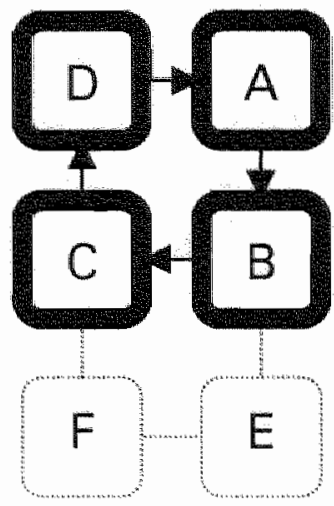

Hypothesis (A) starts with problem formulation (definiteness) and intent of the research. The basic conjecture is the applicability of Lotka-Volterra models to populations of organizations (p. xiii). More fundamental hypothesizing follows with conjectures (pp. 40-44), selection of axioms (pp. $35-40$ ), and strict definitions (precision, pp. $45,53-55,57-59,61$ ). Derivation (B) of these hypotheses requires vigilance, especially when it comes to operationalization (pp. 63, 147). Predictive modeling is elaborated in chapters 5 and 6. Observation (C) includes data collection and the comparison of the data with the prediction of the models (pp. 244, 271, 310). Induction (D) reveals that all models tried are corroborated (pp. 329, 331). The coherence with preceding theories is adequate (pp. xiii). 
Parts of the introductory discourse, switching between subtle mathematically modeled axioms and practical examples, seem unbalanced. The sections in which the sequence hypothesismodeling-method-observation-conclusion is discussed demonstrate a clear and logical method. All four cells A - B - C - D are systematically run through and elaborated to a large degree. Metatheoretical requirements are fully met. Validity is tested. The utility for strategic design is indirect, as considerations for opting in or out specific competitive fields can be guided by the findings of organizational ecology.

\section{Conclusion}

The report is the apex of a long line of research into this particular field. It is methodically flawless. Earlier work of Hawley (1950, human ecology), Stinchcombe (1965, psychological 'imprints' in cohorts), and Carroll (1988, organization ecology) is built upon.

A fecund element of the organizational ecology approach is its opening of new roads toward deeper and broader organizational knowledge. At the end, the authors express hope (p. 331):

'A closely related goal is to develop sociological propositions about organizational change that hold over time and space and across organizational forms. There is currently much pessimism in the social sciences about the prospects for finding any social lawsi, We do not think that such pessimism is warranted in the case of change at the level of organizational populations

Hopefully not only valid theory will be developed but also more knowledge that is directly useful in practice.

\subsection{James S. Coleman}

\section{Bibliographical data}

Coleman, J.S., Foundations of Social Theory, Cambridge MA, 1990 (Chapter 1: Metatheory: Explanation in Social Science, and Chapter 16: The Corporate Actor as a System of Action).

\section{Contextual points}

Coleman ( $1926-1995)$ was a professor of sociology at Chicago University. The author bellongs to the rational choice school of sociology. The historical/social environment of the period is characterized by the new business élan emerging by the late eighties. Coleman's views, focused on the individual and on institutionalism entrepreneurship, fitted well in this atmosphere. 
An important part of the work is an exposition of the author's basic position. It starts with a discourse on sociological metatheory (p. 1). There are said to be two ways of explaining the social behavior of the individual. One is using factors external to the individual. The other one is based on factors internal to him. For the explanation of the behavior of social systems two methods would exist as well: one external to the system (based on either a sample of such systems, using statistical correlations to demonstrate regularities or historical explanations), and one through internal analysis of system behavior. The latter approach is followed in this work.

Coleman's central proposition is based on the (meta-) theory of games (p. 11).

The playing of the game would simulate 'the behavior of some aspect of a social system'. Two separable components exist, namely the players and the structure of the game. The macromicro transition is determined by the structure of the game, the rules determining players' interests, the constraints of action, and the new context imposed by the others' actions. The micro-macro transition is determined by the outcome of the game: how the outcomes of all interactions create a new context. Purposeful action is the name of the game.

Basic contentions include that explanation in sociology must be based on rational action (like in economy). This position can be operationalized by modeling the interplay of lower-level actors by means of game theory, the outcome of which produces the behavior of macrostructures. About corporate organization the author contends that actors within a well-designed structure will achieve the purpose of the corporate actor by pursuing their own interests. This work is relevant for the design of organizational structure.

\section{Process of knowledge development}

As said, the author follows the approach in which explanation is obtained through internal analysis of system behavior. Coleman enumerates his reasons for this choice as follows (p. 3):

1. frequently, the number of integrative systems is too small to draw conclusions, while there are many subsystems available for observation,

2. the interventions derived from explanations normally are administered at elements of systems, not at the total system,

3. explanations based on elements are likely to be more stable than those on the system as a whole, as the whole is determined by properties of the elements,

4. for the same reason, these kind of explanations are more rigorous,

5. "The internal analysis of system behavior is grounded in a humanistically congenial image of man.' In contrast, the system level does not allow for questions addressing the relation of man and society, like morality.

These considerations demonstrate that this type of sociological methodology is appropriate for the study of organizations. The approach is called 'methodological individualism', although explanation not necessarily addresses the level of individual behavior. 'The criterion is instead 
pragmatic: The explanation is satisfactory if it is useful for the particular kinds of intervention for which it is intended' ( $p$. 3). This position perfectly fits the objective of organizational design.

However, a major problem remains to be solved, namely how findings at the micro level can be related to higher levels: the "micro-macro-problem". The author illustrates this metatheoretical problem with a reference to Weber's study on the protestant ethic and capitalism. Weber (1958) proposed that "the same antitraditional orientation and the diligence toward one's calling in Calvinist doctrine ... provided the value system which allowed capitalism to develop.' Coleman depicted Weber's argumentation in the form of a model with a dual-level explanation (figure 5.4).



Figure 5.4. Weber's dual-level explanation, quoted from Coleman (1990, fig. 1.2)

The figure shows the relations between components of social theorizing. Type 1 and 3 represent the argumentation from macro to micro and vice versa, respectively. But type 2 has a different nature:

[It involves the] ... "Principle of action [that] constitutes a necessary fixed kernel, which gives rise to different systemic behavior - that is, different social phenomene - when located in different social contexts and when different person"s actions combine in different ways. There is, in fact, a good rationale for arguing that social theory, as distinct from psychological theory, consists of theory about the working out of various rules within which sets of persons act. This view, as well as the character of macro-to-micro and micro-to-macro transitions, can be understood by imaging a socialsimulation ciame of the sort that is sometimes used in education. Such a game is composed of the following: A set of roles that players take on, each role defining the interests or goals of the plaver.

Rules about the kinds of action that are allowable for players of each role, as well as about the order of the play,

Rules specifying the consaquences that each player"s action has for other players in the game'

Here the major problem mentioned above becomes clear: proposition 3 is ungrounded (pp. 9 , 10): 
"... it is not suggesiting that a single individual's attributes are effectivie in bringing about social change. Rather some sort of combined or joint equregate of the economic behevior of many individuals in bringing about capitalistic development is being proposed. It is here, however, that Weber"s analysis is almost totally silent... it should be obvious that the appropriate transition cennot involve the simple eggregation of individual behavior. ..."

The author gives two reasons for using 'purposive action' (p. 18). First, this definition of action provides greater explanatory power as it offers ways of specification, even of quantification in some cases. Second, it serves parsimony in explanation. In a model that has already three components it is important that part 2 (the component of individual action) remains simple (p. 22):

'Quite clearly, some form of independence must me modeled th the cases like those I have described, for the phenomena to be explained involve interdependence of individuals' actions, not merely aggregated individuall behavior."

Three more basic propositions should be noted. The first defends the hypothesis of rationality as a determinant for action as used by the author (pp. 14, 17, and 18). He argues that rationality must be seen in a broad sense, thus including bounded rationality, elimination-type preferences, and choices based on erroneous assumption, temptation, and emotion:

‘... much of what is ordinarily described as nonrational or irrational is merely so because the observers have not discovered the point of view of the actor, from which the action is rational. "

The second is a derense against the objection that this manner of explanation be teleological ( $p$. 15). The author acknowledges such objections, as made against sociological functionalism or in 'reward'-based psychology. But in his own approach explanation refers to a different level of phenomena, so the rejection of circular argumentation is not applicable in this case.

The third point is a positive assertion. This is a theory of free will (p. 16). The use of purposive action preserves a conscious role for the individual.

In theories based on social change or on technological change a fatalistic view of the future is implied "in which humans are the pawns of natural forces.... At the mercy of these uncontrolled external or internal forces, persons are unable to purposefully shape their destiny.'

Examples of hypothesizing follow one after another in chapter 16.

A starting point in the discussion concerns the corporate actor as a system of action (p. 422):

the problem of collecting of resources and interests of the dispersed principals will be regarded as being solved. There is single principal with the problem of taking action, where the action is complex, involving interdependent actions among many agents.
Athough this chapter applies to many kinds of formal organizations, it focuses on the modern corporation. because it appears to be in active evolution and exhibits a range of variations and innovations that can 
The author's position differs from Weber's propositions. Weber (1968) proposed a practical model for the formal organization, namely 'an authority structure composed of positions; the activities of each position ... directed by the position above it in the hierarchical structure. "In this theory individuals surrender all of their resources to a central authority. However, in practice this is not true for all resources under all circumstances. "The fundamental flaw in this theory is that only the central authority is treated as a purposeful actor.' (p. 423) The author makes references to Michels (1911), Barnard (1938), and Simon (1947), and Simon et al. (1951) to illustrate this point. The latter authors argue that the organization is characterized as follows: 1) as a system of interrelated social behaviors of participants, 2) each of which receives inducements from the organization and in return makes contributions to the organization, 3) the participant will continue to do so as long as he receives a net value from this transaction, 4) all contributions of participants form the source from which the inducements are manufactured, and, hence, 5) an organization is "solvent" - and will stay in existence - only so long as these conditions are satisfied (p. 423).

In addition to the remarks made above about metatheory, the author assumes that organizations have more and more deviated from Weber's principles. Incentive payments were given, and intermediate superiors regained more control over their own actions as they had authority over their subordinates (p. 424). Coleman discusses past and future of the Weberian model (p. 425). He argues that at the beginning of the industrial revolution, people were willing to trade all their resources against the material inducements received. This was the only possible way to escape extreme poverty. Nowadays man has more choices.

"... the Weberien form of rational organization is being replaced by a form which acts largely as an investor. facilitator, and guide to the sugcessful emplowment of the resources it invests."

Next the author refers to Williamson (1975). Coleman argues that social structure is limited to those relationships that entail from the individual interests of each actor and the resources he owns (pp. 425, 426):

The formal organization, in contrast, is] ... a system in which relations among actors are highly constrained by the social structure. ... a relatively small number of relations are permitted without being required.
Requests and other communications must "go through channels":

A person entering a formal organization would have a position with a set of obligations, some with respect to other positions, some to the firm as a whole. He has also a set of expectations belonging to his position, some relating to other positions, some to the corporate actor (pp. 426 , 427): 
The structure of the organization makes the products of one's position activity the resources for those in ather positions. ... What exists is a structure of positions in ralation, nor persons in relation. ... [People] take on the abligations and expectations, the goals and resources, associated with their positions in the way thex put on work clothes for their jobs. '

An important concept is viability of the organization. In a pure market, viability is said to be reciprocal. Every transaction must be in balance or be balanced by a deferred obligation of one party. In a formal organization the corporate actor is the clearinghouse of remaining imbalances from transactions between positions, "as every position has certain obligations and expectations to the corporate actor itself." This is called independent viability (p. 428).

In a market with $n$ parties, $n(n-1) / 2$ relations must be viable. In a formal organization only $n$ relations (between each of the participants and the corporate actor) need to be viable. The corporate actor may accept that only the totality is viable: positions that fall short of yielding a surplus to the firm may be compensated by the surplus from the others. This is called global viability. The danger here is that persons holding positions that create excess value will leave the corporation (p. 429). This problem can be solved by reintroducing individual viability, namely by adjusting the inducement of each position to its marginal contribution. In practice however this would be difficult to achieve. The author proposes other solutions (p. 431). One solution is divisional viability: the introduction of semi-independent divisions or the use of internal transfer prices brings the market back into the firm. The second is forward policing, consisting of feedback of defects to those responsible, and thus improving viability. The third is backward policing, a system of control at Honda in which each department has the right to refuse parts or semi-finished products from other departments that do not meet specifications (and thus, in principle, is entitled to stop production completely). The disadvantages of global viability have led to still more solutions, such as the contracting out of certain operations, or franchising.

Coleman advances three ways of employee inwolvement, like quality circles (the Japanese QWL system), codetermination through representation in the board of directors (German law), and ownership rights for innovative employees (like in some instances in the computer industry, p. 437).

Macro-social hypotheses are connected to these forms of employee involvement (p. 442). Ownership rights to innovators in the US seem to be more closely related to American history, as it represents the "vesting of rights in the individual rather than in a collectivity ..." (p. 442). All agents (employees) are supposed to act in the interest of the same corporate actor. The author now raises a more general question (p. 444):

What principles should govern the partitioning of a task among agents (deparments or individuals), and what prineiples should govern the control of the process by agents among whom the task has been partitioned? 
To answer the question he proposes the principle of backward design. The agent with the most interest in the project should be held accountable for it, and given authority to be exercised in a backward direction (pp. 445, 446):

"... the criteria which shape those actions are dictated in a backward fashion, from the goal to the starting point. Just as backward policing inwolves short feedback loops from end result to actiom, backward design involves short feedback loops form final product to design decision. ... In case the agents" interest differ from those of the corporate actor]... it is to the corporate actor's interest to attempt to bring about jdentification of each agent with the corporation. so the agent will take the corporation's interests as his. own."

Examples of these attempts are the singing of company songs, the wearing of a uniform, social events, and establishing company policies for job security (pp. 445, 446).

At this stage of knowledge development, the study has gradually moved from hypothesis to prescription. Next, general principles concerning the optimizing of internal structure are built. The exemplary evidence is said to suggest a number of principles (p. 446):

'The examples introduced throughout this chapter llead to several intermediate-level principles. Backward policing is superior to forward policing, as it has a shorter feedback loop, control over an activity should remain with those having a strong interest in its success, "the agent with the strongest interests in the success of the corporate activity is the one who, if given authority over design and production decisions affecting that activity, will be most likely to optimize the outcome as whole."

For structuring authority over actions, two guidelines are said to apply (p. 448). The first is to discover for each position which other agents are directly affected by the occupant's decisions. The second guideline follows from the first, saying that 'agents [should be given] rights of" control over what interests that occupant, ${ }_{\text {, }}$ such as wages and promotions. In such an exchange system authority would be allocated in a way almost opposite to the way it is in hierarchical structure. ... The reallocation of rights result in a structure in which supplier-customer relations between various positions in the organization largely replace the relation between corporate actor and employee (principal and agent). Each occupant of a position must achieve what might be called positional viability".

The study ends with an important recapitulation (p. 450):

"The changes in modes of governance... mave in a direction away from authority exercised by a superordinate, and toward a discipline imposed by the structure of incentives." the corporation ... should be seen as a system of action composed of positions (not persons). In such a system the structure of relations: among positions is not autonomously organized, as in a self-constituted social system, but is fixed by central management to bring about the achievement of certain goals, which constitute the purpose of the corporate actor. Actors within the structure pursue purposes of their own. If the structure is well designed, these pursuits will also achieve the purpose of the corporate actor. 
Hypothesis (A) includes axiom formulation (pp. 1,3,11), conceptualization (definiteness, precision, pp. 18,428, 429), and conjectures (pp. 14, 16, 17, 18, 422 - 426). Derivation (B) and intervention (E) are only seemingly present. The rules (recommendations, pp. 429-448)

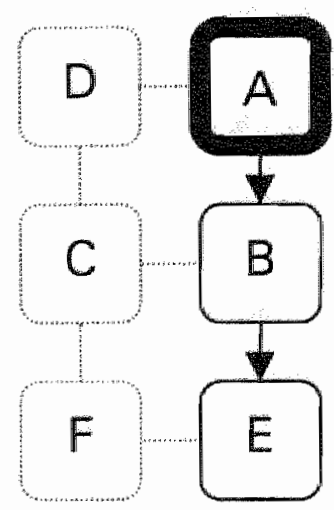
are in fact extensions of the hypothesizing phase.

Hypothesizing is largely worked out, but derivation and prescription are discussed without elaboration. Within box A metatheoretical requirements are fully met. The work is fully coherent with sociological theory (pp. 423, 426).

The theory has important metatheoretical bearing. Validation is not sought, nor is direct practical utility.

\section{Conclusion}

The work is an important basis for the further development of organization theory based on micro- and macro-sociology. The fecund quality of this work lies in the firm ground it offers for modeling specific theoretical questions. Such models have led to testable theories already, as is demonstrated in the work of Lindenberg et al. (1983), specifically in Wippler's model (section 3.6).

Coleman draws on predecessors such as Weber, Michels, Simon and Williamson. He meticulously chooses from their hypotheses, adapts them, and combines them into a set of hypotheses of his own, making a complete new theory. 


\subsection{Results of the examination of 20th-century theories}

\section{Patterns of knowledge development in the cases}

The anthologies of theories that were used to select our cases were primarily intended to demonstrate the progress of ideas, images, and currents in organization science. The characteristics of the development of scientific knowledge, like methodological rigor, have not necessarily been the first point of interest of the collectors. This is however specifically the case for this study. It is not the intention of this study to add one more to the numerous repositories of ideas, but to focus on those characteristics that are relevant for knowledge development in particular. To that end, patterns of such elements are sought hereafter.

The research in this chapter concentrated upon the main objective of this study, the development of an assessment system(section 2.2). In view of this objective, the assessment system has been tried out by applying it to a sample of organization theories.

For the important secondary result data have been gathered leading to the reflection of 20thcentury organization theory.

In this section results concerning the second objective are reported, under four headings. The first two headings concern time clusters in theories. Under the third a typology of theories is devised. Finally, a complete overview of the data from the research is given.

Final conclusions about both ends of the study will be drawn in chapter 7 .

Time clusters, structure and strategy

In figure 5.5 the occurrence of the sample items over time is depicted. For each work its pertinence to structure $(U)$, strategy $(A)$, or both $(B)$, is indicated.

The period before 1950 seems to be a pioneering phase. In our sample, six 'patriarchs' of organization theory appear, namely Taylor, Fayol, Weber, Barnard, the Hawthorne researchers

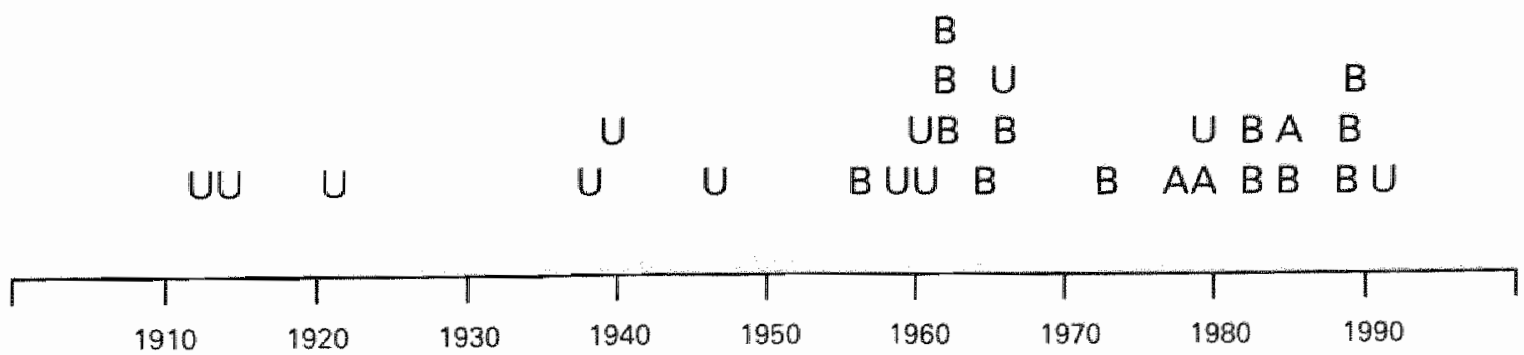

Figure 5.5. Clusters of theories in the sample over time (1). 
(Roethlisberger and Dickson, with their master Mayo), and Simon. These authors greatly influenced the further development of organizational knowledge. Over time, there is at tendency toward academism. Taylor, Fayol, Barnard, and Dickson were practitioners, Weber, Roethlisberger and Simon were academics. It is to be noted that strategy was not yet on the agenda. Early books on the matter like Ansoff's were published in the mid-sixties.

Exceptionally, as mentioned earlier in section 1.2. McKinsey, the founder of the consultancy, advanced the subject before World War II under the name of 'Policy'.

During the post-war period, after 1950, two clusters of theories appear in our sample. The first one is roughly based in the sixties (1958-1967). At this time, strategy is coming into the picture, but still in a combination with structure. Chandler is the first to advance propositions about their interrelationship.

Many writings of this period have marked relationships. March and Simon draw on Simon, like Cyert and March did, with March as the "trait-d'union". Reducing the substance of the proposed hypothesis to keywords produces the following development:

March \& Simon

McGregor

Burns \& Stalker

Blau \& Scott

Chandler

Cyert \& March

Crozier

Katz \& Kahn

Lawrence \& Lorsch

Thompson bounded rationality

"Theory $\mathrm{Y}^{\prime}$ : man is creative, self-controlling and seeking responsibility organismic (not formalistic) organization is appropriate for change characteristics of bureaucracy relate to the type of external actors structure follows strategy bounded rationality and organizational learning in bureaucracies actors controlling uncertainty obtain power open systems concept: organization and environment proper structure is contingent with external demands bounded rationality; structure should reflect external requirements

In these works the large, complex organization is explained by the innate limited rationality of its members and their need for coping with uncertainty, mainly emerging from external sources. The post-war belief in the formal bureaucracy as the one best organizational form is fading as the market and other external forces claim their rights. This coherent set of theories brings together the work of sociologists, psychologists, and the economic historian Chandler.

By the end of the seventies, the full effects of the oil crisis and the emergence of global competition become evident. The cluster of theories in the eighties seems to be less coherent than before. Large organizations get into trouble, and new prophets arrive. Two tendencies can be seen. The first seeks new ways to understanding structure and strategy, either by hypothesizing new theories or by inducing general patterns from empirical observation.

Williamson proposes his theory on markets versus hierarchies. Pfeffer and Salancik stretch the environment to an enacted phenomenon that needs permanent re-interpretation and negotiation. Mintzberg advances his five basic phenotypes of structure. Porter proposes a clear design model for a successful competitive strategy. 
The second tendency is to avoid theorizing and to learn from practical examples. This is quite understandable, as many firms suffer and no witch doctor seems to have a cure. For instance, Peters and Waterman dismiss all foregoing theoretical efforts as inadequate. Six keywords of excellence constitute their thesis. Soon after their claim of truth is rebutted.

So we return to science. DiMaggio and Powell explain organizational structure as the result of imitation. Organizations would mimic forms of other organizations that are subject to the same external conditions. Hofstede surprises his audience with an enormous empirical study of cultural characteristics. The difficulty of implementation of whatever change is due, is discussed by Argyris in a book full of training experience. Bartlett and Ghoshal write on global competition. Kanter reports on elephantine corporations that try to dance. In her book, the letters are back: 'Focused, Fast, Friendly, and Flexible'. Is there a whiff of Peters and Waterman in the air?

Two scientific examples end our sample. Hannan and Freeman produce a capstone on their earlier theories that are far removed from mainstream organization science: the population ecology of organizations. They argue that the organization does not behave like a human being. Organizational populations can be understood to grow or decline following a biotic model, including factors like carrying capacity, intrinsic growth rate, and competition. Willful action is restrained by inescapable inertia.

Our final example is Coleman. For a long time, this sociologist was an outsider to the Mutual Admiration Society of American Sociologists. As will be reiterated in chapter 6, his philosophical framework on sociology, incorporating useful elements from Weber, Barnard, Simon and Williamson, is a promising basis for organization theory.

In contrast to the cluster of the sixties, the eighties present a number of diverse and contradictory assertions. Many are controversial, some because they are considered trivial; others because daring new positions are taken. Maybe this is a transition period in the development of organizational knowledge.

Time clusters in directness

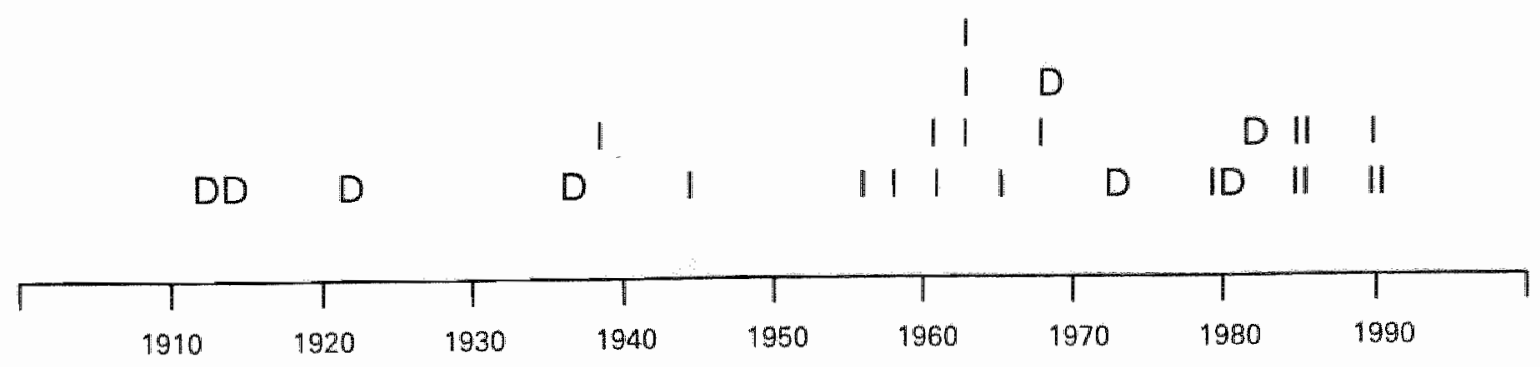

Figure 5.6. Clusters of theories in the sample over time (2). 
One characteristic, the directness of pertinence, is clearly time-related (figure 5.6). The early theories (until 1940) had a direct pertinence (D) to their subject. Their propositions were mainly about structure. Studies from the fifties and sixties addressed the subject more indirectly (I). Either they referred to issues related to structure or strategy but they did not describe, explain or predict organizational elements. Or they had a more or less philosophical nature, in which case they contemplated on organization theories. Around the seventies until the beginning of the eighties direct pertinence to structure and/or strategy is back again, while recent theories in our sample are all indirect.

In this respect, it is typical for contemporary contributions to have a large metaphysical and epistemological content. This point will be discussed further in the next chapters. Anyhow, theories mainly consisting of hypothesis, apodictical theories and testable theories (those covering the four upper phases of knowledge development without staged experiment) seem to be evenly distributed over the 20 th century. It may be concluded that for the assessment of design-oriented organization theories no special criteria are needed that would relate to the time and age of their emergence.

\section{Types of theories}

In the report on the case studies, under the headings of 'Assessment following the A-F scheme', and of 'Conclusion', the content of the different elements of knowledge development is reported in detail.

In the observation of $20^{\text {th }}$-century theory five types can be observed. They can be considered as inductive meta-models of theory development. Each type is symbolized hereafter with a small emblem corresponding to the accents in the development of knowledge involved. In this respect, earlier remarks should be kept in mind. First, philosophy of science does not enable testing against scientific propositions. The appraisal and ordering of theories is no more than an assessment. What is proposed here is an "educated guess". Second, the books from the sample do not necessarily represent the complete oeuvre of the authors.

\section{The hypothesis theory.}

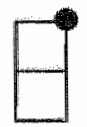

This theory is limited to hypothesis, sometimes with weakly elaborated steps toward derivation and prescription, or a minute run-up of narrative examples or cases. The following theories from the sample belong to this type: Simon, March \& Simon, Blau \& Scott, Katz \& Kahn, Williamson, DiMaggio \& Powell, and Coleman.

2. The historiographical type of theory.

This type is characterized by the fact that historical observations are generalized into hypothesis. Weber represents a distinct sub-species of this type of theory as he replaces induction with the a priori hypothesis of ideal-types. Other books reporting this way of 
knowledge development sometimes include a rudimentary piece of induction. These are the theories of Burns \& Stalker, Chandler, and Crozier.

3. The practice oriented type of theory.

This type starts with hypothesis that seeks the shortest way to the formulation of rules. The intermediate step of derivation may be more or less elaborated. In the sample of this study we find the writings of Fayol, Bamard, McGregor, Thompson, Pfeffer \& Salancik, Mintzberg, and Porter.

4. The speculative, or apodictical theory.



The skipping of boxes is apparent in the speculative or apodictical approach: here observation is not transformed in strictly defined concepts, constructs, and descriptive models. Instead the jump to hypothesis is made. By the same token, hypotheses are followed by rules without much consideration of well-defined observable categories. In general this type of theory adheres to terms and categories of 'ordinary languages. Such a theory may have a tendency toward rhetoric. In the sample Peters \& Waterman, Argyris, and Kanter belong to the type.

\section{The scientific theory.}

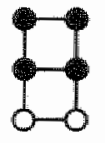

This type comes in two varieties. The $A-B-C-D$-type is limited to the four upper phases, namely hypothesis, derivation, observation, and induction. The most complete one includes prescription with rules for the design of acts of imtervention (manipulation of observables by experiment or by interference in practical situations). This enables observation of the thus provoked situation. In the sample of this study the works of Taylor, Roethlisberger \& Dickson, Cyert \& March, Lawrence \& Lorsch, Hofstede, Bartlett \& Ghoshal, and Hannan \& Freeman belong to one of the varieties of this type.

\section{Overview of data from the material}

In table 5.4 details are given of the characteristics as found in the 28 theories. Hereafter, the terms used in the headings of the columns are explained.

In the column purpose, the central intention of the publication is given, as directly or indirectly indicated in the book.

Three sub-categories are distinguished. E refers to a general exposition of the problem, followed by suggestions for further research, or by some partial or preliminary first steps of elaboration. $\mathrm{R}$ involves the report of an entire research into given domain. In case of $\mathrm{C}$, a 'manifesto' is published, advancing a belief or a conviction that is not or almost not grounded on research. 


\begin{tabular}{|c|c|c|c|c|c|c|c|c|c|c|c|c|c|c|}
\hline 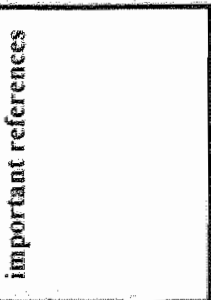 & 䕸 & 喜 & 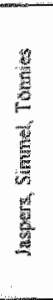 & 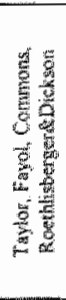 & $\frac{6}{2}$ & 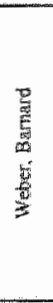 & 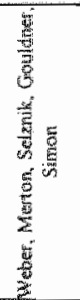 & 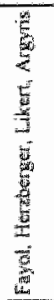 & 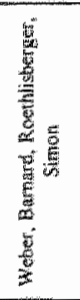 & 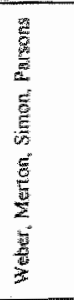 & 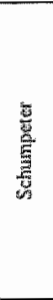 & 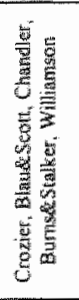 & 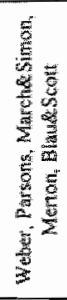 & 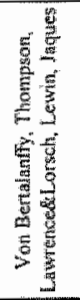 \\
\hline 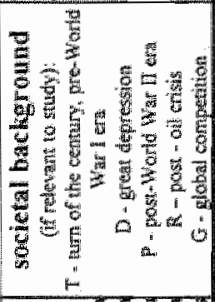 & F & $t$ & $\leftarrow$ & 0 & 0 & 2 & $a$ & $a$ & $\Delta$ & $a$ & $a$ & $\infty$ & 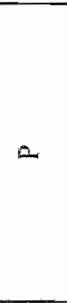 & $a$ \\
\hline 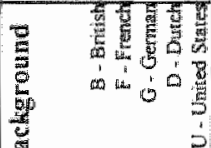 & 0 & $\omega$ & 0 & $=$ & $P$ & 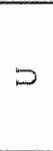 & $\supset$ & $D$ & $\infty$ & $D$ & $\supset$ & $=$ & Lu & $>$ \\
\hline  & e & 2 & in & $a$ & $\infty$ & $\infty$ & $\infty$ & $\omega$ & $\infty$ & $\infty$ & $n$ & $n$ & $n$ & $\infty$ \\
\hline 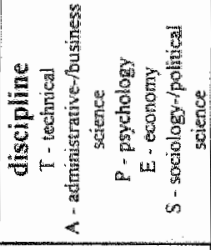 & $\omega$ & $F$ &  & $\alpha$ & $a$ & w & $\begin{array}{l}a \\
\frac{14}{5} \\
4\end{array}$ & $a$ & $\sum_{n}$ & $w_{i}$ & $\omega$ & $a$ & $\infty$ & a \\
\hline 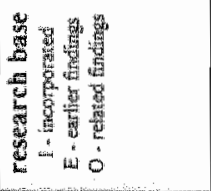 & 42 & ' & w & " & $-n$ & - & - & 0 & $w$ & - & - & - & - & $\begin{array}{l}0 \\
\text { inf }\end{array}$ \\
\hline  & $I$ & - & - & $\stackrel{\omega}{=}$ & $\Sigma$ & 4 & $\omega$ & $I$ & $\stackrel{4}{-2}$ & $\begin{array}{l}I_{1} \\
w^{\circ}\end{array}$ & - & $\begin{array}{l}\Sigma \\
I^{\prime} \\
\text { W }\end{array}$ & - & $\omega$ \\
\hline  & $\alpha$ & w & 叫 & 山 & $\alpha$ & $\omega$ & (i) & $a$ & $\approx$ & $\propto$ & $\alpha$ & $x$ & $\propto$ & $\omega$ \\
\hline$\stackrel{5}{\leftrightarrows}$ & $\frac{2}{2}$ & $\stackrel{0}{a}$ & $\overline{\mathrm{S}}$ & $\stackrel{\infty}{2}$ & $\stackrel{g}{\sigma}$ & 吾 & $\begin{array}{l}\infty \\
\sigma \\
2\end{array}$ & 8 & $\Phi$ & $\stackrel{8}{\mathscr{2}}$ & 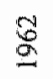 & 8 & $\stackrel{8}{2}$ & $\stackrel{8}{8}$ \\
\hline$\frac{\sqrt{3}}{5}$ &  & 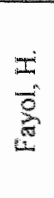 & $\frac{\sum}{3}$ & 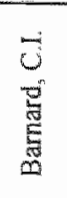 & 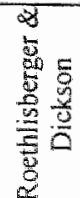 & 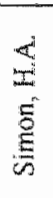 & 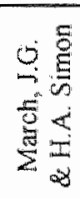 & 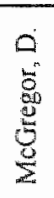 & 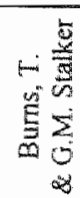 & 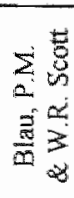 & 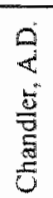 & 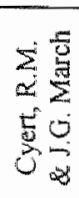 & 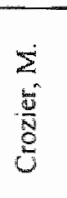 & 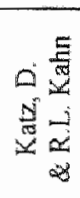 \\
\hline
\end{tabular}




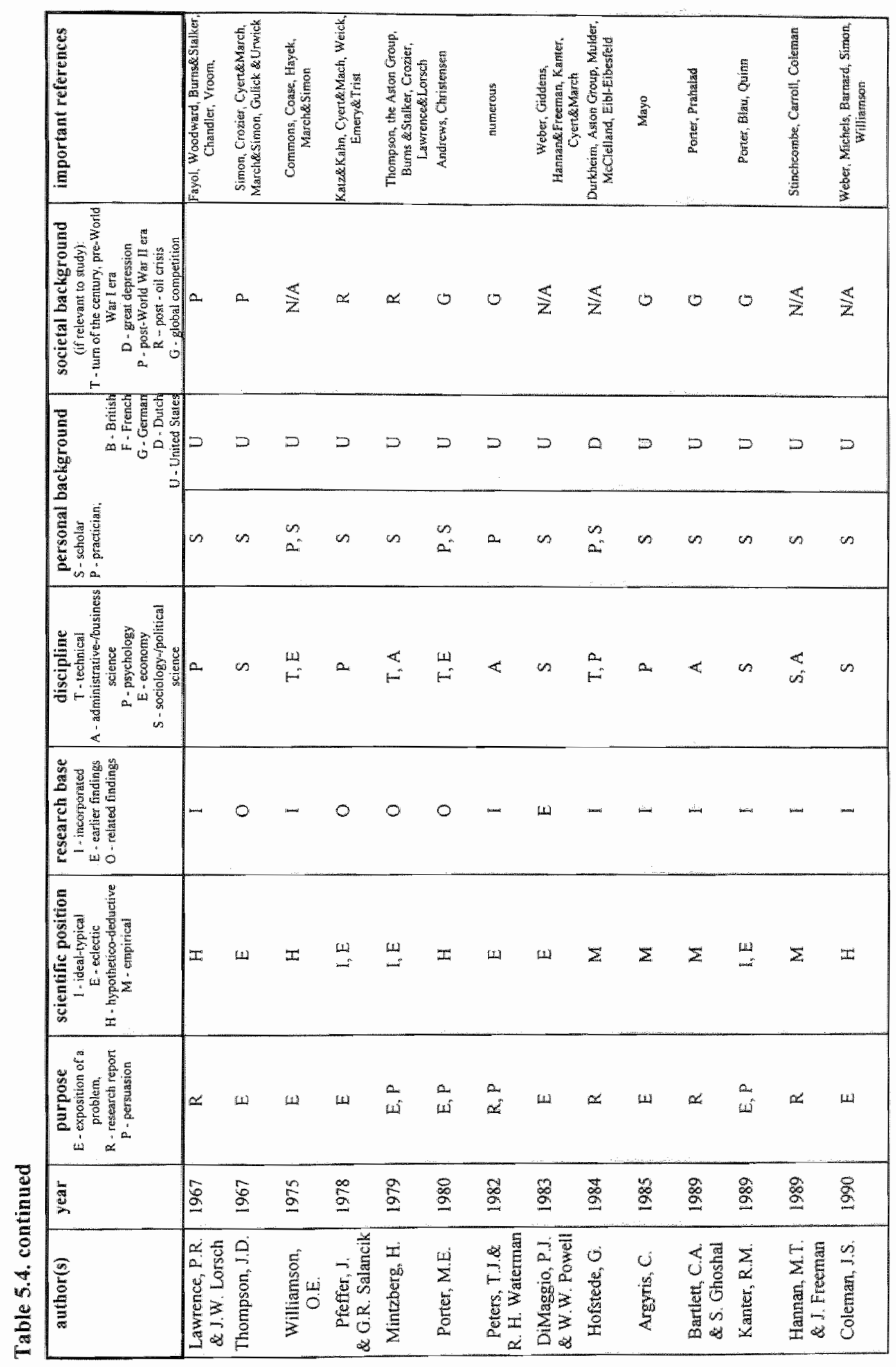




\begin{tabular}{|c|c|c|c|c|c|c|c|c|c|c|c|c|c|c|c|}
\hline 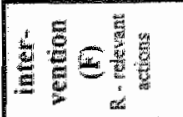 & $\approx$ & & & & $\propto$ & & & & & & & & . & & \\
\hline & $\vec{s}$ & 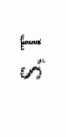 & & ns & bi & & & & - & ' & ' & & . & & \\
\hline 鄫 & $\mid \begin{array}{l}0 \\
0 \\
0 \\
0 \\
0 \\
0 \\
0\end{array}$ & & $\frac{\frac{\pi}{g}}{8}$ & & 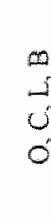 & & & & & $\stackrel{m}{\stackrel{m}{s}}$ & & 站 & & 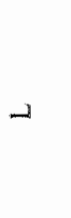 & \\
\hline 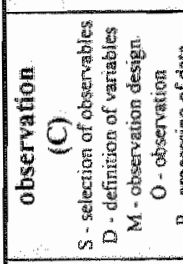 & $\begin{array}{l}2 \\
0 \\
0 \\
5 \\
0 \\
0 \\
0\end{array}$ & 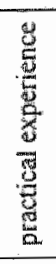 & is & 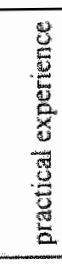 & $\begin{array}{l}0 \\
0 \\
\dot{2} \\
0 \\
\text { in }\end{array}$ & & & & & & 0 & 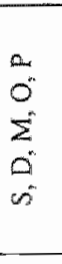 & $\begin{array}{l}a \\
0 \\
\Delta \\
\Delta \\
0 \\
\text { sis }\end{array}$ & 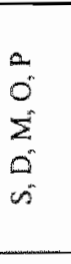 & \\
\hline 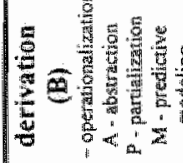 & $\mid \begin{array}{l}\mid \\
\vdots \\
d \\
d \\
0 \\
0\end{array}$ & 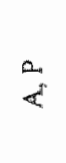 & $\sum_{\Delta=}$ & se & $\begin{array}{l}\Sigma \\
0 \\
0 \\
0 \\
0\end{array}$ & t & & & $\Sigma$ & & $\begin{array}{l}\Sigma \\
\Sigma^{\prime}\end{array}$ & . & $\begin{array}{l}\sum_{0} \\
0 \\
\& \\
0\end{array}$ & $\Sigma$ & \\
\hline 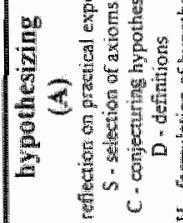 & $\begin{array}{l}x \\
0 \\
0 \\
5 \\
5 \\
2 \\
2\end{array}$ & $\begin{array}{l}0 \\
u \\
\approx \\
\approx\end{array}$ & $\begin{array}{l}I \\
\text { s. } \\
s \\
\text { s }\end{array}$ & $\begin{array}{l}I \\
0 \\
0 \\
w \\
\vdots\end{array}$ & $\begin{array}{l}I \\
0 \\
0\end{array}$ & y & & 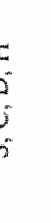 & 集 & 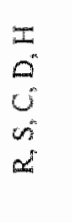 & $\begin{array}{l}I \\
\text { S } \\
\text { v } \\
\text { os }\end{array}$ & $\begin{array}{l}\frac{\pi}{2} \\
\text { s. } \\
\text { v }\end{array}$ & $\begin{array}{l}x \\
0 \\
0 \\
\text { of }\end{array}$ & 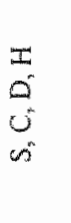 & $\begin{array}{l}\text { z } \\
\text { s } \\
\text { is } \\
\text { is }\end{array}$ \\
\hline 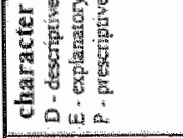 & 离 & $\stackrel{\circ}{\circ}$ & $\stackrel{\omega}{\nu}$ & 星 & 埌 & 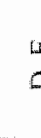 & & P & 2 & $\stackrel{\leftrightarrow}{\circ}$ & "w & $\stackrel{\vec{w}}{\mathrm{w}}$ & $\stackrel{\omega}{\Delta}$ & 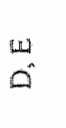 & 茨 \\
\hline 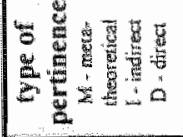 & D & 0 & D & 0 & - & 8 & & 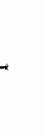 & - & - & $\bar{\Sigma}$ & - & - & $\vec{\Sigma}$ & $\vec{\Sigma}$ \\
\hline 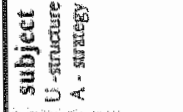 & $p$ & $=$ & כ & כ & & & & 5 & P & D & $\begin{array}{l}3 \\
5\end{array}$ & 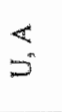 & 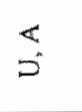 & 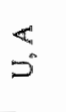 & $\$$ \\
\hline 总 & \begin{tabular}{|l} 
\pm \\
$\vdots$ \\
\end{tabular} & $\stackrel{8}{\circ}$ & $\vec{\Xi}$ & $\stackrel{\infty}{2}$ & 要 & 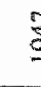 & & 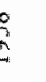 & 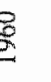 & $\vec{\Phi}$ & ఏ & 苂 & 兽 & 怘 & 总 \\
\hline 离 & 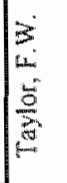 & 蓠 & 5 & 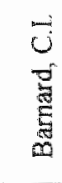 & & & & & & 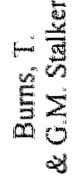 & & 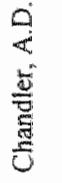 & 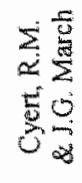 & 忘 & 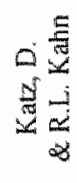 \\
\hline
\end{tabular}




\begin{tabular}{|c|c|c|c|c|c|c|c|c|c|c|c|c|c|c|}
\hline 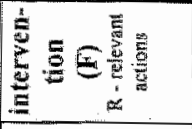 & 1. & ' & . & ' & . & & ' & : & ' & ' & t & ' & ' & ' \\
\hline 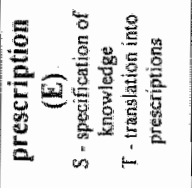 & $\operatorname{los}$ & $n$ & $n$ & $\infty$ & $\Leftrightarrow$ & $\overrightarrow{w^{n}}$ & L & . & " & $\stackrel{t}{s}$ & in & $\stackrel{t}{\text { is }}$ & . & . \\
\hline 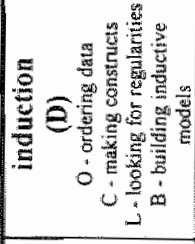 & $\begin{array}{l}\infty \\
0 \\
0 \\
0\end{array}$ & ' & & ' & " & , & " & . & $\begin{array}{l}0 \\
5 \\
0\end{array}$ & , & $\begin{array}{l}\infty \\
3 \\
0 \\
0\end{array}$ & $山$ & $\begin{array}{l}\infty \\
-1 \\
0 \\
0\end{array}$ & , \\
\hline 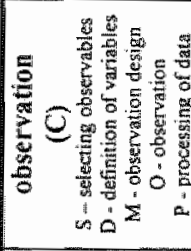 & $\mid \begin{array}{l}2 \\
0 \\
5 \\
0 \\
0 \\
\infty\end{array}$ & ' & ' & ' & ' & ' & $\begin{array}{l}0 \\
\Sigma\end{array}$ & , & $\begin{array}{l}a \\
0 \\
\Sigma \\
0 \\
0 \\
n\end{array}$ & $\begin{array}{l}0 \\
0 \\
\dot{2}\end{array}$ & $\begin{array}{l}a \\
0 \\
\sum^{n} \\
0 \\
0\end{array}$ & $\begin{array}{l}0 \\
\dot{0} \\
i\end{array}$ & $\begin{array}{l}a \\
0 \\
\sum^{2} \\
0 \\
0 \\
\text { in }\end{array}$ & , \\
\hline 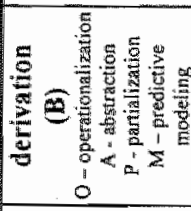 & $\left\{\begin{array}{l}\Sigma \\
0 \\
5 \\
0\end{array}\right.$ & 0 & $=$ & a & $\ll$ & $\begin{array}{l}\Sigma \\
0 \\
4 \\
0\end{array}$ & ' & " & $\begin{array}{l}\Sigma \\
a \\
2 \\
0\end{array}$ & ' & $\begin{array}{l}\Sigma \\
0 \\
5 \\
0\end{array}$ & & $\begin{array}{l}\sum \\
a^{2} \\
\vdots \\
0\end{array}$ & " \\
\hline 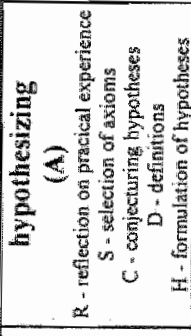 & \begin{tabular}{|l} 
\\
0 \\
0 \\
0 \\
$\infty$
\end{tabular} & $\begin{array}{l}I \\
0 \\
0 \\
i\end{array}$ & $\begin{array}{l}I \\
0 \\
0 \\
i \\
i n\end{array}$ & $\begin{array}{l}I \\
0 \\
0 \\
i n\end{array}$ & $\begin{array}{l}I \\
Q^{n} \\
u \\
n\end{array}$ & $\begin{array}{l}I \\
0 \\
u \\
\dot{n}\end{array}$ & $\begin{array}{l}I \\
\omega^{\prime \prime} \\
\alpha\end{array}$ & $\begin{array}{l}I \\
0 \\
0 \\
\text { on }\end{array}$ & $\begin{array}{l}I \\
0 \\
u \\
\vdots \\
\alpha^{3}\end{array}$ & in & $\begin{array}{l}I \\
0 \\
u \\
u \\
w \\
0\end{array}$ & $\begin{array}{l}I \\
0 \\
0\end{array}$ & $\begin{array}{l}I \\
0 \\
0 \\
0\end{array}$ & $\begin{array}{l}I \\
0 \\
u \\
0\end{array}$ \\
\hline 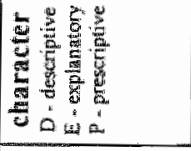 & $\begin{array}{l}\hat{E} \\
\omega^{\prime \prime} \\
a^{\prime}\end{array}$ & u & $\ddot{\omega}^{\prime \prime}$ & $\frac{\Delta}{0}$ & 0 & $\vec{a}$ & $a$ & $\stackrel{\omega}{a}$ & $\omega^{\circ}$ & $\begin{array}{l}a \\
u^{\prime \prime \prime} \\
a^{\prime \prime}\end{array}$ & $\stackrel{w}{a}$ & 0 & w & D. \\
\hline 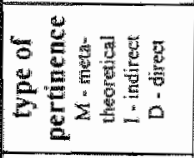 & $e^{6} \leq$ & & $e_{0}^{5}$ & 送 & 0 & 0 & 0 & - & - & - & - & - & - & $\Sigma$ \\
\hline 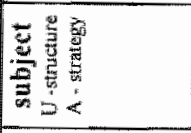 & $<$ & $=$ & 5 & $\ll$ & $\supset$ & $\alpha$ & 5 & 5 & 5 & $\ll$ & 5 & 5 & 5 & $b$ \\
\hline 齿 & 2 & 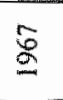 & $\frac{m}{2}$ & $\stackrel{\infty}{\Xi}$ & $\frac{2}{2}$ & $\underset{\Xi}{\mathscr{\Xi}}$ & $\stackrel{g}{g}$ & $\stackrel{8}{2}$ & 尌 & $\stackrel{\alpha}{\alpha}$ & 器 & $\underset{\stackrel{g}{a}}{\stackrel{a}{a}}$ & $\stackrel{g}{g}$ & 呑 \\
\hline 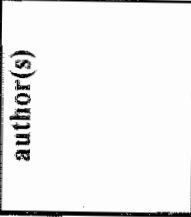 & 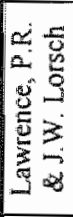 & 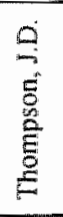 & 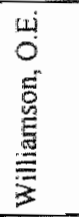 & 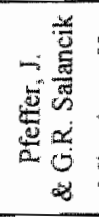 & 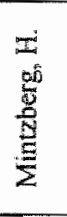 & 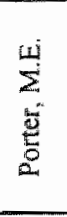 & 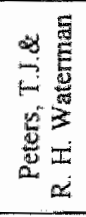 & 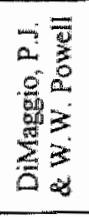 & 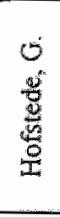 & $\begin{array}{l}0 \\
\frac{4}{E}\end{array}$ & 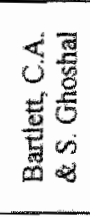 & 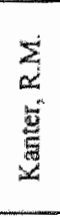 & 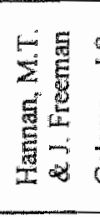 & 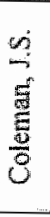 \\
\hline
\end{tabular}


The author of a work may assume different scientific positions. He may build a system of concepts called ideal-types as introduced by Weber, that summarize and abstract the main traits of categories of observed phenomena. In our scheme of knowledge development idealtypes are constructs or descriptive models. This is sub-category $I$.

A different position is the eclectic one (E), in which authors collects existing theories as a base for their own project. The hypothetico-deductive approach $(\mathrm{H})$ starts from a set of basic contentions and attempts to link these to observation, followed by comparison of expectation and observation. Finally, the empirical position (M) refers to approaches in which hypotheses about a field of inquiry are absent or unsatisfactory. The research may start then with the collection of observable phenomena in order to explore the subject.

The scientific position may be characterized by more than one sub-category. A proposed theory may be based on general, conventional knowledge. For the purpose of this study, this is considered as the absence of a research base.

If the research is reported in the book itself, this is indicated by $I$. When the author refers to earlier investigation of the same observables, by himself or others, this is indicated by $\mathrm{E}$ (earlier research). If related findings are referred to, $O$ (other) applies. The choice made between $\mathrm{E}$ and $\mathrm{O}$ may rely on an "educated guess", as not all sources of the works have been examined.

The research base may have more than one characteristic.

Discipline refers to the scientific background from which the author is supposed to have been working. Their educational background is used to establish this point.

The entry personal background indicates the occupational (scholar or practitioner) and national background of the author(s). Some of the works are clearly related to the societal background of their time and age. Frequently, authors themselves link their projects to particular societal circumstances or developments. In other cases, the connection becomes clear without specific reference being made. In both cases, the characteristics of some broad eras are linked to the books, namely "turn-of-the-century until World War I' (T), "the great depression' (D), the period after World War II (P), the years of recovery after the oil crisis (R), and the era of emerging global competition (G).

When, however, a writer proposes a theory that apparently is not linked to the then societal circumstances, the societal background is indicated as "not applicable" (N/A).

In a number of books, especially the older ones, the importance of the knowledge of organization for society as a whole is stressed. Salient examples are Taylor, Fayol, Weber, Barnard, (all before the first World War), Blau \& Scott and Crozier in 1963, and finally Kanter, not too long ago. Many others expressed the importance of their work for global or American economic life.

The most important mutual references between the authors from our selection are reported. References to other authors are given when they seem to be illustrative for the systematic examination.

Structure (U) or strategy (A), or both, may be subject of the works examined.

The next column is about the type of pertinence. In some books, propositions are made about the way problems of structure and strategy should be theorized upon, and how research should 
be carried out. These are indicated with $\mathrm{M}$, for metatheoretical. If pertinence to structure and strategy is direct (like concrete propositions, explanations, prescriptions), D applies. If theories refer to concepts that have an indirect bearing on structure or strategy, this is indicated with $I$. The columns hypothesizing, derivation, observation, induction, prescription, and intervention (with their symbols A through F) correspond to the scheme depicted in figures 3.11 and 3.12. In each box, the elements that may be part of the main heading are given. In the table, the presence of each of these constituents in the theory being examined is indicated. Absent or scarcely discussed categories have a dashed frame. 


\title{
6. Six contemporary theories
}

\author{
6.1. The material
}

In chapter 5 a sample of theories have been assessed that are representative for the harvest of 20 th century organizational knowledge. In addition to these now some contemporary theories will be examined. This cross-section of knowledge is meant to reveal whether metatheoretical rigor has reached a higher level than was the case over the past 100 years. Next to that the sample is used to examine the usefulness of the assessment system for today's theory.

All articles are chosen from the 1995 volume. A preselection is made to make sure that each article relates to structure and strategy.

From each of the following journals, one paper is chosen.

- Academy of Management Journal,

- Administrative Science Quarterly,

- Harvard Business Review,

- Long Range Planning.

- Organization Studies,

- Strategic Management Journal.

The choice represents prominent journals covering the subjects involved, from American as well as European origin.

The sample comprises the following articles:

1. Phan, P.H., and C.W.L. Hill, Organizational Restructuring and Economic Performance in Leveraged Buyouts: An Ex Post Study, Academy of Management Journal, 1995, Vol.38, No.3, pp. 704 - 739,

2. Lomi, A., The Population Ecology of Organizational Founding: Location Dependence and Unobserved Heterogeneity, Administrative Science Quarterly, 1995, Vol. 40, pp. $111-144$,

3. Bower, JL., \& C.M. Christensen, Disruptive Technologies: Catching the Wave, Harvard Business Review, January-February 1995, Vol. 73, pp. 43 - 53, 
4. Lasserre, P., Corporate Strategies for the Asia Pacific Region, Long range Planning, 1995, Vol. 28, No. 1, pp. 13 - 30,

5. Lynn, L.H. \& H. Rao, Failures of the Intermediate Forms: A Study of the Suzuki Zaibatsu, Organization Studies, 1995, Vol. 16, No.1, pp. $55-80$,

6. Robins, J.\& M.F. Wiersema, A Resource-based Approach to the Multibusiness Firm: Empirical Analysis of Portfolio Interrelationships and Corporate Financial

Performance, Strategic Management Joumal, 1995, Vol. 16, pp. 277 - 299.

These articles will be discussed hereafter in this order.

The same questionnaire will be used as in chapter' 5, except that the headings 'Bibliographical data' and 'Contextual points' will be combined, while the entry 'Conclusion' is omitted, these subjects being discussed at the end of the heading 'Assessment following the A-F - scheme'. As stated, in this section the usefulness of the assessment scheme for the examination of the theory involved will be discussed in more detail. Therefore, a final heading is added, that reads 'Remarks on the assessment system'.

\subsection{Phillip H. Phan and Charles W.L. Hill}

\section{Bibliographical data and contextual points}

Phan, P.H., and C.W.L. Hill, Organizational Restructuring and Economic Performance in Leveraged Buyouts: An Ex Post Study, Academy of Management Joumal, Vol.38, No.3 1995, pp. $704-739$

Phan is an assistant professor of strategic management at York University (Canada). Hill is a professor of strategic management at the University of Washington.

\section{Contents and relevance}

The authors conducted an ex post study of LBOs (leveraged buyouts), aimed at the testing of the agency theory. This theory, as proposed by Jensen (1986) and others, is explained hereafter (p. 705).

'Agency theorisits argue that within public corporations a conflict arises between the goals of professional managers and those of stockholders. ... Building on that basis, Jensen (1986) argued that a serious source af conflict between management and stockholders is the utilization of free cash flow, defined as ciash flow in excess of that required to fund all investment projects whose forecasted finencial return is positive when discounted at the relevant cost of capital. Since free cash flow cannot be profitably reinwested within a company, Jensen argued that it shoulid be distributed to stock holders in the form of diwidends or stock buybacks. However, managers mav resist distributing surplus cash resources to stockholders and may instead invest them in growth maximizing or empire- 
Phan and Hill have found that this theory is not to be rejected on the basis of their research. 14 out of 20 hypotheses they formulated receive support. In summary their findings include that a larger degree of management holdings, in combination with an increased debt ratio, leads to more emphasis on efficiency but less on growth. Furthermore this construct would lead to increased decentralization, a smaller scope of diversification, and a decreased hierarchical complexity. All together these factors are associated with an increase of performance. The study addresses structure as well as strategy. A leveraged buyout is based on a fundamental strategic decision, taken with consideration of its structural effects. The affirmation of agency theory effects is of direct importance and useful for the design of structure and strategy.

Metaheoretical importance of the article lies in its meticulous treatments of the method used and in its discussion of its scope and limitations, for example on page 733:

In closing, a few words of caution are appropriate. Our study is vulnerable to all of the standard criticisms levelled at studies that use survey data, concerning social desirability effects, common method variance, inherent ambiguity, and nonresponse bias. We have two replies to this potential criticism. First, survey data were the only way to test the hypotheses for a large sample of firms. Second, we were careful in constructing the surver, consulting with those involved in LBOs and pilot-testing with a small sample before settling on a final design. Moreover, as reported earlier. we conducted all the standard tests for nonresponse bias and reliability, checking the reliability of both recall and accuracy. We are thus as confident as is possible that our survey measured what it was intended to measure but allso recognize that sociall desirability effects may bias our sample toward better performers."

Another example of metatheoretical rigor lies in their treatment of a rival hypothesis. PIMS (see hereafter) is an immense database of firm performance that is frequently used to support strategic suppositions (p. 709).

"At this point, a counterargument should be racognized. Work on the Profit Impact of Market Strutegies (PIMS) database seems to suggest a positive correlation between market share and firm performance (Buzzell G Gale, 1987). If thent is the case, managers looking for efficiencies should not ignore market shar goals but instead emphasize them. The issule however. is not clear-cut. On the ane hand. evidence supports the PIMS position (e.g." Mueller.
1985: Scherer, 1980y. On the other hand, empirical work using refined statistical techniques has contradicted it: Rumelf and Wensley (1980), Jacobsen and Aaker (1985), and Jacobsen (1988) suggested that the market share effects found in PIMS studies are spurious and due to failure to control for unobservable factors. Once these are controlled for, market share effects disappear."

The agency theory in its more specified form as obtained by the authors, together with the considerations of the final discussion, offer a useful tool for the larger commercial 
organization. The aspects addressed are those referred to in the basic contentions above. Process of knowledge development

Hypothesis takes an important part in the study. 20 hypotheses are proposed. The basis for this set is depicted in a model that is cited hereafter. As an example, the box at the center left in the model leads to the following formulation:

"Hypothesis 1: Following a leveraged buyout, the proportion of equity held by mainagement will increase"

\section{FIGURE 1}

\section{Impact of Strategy and Structure on Post-LBO Firm Perfomance}

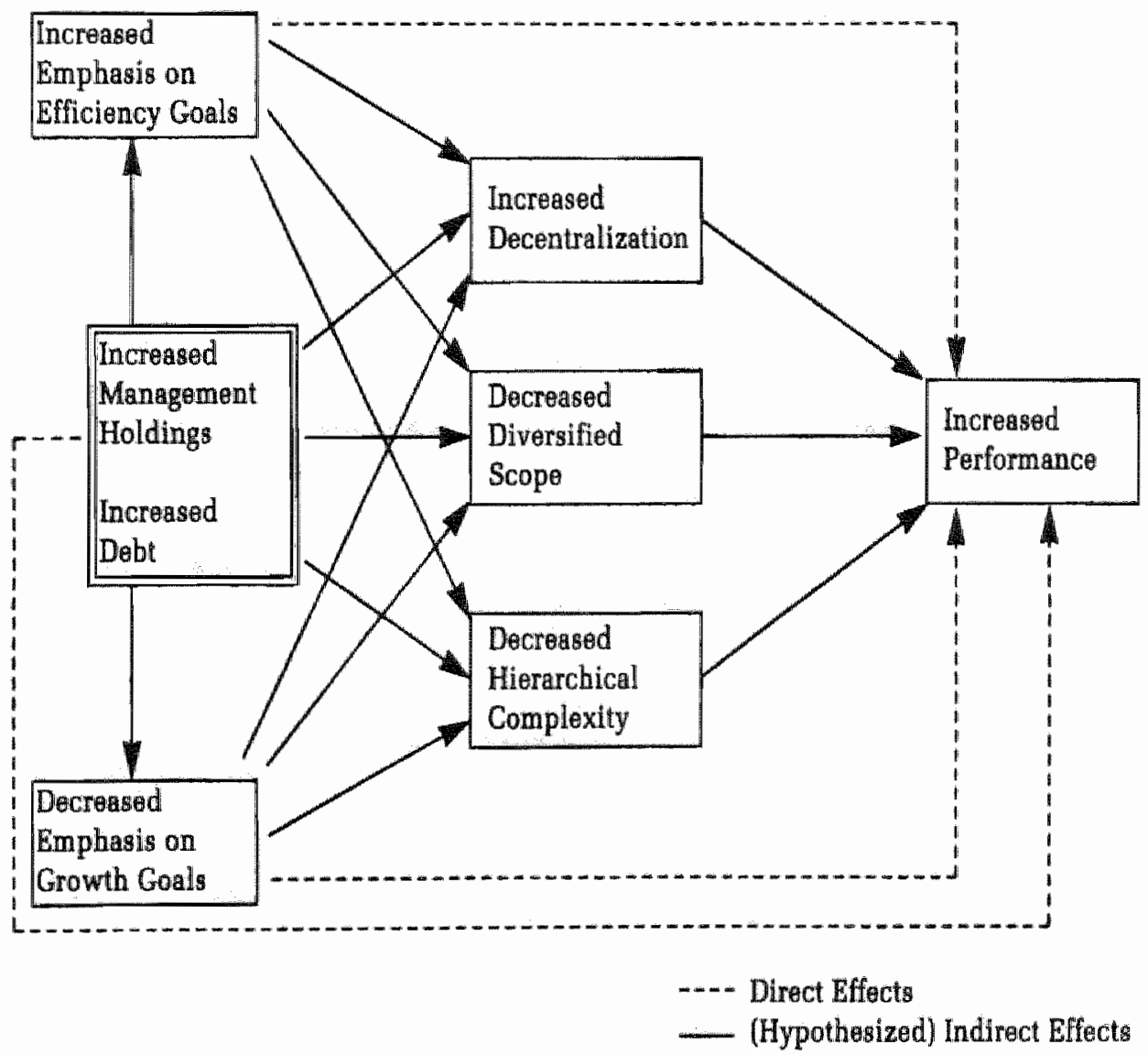

Figure 6.1. Quoted from Phan \& Hill (1995, p. 707)

Every arrow in the picture is transformed into a testable hypothesis. Each hypothesis is introduced with an elaborate discussion of relevant literature. 
During hypothesizing, arguments pro and con are discussed before a position is chosen (pp. $714,715)$

In the next phase, mathematical models are built in the process of derivarion (p. 715):

"The models used to test the above hypotheses compared the sifuation in a firm one year prior to its leveraged buyout to that existing one year after the LBO, we thus observed three-year periods. In model 1 , we regressed the change in the goals of a firm against the change in its level of debt and maragement holdings. This model was used to test Hypotheses 2 to 5. Model 2, in which we regressed the change in an organizational characteristic (a measure of strategy or structure) against the change in the level of debt, management holdings, and gaals, was used to test: Hypotheses 6 through 9,11 through 14 and 16 through 19. Model 3, which regressed the change in performance agaimst the change in debt and management holdings, the change in goals, and the changes in strategy and structure, was used to test Hypotheses 10, 15, and 20. Hypothesis 1 was tested by a t-test.

As LBOs normally go 100 percent private no detailed data were publicly available. For the gathering of information a survey was designed and conducted. For this survey response bias and data reliability were examined and corrected (pp. 716,717). All variables were carefully defined.

Next to this stage, observation took place.

The - phase of induction is reported in the discussion section of the article (p. 730).

"In sum. 14 of the 20 hypotheses receiwed some

suppoirt. Figure 2 summarizes results, which suggest the following: First in wdition to an increase in debt; LBOs are associated with an increase in management holdings. Second, the change in governance structure that occurs with an LBO does affect firm goals. strtitegy, and structure. Efficiency receives mare amphasis, and growth less emphasis: diversified scope and hierarchical complexity diminish, and decentralization increases. Third, as hypothesized, these changes in goals, strategy, and structure faster greater efficiency, as demonstrated by increases in productivity and profitability. Fourth management holdings seem to have a greater impact upon goals, strategy, and structure than debt.

On the basis of these results, we cannot relect either the free cash flow or agency theory assertions that leveraged buyouis lead to an increase in enterprise efficiency. This conclusion is consistent with event study evidence (DeAngelo et all., 1984; Madden et al., 1990 ) and with other ex post studies of LBO performance....

Prescription and intervention are not discussed in this article.

Assessment following the $\mathrm{A}-\mathrm{F}$ - scheme

Clear-cut hypothesizing (A) takes an important part in the article. It includes problem formulation and the selection of axioms, which are discussed in an exposition of agency theory and its presumed predictive value for the effects of "leveraged buyouts" (pp. 704 - 706). In addition, conjecturing and formulation encompasses no less than 20 hypotheses (definiteness 


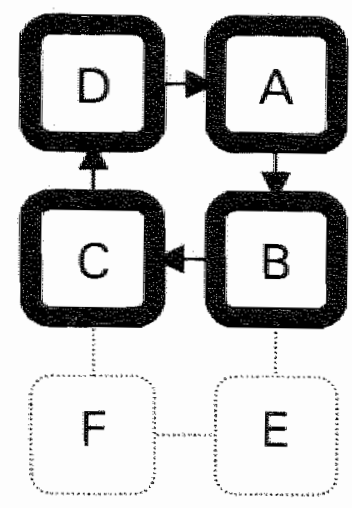

and precision pp. $707-714)$. Some of the concepts involved are unambiguous, like "the proportion of debt held by management" ( $p$. 708), others require operationalization, like "an increased emphasis on efficiency goals' (p. 709). Definitions for such concepts are implied in the phase of derivation.

The core of derivation (B) is the quoted predictive model ( $\mathrm{p} .707)$ that by its nature is abstracted and partialized. Every hypothesis can be assumed to be represented by the value of elements of the model and their relationships. Operationalization of the concepts is effectuated by the formulations used in the survey.

This phase, observation (C), includes the selection of variables, and the definition of variables. The design of the observation method ( $\mathrm{pp}$.

$715,716)$ included a preliminary orientation with interviews and the design of a suitable questionnaire. Observing values and the processing of variables is reported on page 717 and 718.

The data obtained were used in the phase of induction (D). This part started with the ordering of data and the making of constructs, using 'Cacciopo and Petty's model for construct development" (p. 718). The statistical methods used in the interpretation and examination of results are amply discussed (pp. 719 - 730). It appears that 14 of the 20 hypotheses "receive some support' (pp. 730 - 732). Validation was carefully treated. The theory has indirect willity for both structural and strategic organizational design by elucidating matters of choice between keeping business within the organization or stimulating their opting out.

Coherence is demonstrated on page 709. The article has considerable metatheoretical rigor. The research was not intended to include prescription $(\mathrm{E})$ or intervention $(\mathbb{F})$.

\section{Conclusion}

The work demonstrates a flawless metatheoretical approach. It offers new and valid knowledge on a highly topical subject, namely agency theory and its implications for leveraged buy-outs.

\section{Remarks on the assessment system}

The application of the assessment system in this case was consistent with the expectations. One extra point became clear, however. In the assessment of the method used to prove or disprove a theory, attention must be given to the limitations of mathematical statistics in the testing procedure. The elaboration on this subject, as usual in contemporary organizational literature, should not distract us from the fact that a high level of confidence means no more than that the hypothesis cannot be rejected on the basis of the experiment. But perhaps rival hypotheses would not be rejected either. It should not be applied unthinkingly. Furthermore, if an association among the values of variables is found, this does not tell anything about what causes are and what effects. The explanandum may be absent in the phenomena observed. This aspect should be taken well into account when applying the assessment method. 


\subsection{Alessandro Lomi}

\section{Bibliographical data and contextual points}

\section{Lomi, A., The Population Ecology of Organizational Founding: Location Dependence and}

Unobserved Heterogeneity, Administrative Science Quarterly 1995, Vol. 40, pp. $111-144$. Lomi joined London Business School as a postdoctoral fellow in 1991 and joined the faculty in 1992. He is now an Associate professor at the School of Economics of the Uniwersity of Bologna.

\section{Contents and relevance}

In organizational ecology the dynamics of populations of organizations are the object of research. In such studies the definition of a population often ignores geographical differentiation. This unobserved heterogeneity obscures certain significant spatial effects. 'The findings ... [of this study] ... demonstrate how an ecological approach that incorporates information on the spatial structure of the population can provide a more detailed understanding of the evolutionary dynamics of organization' (p. 111).

Contrary to the usual assumption that markets and institutional arenas are homogeneous at the national (and higher) level, in this article the position is taken that for many industries the spatial component is preponderant, as is illustrated by "... the manufacturing belt in the U.S., the tile cluster and the textile district in northern Italy, the research triangle in North Carolina, the machine-tool district in Germany, the networks of suppliers surrounding the kaisha .... in Japan, Silicon Valley ... '(p. 112).

The central tenet of the article is that founding rates of organizations in a certain industry depend on location.

The study does not refer to organizational structure. There is a remote relation with organizational strategy. Direct or indirect design rules cannot be derived from the study. The article has metatheoretical importance as it contributes to the knowledge of the ecology of populations of organizations.

For the reasons mentioned there is no direct practical usefulness as yet for problems of management or organization.

\section{Process of knowledge development}

The article is an example of rigorous scientific methodology. A mathematical model is designed with a range of assumptions about sub-models and parameters. Using the available data the occurrence of foundings is tested against a set of descriptive models. The assumed locality dependence as defined through the model is found to be significant. 
The central hypothesis of locality dependence of the founding rate of organizations is illustrated with conjectured causes of the phenomenon, like region-specific legislation, spatial isolation, and competition and other effects of carrying capacity. Definitions are those of the population ecology school. The definition of the level of aggregation however is more specific as it is related to the local specificity. This is explained as follows (p. 115):

\footnotetext{
"The kev point to this discussion is that shifting the level of aggregation involves redefining the population boundaries, because the level of analysis implicitly determines the relevant context for legitimation and competition processes. ... Unfortunately. population ecology theories of organizations offer no specific guidance on how to choose among alternative. but equally plausible population boundaries. Choosing the appropriate level is crucial to test ecological theories of organizational founding because density acts in different ways across levels of analysis. It is plausible
}

\begin{abstract}
to think that potential founders will be more sensitive to local wariations in the levels of legitimation and competition because of limits in their capacity to collect information on monsocial resource conditions and becaluse of the ambiguity involved in interpreting events taking place in more distant sites. For these reasons, density dependence in arganizational founding rates is expected to operate mote strongly at lower levels of analysis and the model of derisity. dependent founding rates to be better specified at the local than the netional level of analysis."
\end{abstract}

Derivation (operationalization, abstraction, partialization, deductive modeling) has the form of predictive modeling, in the elements of which operationalization and abstraction take place. From the general position a typical ecological model is reduced, namely partialized as well as abstracted. It expresses that the founding rate of members of the population at a certain point of time (the derivative of the number of foundings at time $t$ ) is a linear expression of a number of variables. Normally these variables encompass a constant, the number of occupants in the industry and its square, the amount of contestants from other industries for the same resources, and some environmental covariates that account for specific stimulating or inhibiting influences typical for the periods observed. In Lomi's model a factor is introduced accounting for a period of legal block to the entry of new organizations that has been effective over some years. Most typical, however, is the introduction of local factors in the covariate term.

It is of methodological importance that the author applies a number of models with different parametric assumptions in order to show that in all cases the results tend to the same conclusion (p. 140).

\footnotetext{
The estimation strategy adopted here ensured that the inferential conclusions reported do not hinge on arbitrary distributional assumptions about the
} heterogeneity components and therefore produced more reliable result:"

For this model an instance of observation is sought and found in the industry of Italian rural cooperative banks (RCBs). Between 1964 and 1989 some 220 foundings of RCBs took place, all over Italy. For testing the model this is an ideal guinea pig, as specific data are available. The first environmental covariate to be chosen is agricultural employment, supposed to support the founding of RCBs. But other variables had been examined as well (p. 124): 
"Other wariables were used in the early stage of the research to control fir market and community size, uncluding regional population, labor force, and employment, but none of these seemed to make a difference in terms of the conclusions supported by the model presented".

This citation illustrates the fact that building a model requires some tinkering, and the repeated switching between surmise and reality.

The second covariate is the number of Popular Cooperative Banks (PCBs), which may support (by expressing community-level mutualism) or restrain the founding rate of $\mathrm{RCBs}$ (through competition). Other covariates are the value of bank deposits in the region, and the number of mergers and acquisitions among $\mathrm{RCBs}$, the latter because of concentration is the only way to grow for a RCB (their branching is prohibited by law).

In the discussion part of the article (p. 137), conclusions are induced. The first finding is that the model corroborates the hypothesis that the effects of density in population ecology should be considered at the local level. 'When heterogeneity is controlled for without making any assumption about the distribution of unobservable components across regions, the effects of density lose statistical significance...' (p. 138).

Three final conclusions are drawn, all of a metatheoretical nature. "From a theoretical point of view, the study contributes to a growing literature showing that organizational populations are internally differentiated and that vital rates vary systematically across heterogeneous segments of the population.' (p. 139). The second conclusion is about the non-parametric statistical methodology and has been reported above. The most interesting conclusion is the one about substance.

\begin{abstract}
'From the substantive point of view, our understanding of the evolution of cooperative banks in Ifaly is onhanced by binging the rolle of spatial factors back into the sudy of organizational dynamics. Ecological factors related to location will be of crucial importance for the survival of the se specialist banks bec ause large-scale institutional change is repidy eroding the historical. Jags. and cullural boundaries
\end{abstract} around populations of banking organizations in Europe.
Whether these institutional blending processes will result in niche desegregation, how this will affect the survival chances of specialist and generalist organizations, and what agency arrangements will enjoy an evolutionary advantage under the new regime are all future research questions that have the potential to provide us with a greater understandling of the dvnamics of organizational populations and communities."

The study does not deal with prescription and intervention.

Assessment following the $A-F-$ scheme

Hypothesizing (A) starts with problem formulation (definiteness, pp. 111 - 112). Conjecturing and formulation and defming include the refinement of existing theory (pp. 114-117). 


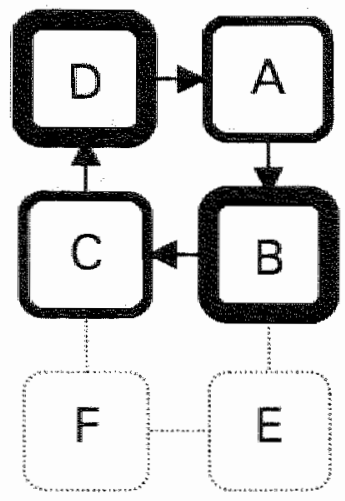

Derivation (B), with operationalization and the development of predictive models is discussed on pages $121-128$.

Observation (C) encompasses the observing of values, and their processing (precision, pp. 129-137).

In the discussion (pp. 137-140), induction (D) leads to the conjecture of the refined theory in the form of a selected predictive model.

Prescription (E) intervention (F) are not sought in this study.

Coherence with organization ecology is complete. The study has a high degree of metatheoretical rigor.

Validation is well treated. The utility of the study is indirect, as is normally the case in research of organizational ecology so far.

Conclusion

The theory is a step further into this particular field. It specifies knowledge in this area. It builds on the work of Hannan, Freeman, and Carroll, as discussed in preceding sections.

Remarks on the assessment system

This case illustrates the usefulness of the assessment method in distinguishing subsequent phases of inductive and deductive modeling. In addition, its value for spotting the author's metatheoretical points of departure is demonstrated.

\subsection{Joseph Bower and Clayton Christensen}

Bibliographical data and contextual points

Bower, J.L., and C.M. Christensen, Disruptive Technologies: Catching the Wave, Harvard Business Review January/February 1995, Vol. 73, $43-53$.

The article got the McKinsey Award 1995. Bower is a professor at Harvard Business School. Christensen is an assistant professor at the same institution.

\section{Contents and relevance}

Leading companies often fail to stay ahead of the competition. This can be demonstrated with examples from industries like tires, copiers, mechanical earth move equipment, consumer goods, and computers. Why is it that companies fail to invest in the markets of future customers, or in the future markets of their current customers? Because they stay too close to the present interests as perceived by their clients. By asking the right questions to the right 
people certain new areas can be discovered and assessed. A unit outside the mainstream organization should develop and market these new products.

The article addresses both structure and strategy. Strategy is the leading subject. From the results of the discussion, rules for structure are derived.

A set of rules is proposed that can serve as design prescripts. The strategic rules are only indicative, mostly directed at the analysis of future opportunities and threats. The conditions under which a separate unit must be created are unambiguously formulated.

The metatheoretical importance of this theory is that theories with the proverb 'stay close to the customer" are effectively challenged. A more specific formulation of this recommendation enables the timely discovery and assessment of potentially profitable new technology/product/market combinations.

As for type and size of the organization, the propositions apply to commercial technologyoriented organizations that are big enough for the development of new technologies. Aspects addressed especially are strategic decisions concerning the pursuit of related innovations.

\section{Process of knowledge development}

Hypothes is includes an important characterization, reading: A disruptive technology strays from the mainstream customers' historically value. It starts with a bad performance on one of the value dimensions.

The central hypothesis about the general problem is that the usual clients do not support suppliers" development of disruptive technologies.

Some more hypotheses are (pp. $45-52$ ):

The processers of successful companies are incapable of funneling resources into programs that current customers explictly don't want. ... In case a supplier is better informed about ploneering opportunities than his clients. it s better not to stex"tor close to the customer. ... Smell, hungry arganizations are good at agilely changing product and market strategies. ... Every company that has tried to manage mainstream tund disuptwe technologies within a single organization failled. ... The only way to protect ... [maverick technologies] ... is to create organizations. that are completely independent from the mainstream business. ... [This is necessary when the new technologyl ... has a lower profit margiri and must serve the unique needs of a new sett of customers. ... In order that it may live, corporation must be willing to see business. units die."

As for derivation this narrative article iterates between tenets, single observations, case descriptions, and rules. Although it is clearly comprehensible, it is difficult to discern the logic of argument. A distinct step from suppositions to operationalized, testable contentions is not made.

A number of observations are reported. One type is about the development of firms that are confronted with disruptive technologies. Technological observations include that industrial clients tend to stick to familiar technologies. They welcome the enhancement of existing 
products, but reject certain disruptive technologies that seem to be of no direct interest for their own markets. The first hydraulic excavators were small, while clients wanted ever-bigger earth moving equipment. But there was an emerging market for these versatile hydraulic machines. After the take-off of this market, growing sales enabled the development of larger hydraulic systems, which eventually took over large segments of the traditional demand.

The same goes for computer disk drives. In the seventies, mainframe manufacturers used 14" Winchester disk drives. Due to technical improvements, the capacity of these drives grew faster than the needs of the market. After the development and introduction of the 8 " drives in 1977 their capacity increased at a speed higher than the growing requirements of the minicomputer market. But in the beginning those drives were not powerful enough for mainframes. Hard-disk drives of $5.25^{\prime \prime}$ were stronger than required by the PC-makers right from the beginning in 1980, but they did not meet the specified capacity of mini systems. Since 1985 hard disk drives of $3.5^{\prime \prime}$ are used in portable computers, with a capacity that outgrows specifications. In 1987 already these were strong enough to meet the needs of PC. makers. Now drives of $1.8^{\prime \prime}$ are being produced. In all these transitions, traditional clients were not interested in the new development, because the cheaper - and, in the long run, more promising - new technologies were not powerful enough at the beginning.

Most of these 'maverick' technologies were not radically new but they had a different package of performance attributes. (p. 44)

An important construct is induced by the performance trajectory. For each technology, properties of the products as required and as supplied are plotted over time. For excavators: cubic yards per hour and fuel consumption, for copiers: number of copies per minute, for disk drives: storage capacity versus space occupied and energy consumption.

Prescription (specification of knowledge, translation into prescriptions) is found in a number of design rules that are formulated (pp. $49-52$ ):

"Determine whether the technology is disruptive or sustaining ... Define the strategic significance of the disruptive techmology $y^{*}$.. Locate the initial market for the disruptive technology" ... Place responsibility for

No intervention is reported.

Assessment following the $A-F$ - scheme

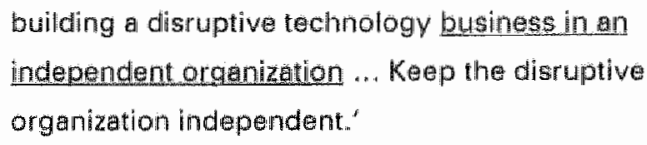

Hypothesis (A) includes problem formulation (definiteness) and the conjecturing and formulation of hypotheses (precision, p. 43). The central research question is why companies fail to invest in future customers. The answer is the hypothesis that they stay too close to their

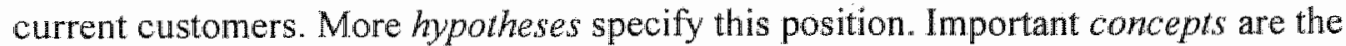
'performance trajectory' (pp. 45, 46) and the "disruptive technology' (p. 49). 


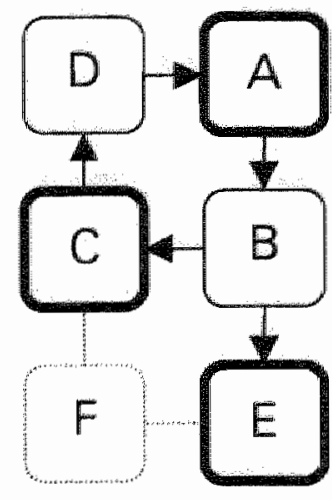

Derivation $(B)$ includes operationalization in which the variable performance improvement is introduced (p. 49).

Observation (C) comes in two stages, one preliminary to the hypothesizing with examples from other industries (p. 43), and a second about the hard-disk-drive industry (pp. 45-49).

Induction (D) refines and expands the hypotheses. These are directly translated into rules (Intervention, E), that describe step by step how to identify disruptive technologies, and how to cope with them (pp. 49 $-53)$.

The conclusions drawn from the long-term observation of technology development in relation to the conduct of firms give a more specified insight into the question: how close should one stay to the customer?

The article contributes to the knowledge needed to take the right strategic and structural decisions in practice.

The degree of elaboration is intermediate for $\mathrm{A}, \mathrm{C}$, and $\mathrm{E}$, while $\mathrm{B}$ and $\mathrm{D}$ are discussed but not worked out. The theory is practical and narrative. Scientific validation is not sought, meaning that metatheoretical rigor is limited, but the tenets are highly useful for the design of organizational strategy.

\section{Conclusion}

This theory is a typical example of the practical approach that leads to clear and precise and specific rules. In this respect it is akin to the work of Porter (1980). It refutes the sloppy defined principle reading "stay close to your customer'. In doing so it might lead the way to solve pseudomparadoxes by a more precise and specific treatment of concepts. At a later stage of knowledge development this would require however a more scientific methodology.

Remarks on the assessment system

From this sample theory the assessment method appears to be useful. No important aspects and elements of the theory and its importance for the purpose as formulated seem to be overlooked or underexposed.

\subsection{Philipe Lasserre}

Bibliographical data and contextual points

Lasserre, P., Corporate Strategies for the Asia Pacific Region, Long range Planning, 1995, Vol. 28, No. 1, pp. $13-30$ 
Philippe Lasserre is a professor of strategy and Asian business at INSEAD and the Europe Asia Centre, France.

Contents and relevance

From the executive summary the following text is cited to illustrate the tenets presented:

The Asia Pacific region will remain the engine of world economic growth. Western companies interested in the region need to develop a strategic framework to exploit the potential which takes into account ambition, capabilities, organization and positioning. ... Asia

Pacific represents a significant resource base for gaining competitive advantage. South East Asia has a wide range of natural resources. Though labour productivity and discipline vary, wages are generally far below those in the West. The combination of avaliable resources provides major elements of competitive advantage: cost quality, time, and flexibility.... If the aim is based on access to resources, then the company should focus on the cheapest and/or best supply sources. In the case of a market-based strateqy, a company would need to set up local marketing and, on occasion, local manufacturing.

The selection of cauntries will be guided by market. resource, and political (or business) attractiveness. There are five tyoes of countries-the platform countries for a base or launch pad, emerging countries like Vietnam, growth ones like China, and mature economies like Korea. The specific strategy adopted will depend on experience and "fit" with corporate objectives. Business segmentation and therefore strategy selection are complex, ranging from Japan at one end to Chins at the other. The campany will need to clecide whether it wants to adopt a regional or country-by-country approach. ... Successful investment in Asia Pacific entails a complete transformation of organizational practices $s_{n}$ in fact a "paradigmatic transformation" "

The author wishes to present a broad theory (p. 13):

\section{"Western firms need to define very" ambitious} abjectives for developing their presence in the region. Asia strategy is more than the sum of individual countries strategy; if requires specific investment effects to develop human resources, to build assets and competencies. Strategic intelligence and relationships management are the key competencies which are needed. For Western firms it implies complete transformation of managemant culture,

Strategy is specifically addressed. The consequences of a selected strategy for structure are also discussed.

Rules are presented for the designing of both strategy and structure.

The author recommends that the Asian strategy of a company should be part "of its overall, world-wide strategic effort.' (p. 14). An important point of metatheoretical importance is the distinction between strategic planning in the sense of "frameworks and processes by which strategy is formulated' (note on page 29), and 'the concept of a strategic framework' as intended in this article. The author refers to Pascale (1990), Peters (1987), and Mintzberg (1990) who "argue that strategic planning hampers real strategy formulation by its excessive focus on 
quantitative aspects." What Lasserre does, however, is offering a design theory for Asian strategy. This may be used as an agenda for the discussion among those responsible for strategic actions (the right thing according to the quoted writers), or by staff people drawing the "hampering" formal blueprints for strategy (the wrong thing). But Lasserre's is a design theory anylhow, albeit without mathematics.

The tenets address the largest commercial organizations, able to play at the global theatre. Aspects addressed are most of the strategic elements for the Asian-Pacific region.

\section{Process of knowledge development}

No explicit hypothesis is formulated, except those embodied in definitions and typologies. Examples are the distinction of countries related to established markets (Japan), maturing markets (Taiwan, Korea), growth markets (China, Thailand, Indonesia, Malaysia, India, Philippines), emerging markets (Vietnam, Burma, Laos, Cambodia) and platforms.

As explicit hypotheses are absent there is no derivation either.

There is no purposeful observation reported. Examples given serve as illustration of rules. The same goes for induction.

The article is mainly aimed at prescriptions. It is a structured checklist with knacks and prescripts for strategy formulation in the Asian Pacific (AP) region. A structured summary of this list reads as follows:

1. Establish the company's ambition for this area with the aspects:

- Importance (based on regional output of relevant products, AP market share of Western firms, and the need to use the region as a learning field for competitiveness)

- Key countries (with attention for special interesting aspects, locations, modes of entry per country, activities versus country, ways of integrating various local operations)

- Business share to be obtained in next 10 years.

2. Select types of capabilities to be created in the AP region (resources, assets, and competencies).

3. Take into account the difficulties of this region with respect to the lack of business information, the long time needed to establish trust, the ample means that are necessary, and other cultural obstacles.

4. Transform usual management practices in order to achieve success in the AP area. A number of tables and diagrams are proposed to map opportunities in two dimensions. No intervention is reported.

\section{Assessment following the $\mathrm{A}-\mathrm{F}$ - scheme}

Hypothesis (A) is about problem formulation and the proposition of axioms (p. 13), followed by the conjecturing and formulation of hypotheses.

The next step is the observation (C) of a number of supposedly relevant variables and relationships (pp. $14-18$ ). This phase includes the selection of variables, their definition, and their observation. Requirements of definiteness and precision are met here. 


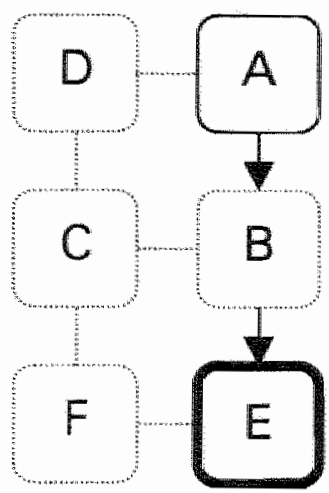

Subsequently, prescription (E) takes place in the form of recommendations (pp. 22 - 29).

Derivation (B), induction (D), and intervention (F) are not reported in the study.

$\mathrm{A}$ and $\mathrm{B}$ are discussed, but only $\mathrm{E}$ is elaborated to an high degree. As stated before the article has no scientific intent. It presents a number of conceptual distinctions combined with rules for action, leading to a great number of practical suggestions.

Validation is not in order. The study is useful as it directly pertains to the design of strategy.

\section{Conclusion}

The article follows the tradition of 'management principles'. It draws on general background knowledge based on long-standing experience, in the tradition of Fayol.

\section{Remarks on the assessment system}

Also for this case the assessment system gives a clear answer to the philosophicall questions that are relevant for the assessment of organization theory.

\subsection{Leonard H. Lynn and Hayagreeva Rao}

Bibliographical data and contextual points

Lynn, L.H. \& H. Rao, Failures of the Intermediate Forms: A Study of the Suzuki Zaibatsu, Organization Studies, Vol. 16, No. 1, 1995.

Lynn teaches at the Weatherhead School of Management, Cleveland. Rao is an associate professor of management and sociology at Emory University, Atlanta.

Contents and relevance

In received theory on organization it is argued that market failures lead to the emergence of hierarchical forms. This view is called transaction-cost economics. Hierarchy may fail as well, however. Writers have tried to explain the existence of intermediate organizational forms that contain elements of both market and hierarchy, as an efficient response to market imperfections. Examples of such network organizations are franchising systems, joint ventures, and the Japanese keiretsu (the network of the large company and its subcontractors). This third way in itself suffers from failure too. The authors argue that the cause of failure of a zaibatsu ("a group 
of diversified businesses owned exclusively by a single family or extended family') lies in three coordination problems (pp. 57, 58,67):

"The Suzuki case suggest: that coordination problems ensue under the following conditionis: (a) there is a lack of mecharisms to allin the interesits and policies of the aperating units with those of the holding company. (b) the 'owners fall to correct managerial inadequacies and, (c) there is a parallel failure of the group's sources of finance to discipline managers. ... Although a harsh economic environment precipitated Suzukits collapse, Suzuki's disintegration was also the outcome of weak internal coordination and a dearth of legitimacy and political support. Resources were misallocated because the holding companies falled to control and coordinate the operating companies effectively, the merchant family failed to take action to address this situation, and the organ bank falled to discipline managers. Moreover, Suzuki lacked support from political parties the bureaucracy, the media and other zaibatsu that might have given it time to restructure. Worse, powerful political and financial groups were all too happy to see Suzuki fail. "

The article pertains to structure, especially to the way intermediate forms between market and hierarchy are structured. The matter discussed in the article is too abstract in its tenets to be of value for organizational design.

It has metatheoretical relevance as it suggests topics of further research in this field.

\section{Process of knowledge development}

The article describes an explorative historical study of the Suzuki Shoten zaibatsu from its establishment in 1874 until its bankruptcy in 1927. Hypothesis follows existing literature in its definitions and concepts. It is argued that the viability of intermediate forms of organization depends on legitimacy and the effectiveness of appropriate financial control mechanisms. Derivation, observation, and induction are all described in common language, without attempts to generalize observations form the history of Suzuki to a higher level of reference. The article does not contribute to the advancement of knowledge about intermediate forms of organization, except for a number of recommendations for future research.

prescription and intervention are not discussed in the article.

\section{Assessment following the $A-F-$ scheme}

Hypothesis (A) includes problem formulation and the selection of axioms (p. 55) stating that 'two gaps in the "organization failure" literature' (p. 56) exist. This observation motivated the researchers to investigate an intermediate organization form, the Japanese zaibatsu (p. 57). After a historiographical exposition (pp. 58 - 67) conjecturing and formulation of hypothesis is conducted (pp. 67 - 74), demonstrating an appropriate degree of definiteness and precision. These hypotheses are discussed and defended using a broad collection of historical data. The approach is coherent with the historiographical methodology and involves and involves a systematic structure. 


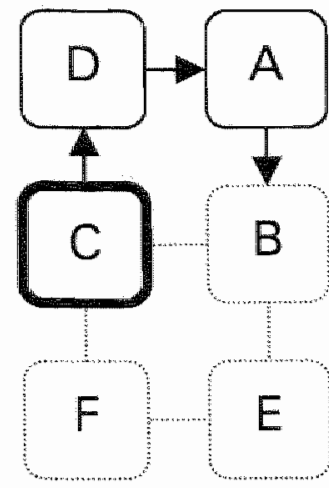

more scientific research.

Remarks on the assessment system

This case gave no indications that the assessment method needs adaptation.

\subsection{James Robins and Margarethe Wiersema}

Bibliographical data and contextual points

Robins, J. \& M.F. Wiersema, A Resource-based Approach to the Multibusiness Firm: Empirical Analysis of Portfolio Interrelationships and Corporate Financial Performance, Strategic Management Journal, Vol. 16, 1995, $277-299$.

Robins is a visiting assistant professor, Wiersema is an associate professor, both at the University of California, Irvine.

\section{Contents and relevance}

The authors examine the resource-based theory. They propose an improved method to test this type of theory.

First they summarize the contentions of the theory and the lack of their evidence (pp. 277 , 279):

The relationship between the composition of a corporation's business portfolio and the firm's economic performance has become a particularly prominent issue in strategic management theory in recent years with the development of the resource- based view of the firm. Resource-based theory argues that interrellationships within corporate portiolios provide the ecanomic foundation for multibusiness organization (Teece. 1982) Shared strategic assets or resources are critical to firm performance, and 
corporate stratsy relies upon scope economies of that type among businosses (Paterat; 1993 ).

Despite extensive empinical and theoretical work on this topic, the impact of portolio composition on economic firm performance remains uncertain. ...

At first clance the empirical evidence described above anpears 1 provide relatively fitle support for the resource-based view However, closer scrutiny suggests that the empirical research may have only a Iimited connection to the theory. Many of the prevailing approaches to anaksis of relatedness are subject to substanilial problems of measurement errors, and is questionable whether they measure the types of relationships among businesses that are impontant in resource-based strategy.

To rephrase this assertion briefly, it states that the resource-based theory assumes that the sharing of capabilities or assets as a common resource in a diversified company will enhance its performance. Next to scarce raw materials or special assets particular (technological) knowledge is expected to be an important instance of such resources. But this theory seems hard to prove. The authors think this is due to difficulties in the analysis of relatedness. The article will discuss these difficulties. It pertains to strategy. Although no direct design rules are derived, it contributes to the further development of relevant knowledge. It has metatheoretical importance in that it shows that improvement of operationalization can lead to the corroboration of intuitive, fruitful notions.

The theory involved is applicable to the large, multiproduct commercial organization. It may contribute to better decisions about diversification for its conceptualization of relatedness.

\section{Process of knowledge development}

Hypothesis is at the basis of the article, as has been discussed above.

The most important part of it lies in the treatment of derivation, especially as far as operaionalization is concerned. The central concept in the theory is 'relatedness' within the product portfolio. In past studies, relatedness was operationalized either categorically or continuously. In the first case the researcher classifies a company is by its type of diversification. The second approach uses measures derived from the various businesses of the company as characterized by their position in the Standard Industrial Classification (SIC) system. This continuous method calculates indexes of diversification, such as the concentric index or the entropy index. These are considered superior to the arbitrary classifications of diversiffication, as they use data from standardized sources, thus enabling replicable and cumulative research.

Both entropy measures have drawbacks, however. They draw on the SIC system, which was developed for macroeconomic analytic purposes. "This has created categorizations that may place close substitutes such as glass and plastic bottles in different groupings while combining very different goods or services in common categories." (p. 281).

The authors argue that knowledge that is common to most or all of the diversified activities is a resource of paramount importance. It is a tacit asset, however. So how can it be operationalized? To this end, they introduce a measurement of technology flows among SIC- 
based industry groups, as developed by Scherer (1982). It is explained by the authors as follows (p. 283):

\footnotetext{
An approach to estimating pontfolio interrelationships of this type was developed using technology flows. among manufacturing industries. This operationalization of 'relatedness' involwed two steps: creation of measures of strategic similarity among industries, and derivation of a firm-level index of interfelationship among the businesses of specific corporate portfolios. Patterns of technology inflows to industries served as indirect indicators of strategic similarity among the industries. Interindustry similarity measures were then combined with data on the distribution of corporate activity across industries to create a summary index of the degree of interrelationship within corporate portfolios. "The resulting index is mot a measure of transfers or sharing of physical assets among the businesses of a corporation. It is an indicator of the potential for symergies or scope economies due to shared underlying capabilities or know- how within the
}

corporate portfolia... Scherer combined information on patent filings with input - output data to consuruct a matrix of $R$ \& D flows between major groups of industries. The flow of technology from an industry of origin to a destination industry was estimated ... from data on the proportion of patents flied in the origin industry that were used in the destination industry and data on interindustry economic transfers drawn from the input-output tables ... Scherer ... reparted technology flows in a 48 by 40 rectangular matrix, with 3-digit SIC industries aggregated into more general categories. The matrix reported by Scherer was edited to create a 37-callegory square matrix of inflows and outflows between groups of industries in the manufacturing sector. Coefficients of similarity for each pair of these 37 manufacturing industry categories were estimated from the matrix using techniques developed for sociometric modeling. "

Next the authors introduce the concept of similarity of industries.

Two cateqories of industry were similar to the degree that they umported technology in similar patterns from other industry categories. The similarity - or structural equivalence - of industries in this model is an indication of the relative positions of those industries in the overall flow of technology within the manufacturing sector of the United States economy.

In this way a measure of shared knowledge is obtained, as follows (p. 284):

\section{'Following the structural equivalence approach ...} measures of similarity between categories of industry were derived from these profiles of intercategory technology flows. Pearson correlation coefficients were calculated for each pair of profile vectors to form a triangular matrix of interindustry correlations. This matrix of correlations between industry categories is a structural equivalence model of the manufacturing sector of the United States economy, based on technology flows. The correlation between any two industry categories is a direct measure of similarity in patterns of technology inflow from the entire sector to each of the two categories. Aperfect correlation of 1.0 would indicate thath paic of industries imported technology from the same categories in precisely the same proportions. A zero correlation would indicate no similarity in patterns of technology imports, and a negative correlation would indicate inverse profiles of technology imports. 
Four predictive models are hypothesized (p. 289). The first one relates corporate financial performance to the control variables only. These are industry profitability, industry concentration, industry asset intensity, firm market share, and firm size. So far any assumption of resource-based influences is absent. Next three sets of resource-based hypotheses are modeled. In two of these the entropy measure and the concentric index are used. The fourth model finally represents the assumptions of the authors.

Subsequently, observation becomes the central issue. The variables are meticulously defined and entered into the models. Regression coefficients and their significance are calculated. From the exercise it appears that the fourth model, representing the hypotheses of the authors, produces the best fit (pp. 292, 293):

\author{
The most important finding of the research is that the \\ resource-based approach to modeling \\ interralationships among businesses developed in this \\ study appears to provide real insight into the \\ multibusiness firm. Indirect indicators of underlying \\ shared strategic assets can help to explain variability in \\ corporate financial performance. Corporations with \\ more highly internelated business portfolios \\ outperform firms with lower levels of portfolio \\ 'relatedness'. \\ This finding is particularly important when wiewed in \\ the context of research on strategic management. One \\ of the distinctive features of stretegy research is an \\ underlying normative interest in the performance of \\ the firm -an orientation not generally shared by other \\ fialds where conomic pertormance is a key issue. \\ such as economies and industrial-organization \\ veonomics...
}

The resourcembased index not only thas a stronger qrounding in theory, it also appears to measure different underlving phenomena than the concentric index and the entropy index....

The fact that measurement techniques grounded in resource-based view of the firm are successful in linking portfolio interrelationships to corporate performance argues that weaknesses in measurement rather than weaknesses in theory may have been the source of ambiguous findings in the past. Although resource-based approaches to corporate strategy are still in an early stage of development, the research reported here represents a real advance in the process of building empirical foundations for a very important contemporary body of theoretical work on stirategic management:

Induction was only a virtual and preliminary phase in this study, as the hypotheses induced from observation were already present at the start of it.

Prescription and intervention do not apply to this article.

\section{Assessment following the $A-F-$ scheme}

Hypothesis (A) includes problem formulation (definiteness, pp. 277, 278). Based on the resource-based view of the firm the study proposes a new way of examination of the interrelatedness among businesses (p. 278). After its development the method is applied to a sample of large manufacturing firms. The conjecturing and formulation of hypothesis centers on this new method, which is claimed to offer better ways of operationalization (pp. 279, 283, 


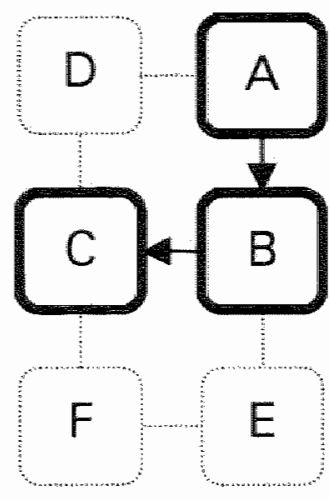

285). All concepts used are available from existing sources of economic data whose definitions are unambiguous (precision and coherence, pp. 282, 283). The degree of elaboration is intermediate. Derivation (B) includes operationalization and the building of predictive models through abstraction and partialization (p. 285). Observation (C), selection and definition of variables, the design of observation method, the observing of values, and the processing of variables (pp. $286-292$ ) lead to the testing of the models. The original hypothesis is supported by the test. Both derivation and observation are elaborated to high degree.

This ends the research. Further induction (D), prescription (E), and intervention $(\mathrm{F})$ are not intended.

The theory has been validated. The outcomes of the research are useful for the design of strategy. The work has a systematic structure and a high degree of metatheoretical rigor. The conclusion can be drawn that the study offers a new, well-documented step into the knowledge based on the resource-based theory of the firm.

Remarks on the assessment system

This case is a fine example of how the assessment system enables to observe and dissect robust scientific work and to describe its distinguishing characteristics in fine detail, as well as the scope and limitations of its validity and utility. 


\section{Conclusion, discussion, and afterthoughts}

\subsection{Conclusion about the assessment system}

Has the goal been met?

This study aimed at two things. The primary objective was the development of a metatheoretical method (an assessment system) for the evaluation of organization theories. An important secondary intended result was the rendering of a systematic representation of the body of organizational knowledge together with its metatheoretical appraisal. The findings relating to that secondary result were reported in section 5.30 .

The primary goal, the formulation of an assessment system for those organization theories that are instrumental for the design of structure and strategy. After being designed it was used in chapter 5 and again in chapter 6 .

In order to see how and to what extent the assessment system is really helpful, let us go back to the problem of this research. It read: how can 20 th-century organizational knowledge be assessed with respect to its validity and utility, in view of its application for the design of structure and strategy of the organization (section 1.5).

In retrospect it can be stated that the system used revealed a clear anatomy of the theories, thus enabling the designer to obtain a structured insight into their claims before using them. By virtue of the result of the assessment the designer is able to indicate whether a specific theory is well-elaborated, what steps of knowledge development it comprises, and if and how its validity has been established. In relation to its degree of validation and the definiteness and precision of its formulations its utility for the use for a certain design problem can be assessed.

\section{$\underline{\text { Conclusion }}$}

It may be concluded that the A - F - scheme with its constituents hypothesis $(\mathrm{A})$, derivation (B), observation (C), and induction (D), complemented with the additional path of prescription (E) and intervention (F), has proved its adequacy for a systematic basis for the description of 
the theories involved. The distinction of procedures and results for each of these elements enables a relevant description and a meaningful discussion of the texts of received theory. The assessment system as a whole as applied in chapters 5 and 6 leads to a satisfactory insight into proposed organizational knowledge that is instrumental to the design of structure or strategy. It emphasizes the clarity and distinctiveness of its tenets in their respective phases of knowledge development. By applying the questionnaire the user of a theory learns about the nature of the underlying hypotheses, their contemplative and empirical foundations, the degree of their testability, their observational, and therefore, tangible concepts, and the limits of their applicability.

\section{Validity conditions and validity itself}

The question of validity of theories requires more attention, however. As stated earlier, validity is the degree of correspondence among the derived consequences of hypothesis and what is observed. Three questions can be posed on this subject. The first is about the necessary conditions for a validity check as part of a theory. The assessment system in itself clearly reveals if such conditions are met. If a theory is incomplete, for instance if it lacks sufficient linking between hypothesis and the observational phase, then validity check is impossible. In examining a theory in the way as was done in this study, such incompleteness can be easily identified.

The second question is whether a validity check has been conducted by the author(s). This matter can be settled in the same manner. Two answers are conceivable, one saying that testing has taken place and is reported sufficiently, and one expressing doubt due to a lack of clarity in the text of the author(s). These questions and answers are on a metatheoretical level. The third question is about the testing itself. In case testing is reported, there is a chance that the test is reported as supportive, while in fact it is not. This situation obtains, for instance, when the theory's tenets are checked against non-relevant rival hypotheses.

In many cases however, the theories in our sample are rendered in a way that does not allow for a judgment of the latter type.

The assessment instrument allows for a distinct metatheoretical insight for the designer in this matter.

\subsection{Discussion on organization theory}

\section{The advancement of organizational knowledge}

Introductory observations in section 1.2 included many critical and sometimes cynical comments on organization theory. My conclusion is that organizational knowledge is progressing but that we must learn to separate the wheat from the chaff by means of applying schemes like the one developed in this study. 
The repository of the 20 th century harvest of organizational knowledge thus obtained has revealed a number of points. First, many proponents of organization theory present their case in a way that makes it difficult to follow their line of thinking. Rhetoric intent or methodological weakness may well blur the demarcation between pure speculation and defendable hypothesis, between hypothetical notions and operationalized variables, and between observation and induced general properties. However, propositions that are not quite flawless in themselwes may involve thought-provoking metaphors or views that open new ways for sound and fruitful research.

In section 5.30 conclusions were drawn from the examination of 28 cases reflecting 20 th century theory. As was expected before the start of the study a great diversity was observed. From the cases it can be concluded that organization theory has wrestled with numerous philosophical problems. This may explain the attempts to start completely from the beginning over and over again, as is exemplified by the appeals from Simon (section 5.7), McGregor (section 5.9), and from Peters \& Waterman section (5.22), calling for new theories and dismissing existing ones. It is also illustrated by the fierce debates between proponents belonging to different scientific paradigms, as those reported in chapter 1 . After the optimism of Taylor, who proclaimed his work to be scientific, many of his successors were in doubt. This study could only give a rough indication of the progress of knowledge. Two lines of observation were followed, one longitudinal study over the century, and one cross-section of theories published in 1995. In order to examine progress in more detail, a third dimension would have to be observed, namely the sequence of a number of very specific lines of thought. Such research was not included in this study. Therefore a general conclusion about the specific future of organization science cannot be drawn.

Some remarks however can be made on the basis of our findings. In some lines of research a certain tradition has emerged that might promise fruitful progress. One is the case of population ecology. Hannan and Freeman (section 5.28) were working already in a long line of research. In 1995, Lomi (section 6.3) expands the same line of inquiry, specifically in its branch of spatial phenomena. Another example is in the article of Bower and Christensen (section 6.4), who refined concepts and relationships concerning the technological implications of strategic choice. In fact, all six theories proposed in the sample of chapter 6 refrained from 'inventing the wheel' of organization theory. But this may be due to the selection, restricted as it was to theories pertaining to the design of organizational structure and strategy. At the same time the finding is an encouraging sign for the progress of this particular type of organizational design theories.

It seems legitimate to conclude that the total picture of organization science is like a jigsawpuzzle in which some growing patches are in the process of being solved, while the total picture is still unknown, and the connection between patches missing. Further steps toward a 'grand theory' will require an open mind and respect for different schools of thought. 


\section{Cultural determinants of organization theory development}

As was reported in section 1.2 it is difficult to determine whether cultural or other contextual factors influence form and contents of organization theories. One could ask if the contextual character of a theory (whether it originated in France, Germany, Britain, the United States or elsewhere, whether it was proposed by an engineer or a sociologist, or its time and age of emergence) is related to its validity or its usefulness. The contribution of this research to this particular question is only minute. One observation however should be noted: the typical French way of theorizing. We have three instances: Fayol (section 5.3), Crozier (section 5.14), and Lasserre (section 6.5). It is tempting to conjecture that the French contemplative and methodological tradition demonstrated by Fayol is still present in the essay of Lasserre. The French seem to be essayists, rather than scientists. This view is supported by the subtitle of the original French version of Crozier's Bureaucratic Phenomenon (section 5.14) reading: 'Essai sur les tendances bureaucratiques des systèmes d'organisation modernes ... '. And when Crozier goes into empirical research, his report is frequently interrupted by substantial philosophical interludes.

\section{Ontological value}

Weber's ideal-typical approach (1976) was of great value for later research. His descriptive theory of bureaucracy offered new ways for scientific investigation, as conducted by Blau \& Scott (1962), Crozier (1964), and many others. The same applies to the Hawthorne experiments (Roethlisberger \& Dickson, 1939) by their virtue of refuting misconceptions, and for Williamson's transaction cost theory (1975) and the population ecology approach of Hannan \& Freeman, among others, for their novel hypotheses.

Ontological value may also be present in methodology, for instance in the method of explanatory models as proposed by Lindenberg et al. (1983).

In the assessment method the axiomatic value and the metatheorefical rigor of a theory must be part of the assessment. The question to be answered here is whether the application of these meta-principles would lead to valid and useful design theories. For the answer to this question an 'educated guess' has been made (see also section 3.9).

\section{$\underline{\text { Partial value and specific applicability }}$}

The importance of the parameter concerning partial value and specific applicability of a theory can be illustrated by the following. Many works underline their affinity to the large industrial company, like Chandler's (1962). However, most compantes are small, most people work in small companies, and small companies contribute largely to the national product. Especially medium-sized enterprises, say, those having over 500 employees (or even less, in case of high capitalization), are enormously important to the economy. Solving their problems of structure and strategy may be of greater value than trying to make the largest elephants dance. And even problems of the largest organizations involve, to a large extent, the design of strategy and 
structure of medium-sized companies, for two reasons. First, changing the large, complex organization as a whole may be as difficult as bringing about a political revolution, as is illustrated by examples like General Motors, Philips Electronics, Crédit Lyonnais, and the large Japanese banks. Solving such problems may be as problematical as bringing about a well organized Russia. The second reason is that the remedy for the ills of the largest organizations mainly rests on the creation of successful medium-sized pseudo-enterprises. Those writers in our sample that focus on the global company, like Bartlett and Ghoshal (1989) stipulate the necessity to give more discretionary competence to sub-units, by decentralization, delegation, the making of independent busmess units, and other forms of empowerment.

The means that theories applying to the medium-sized organization have a greater chance of being practically effective than those addressing the organizational dinosaurs are.

The same goes for other than business organizations. If research is focused on public agencies, like in the cases of Blau \& Scott (1962), and Burns \& Stalker (1961), its relevance for organizations in general must be assessed as a part of the assaying system.

\section{Epistemological considerations}

At best, design rules are as good as the theories on which they are built. Theories may be wrong in that they cherish misconceived suppositions, or because of distorted or misinterpreted observations, or for their methodological flaws. But beyond the discussion a debate goes on a thigher level. This epistemological discussion has invaded the academic literature on organization and management for roughly the last two decades. As in this discourse the very possibility of valid and useful knowledge on organization is challenged, it deserves some attention. For the purpose of this study, however, we limit ourselves to those aspects that directly apply to the assessment method.

Three positions will be discussed that are defended regularly in the debate. The first is about the paradigmatic limits of scientific work. The second has to do with postmodern thinking of science in general. And the third relates to the doubts concerning social reality. These three points will be discussed hereafter in as far as they affect the outcome of this study.

\section{The paradigm problem}

There is a debate tnat rages in academic literature for some time. The capacity of science to obtain truth is queried. Different schools of thought challenge one another or deny critics the right to object to their basics, claiming the 'incommensurability of paradigms". Since Kuhn proposed his metatheory on the progress of science (1962), the students of social knowledge have discussed its consequences for their work. For organization science Burrell and Morgan (1979) proposed that "social theory can be usefully conceived in terms of four key paradigms based upon the different sets of ontological assumptions about the nature of social science and the nature of society". These paradigms are the combinations resulting from two pairs of distinctions. The first distinguishes between 'the sociology of regulation' and 'the sociology of 
radical change' while the second juxtaposes a subjective versus an objective view of reality (p. 24).

"Each set identifies a quite different social-scientific reality. To be located in a particular paradigm is to view the world in a particular way. The four paradigms thus define four views of the social world based upon different meta-theoretical assumptions with regard to the nature of science and of society:

"The four paradigms are founded upon mutually exclusive views of the world" (iix, my emphasis, p. 25). Once a choice is made the scientist cannot abandon it unless he is 'converted', 'akin to Gestalt-switches or changes of religious faith' (p. 25).

Kuhn stated that paradigms are "universally recognized scientific achievements that, for a time, provide model problems and solutions to a community of practitioners' (Kuhn 1962, p. viii). Burrell and Morgan explain that paradigms are regarded as governing the progress of what is called 'normal science', in which the scientist's work is devoted to the articulation and wider application of the accepted paradigm, which is not itself questioned or criticized. Scientific problems are regarded as puzzles, as problems that are known to have a solution within the framework of assumptions implicitly or explicitly embodied in the paradigm. But Burrell and Morgan go further (36n).

"We are using the term "paradigm" in a broader sense than that intended by Kuhn. Within the context of the present work we are arguing that social theory can be conveniently understood in terms of the co-existence of four distinct and rival paradigms defined by very basic meta-theoretical assumptions in relation to the nature of science and society. 'Paradigms',

"problematics", "alternative realities", 'frames of reference". "forms of life" and "universe of discourse" are all related conceptualisations although of course they are not synonymous. Some inter paradigm debate is also possible. .... We believe that model of four conflicting paradigms within sociology is more accurate and that academies' knowledge of 'scientists' within the other three paredioms is lifely to bue very setchy in some cases. Ralations between paradigms are perhaps better described in terms of "disinterested Lostillity" rather than 'debate."

The acceptance of this position would create a problem for our assessment system. After the evaluation of a certain theory, one could object to the outcomes by stating that a theory can only be judged within the framework of the relevant paradigm in which it was developed. Needless to say that this would be the end of the practical application of academic endeavor. No manager or consultant will accept organizational knowledge to be submitted to scholastic scrutinizing before releasing it for safe use, especially not when you have a chance of one in four that the knowledge involved is dismissed for the reasons mentioned.

Willmott (1993) made some well-argumented remarks against the position taken by Burrell and Morgan. He stresses the point that Burrell and Morgan knowingly stray from the meaning Kuhn gave to the term paradigm. He explains that Kuhn (1962) saw the "incommensurability" of paradigms as a temporary situation, that after a period of scientific revolution would end with a new generally accepted paradigm representing 'normal science'. For Burrell and Morgan paradigm distinctions are forever. As Willmott puts it (pp. 710, n4): 
"Burrell and Morgan's usage of the term "paradigm" was not so much "broader" as almost completely and convergent, Burrell and Morgan's are synchronic and divergent."

different. Whereas Kuhnian paradigms are diactronic

Fortunately, another representative of academia convincingly rejected the "paradigm idea' of Burrell and Morgan. Ackroyd (1992) made an eloquent attack on it. He starts to explain his case (p. 103):

The aim of this chapter is to provide some insights into the development of the areai of knowledge variously described as organizetional analysis or organizational studies, in a form that will assist the process of growth of the fileld. It is assumed at the outset that, potentially, the subject is one of immense practical value; and its emergence, along with number of other new human disciplines, could well be held to mark a new phase in the development of the social sciences. In order for this potential to be realized, however, two developments have to take place. One concerns the paradigm idea referred to in the title of this chapter. Arguably, although it was among the most popular ways of thinking about the field during the 1980s, the paradigm idea, together with other ideas of a similar kind, hes exerted a fateful influence over it. It will be argued that this sort of approach to organization must be fully and finally discarded, and new and more creative ways of thinking about the field devised. Il also suggest an alternative to the paradigm idea, and outline some of its advantages."

Willmott concludes about Burrell and Morgan's position that 'Its fundamental limitation is ... that, in giving equal legitimacy to 'functionalist' and 'non-functionalist' paradigms, it transforms an empirical, historical phenomenon into metaphysical, universal principle" (pp. $709, \mathrm{n} 3$ ). The essence of this objection lies in the fact that the defenders of the paradigm view make social theory subject to social theory. This self-reference causes some sort of hermeneutic closure. The paradigm itself is exempt from testing. Organization analysis becomes the collection and ordering of organization theory. Consequently, in the words of Ackroyd (p. 104):

"At many times before the present, the beginnings of a formalized and prectical knowledge of organization has been set out. The writings and practice of Bentham, Chadwick, Taylor, Ford of Fyyol, for example, seem to be likely starting points for a conceptually sophisticated and practically based knowledge of organization. Very little in the way of sustained research was actually developed from these initial statements, however, and knowledge of organization failed to grow from these beginnings."

Both Ackroyd and Willmott refute the idea of lasting paradigm incommensurability. In the debate I share their opinion.

The implication of their arguments is important for the assessment system. This system does not take paradigm positions for granted. It accepts every type of hypothesis provided it is overt and well defined. It distinguishes operationalized and tested hypotheses from those that do not leave the realm of genius. It will earmark untested and untestable articles of faith. 
To summarize: the paradigm view camot dismiss the assessment system. By contrast, the examination method reveals insular paradigmatic postulates.

\section{The postmodem turn}

Nevertheless, one cannot ignore philosophical bedrock. For some time, philosophers have challenged the modemist tradition in science. If their post-modernist critique holds, we have to see whether or not it does affect the foundation of the assessment system. To start with, whe essentials of the modern versus the postmodem stance will be given broad hines, especially those regarding organization theory.

Postmodemism 'is relating to a complex set of reactions to modern philosophy and its presuppositions, rather than to any agreement on substantive doctrines" (Audi, 1995; 634). This means that the specific postmodem view on organization theory needs to be discussed. Burrell (1989) stresses the necessity of a fundamental philosophical debate about managenent theory in which the postmodern position showld be taken into account. But he does not defend that 'postmodernism should be embraced (p.307)'.

One writer is particularly outspoken on the subject (Gergen, 1992). He explains the postmodem implications for organization theory.

Wis first tenet is that there is not such a thing as "the real world", independent of the observer, waiting to be "discovered". The only world we can know is an haterpretation. A theory on organization cannot be objectively "read' from reality (p. 207):

No, here is thttle sense to be made of the assumption that organization theories are read of the wortd as it is, inductively deriwed from our experiential immersion in a world of continuaus flux.

A far more promising alternative for understanding the intelligibility of organizations is to be found in the discursive context. For our theories of organizations: are, first and foremost, forms of language. They are guided by existing rules of grammar, and constructed out of the pool of nouns and verbs, the metaphors, the marrative plots, and the like found within the linguistic context. In this sense, theories of the organization do not exist apart from or independent of the surrounding intelligibilities of the culture. As theorisits we must 'make sense', and if we are to make sense within our own culture, we have no recourse but to obey the culture's rules of intelligibility. We thus borrow and steal from the culturall ways of talking about organizationall lle, for if we do not rely on our surrounds we cannot serve as their insightful informants."

This thesis directly affects our assessment system. It denies the possibility of inducing theories from observation as if these observations were unambiguous and indisputable. I will come back to the point of observable reality in the next section.

Gergen's second point concerns the effects of the necessary interpretation, which is a social act. In his view theory is sense making resulting from discourse. Language would not be a means to describe the world, but it is the world (p. 210): 
In my view the value of organization theory does not Lie in its accuracy how well it matches the things are. In what way can words be matched against visual images, sounds, and the like?

The ory cannot be evaluated by its capacity to predict, for words in themselves are simply sounds or markings, lifeless and inert: words in themselves do not predict. Rather, theory gains its importance from the ectivities which it enables, which essentially means, by the way in which it figures in ongoing patterns of relationship. Thus, by drawing sustenance from the romanticist vocabulary, orgamization theorists hammer out intelligibilities that resonate with a significant part of the cultural vernacular. In this sense, they find an eagerly appreciative audience.

Further, when such intelligibilities are inserted into organizational life, old practices seem wrong-headed, and new forms of organizational life are invited. It is not that the new practices are superior in some sense of "truer" or more fundamental'. Rather, the new practices often enable people to live out their cultural meaning systerris in ways that seem congenial or 'more fully expressive'.

The term 'intelligibility' is crucial here. With its connotations of "understandability", 'comprehensibility', 'clearness', and 'clarity' it is very much the same as 'Verstehen'. In this wiew a good theory is one that is socially built and accepted, resulting from discourse. It is a rhetoric instrument for reflection or action, whose virtues are predominantly esthetic. It should be noted that this strand of thought makes no difference between literature and science. Tolstoi invokes a perfect understanding of war and peace, but he - and I - would reject the idea of him being a scientist.

Now Gergen summarizes postmodern science. Three arguments are proposed. The first is about the replacement of the Real by the Representational (p. 213):

"As demonstrated in these various lines of inquiry, one can make a compelling case that knowledge, as a body of discourse, is governed, influenced or constrained by ideological or waluationilinterests, by social processes, and by the rules or conventions of language formation itself. That is, if what we call the real" is governed by the ideology of the caller, attempts to inform society of what is 'actually the case' must be regarded with suspicion. A genuine interest in discovering the nature of things in themselves seems both naive and misteading.

The second states that representation is a communal act (p. 214):

"Sensemaking is ... collectiva manifastation, ...., joint action - requiling the coordinated participation of two or more persons. This view is favored by
Wittgenstein's views of language games and meanings; it is implied by Kuhn's (1970) work on the history of paradigm shifts; ..."

Finally, he points at the typical self-irony in postmodern philosophy (p. 214):

'If there is one theme that unites most of those confronting the postmodern irony it is a certain sense of ludic humilhty. The view of knowledge-making as a transcendent pursuit, removed from the trivial enthrallments of daily life, pristinely rational, and transparently virtuous, becomes so much puffery. We should view these bodies of language we call knowledge in a lighter vein - as ways of putting things, 
some pretty and some others petty - but in no sense calling for ultimate commitments, condemnations, or profound consequences. We should rather be more playful with our savings. We who utter them are giving voice neither to reality as it is nor to intermal possessions (insights, reasons, intentions). Rather we are engaging in public pestimes, rituals, or lifeforms and for such enterprises there are no vindicating foundationss."

But, according to Gergen, theory is not dead (p. 217):

'As I hawe tried to indicate throughout this chapter", ... the theorist is not rendered woiceless by postmodiern argumentation. To be sure there is little reason to suppose that theories are pictures, and that the concept of kruth is more than hand waving. Yet, we are moved to science only if persuaded by the modernist presumption that objective truth is the only game in town. If the function of theories is not derived from their truth value, but from their pragmatic implications, then the theoretical voice is restored to significance.
And the potential of theoretical work is far greater than that assigned to it under modernist conditions. For under modernism, the proper theory should be fortified with years of research, and its application undertaken by yet another culture (the practitioners). In the pastmadern context, the primary ingredient of theory is not its database but its intelligibility, and the very communication of this intelligibiliny already establishes grounds for its utility. Theory and practice are inseparable."

So, Gergen himself indicates the limitations of postmodern relativism. In this respect it should be noted that certain philosophical opinions place postmodernism not after, but before modernism. It narrows the gap between science and art, once emerging as a result of modernist thinking, and in the accent on self-irony the jester comes to mind, the dateless punctuator of pompous seriousness.

What has this all to do with the assessment system? Insofar as postmodern theory is said to be no more than intelligibility, socially accepted and understood, in my view it is no more than rhetoric. As stated above, rhetoric is an instrument of implementation and action. Bringing about change in organizations and their practices requires discussion, negotiation, persuasion and action. But one instrument to make it all happen is the generalized insight into how things really are. That insight is far more than just images and negotiated pictures of the world. In following the pictorial model of knowledge development as presented in this study, every phase of it holds out under postmodern critique. The only thing to be remembered is that all procedural steps and the results of phases of knowledge development must be open for discussion and correction. That will produce the socially constructed reality that allows us to observe, induce and hypothesize.

The real thing

In organization analysis, we must be careful not to introduce concepts and constructs whose very existence is contested. We may for instance speak of an organization as an entity with human properties, like 'a will', 'goals", and 'making choices'. This type of misconception is 
called reification, or, in earlier philosophical discussions, hypostasis. It is " ... the process of regarding a concept or abstraction as an independent or real entity' (Audi 1995; 352). For organization theory, Silverman $(1970$, p. 141$)$ has pointed out this flaw that may lead to vivid discussions about nothing. He quotes Weber, who was fully aware of it: it is not the State that acts; individuals do conduct acts.

This problem is readily spotted when the assessment method is applied. It should be noted that the assessment system does not necessarily involve a realist perspective. Something is not true because structures come in fives, or because all relevant attributes of something should start with the initial ' $\mathrm{S}$ '. Behind organization science there is no such thing as a platonic reality, waiting to be discovered. In this respect, Dewey's (1920) position is of importance. Nowadays, even in physics the existence of such a reality is disputed (Van Fraassen, 1980). The concepts discussed such as hypothesis, definitions, descriptive or predictive models, observables, are not required to refer to things that must exist outside the experience of the persons involved. They serve to build knowledge necessary for organizational design. That means that all those involved must agree on the meaning of the terms used. As this meaning is individually and socially determined, a common ground among parties involved has to be sought. This is the domain of intersubjectivity or shared subjectivity. The analytic approach of this study is helpful in the discussion necessary to obtain a shared opinion about the meaning of all concepts involved. This can be considered as a negotiated set of concepts. In this respect the discussion of Weick $(1995$, p. 24) is of interest. He points at the fact that man"s perceived world is in reality a past world. This means that shared concepts must rely on shared experience. Many concepts will appear to be common to a larger part of our society. In addition to that, many also will remain invariant over time. To the degree that they satisfy these conditions, general theories expressed in the terms of these concepts, aimed at the design of organizational structure and strategy, are perfectly conceivable.

\subsection{Afterthoughts}

\section{Some recommendations for future organizational research.}

From the foregoing it has become clear that the further development of the body of knowledge on organizational structure and strategy can and should be improved. Three recommendations might be helpful in this respect.

First, a sound metatheoretical framework should be employed. The process of theory development should be specified in unambiguous terms, like those used in this study for the description of knowledge development. Its terms should be definite, precise, and coherent. Second, every serious attempt to develop generic knowledge on organization should start with observation (our square C). Of course, some preconceived framework is unavoidable. But observation should be as unprejudiced as possible. And it should be done with all available means. Interviews, desk research of available data, participating in parts of the processes that 
take place, discussions, maybe also questionnares. Not just a survey or a lisrel-analysis on those Figures that happen to be there. Give the mpressions time to sethe, enter prelminary discussions among observers and observed, then pass through induction (our square D), and let thousand flowers of hypothesis bloom. Pune until some promising thoughts remain. And reiterate the cycle of knowledge development as described.

The third recommendation is to break through boundaries of academic discipline. Modern sociology, as developed by Coleman, together with systems theory, may well be the best starting point for theory building. Predictive models or mathematical representations (section 3.6) may enable detailed operationalization and obserwation. Subsets of the model may be dealt with by specific disciplines, like economy or psychology. Connecting the subsets will require engineering capabilties, game theory, and the mastering of related fields. Apparently a joint effort is required.

\section{Hope or the future}

In this study a large number of organization theories has been examined. In this final section, I will try to say something about the future development of organizational knowledge. This is pure speculation, of course. My suppositions are no more than an "educated guess", probably infuenced by hope.

First, it may be repeated that organization theory is still young and unmoulded. Progress may come from new and better observation linked to improved suppositions, or from better hypothesis connected to observation. This may ink some of the dispersed patches of grounded knowledge we have so far.

Second, it may be expected (and hoped) that in the process the proportion of ontological contributions in the produce of organization theories will dwindle. For the research of chapter six $\mathbb{I}$ browsed through the 1995 volume of some prominent journals. In some of these the number of articles other than those addressing metaphysics, epistemology or ontology was exactly zero. That means that in the terminology of the philosophy of science they are speculative.

No offence meant to philosophy, after all this study is one more in a metatheoretical discipline. But it should be noted that today there seems to be too much contemplation and too little observation. Hopefully, with the immanent demise of postmodernism (its own great narrative being the final one to be deconstructed), researchers may return to the shop floor, the boardroom, and every place in between, in order to observe the consequences of their hypotheses. The approach is not new; it was followed by Taylor 100 years ago and by Roethlisberger 75 years ago. The appeal to follow this approach is not new either. It was expressed already by Simon 50 years ago, as was mentioned in section 5.7 .

Why this reluctance when it comes to scientific observation? For one reason, because it is not the easy way, of course. You have to obtain the permission of organizations to do such research, and you need their cooperation. The work of Mayo (Roethlisberger, Dickson) and Hofstede was only possible with the help of large organizations that were willing to open their doors and their 
books. Most organizations are reluctant to admit consultants even when these are badly needed to help solving problems threatening to occur. Many are not interested in academic research. Isn't there any organizational research, then? Of course there is. In almost every organization, almost everyday, you can find individuals or teams of analysts busy with all kinds of organizational research, ranging from IT projects, via market studies, to boardroom consultancy. Strikwerda (1994, p. 208) reported no less than 276 different fields of management consultancy. The sales figure of these services in the US is estimated at \$15 billion a year, the global market will be many times larger and is growing fast. In addition, many hours of employees' work are devoted to organization research in projects with or without outside consultants. But all these expensive and time-consuming efforts are directed at the immediate interest of the organization involved and devoted to the solution of the problems at hand. The experts are supposed to have the theories in their briefcases and laptops, and not to be searching them. But as we may expect from what we have seen, not all theories are valid or useful.

It is paradoxical that in an industry that can only thrive on good knowledge so little is done to improve this knowledge by scientific endeavor. With scientific endeavor I mean a solid knowledge building program, and not just the publication of some articles now and then. If only a modest percentage of the value of all billings would be devoted to the construction of better theories immense progress could be made. The matter is an organization problem in itself, requiring an adequate structure and strategy. It could be solved by the initiative and close cooperation of the academic world and the larger consultancies. I do not underestimate the difficulties involved, such as how to obtain the cooperation of guinea-pig organizations, how to avoid company information coming into the wrong hands, how to finance such projects, how to mobilize a task force in an industry where every consultant is supposed to produce as much billable hours as possible (and preferably more). Neither do I dismiss the statutory restrictions and day-to-day problems of universities. But these impediments can and must be solved. Hopefully, in the first decade of the new millennium a group of successful researchers will come forward with valid and useful results, saying: 'Heathrow, here we come!' 


\section{References}

The Academy of Management Review, Vol.14, October 1989.

Ackroyd, S. (1992). Paradigms Lost: Paradise Regained? In: Reed \& Hughes, 1992.

Andrews, K.R. (1971). The Concept of Comporate Strategy. Homewood Ill: Irwin.

Ansoff, H.I. (1968). Corporate Strategy. Harmondsworth: Penguin Books.

Argyris, C (1985). Strategy, Change, and Defensive Rowtines. Boston: Pitman.

Aristotle, G.A. Kennedy (ed.) (1991). On Rhetoric: A Theory of Civic Discourse. Oxford University Press.

Astley, W.G. \& A.H. Van de Ven (1983). Central Perspectives and Debates in Organization Theory. Administrative Science Quarterly, Vol. 28, No. 2, pp. $245-273$.

Audi, R. (ed.) (1995). The Cambridge Dictionary of Philosophy. Cambridge University Press.

Babbage, C. (1832). On the Economy of Machinery and Manufactures. London: Knight.

Bacharach, S.B. (1989). Organizational Theories: Some Criteria for Evaluation. Academy of Management Review, Vol. 14, No. 4, pp. 496 - 515.

Bacharach, S.B., P. Gagliardi, \& B. Mundell (eds.) (1995). Research in the Sociology of Organization: Studies of Organizations in the European Tradition. Vol. 13. Greenwich CT.

Barnard, C.I. (1938). The Functions of the Executive. Cambridge MA: Harvard University Press (20th printing 1971).

Bartlett, C.A., \& S. Ghoshal (1989). Managing Across Borders." The Transtational Solution. Boston MA: Harvard Business School. Press.

Bedriffskunde (1994) Vol. 66 No. 1, (a special issue on methodology and theory), with subsequent articles in 1995 and, - again - specials in 1996-No. 2 and - No. 3. (In Dutch).

Bertalanffy, L von (1956). General Sysiems Theory, General Systems. Yearbook of the Society for the Advancement of General System Theory.

Blau, P. M. \& W.R. Scott (1962). Formal Organizations, A Comparative Approach. San Fransisco: Chandller Publishing Company (Britisch ed. pbk. 1963).

Blau, P. (1964). Exchange and Power in Social Life. New York: Wiley \& Sons.

Bodewes, W.E.J. \& E. Woudstra: Bedrijfskunde: een wetenschappelijke discipline?

Bedrijfskunde, (1994) Vol. 68, No.2, p.32. (In Dutch).

Boring, E.G. (1953). The Role of Theory in Experimental Psychology. The American Journal of Psychology, Voll. 66, pp. $169-184$.

Bower, J.L., \& C.M. Christensen (1995). Disruptive Technologies:. Catching the Wave. Harvard Business Review, Vol. 73, January-February, pp. 43 - 53.

Brandon, R.N. (1994). Theory and Experiment in Evolutionary Biology. Synthese, Vol. 99, pp. $59-73$.

Buelens, M. (1997). Het intellectuele verdriet en de pedagogische troost. $M \& O$, Special issue 'Trends in management en organisatiekunde', pp.17-36, Alphen a/d Rijn (In Dutch). 
Bunge, M. (1967a). Scientific Research I: The Search for System. Berlin: Springer Verlag. Bunge, M. (1967b). Scientific Research II: The Search for Truth. Berlin: Springer Verlag. Burns, T. (1958). The Forms of Conduct. American Journal of Sociology, Vol. 64. Burns, T. \& G.M. Stalker (1961). The Management of Innovation. London: Tavistock Publications.

Burrell, G. G. Morgan (1979). Sociological Paradigms and Organisational Analysis. London: Heinemann.

Burrell, G. (1989), The Absent Centre: The neglect of Philosophy in Anglo-American Management Theory. Human Systems Management, Vol. 8, No. 4, pp. 307 - 312.

Carroll, G.R. (ed.) (1988), Ecological Models of Organizations. Cambridge MA: Ballinger. Chandler, A.D. (1962). Strategy and Structure: Chapters in the History of the Industrial Enterprise. Cambridge MA: MIT Press.

Christensen, C.R., K.R. Andrews, \& J.L. Bower (1973): Business Policy: Text and Cases. Homewood Ill: Irwin.

Coase, R.H. (1937). The Nature of the Firm. Economica N.S., Vol. 4, pp. $386-405$.

Coleman, J.S. (1964). Introduction to Mathematical Sociology. London: Collier.

Coleman, J.S. (1990). Foundations of Social Theory. Cambridge MA: Harvard University Press. Commons, J.R. (1934). Institutional Economics. Madison WI: University of Wisconsin Press. Coombs, C.H. (1967). A Theory of data. New York: Wiley \& Sons.

Crozier, M. (1964). The Bureancratic Phenomenon. University of Chicago Press. Cyert, R.M., \& J.G. March (1963). A Behowioral Theory of the Firm. Englewood Cliffs NJ: Prentice-Hall.

De Groot, A.D. (1961). Methodologie, Grondslagen wan onderzoek en denken in de gedragswetenschappen. The Hague: Mouton \& Co. (In Dutch, fourth printing 1968).

Delacroix, J., \& G.R. Carroll (1983). Organizational Foundings: An Ecological Study of the Newspaper Industries of Argentina and Ireland. Administrative Science Quarterly, Vol. 28, pp. $274-291$.

Dewey, J. (1920). Reconstruction in Philosophy. New York: Henry Holt \& Co.

DiMaggio, P.J., \& W.W. Powell (1991). The Iron Cage Revisited Institutional Isomorphism and Collective Rationality in Organizational Fields, in: Powell, W.W. \& P.J. DiMaggio, The New Institutionalism in Organizational Analysis, University of Chicago Press. (First printed version in: American Sociological Review Vol. 48, April, 1983).

Drucker, P. (1954). The Practice of Management. New York: Harper \& Row.

Durkheim, E. (1937). Les Règles de la Méthode Sociologique. Paris: Presse universitaire de France.

Eccles, R. \& N. Nohria (1992). Beyond the Hype. Boston: Harvard Business School Press. 
Eibl-Eibesfelt, I. (1976). Der vorprogrammierte Mensch. München: Deutscher Taschenbuch Verlag.

Emery, F.E., \& E.L. Trist (1965). The Causal Texture of Organizational Environments. Human Relations, Vol. 18, pp. $21-32$.

The Economist (1994). Pocket MBA. The essentials of management thinking and theory from A to $Z$. London.

Fayol, H. (1920). Administration Industrielle et Générale: Prévoyance, Commandement, Coordination, Controle. Paris: Dunod. 1920. (Extrait du Bulletin de la Société de l'Industrie Minérale, $3^{\text {e }}$ livraison de 1916)

Fayol, H. \& C. Storr (1949). General and industrial management. London: Pitman.

Feigl, H. (1953). The Scientific Outlook: Naturalism and Humanism. In: Feigl, H. \& M. Brodbeck. Readings in the Philosophy of Science. New York: Appleton-Century-Crofts. Galbraith, J.R. (1973). Designing Complex Organizations. Reading MA: Addison-Wesley. Gergen, K.J. (1992). Organization Theory in the Pastmodern Era, in Reed \& Hughes, 1992. Gerth, H.H. \& C.W. Mills (eds.) (1958), From Max Weber: Essays in Sociology. Oxford University Press.

Gouldner,A.W. (1954). Patterns of Industrial Bureaucracy. New York: Free Press.

Guillén, M.F. (1994). Models of Management. University of Chicago Press.

Gulick, L. \& L. Urwick (eds.) (1937), Papers on the Science of Administration. New York: Columbia University Press.

Hannan, T.H., \& J. Freeman (1977), The Population Ecology of Organizations, American Joumal of Sociology. Vol. 82, pp. $929-964$.

Hannan, T.H., \& J. Freeman (1989). Organizational Ecology, Cambridge MA: Harvard University Press.

Hayek, F. (1945). The Use of Knowledge in Saciety, American Economic Review, Vol. 35, September, pp. $519-530$.

Hawley, A. (1950). Human Ecology. New York: Ronald Press.

Helmrich, R.L. \& A.C. Merrit (1997). Pilots and their cultures: A summary of research and selected papers, presented to the FAA office.

Henderson, B.D. (1979). Henderson on Corporate Strategy. Cambridge MA: Abt Books.

Herzberg, F., B. Mauser, \& B. Bloch (1959). The Motivation to Work. New York: John Wiley. Hickson, D.J. (1996). The ASQ Years Then and Now through the Eyes of a Euro-Brit. Administrative Science Quarterly. Vol. 41, pp. $217-228$.

Hofstede, G. (1984). Culture's Consequences. Beverly Hills CA: Sage Publications. Jaques, E. (1951). The Changing Culture of a Factory. London: Tavistock Publications. Jensen, M.C. (1986). Agency Costs of Free Cash Flow. American Economic Review, Vol.76, pp. $323-329$. 
Kanter, R. M. (1989). When Giants Learn to Dance. Englewood Cliff, NJ: Simon \& Schuster. Katz, D. (1964). The Motivational Basis of Organizational Behavior. Behovioral Science, Vol. 9. No. 4, pp. 131-146.

Katz, D, \& R.L. Kahn (1966), The Social Psychology of Organizations. Wiley \& Sons, New York.

Ketchen, D.J., J.B. Thomas \& C.S. Snow (1993). Organizational Configurations and Performance: A Comparison of Theoretical Approaches. Academy of Management Journal, Vol. 36, No. 6, pp. $1278-1313$.

Khandwalla, P.N. (1971). Report on the Influence of the Techno-Economic Environment on Firms' Organization. McGill University.

Koontz, H. (1961). The Management Theory Jungle. Journal of the Academy of Management, Vol. 4, No. 3, December, pp. $174-188$.

Krekel, Van der Woerd, Wouterse, management consultants (1987). Toekomststudie van het Nederlandse Baggerbedriff. Rotterdam. (In Dutch).

Kulhn, T.S. (1962). The Structure of Scientific Revolutions. University of Chicago Press.

Lammers, C.I. (1995). (review of Bacharach et al.). Administrative Science Quarterly, Vol. 40, No. 1, March, pp. $213-217$.

Lasserre, P. (1995). Corporate Strategies for the Asia Pacific Region. Long range Planning, Vol. 28, No. 1, pp. $13-30$.

Lawrence, P.R., \& J.W. Lorsch (1967). Organization and Environment: Managing Differentiation and Integration. Cambridge MA: Harvard University Press.

Lewin, K. (1945). The research center for group dynamics at M.I.T. Sociometry, Vol. 8, pp. 126 $-136$.

Lewin, K. (1951). Field theory in social science. New York: Harper \& Brothers.

Lewin, K. (1958), Group decision and social change. In: G.E. Swanson, T.M. Newcomb, \& E.L. Hartley (eds.). Readings in Social Psychology. New York: Holt, Rinehart \& Winston.

Likert, R. (1961). New Patterns of Management. New York: McGraw-Hill.

Lindenberg, S. (1983). Afbeelden en verklaren met modellen in de sociologie. In: Lindenberg, S. \& F.N. Stokman, Modellen in de sociologie. Deventer: Van Loghum Slaterus. (In Dutch). Lindenberg, S., \& H. Schreuder (eds.) (1993). Interdisciplinary Perspectives on Organization Studies. Oxford: Pergamon Press.

Lomi, A. (1995). The Population Ecology of Organizational Founding: Location Dependence and Unobserved Heterogeneity. Administrative Science Quarterly, Vol. 40, No. 2, pp. 111 144.

Lynn, L.H. \& H. Rao (1995). Failures of the Intermediate Forms: A Study of the Suzuki Zaibatsu. Organization Studies, Vol. 16, No.1, pp. 55-80.

March, J.G., \& J.P. Olsen (1976). Ambiguity and Choice in Organizations. Bergen: Universitetsforlaget. 
March, J.G. \& H.A. Simon (1958). Organizations. New York: John Wiley.

McClelland, D.C. (1961), The achiewing society. Princeton: Van Nostrand Reinhold.

McGregor, D. (1957). The Human Side of Enterprise. Management Review. Vol. 46, No. 11 (November).

McGregor, D. (1960). The Human Side of Enterprise, New York, McGraw-Hill.

Mckinsey, J. O. (1932). Adjusting Policies to Meet Changing Conditions. General Management Series. G.M. 116. New York.

Merton, R.K. (1940). Bureaucratic Structure and Personality. Social Forces, XVIII.

Merton, R.K. (1957). Social Theory and Social Structure. New York: Free Press.

Merton, R.K. (1990), Epistolary notes ... In Calhoun, C., M.W. Meyer, \& W.R. Scott (eds.).

Structures of Power and Constraint: Papers in Honor of Peter $M$. Blau. Cambridge University Press.

Meyer, M.W. et al. (1978). Enviromments and Organizations. San Francisco: Jossey-Bass.

Michels, R. (1909). Der konzervative Grundzug der Partei-Organisation. Monatschift für Soziologie, No. 1. (In German).

Michels, R. (1911). Zur Soziologie des Parteiwesens in der modernen Demokratie. English translation a/o: Political Parties: A Sociological study of the Oligarchical Tendencies of Modern Democracy. Glencoe: Free Press, 1958.

Micklethwait, J., \& A. Wooldridge (1996). The Witch Doctors. London: Heinemann.

Miller, D. \& P.H. Friesen (in cooperation with H. Mintzberg) (1984). Organizations: a quantum view. Englewood Cliffs NJ: Prentice-Hall.

Miller, D. \& H. Mintzberg (1983). The Case for Configuration. In: Morgan, G. (ed.). Beyond Method, Strategies for Social Research (pp. 57 - 73). Sage Publications, Beverly Hills, CA.

Mintzberg, H. (1979). The Structuring of Organizations: A Synthesis of the Research.

Englewood Cliffs NJ: Prentice-Hall.

Mintzberg, H. (1990). Mintzberg on Strategy. New York: Free Press.

Mulder, M. (1977). The daily power game. Leiden: Martinus Nijhof.

Ouchi, W.G. (1981). Theory Z: How American Business Can Meet the Japanese Challenge, Reading MA: Addison-Wesley.

Parsons, T. (1960). Structure and Process in Modern Societies. Glencoe Ill: Free Press.

Pascale, R.T. (1990). Managing on the Edge: How Successful Companies Use Conflict to Stay Ahead. London: Viking Penguin.

Peteraf, M. (1993). The cornerstones of competitive advantage: A resource-based view.

Strategic Managemeni Joumal, Vol. 14, No.3, pp. $179-191$.

Peters, T.J., \& R.H. Waterman (1982). In Search of Excellence: Lessons from America's BestRun Companies. New York: Harper \& Row.

Peters, T.J. (1987). Thriving on Chaos. New York: Macmillan. 
Pfeffer, J., \& G.R. Salancik (1978). The External Control of Organizations. New York: Harper \& Row.

Phan, P.H., \& C.W.L. Hill (1995). Organizational Restructuring and Economic Performance in Leveraged Buyouts: An Ex Post Study. Academy of Management Journal, Vol.38, No.3, pp. 704 - 739 .

Porter, M.E. (1979). How Competetive Forces Shape Strategy. Harvard Business Review, Vol. 57, No. 2. (March-April).

Porter, M. E. (1980). Competitive Strategy: Techniques for Analyzing Industries and Competitors. New York: Free Press.

Porter, M. (1987). From Competitive Advantage to Corporate Strategy. Harvard Business Review, Vol.65, No.3. (May-June).

Pugh, D.S., D.J. Hickson, C.R. Hinings, K.M. Macdonald, K.M. Turner, \& T. Lupton (1963). A Conceptual Scheme for Organization Analysis, Administrative Science Quarterly, Vol. 8, No. 3, pp. $289-315$.

Pugh, D.S., \& D.J. Hickson (1976). Organizational structure in its context: The Aston programme I, London, and, Pugh, D.S., \& C.R. Hinings (eds.) (1976). Organizational structure: Extensions and replications. The Aston programme II. Farnborough: Saxon House.

Pugh, D.S., \& D.J. Hickson (eds.) (1997). Writers on Organizations. Thousand Oaks, CA: Sage Publications.

Quinn, J.B. (1985). Managing Innovation: Controlled Chaos. Harvard Business Review, Vol. 63 No. 3 (May-June), pp. $73-84$.

Reed, M. \& M. Hughes (eds.) (1992). Rethinking Organization. London: Sage Publications. Robins, J. \& M.F. Wiersema (1995). Resource-based Approach to the Multibusiness Firm: Empirical Analysis of Portfolio Interrelationships and Corporate Financial Performance. Strategic Management Jowmal, Vol. 16, pp. $277-299$.

Roethlisberger, F.J., \& W.J. Dickson (1939). Management and the Worker. Cambridge MA: Harvard University Press.

Roskam, E.E. (1990). Formalized theory and the explanation of empirical phenomena. In: Hox, J.J., \& De Jong-Gierveld, J. (eds). Operationalization and Research Strategy. Amsterdam:

Swets \& Zeitlinger.

Rumelt, R.P., D.E. Schendel \& D.J. Teece (eds.) (1994). Fundamental Issues in Strategy; a Research Agenda. Boston: Harvard Business School Press.

Scaff, L.A. (1989). Fleeing from the Iron Cage: Culture, Politics and Modernity in the Thought of Weber. Berkeley: University of California Press.

Schein, E.H. (1985). Organizational Culture and Leadership. San Fransisco: Jossey-Bass.

Scherer, F.M. (1982). Intra-industry technology flows in the U.S. Research Policy, Vol. 11, pp. $227-245$. 
Sculley, J., J. Byme (1987). Odyssey: Pepsi to Apple ... A Jowney of Adventures, Ideas, and the Future, New York: Harper \& Row.

Selznick, P. (1948). Foundations of the Theory of Organization. Americam Sociological Rewew, Vol. 13 , pp. $25-25$.

Shafritz, I.M., \& I.S. Ott (eds.) (1992). Classics of Organization Theomy, 3rd ed. Belmont CA: Wadsworth, Inc.

Silverman, D. (1970). The Theory of Organizations. London: Heinemamn.

Simon, H.A. (1947). Administrative Behavior: A Study of Decision-Making Processes in Administrative Organization. New York: MoMillan. (Second edition 1957).

Simon, H.A., D.W. Smithburg, \& V.A. Thompson (1950). Public Administration. New York.

Simon, H.A. (1957). Models of Man, Social and Rational. New York: Wiley \& Sons.

Smith, A. (1776). The Wealth of Nations (Chapter I). London: printed for W. Strahan and T.

Cadell.

Stacey, R.D. (1993). Strategic Management and Organizational Dynamics. London: Pitman Publishing.

Stinchcombe, A.L. (1965). Social Structure of Organizations. In March. J. (ed.), Handbook of Organizations, Chicago: Rand MoNally.

Strikwerda, J. (1994). Organisatie-advisering: wetenschap en pragnatiek. Delft: Eburon. (In Dutch).

Taylor, F.W. (1914). The Principles of Scientific Management. New York: Harper.

Teece, D.J. (1993). Towards an economic theory of the multiproduct firm. Joumal of Economic Behavior and Organization, Vol, 3, pp. 39-63.

Thompson, J.D. (1967). Organizations in Action: Social Science Bases of Administrative Theory. New York: McGraw-Hill.

Towne, H.R. (1886). The Engineer as an Economist. Transactions of the ASME, Vol.7.

Trist, E.L., \& K.W. Bamford (1951). Some social and psychological consequences of the longwall method of coal-getting. Human Relations, Vol 4.

Üsdiken, B. \& Y. Pasadeos (1995). Organizational Anallysis in North America and Europe: A Comparison of Co-citation Networks. Organization Studies, Vol. 16, No. 3, pp. $503-526$.

Van Aken, J.E. (1994a). Strategievorming en Organisatiestructurering. Technische Universiteit Eindhoven (In Dutch).

Van Aken, J.E. (1994b). De Bedrijfskunde als Ontwerpwetenschap: De Regulatieve en de Reflectieve Cyclus. Bedrijfskunde, Vol. 66, No. 1, pp. 16-26. (In Dutch).

Van Fraassen, B.C. van (1980). The Scientific Image. Oxford University Press.

Van Strien, P.J. (1986). Praktijk als wetenschap, methodologie van het sociaalwetenschappelijk handelen. Assen: Van Gorcum. (In Dutch).

Van de Ven, A.H. (1983). Book review of In Search of Excellence, Administrative Science Quarterly, Vol. 28, No. 4, December, pp .621-624. 
Van de Vijver, $F_{,}$\& K. Leung (1997). Methods and Data Analysis for Cross-Cultural Research. Thousand Oaks, CA: Sage Publications.

Van der Zwaan, A.H. (1996). Methodologie of theorie. Bedriffskunde, Vol. 68, No. 2, pp. 9-13 (In Dutch).

Verburg, P. (1959). Organiseren en Organisatieonderzoek. Leiden: Stenfert Kroese (In Dutch). Visser, H. (1990). Flexibele begrippen in kennistheorie en kunstmatige intelligentie. Algemeen Nederlands Tijdschrift voor Wijsbegeerte, Vol. 82, pp. 141 - 157. (In Dutch).

Visser, H. (1993). Procrustes, or the future of flexibility, in: Jorna, R.l. \& B. van Heusden: Signs, seanch and communication: semiotic aspects of artificial intelligence, pp. $201-212$. Berlin: De Gruyter.

Vroom, V.H. (1960). Some Personality Determinants of the Effects of Participation. Englewood Cliffs NJ: Prentice-Hall.

Weber, M. (1947). The Theory of Social and Economic Organization, New York: Free Press. Weber, M. (1958). The Protestant Ethic and the Spirit of Capitalism. New York: Scribner. Weber, M (1968) Economy and Society: An Outline of Interpretive Sociology. New York: Bedminster Press.

Weber, M. (1976). Wirtschaft und Gesellschaft; Grundriss der verstehenden Soziologie, Kapitel I: Soziologische Grundbegriffe; Kapitel IX, 2. Abschnitt: Wesen, Voraussetzungen und Entfaltung der bürokratische Herrschaft, Tübingen: Mohr. (In German, original text 1921). Weick, K.E. (1969). The Social Psychology of Organizing. Reading MA: Addison-Wesley. Weick, K.E. (1985). Sensemaking in Organizations. Thousand Oaks CA: Sage Publcations. Weihrich, H., \& H. Koontz (1994). Management, a Global Perspective. New York: McGrawHill.

Williamson, O.E. (1975). Markets and Herarchies. New York: Free Press (pbk. edition 1983). Willmott, H. (1993). Breaking the Paradigm Mentality. Organization Studies, Vol. 14, No. 5, pp. $681-719$.

Wippler, R. (1983). Een model van oligarchiseringsprocessen in democratische organisaties. In: Lindenberg, S. \& F.N. Stokman: Modellen in de sociologie. Deventer: Van Loghum Slaterus. (In Dutch).

Woodward, J. (1958). Management and Technology. London: her Majesty's stationery office. Yin, R.K. (1993). Applications of Case Siudy Research. Newbury Park: Sage Publications. Young, R. (1988). Is population ecology a useful paradigm for the study of organizations? American Jownal of Sociology, Vol 94, No. 1, pp. I - 24. 


\section{Summary}

In this study a system is developed for the assessment of theories on organization, specifically those theories that are instrumental for the design of the structure and the strategy of organizations. Being an enterprise of methodology it aims at the design of the assessment system proper together with a general metatheoretical appraisal of such theories.

In chapter 1 the necessity for the systematic examination of the validity and utility of organization theory is exposed. Although systematized knowledge of this field is of vital importance, both the studies by practitioners and those from universities and business schools are said to be often ungrounded or to lack practical applicability. Books excelling in rhetoric more than in scientific rigor have been called "Heathrow Organization Literature" for their abundance in the bookstalls at airports.

In chapter 2 the main objective of the study and its secondary result are formulated in more detail. The primary goal is the development of the metatheoretical method for the evaluation of organization theories. An important secondary result is the rendering of a systematic description of the body of organizational knowledge as it was proposed over the 20th century.

Chapter 3 is about knowledge development in general. Two directions of knowledge building are observed. The first one starts with empirical observation ( $C$, see figure). Repeated coincidences, patterns, and other regularities found in observed material may lead by induction (D) to general statements about the subject matter. The second way around starts with postulates and supposed regularities (A). From these hypotheses testable attributes of ensuing specific reality are derived (B). By connecting the two directions a closed cycle of

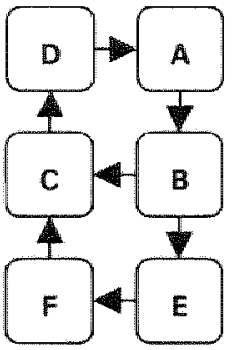
theory building is obtained. This path, called the A - B - C - D - cycle, may be run through repeatedly in order to hone the theory until a sufficient state of validity is obtained.

From derivation (B) an extra sub-cycle $\mathrm{E}-\mathrm{F}$ will emerge if the knowledge available from $\mathrm{B}$ is used to formulate rules for action. This is called prescription, symbolized by $\mathrm{E}$. Rules may serve for the design of the structure and strategy of an organization. From $\mathrm{E}$ intervention $(\mathrm{F})$ may follow, which may include staged experiment, or, for example, the implementation of an improved organizational structure. Next, enriched observation is possible. The position as discussed leads to the core-element of this study, namely the $A-F$ - scheme of knowledge development.

In chapter 4 this framework is used to design a questionnaire for the assessment of organization theories based on metatheoretical criteria.

In chapter 5 this tool is used to examine a sample of 28 organization theories ranging from Taylor (1914) to Coleman (1990), reflecting the harvest of 20 th century organizational knowledge. To avoid interpretation ample quotations from the original texts are rendered. Five types of organization theories are found with respect to their emphasis (or lack of it) on the elements of knowledge development.

In chapter 6 six more theories are examined. This time a contemporary cross-section of propositions is chosen by taking articles from the 1995 volume of six leading journals. In doing 
so, today's state of the art is sketched. At the same time the functioning of the testing tool is examined.

In chapter 7 conclusions of the study are reported and some afterthoughts are discussed.

\section{About the author}

Gerrit Prins (Amsterdam, 1932) obtained his degree as a civil engineer at Delft University of Technology in 1956. In 1958, after his training as a reserve officer of the Dutch Corps of Engineers, he became a management consultant in an Amsterdam based consultancy. In 1963 he joined a construction company in Breda, Holland, as a chief engineer, responsible for industrial and commercial building projects. As a contract manager in a French-Dutch joint venture he was in charge of special constructions in large diameter pipelines. In 1970 he joined Krekel, Van der Woerd, Wouterse (KWW), management consultants in Rotterdam, as a partner, and, for some years, as CEO of the firm. He conducted many assignments on structure and strategy for large companies and public authorities. In addition he supervised a great number of studies into industries, ranging from books (publishing, retailing, distribution) to dredging. After his retirement in 1992 he studied philosophy of science at Tilburg University (KUB). He is now on the board of some cultural organizations. He wrote two books and a number of articles in the field of technology and organization. 


\section{Samenvatting}

In dit onderzoek wordt een systeem ontwikkeld om organisatietheorieën te beoordelen. Het gaat daarbij in het bijzonder om die theorieën waaraan ontwerpregels voor de structuur of de strategie van een organisatie kunnen worden ontleend. De studie behoort tot de methodologie en wil, naast het ontwerp van het eigenlijke toetsingsinstrument, een algemene metatheoretische beoordeling van zullke theorieën geven.

In hoofdstuk 1 wordt de noodzaak viteengezet van het systematisch vaststellen van de waarheidsgetrouwheid en de bruikbaarheid van organisatietheorieën. Hoewel stelselmatig opgebouwde kennis op dit gebied van levensbelang is, zouden zowel de studies van praktijkmensen als academische studies vaak ongefundeerd zijn of praktische bruikbaarheid missen. Boeken die uitmunten in retoriek maar niet in wetenschappelijke gedegenheid worden wel aangeduid met "Heathrow Organization Literature", naar de stapels die in de kiosken op luchthavens liggen.

In hoofdstuk 2 worden het hoofddoel van de studie en het bijkomende resultaat nader geformuleerd. Het primaire doel is het ontwikkelen van een metatheoretische werkwijze voor het beoordelen van organisatietheorieën. Een belangrijk secundair resultaat is de systematische beschrijving van het geheel van kennis over organisaties, zoals geponeerd gedurende de 20 ste eeuw.

Hoofdstuk 3 gaat over kennisontwikkeling in het algemeen. Hierin kunnen twee routes worden waargenomen. De eerste begint met empirische waarneming (zie figuur, C). Herhaalde samenlopen, patronen en andere regelmatigheden bij wargenomen verschijnselen kunnen via inductie (D) leiden tot algemene uitspraken over het betreffende onderwerp. De

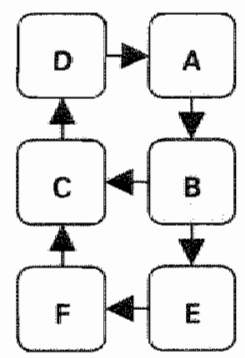
andere richting begint met postulaten en veronderstelde wetmatigheden (A). Uit deze hypotheses kunnen toetsbare eigenschappen worden afgeleid van de waar te nemen werkelijkheid (B). Door beide routes te verbinden ontstat een gesloten cyclus van theorieontwikkeling. Dit pad, aangeduid als de A - B - C $\mathrm{D}$ - cyclus, kan herhaaldelijk worden doorlopen teneinde de theorie zolang bij te slijpen tot een voldoende mate van waarheidsgetrouwheid is bereikt. Vanuit derivatie $(B)$ kan een extra lus $(E-F)$ beginnen wanneer uit de in $B$ ontwikkelde kennis handelingsregels worden afgeleid. Dit wordt voorschrijven (prescriptie) genoemd, met $\mathbb{E}$ als symbool. Regels kumnen dienen om de structuur of de strategie van een organisatie te ontwerpen. Uit $E$ kan tussenkomst (interventie, $F$ ) volgen, waaronder opgezette experimenten kunnen vallen, of bij voorbeeld de invoering van een verbeterde organisatiestructuur. Dit kan weer leiden tot aangescherpte waarnemingen. De zienswijze zoals besproken leidt tot het kernpunt van deze studie, namelijk het $A$ - $F$-schema van kennisontwikkeling.

In hoofdstuk 4 wordt dit schema gebruikt om een vragenlijst te maken waarmee organisatietheorieën op metatheoretische criteria kunnen worden beoordeeld.

In hoofdstuk 5 worden met dit gereedschap 28 organisatietheorieën onderzocht, variërend van Taylor (1914) tot Coleman (1990), die de oogst van organisatiekennis uit de 20ste-eeuwse 
weerspiegelen. Om interpretatie te vermijden worden omwangrijke citaten uit de oorspronkelijke tekst weergegeven.

Er worden wijf soorten organisatietheorieën gevonden, onderscheiden naar hun nadruk (of het ontbreken daarvan) op de onderdelen wan het proces van kennisontwikkeling. In hoofdstuk 6 worden nog zes theorieën onderzocht. Ditmaal is een hedendaagse dwarsdoorsnede van ideeen gekozen door artikelen te nemen uit jaargang 1995 van gezaghebbende tijdschriften. Hiermee wordt de huidige stand van de wetenschap geschetst. Tegelijkertijd wordt de werking van het beoordelingsinstrument gecontroleerd.

In hoofdstuk 7 worden conclusies uit het onderzoek getrokken, gevolgd door enkele nadere overwegingen.

\section{Curriculum vitae}

Gerrit Prins (Amsterdam, 1932) studeerde in 1956 af aan de Technische Hogeschool te Delft als civiel ingen ieur. Na zijn opleiding tot genieofficier werkte hij vanaf 1958 als organisatieadviseur bij Bosboom en Hegener in Amsterdam. In 1963 werd hij hoofdingenieur bij het aannemingsbedrijf IGB te Breda, verantwoordelijk voor utiliteitsbouwprojecten. Als contractmanager bij een joint venture van dit bedrijf met een grote Franse bouwonderneming was hij belast met de aanleg van speciale constructies in grote pijpleidingen. In 1970 trad hij als partner toe tot Krekel, Van der Woerd, Wouterse (KWW), management consultants te Rotterdam, van welk bureau hij enkele jaren statutair directeur was. Hier voerde hij een groot aantal opdrachien uit op het gebied van structuur en strategie voor grote ondernemingen en overheidsinstanties. Daarnaast leidde hij vele sector-structuuronderzoeken, varièrend van de boekenbranche (uitgeverijen, boekhandels, distributie) tot de baggersector. Na zijn pensionering in 1992 volgde hij colleges wetenschapsfilosofie aan de KUB in Tilburg. Hij vervult nu enkele bestuursfuncties op cultureel gebied.

Hij heeft twee boeken en een aantal artikelen geschreven op technisch en organisatorisch terrein. 